\title{
Administración pública y
}

gobernanza en México. Análisis del cambio institucional en la agenda de buen gobierno

\section{PÉREZ-RAMÍREZ, Rigoberto}

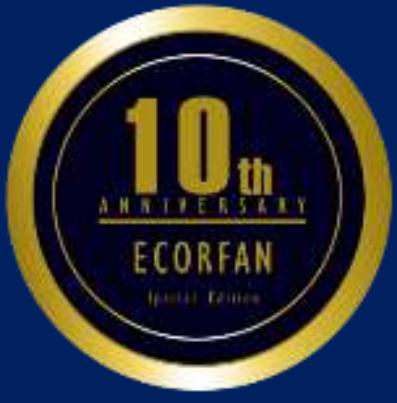




\section{ECORFAN-México}

Editora en Jefe

RAMOS-ESCAMILLA, María. PhD

\section{Autor}

PÉREZ-RAMÍREZ, Rigoberto

Redactor Principal

SERRUDO-GONZALES, Javier. BsC

\section{Asistente Editorial}

ROSALES-BORBOR, Eleana. BsC

SORIANO-VELASCO, Jesus. BsC

\section{Director Editorial}

PERALTA-CASTRO, Enrique. MsC

\section{Editor Ejecutivo}

VARGAS-DELGADO, Oscar. PhD

Editores de Producción

ESCAMILLA-BOUCHAN, Imelda. PhD

LUNA-SOTO, Vladimir. PhD

\section{Administración Empresarial}

REYES-VILLAO, Angélica. BsC

\section{Control de Producción}

RAMOS-ARANCIBIA, Alejandra. BsC

DÍAZ-OCAMPO, Javier. BsC
Administración pública y gobernanza en México. Análisis del cambio institucional en la agenda de buen gobierno

Ninguna parte de este escrito amparado por la Ley de Derechos de Autor, podrá ser reproducida, transmitida o utilizada en cualquier forma o medio, ya sea gráfico, electrónico o mecánico, incluyendo, pero sin limitarse a lo siguiente: Citas en artículos y comentarios bibliográficos, de compilación de datos periodísticos radiofónicos o electrónicos. Visite nuestro sitio WEB en: www.ecorfan.org

\section{Primera edición}

ISBN: 978-607-8534-89-0

Sello Editorial ECORFAN: 607-8534

Número de Control B: 2019-02

Clasificación B (2019):240219-0102

A los efectos de los artículos 13, 162, 163 fracción I, 164 fracción I, 168, 169,209, y otra fracción aplicable III de la Ley del Derecho de Autor 


\section{Books}

\section{Definición de Books}

\section{Objetivos Científicos}

Apoyar a la Comunidad Científica Internacional en su producción escrita de Ciencia, Tecnología en Innovación en las Áreas de investigación CONACYT y PRODEP.

ECORFAN-Mexico S.C es una Empresa Científica y Tecnológica en aporte a la formación del Recurso Humano enfocado a la continuidad en el análisis crítico de Investigación Internacional y está adscrita al RENIECYT de CONACYT con número 1702902, su compromiso es difundir las investigaciones y aportaciones de la Comunidad Científica Internacional, de instituciones académicas, organismos y entidades de los sectores público y privado y contribuir a la vinculación de los investigadores que realizan actividades científicas, desarrollos tecnológicos y de formación de recursos humanos especializados con los gobiernos, empresas y organizaciones sociales.

Alentar la interlocución de la Comunidad Científica Internacional con otros centros de estudio de México y del exterior y promover una amplia incorporación de académicos, especialistas e investigadores a la publicación Seriada en Nichos de Ciencia de Universidades Autónomas - Universidades Públicas Estatales - IES Federales Universidades Politécnicas - Universidades Tecnológicas - Institutos Tecnológicos Federales - Escuelas Normales - Institutos Tecnológicos Descentralizados - Universidades Interculturales - Consejos de CyT Centros de Investigación CONACYT.

\section{Alcances, Cobertura y Audiencia}

Books es un Producto editado por ECORFAN-Mexico S.C en su Holding con repositorio en México, es una publicación científica arbitrada e indizada. Admite una amplia gama de contenidos que son evaluados por pares académicos por el método de Doble-Ciego, en torno a temas relacionados con la teoría y práctica de las Área de investigación CONACYT y PRODEP respectivamente con enfoques y perspectivas diversos, que contribuyan a la difusión del desarrollo de la Ciencia la Tecnología e Innovación que permitan las argumentaciones relacionadas con la toma de decisiones e incidir en la formulación de las políticas internacionales en el Campo de las Ciencias. El horizonte editorial de ECORFAN-Mexico® se extiende más allá de la academia e integra otros segmentos de investigación y análisis ajenos a ese ámbito, siempre y cuando cumplan con los requisitos de rigor argumentativo y científico, además de abordar temas de interés general y actual de la Sociedad Científica Internacional. 


\section{Consejo Editorial}

ANGELES - CASTRO, Gerardo. PhD

University of Kent

SALGADO - BELTRÁN, Lizbeth. PhD

Universidad de Barcelona

ARANCIBIA - VALVERDE, María Elena. PhD

Universidad San Francisco Xavier de Chuquisaca

SEGOVIA - VARGAS, María Jesús. PhD

Universidad Complutense de Madrid

PEREIRA - LÓPEZ, Xesús. PhD

Universidad de Santiago de Compostela

NIÑO - GUTIÉRREZ, Naú Silverio. PhD

Universidad de Alicante

DE SAN JORGE - CARDENAS, Xóchitl Ma Del Carmen. PhD

Universidad de Granada

MARTÍNEZ - PRATS, Germán. PhD

Universidad Nacional del Sur

FRANZONI - VELAZQUEZ, Ana Lidia. PhD

Institut National des Telécommunications

HIRA, Anil. $\mathrm{PhD}$

Claremont Graduate School

BANERJEE, Bidisha. PhD

Amity University

IBARRA - ZAVALA, Darío Guadalupe. PhD

New School for Social Research

BARDEY, David. PhD

University of Besançon

GARCÍA Y MOISES, Enrique. PhD

Boston University

BLANCO - ENCOMIENDA, Francisco Javier. PhD

Universidad de Granada

SUYO - CRUZ, Gabriel. PhD

Universidad de Santiago de Compostela

CHAPARRO, Germán Raúl. PhD

Universidad Nacional de Colombia

FELDMAN, German. PhD

Johann Wolfgang Goethe Universität

VARGAS - HERNANDEZ, José G. PhD

Keele University 
RAMÍREZ - MARTÍNEZ, Ivonne Fabiana. PhD

Universidad Andina Simón Bolívar

ALIAGA - LORDEMANN, Francisco Javier. PhD

Universidad de Zaragoza

YAN - TSAI, Jeng. PhD

Tamkang University

GUZMÁN - HURTADO, Juan Luis. PhD

Universidad de Santiago de Compostela

SANCHEZ - CANO, Julieta Evangelina. PhD

Universidad Complutense de Madrid

BELTRÁN - MORALES, Luis Felipe. PhD

Universidad de Concepción

GARCIA - ESPINOZA, Lupe Cecilia. PhD

Universidad de Santiago de Compostela

MIRANDA - GARCÍA, Marta. PhD

Universidad Complutense de Madrid

TORRES - HERRERA, Moisés. PhD

Universidad Autónoma de Barcelona

GÓMEZ - MONGE, Rodrigo. PhD

Universidad de Santiago de Compostela

POSADA - GÓMEZ, Rubén. PhD

Institut National Polytechnique de la Lorraine

VILLASANTE, Sebastián. PhD

Universidad de Santiago de Compostela

ORDÓÑEZ - GUTIÉRREZ, Sergio Adrián. PhD

Universidad Paris VIII

BLANCO - GARCÍA, Susana. PhD

Universidad Complutense de Madrid

VALDIVIA - ALTAMIRANO, William Fernando. PhD

Universidad Nacional Agraria La Molina

DE AZEVEDO - JUNIOR, Wladimir Colman. PhD

Universidade Federal do Amazonas

VARGAS - DELGADO, Oscar René. PhD

Universidad de Santiago de Compostela

LUO, Yongli. PhD

Universidad de Chongqing

CUBÍAS-MEDINA, Ana Elizabeth. PhD

Universidad Carlos III de Madrid

SEGURA - DE DUEÑAS, Cecilia Elizabeth. PhD

Universidad Autónoma de Barcelona 
ROSILLO - MARTÍNEZ, Alejandro. PhD

Universidad Carlos III de Madrid

MIRANDA - TORRADO, Fernando. PhD

Universidad de Santiago de Compostela

PALACIO, Juan. PhD

University of St. Gallen

CAMPOS - QUIROGA, Peter. PhD

Universidad Real y Pontifica de San Francisco Xavier de Chuquisaca

BARRERO-ROSALES, José Luis. PhD

Universidad Rey Juan Carlos III

GUZMAN - SALA, Andrés. PhD

University of California

DIMAS - RANGEL, María Isabel. PhD

Universidad José Martí de Latinoamérica

DANTE - SUAREZ, Eugenio. PhD

Arizona State University

D. EVANS, Richard. PhD

University of Greenwich

ALVARADO - BORREGO, Aida. PhD

Universidad Autónoma de Sinaloa

CERVANTES - ROSAS, María de los Ángeles. PhD

Universidad de Occidente

DOMÍNGUEZ - GUTIÉRREZ, Silvia. PhD

Universidad de Guadalajara

ARRIETA - DÍAZ, Delia. PhD

Escuela Libre de Ciencias Políticas y Administración Pública de Oriente

LUIS - PINEDA, Octavio. PhD

Instituto Politécnico Nacional

REYES - MONJARAS, María Elena. PhD

Universidad Veracruzana

RUIZ - MARTINEZ, Julio César. PhD

Instituto Politécnico Nacional

VELÁSQUEZ - SÁNCHEZ, Rosa María. PhD

Instituto Tecnológico de Oaxaca

PÉREZ - SOTO, Francisco. PhD

Colegio de Postgraduados

SANROMÁN - ARANDA, Roberto. PhD

Universidad Panamericana

IBARRA - RIVAS, Luis Rodolfo. PhD

Universidad Autónoma del Estado de Morelos 
SALDAÑA - CARRO, Cesar. PhD

Colegio de Tlaxcala

TAVERA - CORTÉS, María Elena. PhD

Colegio de Postgraduados

CONTRERAS - ÁLVAREZ, Isaí. PhD

Universidad Autónoma Metropolitana

MÁRQUEZ - IBARRA, Lorena. PhD

Instituto Tecnológico de Sonora

ESPINOZA - VALENCIA, Francisco Javier. PhD

Instituto Pedagógico de Posgrado en Sonora

VÁZQUEZ - OLARRA, Glafira. PhD

Universidad Michoacana de San Nicolás de Hidalgo

PELAYO - MACIEL, Jorge. PhD

Universidad de Guadalajara

GARCÍA - ROJAS, Jesús Alberto. PhD

Universidad de Puebla

CAMELO - AVEDOY, José Octavio. PhD

Universidad de Guadalajara

GAZCA - HERRERA, Luis Alejandro. PhD

Instituto de Administración Pública del Estado de Veracruz

LANDAZURI - AGUILERA, Yara. PhD

Universidad Autónoma de Nuevo León

TAPIA - MEJIA, Erik. PhD

El Colegio de Tlaxcala 


\section{Comité Arbitral}

MANRÍQUEZ - CAMPOS, Irma. PhD

Instituto de Investigaciones Económicas - UNAM

MAGAÑA - MEDINA, Deneb Elí. PhD

Universidad del Mayab

QUIROZ - MUÑOZ, Enriqueta María. PhD

Colegio de México

VILLALBA - PADILLA, Fátima Irina. PhD

Instituto Politécnico Nacional

RASCÓN - DÓRAME, Luis Tomas. PhD

Instituto Pedagógico de Posgrado de Sonora

SÁNCHEZ - TRUJILLO, Magda Gabriela. PhD

Universidad de Celaya

ELIZUNDIA - CISNEROS, María Eugenia. PhD

Universidad Nacional Autónoma de México

FERNÁNDEZ - GARCÍA, Oscar. PhD

Instituto Politécnico Nacional

ARCOS - VEGA, José Luis. PhD

Universidad Iberoamericana

MORENO - ELIZALDE, María Leticia. PhD

Instituto Universitario Anglo Español

HERNÁNDEZ - LARIOS, Martha Susana. PhD

Universidad Cuauhtémoc

SALAMANCA - COTS, María Rosa. PhD

Universidad Nacional Autónoma de México

ÁVALOS - RODRÍGUEZ, María Liliana. PhD

Universidad Michoacana de San Nicolás de Hidalgo

ELISEO - DANTÉS, Hortensia. PhD

Universidad Hispanoamericana Justo Sierra

FORNÉS - RIVERA, René Daniel. PhD

Instituto Tecnológico de Sonora

LEGORRETA - BARRANCOS, Leydi Elena. PhD

Instituto Humanista de Estudios Superiores

GONZALEZ - GARCIA, Guadalupe. PhD

Instituto de Estudios Superiores ISIMA

LÓPEZ - TORRES, María del Rosario. PhD

Universidad del Estado de Puebla

MALDONADO - SANCHEZ, Marisol. PhD

Universidad Autónoma de Tlaxcala 
RIOS - VAZQUEZ, Nidia Josefina. PhD

Instituto Tecnológico de Sonora

SALAZAR - VÁZQUEZ - Fernando Adolfo. PhD

Instituto Universitario Internacional de Toluca

SÁNCHEZ - VÁZQUEZ, Elizabeth. PhD

Universidad ETAC

GALICIA - PALACIOS, Alexander. PhD

Instituto Politécnico Nacional

BUJARI - ALLI, Ali. PhD

Instituto Politécnico Nacional

GIRÓN, Alicia. PhD

Universidad Nacional Autónoma de México

COBOS - CAMPOS, Amalia Patricia. PhD

Universidad Autónoma de Chihuahua

CÓRDOVA - RANGEL, Arturo. PhD

Universidad Nacional Autónoma de México

PERALES - SALVADOR, Arturo. PhD

Universidad Autónoma de Chapingo

AZIZ - POSWAL, Bilal. PhD

Instituto Politécnico Nacional

CAMPOS - RANGEL, Cuauhtémoc Crisanto. PhD

Universidad Autónoma de Tlaxcala

MORÁN - CHIQUITO, Diana María. PhD

Universidad Autónoma Metropolitana

NOVELO - URDANIVIA, Federico Jesús. PhD

Universidad Autónoma Metropolitana

CRUZ - ARANDA, Fernando. PhD

Instituto Tecnológico y de Estudios Superiores de Monterrey

ÁLVAREZ - ECHEVERRIA, Francisco Antonio. PhD

Universidad Nacional Autónoma de México

GÓMEZ - CHIÑAS, Carlos. PhD

Instituto Politécnico Nacional

ORTIZ - ARANGO, Francisco. PhD

Instituto Tecnológico y de Estudios Superiores de Monterrey

LINAREZ - PLACENCIA, Gildardo. PhD

Centro Universitario de Tijuana

HERNÁNDEZ, Carmen Guadalupe. PhD

Instituto Politécnico Nacional

VARGAS - SANCHEZ, Gustavo. PhD

Universidad Autónoma Metropolitana 
GUILLEN - MONDRAGÓN, Irene Juana. PhD

Universidad Autónoma Metropolitana

CASTILLO - DIEGO, Teresa Ivonne. PhD

Universidad Autónoma de Tlaxcala

TREJO - GARCÍA, José Carlos. PhD

Instituto Politécnico Nacional

MANJARREZ - LÓPEZ, Juan Carlos. PhD

El Colegio de Tlaxcala

SANTILLÁN - NÚÑEZ, María Aída. PhD

Escuela Normal de Sinaloa

MARTÍNEZ - SÁNCHEZ, José Francisco. PhD

Instituto Politécnico Nacional

COTA - YAÑEZ, María del Rosario. PhD

Universidad de Guadalajara

GARCÍA - ELIZALDE, Maribel. PhD

Universidad Nacional Autónoma de México

MARTÍNEZ - GARCÍA, Miguel Ángel. PhD

Instituto Politécnico Nacional

GONZÁLEZ - IBARRA, Miguel Rodrigo. PhD

Universidad Nacional Autónoma de México

ESCALETA - CHÁVEZ, Milka Elena. PhD

Universidad Autónoma de San Luis Potosí

MARTÍNEZ - HERNÁNDEZ, Mizraim. PhD

Colegio Universitario de Distrito Federal

GAVIRA - DURÓN, Nora. PhD

Instituto Politécnico Nacional

BECERRIL - TORRES, Osvaldo U. PhD

Universidad Autónoma del Estado de México

CAMPOS - ALVAREZ, Rosa Elvira. PhD

Universidad Autónoma de Durango

CAPRARO - RODRÍGUEZ, Santiago Gabriel Manuel. PhD

Universidad Nacional Autónoma de México

ISLAS - RIVERA, Víctor Manuel. PhD

Instituto Politécnico Nacional

PÉREZ - RAMÍREZ, Rigoberto. PhD

Universidad Nacional Autónoma de México

RIVAS - CASTILLO, Jaime Roberto. PhD

Centro de Investigaciones y Estudios Superiores en Antropología Social

PELÁEZ - PADILLA, Jorge. PhD

Universidad Nacional Autónoma de México 
NIEVA - ROJAS Jefferson. PhD

Universidad Autónoma de Occidente

BURGOS - MATAMOROS, Mylai. PhD

Universidad Nacional Autónoma de México

OLIVO - ESTRADA, José Ramón. PhD

Instituto Pedagógico de Estudios de Posgrado

HUERTA - QUINTANILLA, Rogelio. PhD

Universidad Nacional Autónoma de México

PEREZ - BRAVO, Julia. PhD

Escuela Libre de Ciencias Políticas y Administración Pública

GONZÁLEZ - HERRERA, Karina Concepción. PhD

El Colegio de Tlaxcala

REYNOSO - IBARRA, Omayra Yolanda. PhD

Instituto Tecnológico Superior de San Luis Potosí

PEREZ - VEYNA, Oscar. PhD

Universidad Juárez del Estado de Durango

QUIJANO - GARCIA, Román Alberto. PhD

Universidad Anáhuac Mayab

GARCÍA - VILLALOBOS, Alejandro Rodolfo. PhD

Universidad Cuauhtémoc

AHUMADA - TELLO, Eduardo. PhD

Universidad Iberoamericana del Noroeste 


\section{Cesión de Derechos}

El envío de una Obra Científica a ECORFAN Books emana el compromiso del autor de no someterlo de manera simultánea a la consideración de otras publicaciones científicas para ello deberá complementar el Formato de Originalidad para su Obra Científica.

Los autores firman el Formato de Autorización para que su Obra Científica se difunda por los medios que ECORFAN-México, S.C. en su Holding México considere pertinentes para divulgación y difusión de su Obra Científica cediendo sus Derechos de Obra Científica.

\section{Declaración de Autoría}

Indicar el Nombre de 1 Autor y 3 Coautores como máximo en la participación de la Obra Científica y señalar en extenso la Afiliación Institucional indicando la Dependencia.

Identificar el Nombre de 1 Autor y 3 Coautores como máximo con el Número de CVU Becario-PNPC o SNICONACYT- Indicando el Nivel de Investigador y su Perfil de Google Scholar para verificar su nivel de Citación e índice $\mathrm{H}$.

Identificar el Nombre de 1 Autor y 3 Coautores como máximo en los Perfiles de Ciencia y Tecnología ampliamente aceptados por la Comunidad Científica Internacional ORC ID - Researcher ID Thomson - arXiv Author ID - PubMed Author ID - Open ID respectivamente

Indicar el contacto para correspondencia al Autor (Correo y Teléfono) e indicar al Investigador que contribuye como primer Autor de la Obra Científica.

\section{Detección de Plagio}

Todas las Obras Científicas serán testeadas por el software de plagio PLAGSCAN si se detecta un nivel de plagio Positivo no se mandará a arbitraje y se rescindirá de la recepción de la Obra Científica notificando a los Autores responsables, reivindicando que el plagio académico está tipificado como delito en el Código Penal.

\section{Proceso de Arbitraje}

Todas las Obras Científicas se evaluarán por pares académicos por el método de Doble Ciego, el arbitraje Aprobatorio es un requisito para que el Consejo Editorial tome una decisión final que será inapelable en todos los casos. MARVID® es una Marca de derivada de ECORFAN® especializada en proveer a los expertos evaluadores todos ellos con grado de Doctorado y distinción de Investigadores Internacionales en los respectivos Consejos de Ciencia y Tecnología el homologo de CONACYT para los capítulos de America-Europa-AsiaAfrica y Oceania. La identificación de la autoría deberá aparecer únicamente en una primera página eliminable, con el objeto de asegurar que el proceso de Arbitraje sea anónimo y cubra las siguientes etapas: Identificación del ECORFAN Books con su tasa de ocupamiento autoral - Identificación del Autores y Coautores- Detección de Plagio PLAGSCAN - Revisión de Formatos de Autorización y Originalidad-Asignación al Consejo EditorialAsignación del par de Árbitros Expertos-Notificación de Dictamen-Declaratoria de Observaciones al AutorCotejo de la Obra Científica Modificado para Edición-Publicación. 
Administración pública y gobernanza en México. Análisis del cambio institucional en la agenda de buen gobierno

Public administration and governance in Mexico. Analysis of institutional changein the agenda of good government

PÉREZ-RAMÍREZ Rigoberto

Universidad Autónoma del Estado de México

ID $1^{\text {er }}$ Autor: Rigoberto Pérez-Ramírez / ORC ID: 0000-0003-2982-2676, Researcher ID Thomson: B-2673-2016, arXiv Author ID: rperezr, CVU CONACYT-ID: 88934 


\section{Administración pública y gobernanza en México. Análisis del cambio institucional en la agenda de buen gobierno}

El Book ofrecerá contribuciones seleccionadas de investigadores que contribuyan a la actividad de difusión científica de la Universidad Autónoma del Estado de México para su área de investigación en la función de la Universidad ante los retos de la Sociedad del Conocimiento. Además de tener una evaluación total, en las manos de los directores de la Universidad Autónoma del Estado de México se colabora con calidad y puntualidad en sus capítulos, cada contribución individual fue arbitrada a estándares internacionales (RESEARCH GATE, MENDELEY, GOOGLE SCHOLAR y REDIB), el Book propone así a la comunidad académica, los informes recientes sobre los nuevos progresos en las áreas más interesantes y prometedoras de investigación en la función de la Universidad ante los retos de la Sociedad del Conocimiento. 


\section{Contenido}

Prefacio

Resumen

Abstract

Introducción

Capítulo 1 Fundamentos teóricos del nuevo institucionalismo 9

$\begin{array}{lr}1.1 \text { Definición de institución } & 10\end{array}$

$\begin{array}{ll}1.2 \mathrm{El} \text { institucionalismo sociológico } & 11\end{array}$

$\begin{array}{lr}1.3 \text { El nuevo institucionalismo económico } & 13\end{array}$

$\begin{array}{lr}\text { 1.3.1 Cambio institucional } & 17\end{array}$

$\begin{array}{lr}\text { 1.3.2 Costos de transacción } & 19\end{array}$

$\begin{array}{lr}\text { 1.3.3 Derechos de propiedad } & 21\end{array}$

$\begin{array}{ll}\text { 1.3.4 Información incompleta y asimétrica } & 22\end{array}$

$\begin{array}{ll}\text { 1.3.5 Desempeño económico } & 23\end{array}$

Capítulo 2 El nuevo institucionalismo y la administración pública 24

$\begin{array}{lr}2.1 \text { La administración pública } & 24\end{array}$

$\begin{array}{ll}2.2 \text { Nuevo institucionalismo y administración pública } & 25\end{array}$

$\begin{array}{ll}2.3 \text { Cambio institucional y administración pública. } & 27\end{array}$

$\begin{array}{lr}2.4 \text { Desempeño institucional y gestión pública } & 28\end{array}$

$\begin{array}{lr}2.5 \text { Gobernanza } & 30\end{array}$

2.6 Nueva gestión pública y gobernanza $\quad 33$

Capítulo 3 El cambio institucional en la Agenda de Buen Gobierno 36

3.1 El principio de la innovación gubernamental 36

3.2 Modelo Estratégico para la Innovación y la Calidad Gubernamental 38

3.3 Reformas legales para el cambio democrático institucional 43

3.3.1 Ley Federal de Responsabilidades Administrativas de los Servidores Públicos 45

3.3.2 La Ley de Transparencia y Acceso a la Información Pública Gubernamental 47

3.3.3 Ley de Servicio Profesional de Carrera de la Administración Pública Federal 47

$\begin{array}{ll}3.4 \text { Agenda de Buen Gobierno } & 48\end{array}$

$\begin{array}{lr}3.4 .1 \text { Gobierno honesto y transparente } & 49\end{array}$

$\begin{array}{lr}\text { 3.4.2 Un gobierno profesional } & 54\end{array}$

$\begin{array}{lr}\text { 3.4.3 Un gobierno de calidad } & 56\end{array}$

$\begin{array}{lr}3.4 .4 \text { Un gobierno digital } & 59\end{array}$

$\begin{array}{lr}3.4 .5 \text { Gobierno con mejora regulatoria } & 62\end{array}$

$\begin{array}{ll}\text { 3.4.6 Gobierno que cueste menos } & 63\end{array}$

$\begin{array}{lr}3.5 \text { Buena gobernanza } & 64\end{array}$

Capítulo 4 Análisis del desempeño del cambio institucional en la administración pública mexicana 2000-2006

4.1 Transparencia

4.1.1 La transparencia reduce costos de la asimetría de información 76

$\begin{array}{ll}\text { 4.2 De la transparencia a la rendición de cuentas } & 78\end{array}$

$\begin{array}{lr}\text { 4.2.1 La rendición de cuentas en el modelo principal-agente } & 80\end{array}$

$\begin{array}{lr}\text { 4.2.2 Rendición de cuentas vertical } & 81\end{array}$

$\begin{array}{ll}\text { 4.2.3 Rendición de cuentas horizontal } & 83\end{array}$

4.3 La institucionalización del servicio profesional de carrera $\quad 85$

$\begin{array}{lr}4.4 \text { El combate a la corrupción } & 90\end{array}$

$\begin{array}{ll}\text { 4.4.1 Corrupción y costos de transacción } & 95\end{array}$

\begin{tabular}{lr} 
Conclusiones & 98 \\
\hline
\end{tabular}

$\begin{array}{lr}\text { Referencias } & 103\end{array}$

$\begin{array}{lr}\text { Siglas } & 113\end{array}$ 


\section{Prefacio}

El presente trabajo es resultado del debate y desarrollo enriquecedor de ideas en seminarios de investigación doctoral tales como: Gobernabilidad y Administración Pública, Gestión Pública y Gobernanza, Investigación Política y Gobierno, durante mi estancia de postgrado en la Universidad Nacional Autónoma de México. Impulsando un espíritu por examinar el papel del cambio institucional de la administración pública mexicana como componente de la capacidad y eficacia directiva del proceso de gobierno, de la gobernanza, que guarda una relación con los instrumentos de transparencia, rendición de cuentas, estado de derecho, profesionalización administrativa, entre otros, los cuales van a permitir observar la calidad de las políticas públicas implementadas por la Agenda de Buen Gobierno. Y de esta forma responder a cuestiones de suyo complejas, pues las preguntas no lo son menos: ¿El diseño propuesto por la Agenda de Buen Gobierno responde a su lógica interna de burocracia, o responde a una nueva lógica de administrar y gobernar? ¿Las estrategias de la Agenda de Buen Gobierno responden a la mejora, la innovación y la modernización de administración pública? ¿Los cambios institucionales en la administración pública basados en el servicio profesional de carrera, la rendición de cuentas, la transparencia y el combate a la corrupción, se tradujeron en un mejor desempeño gubernamental? ¿Cuáles fueron los alcances y límites de la Agenda de Buen Gobierno bajo el modelo de la nueva gestión pública? y ¿En qué medida la estrategia de innovación gubernamental de la administración Fox constituye un perfil de buena gobernanza?

Éstas y más interrogantes habrán que analizarse a la luz del presente de un gobierno como el de Vicente Fox, que arribó al poder con gran legitimidad pero que el transcurso de su ejercicio de poder, es decir, la racionalización de su gestión, la eficacia de su acción, la participación ciudadana y los usuarios de los servicios públicos, fue perdiendo apoyo popular, haciendo caer a los ciudadanos en la más pura indiferencia en las acciones de gobierno.

En el México posrevolucionario las limitantes institucionales resultantes de la planeación del desarrollo y de la expansión de papel del Estado dentro de una política económica a sustituir importaciones, fueron encauzadas a través de la creación de instituciones ad hoc. Bancos de fomento y/o instituciones especializadas fueron creados para manejar los esfuerzos específicos de las inversiones y las funciones del desarrollo. También hubo algunos esfuerzos parciales para modernizar los sistemas de presupuestos, de adquisiciones y de servicio civil. El uso de unidades de proyectos o de agencias autónomas al margen de las secretarías tradicionales de gobierno, así como las empresas públicas, devinieron en instrumentos institucionales para la acción del Estado.

El resultado de esta política fue el sucesivo debilitamiento de las secretarías tradicionales de gobierno y de una administración pública paralela, con condiciones de trabajo privilegiadas y que en muchos casos respondía más a la orientación de los donantes externos que a las autoridades políticas nacionales. Se usaron empresas públicas para compensar la debilidad de las empresas privadas nacionales, pero en la mayoría de los casos acabaron convirtiéndose en ineficientes drenajes de los tesoros nacionales. 
Este sistema institucional dual, además de minar la rendición de cuentas a las autoridades elegidas y de debilitar con ello la gobernación (acción y efecto de gobernar), engendraba que las burocracias tradicionales y los grupos tradicionales de poder impusieran un fuerte sistema de privilegios, prebendas y negocios que giraban alrededor del sector público llegando a convertirse en una fuerte traba para mejorar y modernizar las políticas de gobierno en aspectos importantes: licitación pública de los contratos; desregulación y simplificación del aparato regulatorio y del sistema de permisos y licencias; implantación de mecanismos de rendición de cuentas, control y fiscalización del gobierno más eficientes y con mayor participación social.

Por ello, la lógica consecuencia institucional del papel reducido del Estado en términos del menor ámbito funcional que el ajuste estructural requiere y su impacto sobre la estructura general del Estado recibió inicialmente una atención escasa y verdaderamente no sistemática. La teoría económica contemporánea ha abordado el tema del papel del Estado, pero lo ha hecho exclusivamente desde la perspectiva económica clásica no tomando en cuenta la perspectiva de la llamada teoría neoinstitucional.

Sin embargo, ello ha cambiado pues algunas investigaciones sobre aspectos institucionales emprendidas bajo los auspicios del Banco Mundial y el Fondo Monetario Internacional, reconocen explícitamente la importancia de las instituciones para el desempeño económico, cuando apenas hace poco tiempo habían supuesto que las reformas de mercado, por sí solas, serían condición suficiente para que los países en desarrollo o en transición al mercado (caso México) remontarán sus ancestrales problemas de pobreza, desigualdad y estancamiento económico. En la actualidad estos organismos reconocen que se necesita una "segunda generación" de reformas cuyo componente básico es justamente la reforma institucional donde la gobernanza es factor importante.

Como muestra la experiencia en México el paquete de reformas del mercado (privatización, desregulación, apertura comercial) que responden al proceso de globalización han conducido a una pérdida sustancial de la legitimidad del gobierno debido a una combinación de acciones arbitrarias del ajuste estructural o una falta de instituciones adecuadas que coordinen dicho ajuste de manera menos vulnerable para la sociedad.

El cambio político en el año 2000, en que después de 71 años el PRI pierde el poder, dando paso a la alternancia política con el PAN, significó que el Ejecutivo Federal bajo el esquema de legitimidad que le dieron los resultados electorales, emprendió un ambicioso paquete de reformas a la gestión pública. Éste a su vez podía traducirse en un elemento útil de afianzar tal legitimidad y devolver la credibilidad a la ciudadanía en el gobierno. En este contexto, considero que la importancia de la investigación radica en resaltar que en un periodo de cambio como el que se analiza, el papel del cambio institucional de la administración pública mexicana como componente de la capacidad y eficacia directiva del proceso de gobierno, de la gobernanza.

Sin embargo, como ocurre en casi todo lo humano, muchas aspiraciones quedan incumplidas o diferidas, con la espera de que las futuras instancias vitales permitan su realización. Este esfuerzo que hoy se objetiva mañana será trozo de un pasado y base de una búsqueda de nuevos horizontes intelectuales. Ojalá este trabajo en algo contribuya a los interesados en el enriquecimiento de la administración pública y la gobernanza.

La secuencia metodológica de la presente investigación se apoya en la inferencia lógica, cuyo razonamiento importa porque es la forma de elaborar de modo actual premisas y conclusiones, que permiten definir desde la retórica y la dialéctica, la argumentación que es la base del trabajo debido al objeto de estudio.

Con base en las ideas de Giandomenico Majone (2005), la investigación descansa en el análisis como trabajo artesanal que proporciona categorías (datos, información, herramientas, evidencia, argumento) aplicables a cualquier tipo y estilo de análisis, sea retrospectivo como prospectivo, descriptivo como prescriptivo, argumentativo como "científico". $\mathrm{Y}$ en este sentido, se aplica la inferencia lógica. 
La inferencia lógica en el estudio de la relación causal entre cambio institucional de la administración pública y la gobernanza se enfoca principalmente en el análisis de la agenda de buen gobierno en un periodo particular de 2000 a 2006, lo cual permitirá explicar los indicadores cualitativos de la agenda. Por ejemplo, "las estadísticas económicas son resultado de la manipulación burocrática de cantidades enormes de piezas de información fragmentarias y aun ambiguas [...]" (Majone, 2005: 99). Por ello, esta investigación en lo particular es cualitativa y también se apoya en el método hermenéutico que consiste en interpretación de las fuentes primarias (estudio de gabinete) que nos conduzcan a una disertación y comprensión del objeto de estudio que tiene un carácter teórico e histórico. En el trabajo se recurre a fuentes bibliográficas, hemerográficas y de internet, como técnicas de recopilación de la información. 


\title{
Resumen
}

Administración Pública y Gobernanza en México. Análisis del Cambio Institucional en la Agenda de Buen Gobierno, tiene como objetivo principal analizar el proceso del cambio institucional de la administración pública mexicana a partir de la Agenda de Buen Gobierno en un periodo de cambio político (2000-2006), con la finalidad de explicar los alcances y límites de dicha agenda en la mejora, innovación y modernización de la gestión pública. Para explicar el proceso del cambio institucional en la Agenda de Buen Gobierno, se pone énfasis en las corrientes del nuevo institucionalismo sociológico y nuevo institucionalismo económico a través de las categorías cambio institucional, costos de transacción, información incompleta y asimétrica, desempeño institucional, isomorfismo institucional e institucionalización. De tal suerte, la secuencia metodológica de la presente investigación se apoya en la inferencia lógica, cuyo razonamiento importa porque es la forma de elaborar de modo actual premisas y conclusiones, que permiten definir desde la retórica y la dialéctica, la argumentación que es la base del trabajo debido al del objeto de estudio. Ello nos ofrece una forma de pensar diferente y contribuir al análisis de la administración pública, guiados por la premisa de averiguar qué actor gubernamental hace qué, cómo lo hace y con qué resultados.

\section{Administración pública, Gobernanza, Cambio institucional}

\begin{abstract}
Public Administration and Governance in Mexico. Analysis of Institutional Change in the Good Government Agenda, has as main objective to analyze the process of institutional change of the Mexican public administration from the Good Government Agenda in a period of political change (2000-2006), with the purpose of explain the scope and limits of said agenda in the improvement, innovation and modernization of public management. To explain the process of institutional change in the Good Government Agenda, emphasis is placed on the currents of the new sociological institutionalism and new economic institutionalism through the categories institutional change, transaction costs, incomplete and asymmetric information, institutional performance, institutional isomorphism and institutionalization. In this way, the methodological sequence of the present investigation is based on the logical inference, whose reasoning matters because it is the way to elaborate in a current way premises and conclusions, that allow to define from the rhetoric and the dialectic, the argumentation that is the basis of work due to the object of study. This offers us a different way of thinking and contributes to the analysis of public administration, guided by the premise of finding out which governmental actor does what, how he does it and with what results.
\end{abstract}

\section{Public administration, Governance, Institutional change}




\section{Introducción}

En México, la crisis del modelo de Estado intervencionista se manifestó claramente en la década de los ochenta, acelerada por el proceso de globalización de la economía mundial. Ésta se caracterizó por el agotamiento del modelo proteccionista de subsidios y sustitución de importaciones, que dejó de ser exitoso en cuanto a promover la industrialización del país a principios del decenio de los setenta, expresando el fracaso para crear un Estado de bienestar social, en la provisión de bienes y servicios públicos para beneficio del conjunto de la nación.

En la política intervencionista, la administración pública quedó sujeta a la centralización de funciones para el fomento de la normatividad, la planeación y la coordinación, supeditadas al proyecto de estabilidad económica. Así como, el fortalecimiento del ejecutivo -concretamente el presidente-, con la ascensión de la burocracia como grupo privilegiado de la negociación política.

También en la década de los ochenta, el Estado mexicano fue sacudido por la demanda social de democratización y redimensionamiento del aparato público, dos aspectos de una misma unidad, que florecieron a la luz del régimen mexicano que combinaba autoritarismo e hipertrofia, en el cual el ámbito estatal y el aparato gubernamental se acompañaron con el autoritarismo burocrático.

Los problemas del Estado mexicano de entonces crecieron simultáneamente bajo dos lógicas: a) crecimiento de formas de representación política derivada de la creciente, aunque incipiente, pluralidad de la sociedad mexicana; y b) un avance constante de las desigualdades sociales, incremento de la extrema pobreza, rezagos en el servicio administrativo, así como ausencia en la definición de políticas que integraran el sentido de servicio al Estado. Asimismo, otro problema era enfrentar las viejas limitaciones de la decisión y gestión gubernamental, como: la conducción centralizada, la tentación patrimonialista, el descuido de recursos y bienes públicos, la burocratización de las iniciativas y, principalmente, la fundamentación factual, narrativa y proyectual del Estado (en vez de una normativa, argumentativa y estratégicamente funcional). Este arreglo funcional del Estado mexicano se distinguió en lo político por un poder centralizado y unipersonal; y en el ámbito administrativo público por el gigantismo burocrático, los excesivos gastos públicos, entre otros.

De tal suerte, que el país ha venido emprendiendo esfuerzos tendientes a la reforma institucional del Estado y la modernización de la administración pública, que abarcan desde el redimensionamiento de la estructura organizativa de la administración pública hasta el diseño institucional del Estado con los aportes de los enfoques del nuevo institucionalismo en las ciencias sociales, adaptando esquemas y procedimientos de operación de las tendencias y entidades públicas a las exigencias de competitividad del momento, como la Nueva Gestión Pública (NGP) y la Gobernanza.

En la actualidad las transformaciones que vive la administración pública mexicana se centran en el cuestionamiento de su capacidad de gobierno, haciendo énfasis en la eficiencia y eficacia de la Administración Pública (AP) que con limitados recursos tiene que atender de manera adecuada y oportuna, las necesidades y requerimientos crecientes de una sociedad más participativa y demandante, convirtiéndose la AP en la parte más visible del gobierno, la cual está recuperando su carácter público en la medida en que la vida pública es objeto de desestatización y desburocratización.

Ello contrasta con el hecho de que los esquemas administrativos tradicionales no necesariamente propiciaron una participación activa de la sociedad, lo que impidió un compromiso claro de la administración pública con los fines y valores del servicio público. Estas disfunciones favorecieron patronazgos, clientelismos, corrupción entre otros comportamientos indeseables, que se evidenciaron de muchas maneras, particularmente en el momento de cambiar las administraciones. El escenario actual es de una ciudadanía más exigente y de una administración pública con serios rezagos que han puesto de manifiesto la necesidad de realizar cambios en la administración, que resuelvan, o, al menos, aminoren esos problemas.

La aparición de nuevas necesidades sociales y problemas colectivos como la inseguridad global, la crisis energética, los riesgos medioambientales, las migraciones, la pobreza extrema, el desempleo, entre otros, están trasladando a los gobiernos problemas que ni las personas -individualmente o asociándose en forma privada- ni los mercados son capaces de resolver. 
Lo anterior reclama la integración de una agenda pública para cuyo desarrollo los gobiernos y sus organizaciones carecen de capacidad y de la legitimidad que les habían venido permitiendo un protagonismo casi exclusivo en la producción de respuestas públicas. El gobierno sigue siendo un actor central, pero debe compartir la esfera pública con otros actores públicos y privados.

En este contexto, esta obra intitulada Administración Pública y Gobernanza en México. Análisis del Cambio Institucional en la Agenda de Buen Gobierno, tiene como objetivo principal analizar el proceso del cambio institucional de la administración pública mexicana a partir de la Agenda de Buen Gobierno en un periodo de cambio político (2000-2006), con la finalidad de explicar los alcances y límites de dicha agenda en la mejora, innovación y modernización de la gestión pública.

Para llevar a cabo el cambio y la transformación de la administración pública y focalizar los resultados en buen gobierno, la administración de Vicente Fox, a través de la Oficina de Innovación Gubernamental (OIG), encabezada por Ramón Muñoz Gutiérrez, presentó el Modelo Estratégico para la Innovación del Gobierno (MEIG). El modelo estratégico consideró la innovación del gobierno como un movimiento de carácter cultural y estructural, que buscaba reformar radicalmente la orientación, la capacidad y velocidad de respuesta estratégica de la Administración Pública Federal, revisualizándolo todo desde múltiples perspectivas. De esta manera, se destacó la presencia de conceptos y definiciones que se establecían en el contexto internacional -innovación y calidad gubernamental, reingeniería de procesos, gestión estratégica y buen gobierno-.

La innovación gubernamental en su génesis se basó en los principios relacionados con la new public management o nueva gestión pública, la cual se caracterizó por la incorporación de prácticas corporativas al gobierno cuya institucionalización alrededor del mundo se inicia entre mediados y finales de la década de los ochenta. Así como, la incorporación de normas básicas de acción gubernamental (gobernanza): apego a la legalidad, gobernanza democrática, transparencia y rendición de cuentas, y combate a la corrupción.

Lo anterior permite orientar este trabajo en el sentido de que el factor decisivo para que el gobierno asuma los cambios institucionales con base en la Agenda de Buen Gobierno (ABG) para la mejora, innovación y modernización de la administración pública, corre a cargo de la nueva gestión pública y la gobernanza, es decir, de la incorporación de principios de eficiencia y eficacia, y de la cooperación e interacción de las redes interdependientes de actores que comprenden el gobierno, la sociedad y el sector privado.

La obra se sustenta en cuatro capítulos para argumentar la discusión conceptual sobre el papel que juega la nueva gestión pública y la gobernanza en el cambio institucional y la formulación de la ABG. En los dos primeros capítulos se desarrolla una reconstrucción de la teoría neo-institucionalista en diversos ámbitos y sus relaciones con la gobernanza a través de conceptos tales como "costos de transacción", "información incompleta y asimétrica", cuya disminución en la esfera de la administración pública es crucial para fortalecer los procesos de transparencia, rendición de cuentas y control de la corrupción en el ámbito de una sociedad democrática. En los siguientes dos capítulos se revisa cronológicamente y a través de diversas fuentes la formulación de la Agenda de Buen Gobierno durante la administración de Vicente Fox, así como la promulgación de leyes y formación de instituciones de transparencia y rendición de cuentas bajo una perspectiva analítica y crítica que se desarrolla en el capítulo cuatro. De tal suerte que el trabajo se divide, a saber:

Capítulo 1. Fundamentos teóricos del nuevo institucionalismo.

Capítulo 2. El nuevo institucionalismo y la administración pública.

Capítulo 3. El cambio institucional en la Agenda de Buen Gobierno.

Capítulo 4. Análisis del desempeño del cambio institucional en la administración pública mexicana.

El capítulo 1. Fundamentos teóricos del nuevo institucionalismo, analiza la construcción teóricometodológica de los distintos enfoques del nuevo institucionalismo para explicar el proceso del cambio institucional en la Agenda de Buen Gobierno en la administración pública mexicana, poniendo énfasis en las corrientes del nuevo institucionalismo sociológico y nuevo institucionalismo económico a través de las categorías cambio institucional, costos de transacción, información incompleta y asimétrica, desempeño institucional, isomorfismo institucional e institucionalización. 
En este sentido, se está frente a un enfoque multidisciplinario que enriquece el debate y la investigación, convirtiéndose en el nuevo paradigma dominante del pensamiento de las ciencias sociales. Como bien argumentan algunos autores, en el estudio de las instituciones hoy en día, no basta con tomar tan sólo una disciplina, sino hace falta retomar diversos enfoques para tener un estudio más profundo y completo, lo cual hace que estas interpretaciones ratifiquen la dimensión multianalítica del nuevo institucionalismo.

El capítulo 2. El nuevo institucionalismo y la administración pública, analiza a través del término cambio institucional el tránsito de la administración pública burocrática a la administración pública postburocrática por medio de la nueva gestión pública y la gobernanza, como nuevos modos de administrar y gobernar, a fin de comprender la propuesta de la Agenda de Buen Gobierno. Ello permite establecer la hipótesis central que orientará el trabajo, en el sentido de que el factor decisivo para que el gobierno asuma los cambios institucionales con base en la Agenda de Buen Gobierno para la mejora, innovación y modernización de la administración pública, corre a cargo de la nueva gestión pública y la gobernanza, es decir, de la incorporación de principios de eficiencia y eficacia, y de la cooperación e interacción de las redes interdependientes de actores que comprenden el gobierno, la sociedad y el sector privado.

La administración pública ha experimentado cambios que van desde la acentuada y arraigada visión gubernamentalista, internalista del Estado a la construcción de una visión y práctica alternativa de la administración pública, donde se busca concretamente incorporar y validar la posición de que la extensión del gobierno y de la administración era (debía ser) algo constituido por el público ciudadano, y que los ciudadanos mismos, mediante sus organizaciones privadas, sociales, no gubernamentales, podían ser también los sujetos de la administración pública, haciéndose cargo de la gestión de los (varios, no todos) asuntos públicos en cooperación con el gobierno o con la presencia del gobierno. De esta manera, la administración pública ha ido recuperando progresivamente su espacio original incursionando en las políticas públicas, los asuntos públicos, la ciudadanía y la gobernabilidad, también entendida como la relación entre gobernantes y gobernados.

El capítulo 3. El cambio institucional en la Agenda de Buen Gobierno analiza las estrategias de la $\mathrm{ABG}$ a fin de comprender el proceso de gobierno para la mejora, innovación y modernización de la administración pública. El diseño de una nueva estructura orgánica-funcional de la administración pública durante el mandato del presidente Vicente Fox, estuvo a cargo de la OIG, la cual a través de la implementación de las estrategias de la Agenda de Buen Gobierno buscó un cambio institucional incorporando elementos de la nueva gestión pública, que permitieran institucionalizar las tareas del quehacer público para responder de manera eficiente, eficaz y oportuna a la sociedad.

El capítulo 4. Análisis del desempeño del cambio institucional en la administración pública mexicana, analiza el desempeño del cambio institucional de la administración pública, que generó una nueva institucionalidad administrativa basada principalmente en el servicio civil de carrera, la transparencia, la rendición de cuentas y el combate a la corrupción, como parte de las acciones de gobierno (gobernanza) a fin de evaluar los resultados de su desempeño.

Los cambios institucionales analizados por las vías de las estrategias de la Agenda de Buen Gobierno se han visto favorecidos por las reformas normativas, instituciones, estructuras y prácticas de gobierno, acordes con los nuevos paradigmas de la nueva gestión pública y la gobernanza, en función de los cuales se introducen mejoras e innovaciones para la modernización y mejor desempeño de la administración pública.

Con la creación de nuevas leyes como la Ley Federal de Responsabilidades Administrativas de los Servidores Públicos (2002), la Ley Federal de Transparencia y Acceso a la Información (2002) y la Ley del Servicio Profesional de Carrera de la Administración Pública Federal (2003), comienza un nuevo proceso de institucionalización de la transparencia, la rendición de cuentas, el combate a la corrupción y a la opacidad de los asuntos gubernamentales. Para acelerar el proceso de institucionalización fue importante la participación ciudadana, de las organizaciones no gubernamentales y de actores de la sociedad civil, en el sentido de transparentar los asuntos de gobierno. 
En términos de gobernanza, la transparencia está transformando el significado de la acción de gobernar hacia nuevas prácticas administrativas que ponen al alcance del ciudadano la posibilidad de vigilar lo que sucede dentro de la estructura administrativa de gobierno, permitiéndole participar como una medida de control externo sobre las acciones de los servidores públicos. De esta forma, la gobernanza nos ofrece una forma de pensar diferente a la administración pública, guiados por la premisa de averiguar qué actor gubernamental hace qué, cómo lo hace y con qué resultados.

Al final del cuarto capítulo, se presentan las conclusiones generales con base al contenido de la investigación, la bibliografía y hemerografía consultadas, así como, el índice de cuadros, figuras y gráficas, que componen la obra. Ojalá que este libro contribuya a enriquecer la administración pública y comprender el cambio institucional en México en los años que corren del siglo XXI. 


\section{Capítulo 1 Fundamentos teóricos del nuevo institucionalismo}

En la teoría social contemporánea se observa el resurgimiento de la preocupación por el estudio de las instituciones, el cual fue identificado por James March y Johan Olsen, en 1984, como nuevo institucionalismo que atraviesa a la ciencia política, la historia, la sociología y la economía. Esta perspectiva es una reacción a los enfoques conductista y de la elección racional en las ciencias sociales (Powell, \& DiMaggio, 2001: 33-75). Para estos desarrollos teóricos, los resultados sociales eran, o bien producto de los resultados de las conductas individuales que consideraban a las instituciones epifenoménicas, la simple suma de las propiedades individuales, o bien eran reflejo de la acción del individuo racional, que busca maximizar su utilidad en un marco de restricciones institucionales. La omisión de estas orientaciones del contexto social y de la permanencia de las instituciones sociales trajo un costo muy alto, esencialmente en un mundo en el que "las instituciones sociales, políticas y económicas se han expandido, se han vuelto más complejas y cuentan con más recursos, y prima facie son más importantes para la vida colectiva" (March \& Olsen, 1984: 734). A diferencia de estos dos enfoques (conductista y de la elección racional), la perspectiva del nuevo institucionalismo define a las instituciones como las reglas del juego que permitirán vivir con un grado de mayor certidumbre a la sociedad.

Por otra parte, aun cuando la disertación de las instituciones ha cobrado impulso en las últimas décadas cierto escepticismo existe en la comunidad académica la cual considera qué el nuevo institucionalismo no es tan nuevo. Por ejemplo, la ciencia política, desde sus inicios, se ha enfocado al estudio de las instituciones. El Estado ha sido esencial para el estudio de la política, y por ende, "traer de nuevo" el estudio de sus instituciones no significa una gran innovación. También se ha generado gran confusión debido a que los enfoques del nuevo institucionalismo no comparten una definición globalmente aceptada de "institución", ni tampoco comparten un programa común de investigación o metodología (Immergut, 2006: 387-388). Desde el paradigma kuhniano esto podría interpretarse como un fallo en encontrar un paradigma que orientara esta tarea en una dirección determinada. Pero si no tenemos un paradigma único, si carecemos de una idea orientadora, poseemos, en cambio, varias ideas paradigmáticas que se complementan entre sí para ganarse los adeptos y para ofrecer la mejor explicación posible de aquello que consideran aspectos relevantes del papel de las instituciones en el ámbito económico, político y social.

En este sentido, se está frente a un enfoque multidisciplinario que enriquece el debate y la investigación, convirtiéndose en el nuevo paradigma dominante del pensamiento de las ciencias sociales. Como bien argumentan algunos autores, el estudio de las instituciones hoy en día, no basta con tomar tan solo una disciplina, sino hace falta retomar diversos enfoques para tener un estudio más profundo y completo, lo cual hace que el nuevo institucionalismo se constituya en una unidad de análisis multidisciplinaria. Como expresa Guy Peters, en su libro "El nuevo institucionalismo. La teoría institucional en la ciencia política" (2003), "los diversos enfoques [del nuevo institucionalismo] deben considerarse como explicaciones complementarias y no competitivas de los fenómenos políticos [económicos y sociales]" (Peters, 2003a: 14, subrayado mío).

En su ensayo "El neoinstitucionalismo y la revalorización de las instituciones" (2003), Rivas Leone, considera que la perspectiva del nuevo institucionalismo es "sumamente rica para adentrarnos en el estudio de nuestros sistemas políticos, los cambios que adquiere el Estado en su arquitectura y fisonomía, la cuestión de la [gobernanza], el desempeño institucional y gubernamental [...] el institucionalismo constituye una de las expresiones más acabadas de la transdisciplinariedad y naturalmente, de los avances de la economía y la ciencia política" (Leone, 2003: 44), o como bien dice Elinor Ostrom, en su obra seminal "El gobierno de los comunes" (1990), estas interpretaciones ratifican la dimensión multianalítica del nuevo institucionalismo. Así, resulta que los enfoques del nuevo institucionalismo se complementan porque comparten un piso común, a saber: a) un rechazo a los reduccionismos, conductista; b) la convicción de que los arreglos institucionales ${ }^{1}$ cuentan en la explicación de la vida social, económica y política, y c) una definición básica muy general de las instituciones como reglas del juego en la sociedad (Romero, 2001: 19).

\footnotetext{
${ }^{1}$ Los arreglos institucionales se refieren al entorno jurídico y político (leyes, normas y disposiciones, estrategias para la implementación de las políticas) que los hacen posible; los actores y las entidades directas del suministro del servicio público; las organizaciones que apoyan a esas entidades en el manejo de los servicios públicos mediante el suministro de bienes y servicios; procesos, prácticas y actividades diversas.
} 


\subsection{Definición de institución}

El estudio de las instituciones tiene una larga tradición en la filosofía política, la historia, el derecho, las ciencias publiadministrativas, la sociología y la ciencia política. Sin embargo, la necesidad de construir una definición de institución no devino en una verdadera prioridad para estos enfoques (Torres \& Pineda, 2009).

Para el viejo institucionalismo (Peters, 2003a: 13-39)² el concepto "institución” se asoció a una noción demasiado general, de carácter ambigua y confusa de "normas generales" emanadas de la sociedad y, sobre todo, del Estado y su orden jurídico. Esto explica nociones tan ambiguas como las "normas instituidas" de Rousseau, "universalidad objetiva" de Hegel, "hecho social" de Durkheim y "elemento del sistema jurídico" de Duguit (Peters, 2003a: 17-18, Lourau, 1994)33.

Esta deficiencia fue heredada al nuevo institucionalismo, que ha puesto poca atención a la clarificación del concepto "institución" (Romero, 2001: 7-8), destacándose en este punto la excesiva "vaguedad conceptual" (Jepperson, 2001: 193). A pesar de ello, autores como Theda Skocpol y Peter Hall en la sociología histórica, Douglass C. North en la historia económica, Walter W. Powell y Paul J. Dimaggio en la sociología de las organizaciones, coinciden en la necesidad de recuperar a las instituciones como centro de análisis (Romero, 2001: 8), y todas las versiones del nuevo institucionalismo abordan la pregunta ¿cómo cambian las instituciones? Un inusual acuerdo entre ellas es el reconocimiento de que la fuente principal de todo cambio institucional es "la relación entre institución y ambiente" y que dicho cambio tiene lugar de manera gradual, esto es, "poco a poco sobre plazos de tiempo relativamente largos" (Vergara, 1997: 19-20).

De manera inicial se puede mencionar que existe un frágil acuerdo en la comunidad académica acerca del significado de institución, tradicionalmente se reconocen las instituciones como los procedimientos formales e informales, las rutinas, normas y convenciones pertenecientes a una estructura organizacional tanto en el ámbito político como económico (Espino, 2011). Empero, es necesario precisar algunos de estos componentes y agregar otros que serían útiles para estudiar los procesos de cambio institucional en los sistemas políticos, económicos y sociales.

Douglass C. North, representante del institucionalismo económico, con mayor rigor conceptual, en su libro "Instituciones, Cambio Institucional y Desempeño Institucional" (1990), define a las instituciones como las limitaciones establecidas por los individuos, las cuales estructuran sus interacciones; y agrega, que éstas incentivan los intercambios políticos y económicos a lo largo del tiempo, determinan el desempeño del sistema económico con base en los costos de transacción y reducen la incertidumbre (North, 1990: 13-14).

Masahiko Aoki, en su libro "Toward a Comparative Institutional Analysis" (2001), propone una definición relativamente cercana al atribuir cinco propiedades a la institución: a) es una creación endógena que perdura en tanto que ningún agente se interese en modificar unilateralmente su comportamiento; b) es un medio para reducir la incertidumbre; c) las reglas institucionales son robustas en el tiempo; d) existe una diversidad de instituciones ya que ellas no son contingentes y, e) es una creencia compartida.

\footnotetext{
${ }^{2}$ Guy Peters (2003a), denomina como en el viejo institucionalismo existían diversas corrientes de trabajo, como el holismo, el historicismo y el análisis normativo, de acuerdo con los aspectos fundamentales de su enfoque. Así, el legalismo era el elemento de estudio más destacado en los países de tradición de Derecho Administrativo, es decir, los de la Europa continental. En este contexto la ley constituye tanto la estructura del sector público mismo como una herramienta fundamental del gobierno para incidir en el comportamiento de los ciudadanos. Por otra parte, el estructuralismo analizaba las instituciones bajo la idea básica de que la estructura determina el individuo, no interesando el análisis de las conductas individuales salvo la de los denominados grandes hombres. Por su parte, el holismo como corriente intentaba complementar el análisis formal con elementos de comparación de otros sistemas diferentes del propio. Así, se centraban en estudios que no eran propiamente comparados, sino sucesión y yuxtaposición de descripciones de sistemas. El historicismo intentaba dar una sólida fundamentación al presente socioeconómico y cultural en que se insertaban las instituciones políticoadministrativas. Por último, existía un análisis de carácter normativo, que aludía a las normas y los valores.

${ }^{3}$ Cabe mencionar, que The Random House Dictionary of the English Language (2012), establece cinco definiciones convencionales de instituciones: a) una organización o establecimiento dedicado a la promoción de un objetivo, por ejemplo, la educación pública; b) el edificio construcción dedicado para tales fines, por ejemplo, la escuela pública; c) un modelo bien establecido y estructurado de comportamiento o de las relaciones que son aceptadas como parte fundamental de la vida cultural, por ejemplo, la familia y el matrimonio; d) cualquier ley o costumbre establecida; e) el acto de instituir o establecer algo: la institución de ley.
} 
De lo anterior se desprenden varias perspectivas. Las instituciones son las reglas del juego, versión que se relaciona con el enfoque de la elección racional por medio de la teoría de juegos. Las instituciones dan nacimiento a estructuras organizacionales que pueden tomar formas de empresas o mercados, punto de vista que coincide con el enfoque histórico del nuevo institucionalismo, donde destacan el papel de la conducta individual, las asimetrías del poder vinculadas con el funcionamiento de dichas estructuras y las trayectorias históricas con sus inesperados eventos.

Asimismo, las instituciones se visualizan como una conjunción de otra serie de factores vinculados con la interpretación sociológica: las normas y los patrones de cultura adquiridos a lo largo del tiempo, prácticas que se manifiestan en un sistema de símbolos específicos, procesos cognitivos y estructuras interpretativas que guían la acción humana. Toda esta serie de elementos no se había investigado de manera sistemática por las principales corrientes del pensamiento económico, pero no por ello significaba que las instituciones carecían de importancia (citado por Riojas, 2010: 135-136). Aquí radica una de las principales aportaciones del nuevo y viejo institucionalismo. Dentro de las mismas vertientes institucionalistas, se propone desarrollar una sintaxis gramática institucional con la finalidad de facilitar el análisis entre los distintos tipos de instituciones existentes y sus respectivas evoluciones.

Los componentes básicos de la institución en esta concepción son las formas permanentes de los patrones de conducta humana sustentados en expectativas comunes, las cuales se estructuran por medio de normas, leyes y estrategias colectivas en función del mundo físico donde se desenvuelven los individuos. La institución como norma supone que existen patrones de conducta sustentados en percepciones mutuas de lo que es apropiado o inapropiado de acuerdo con las diversas situaciones que enfrenta el ser humano; en esta perspectiva, la variable temporal de corto plazo no desempeña un papel crucial y su aceptación puede darse fuera de cualquier acuerdo gubernamental; es decir, los arreglos sociales que los individuos aceptan, cuyo término desde el punto de vista temporal, es indefinido.

Mientras que la institución como ley se sustenta en los patrones de conducta e interacciones, bajo un entendido común sobre cuáles son las actitudes permitidas o penalizadas, en lo que respecta a la penalización, al menos los individuos tienen información por parte de la autoridad sobre el tipo de castigo que recibirán en caso de incumplimiento. La institución como ley tiene un carácter netamente temporal, tanto de corto como de largo alcance, se vincula con las distintas formas de gobernar; las estrategias comunes se sustentan en un lenguaje compartido por todos los actores, el cual prescribe, facilita o advierte sobre el tipo de acciones que es posible llevar a cabo ( Crawford \& Ostrom, 1995: 582-583).

Peter Berger, en su libro "La construcción social de la realidad" (2003), considera que en el nuevo institucionalismo, son las propias instituciones las que proporcionan a la sociedad las formas de actuar más convenientes que modelan y articulan la conducta humana en situaciones determinadas. En consecuencia, son las instituciones el fundamento básico del ordenamiento de la sociedad y el funcionamiento del sistema social.

En gran medida las definiciones anteriores de institución hacen alusión a elementos de carácter político, sociológico, los cuales interactúan con sus similares económicos. Así, la institución se entendería de manera holística como las reglas del juego que dan nacimiento a las estructuras organizacionales, en las que sus normas y sus patrones de cultura adquiridos a lo largo del tiempo, dan cuenta de los arreglos institucionales que guían la acción humana. Dicha situación se presenta en los procesos de cambio institucional.

\subsection{El institucionalismo sociológico}

La escuela del institucionalismo sociológico surge como parte de la teoría organizacional de los años setenta del siglo pasado. Esta corriente considera que los mecanismos y procedimientos organizacionales fueran vistos a la luz de prácticas culturalmente específicas y asimiladas dentro de las organizaciones no sólo para incorporar la eficiencia y los propósitos administrativos, sino también se revelan como resultado de los tipos de procesos asociados con la transmisión de prácticas culturales más generales. 
La corriente sociológica tiene tres rasgos distintivos, a saber: 1) tiende a definir a las instituciones de manera más general que los estudios de la elección racional, incluyendo no sólo las reglas, los procedimientos o normas formales, también los sistemas de simbología, los patrones morales que proporcionan los significados, los códigos que orientan las acción humana; 2) comprende la relación entre las instituciones y la acción individual, en el sentido de que los individuos en un marco institucional han sido socializados en los roles organizacionales específicos, interiorizando las normas identificadas con los roles, arribando, de esa manera, a que las instituciones afecten el comportamiento individual, pero partir de la acción recíproca; roles organizacionales y acción cultural son formas complementarias; y 3) se refiere a que la acción individual surge con la interpretación. De ahí que se insista en que un individuo que enfrenta una situación dada debe encontrar las maneras de reconocerla y responder a ella con base en su experiencia organizacional (Perlman y Pineda: 2006: 83-86).

Los institucionalistas sociológicos le dan un lugar central "al asunto de la legitimidad o convivencia social, en el sentido de los acuerdos institucionales que se generan entre individuos y organizaciones. Por ello, le dan significado al Estado contemporáneo de amplia competencia regulatoria, pues impone prácticas públicas en organizaciones sociales, mediante el consenso y la legitimidad" (Perlman \& Pineda: 2006: 85).

La teoría de la organización tiene larga tradición, pero desde la perspectiva del nuevo institucionalismo, la crítica hacia la racionalidad que emite la escuela Carnegie constituye el centro de esta perspectiva (Herbert, 1992). Los límites inherentes del conocimiento -ya sea humano, organizacional y artificial- imposibilita una toma de decisiones racional. El tiempo y la información no son lo suficientemente extensos como permitir a los individuos calcular sus preferencias basadas en un gran balance de todas las alternativas y sus consecuencias.

En cambio, las ventajas de una racionalidad acotada, como la dependencia en procedimientos operativos estándar, posibilitan a los individuos la toma de decisiones. De tal suerte, la conducta no expresa preferencias sino resultados de numerosos medios que los individuos adoptan para sobrepasar los límites cognoscitivos. Los mismos procesos cognoscitivos no sólo son relevantes por unir actos individuales en decisiones organizacionales, sino que son esenciales para entender cómo incluso es posible la acción coordinada de individuos.

Por su parte, March y Olsen (1997), insisten que en el nuevo institucionalismo sociológico se destacan los elementos cognitivos en la relación entre individuos e institución y concibe a las instituciones, por ende, como marcos de referencia cultural que determinan el comportamiento de los individuos. Dentro de esta corriente sociológica no habría cabida para ningún ejercicio racional; las prácticas institucionales son simplemente productos culturales y los individuos se apegan a ellas porque pueden considerar otras alternativas de comportamiento que las prescritas por la cultura institucional en la que viven y han sido socializados.

En este enfoque, se parte de concebir y tener a las instituciones como grandes marcos de referencia cultural, conciben a un actor que no sólo se mueve en función de la racionalidad, que desde esta perspectiva es limitada, sino principalmente a través de patrones de conducta, roles, agencias y procesos de socialización e interacción respectivamente que son gestados y reproducidos a lo largo de la historia.

Para Leone (2003), las instituciones y los procesos que se estructuran alrededor de ellas (socialización-deliberación-participación) son antes que nada creación humana, las mismas tienen como fin no sólo servir de soporte social, sino además imponen roles, conductas, usos, costumbres, sancionan y premian, incentivan y castigan tanto al ciudadano como a los grupos, respectivamente y, en fin, moldean y canalizan nuestras expectativas y preferencias sociales, políticas, económicas, culturales, etcétera.

Cabe mencionar, que dentro del nuevo institucionalismo una cuestión que ha demandado atención está referida al "cambio institucional" el cual delinea la forma en que la sociedad evoluciona en el tiempo y es, a la vez, clave para entender el cambio histórico. Según Jepperson, el proceso de cambio institucional incluiría cuatro etapas: a) la formación institucional, b) el desarrollo institucional, c) la desintitucionalización, y d) la reinstitucionalización (Jepperson, 2001: 206). 
La formación institucional es una salida a la entropía social, o de patrones de comportamiento no reproductores, o de patrones reproductores basados en la acción. Por su parte, el desarrollo institucional representa la continuación institucional más que una salida - un cambio dentro de una forma institucional, por ejemplo, la expansión de la ciudadanía-.

La desinstitucionalización representa una salida de la institucionalización hacia la producción por medio de la acción recurrente, o de patrones no reproductores, o de entropía social. Por ejemplo, las crecientes desinstitucionalizaciones de género, o de las estructuras corporativas de la comunidad, como medios socio-organizacionales centrales.

La reinstitucionalización representa una salida de la institucionalización y la entrada a otra forma institucional, organizada en torno a diferentes principios y reglas. Un ejemplo de la reinstitucionalización de una fuerza social persistente es la larga transformación de la religión en sociedades occidentales, registrada en las discusiones sobre la secularización.

Con respecto a las organizaciones, la institución crea certidumbre. La organización se caracteriza por la importancia principal dada la eficiencia de su funcionamiento. La institución puede desinstitucionalizarse mientras que la organización no se desorganiza, sino que cambia o desaparece convirtiéndose en otra organización.

La acepción otorgada aquí a la institución se caracteriza por el hecho de que se define como aquella que contribuye al logro del "bien común" (como el caso de un hospital), por lo que goza de un estatus legal y simbólico, en tanto, que la organización tiende a realizar objetivos específicos en el contexto de la eficiencia (como en las empresas). No se puede olvidar que hay una organización en la institución (la institución debe estar organizada para cumplir su misión), aún si es el componente institucional el que prevalece. Del mismo modo, hay institución en la organización se refiere a los aspectos considerados como "indiscutibles" en el sentido antropológico del término.

Entonces es necesario distinguir:

- El nivel intra-organizacional de la institucionalización con temas relativos a las rutinas organizacionales.

- $\quad$ El nivel inter-organizacional de la institucionalización de la organización, en donde las normas privadas (del dominio de la organización) deben ser legítimas en el plano público; comprende por ejemplo, normas de calidad y sobre todo normas técnicas que tienden a acercar lo interorganizacional y lo inter-operable connotando así una "conectividad" y por ende una lógica de "asociación”, de “cooperación”, de "colaboración”, de "mutualización”. Esta es en primer lugar la perspectiva de la institucionalización que hay, pero la perspectiva de esta institucionalización es también el fundamento de la comprensión de una lógica relacional que no es aquella de la jerarquía, ni de la yuxtaposición sino de aquella de la asociación.

- $\quad$ El nivel supra-organizacional que es el de la institución propiamente dicha (Pexqueux, 2009: 745).

En resumen, el nuevo institucionalismo sociológico da importancia al estudio del ambiente y de los entornos culturales, sociales y políticos, a través de los cuales los distintos actores y agencias intervienen y se desempeñan, teniendo así relaciones estrechas entre los individuos (ciudadanos) y las agencias (organizaciones) dentro de un determinado sistema social y político.

\subsection{El nuevo institucionalismo económico}

El nuevo institucionalismo económico ${ }^{4}$ encuentra sus orígenes en la teoría institucional clásica representada por Thorstein Veblen, John R. Commons y Wesley C. Mitchell (1898, 1904, 1971), la cual centra su teoría en que los individuos como agentes económicos con preferencias, están influidos por condiciones de las instituciones en las que se encuentran incrustados. A su vez, las instituciones son resultado de largos procesos de interacciones de los agentes sociales.

\footnotetext{
${ }^{4}$ El neoinstitucionalismo también se denomina "Economía de las Instituciones", "Nueva Economía Institucional", "Nueva Organización Industrial”, "La Nueva Historia Económica”, entre otras.
} 
Uno de los conceptos del institucionalismo tradicional se refiere a la captación de hábitos y rutinas. Las rutinas son instituciones que incluyen la acción dominada por el interés propio, pero que al mismo tiempo afirman la existencia de diversas inercias de comportamiento humano. Limitaciones de las capacidades cognitivas humanas en relación con los problemas de decisiones reales que enfrentan en la vida cotidiana y limitaciones del tiempo real para pensar a fondo un problema hacen que la comprensión humana de una situación tiende a ser simplificada. Por estas razones, individuos, pero también organizaciones, recurren consciente e inconscientemente a rutinas que permiten orientar las actividades (Gandlgruber, 2004: 39).

Los hábitos son por definición instituciones que se originan en la interdependencia de lo individual y lo colectivo y expresan la propensión a repetir una pauta de comportamiento previo (Treviño, 2002: 264). De esta manera, los hábitos permiten a las instituciones y organizaciones ${ }^{5}$ asociar problemas repetitivos y situaciones difusas con información incompleta a reglas de decisión existentes. Por su estabilidad, los hábitos le permiten al actor enfrentar situaciones de decisión diversas con un bagaje conceptual acumulado en el pasado. Esto implica al mismo tiempo una rigidez que no excluye hábitos ineficientes o inadecuados (Gandlgruber, 2004: 40).

Como bien entendió Veblen (citado Kalmanovitz, 2003), al definir a las instituciones como "hábitos de pensamiento decantados que son comunes en la generalidad de los hombres", o "el surgimiento de procesos de rutinizados que son compartidos por un gran número de personas en la sociedad", así el autor consideró a aquéllas "como un conjunto de hábitos y costumbres, maneras de hacer las cosas y formas de pensar acerca de las cosas, ambas aprobadas por prácticas repetidas en el tiempo y por la aceptación de la comunidad [...] La persistencia de las instituciones se derivaba principalmente de la incrustación de los hábitos de pensamiento y acción en las estructura social" (Kalmanovitz, 2003: 193-194).

Aquí los primeros institucionalistas fueron influidos por la teoría de la evolución de Darwin, en el sentido de que las rutinas preservan el conocimiento, principalmente tácito, lo que permite distinguir a las instituciones que facilitan la conservación y transmisión de capacidades. Otro concepto básico del enfoque tradicional de las instituciones se refiere a la cooperación, la cual es anterior y resultado de acuerdos para llevar a cabo la competencia en los mercados, pues aquélla consiste en las relaciones sociales que agrupan las actividades de los hombres para alcanzar un cierto fin social.

De acuerdo con Marx, el capital, es la relación básica que facilita la organización productiva en la fábrica. Pero también, dentro de la competencia existe la cooperación o pactos para disminuir los costos de transacción entre empresas, efectuados mediante relaciones mercantiles imbricadas en la circulación de capital. Por ende, para (Treviño, 2002), se cuentan dos ámbitos de la cooperación: a) al interior de la empresa, y b) al exterior, entre los agentes económicos para regular la competencia.

Por su parte, el nuevo institucionalismo representado por Ronald Coase, Oliver Williamson y Douglass C. North, entre otros, aun cuando también se pregunta respecto al origen de las instituciones, entre ellas el mercado y el Estado, de su evolución, guardando similitud metodológica con la teoría evolucionista; se orienta a las reglas de juego que guían el comportamiento de los agentes en la sociedad fundamentales para explicar los fenómenos económicos, políticos y sociales.

El nuevo institucionalismo económico crítica la racionalidad instrumental de la microeconomía neoclásica que bajo los supuestos: maximización de la utilidad, racionalidad de la elección, escala de valores establecida, información y competencia perfecta y, por tanto, clarificación de los mercados, crean un vacío al no considerar el papel que desempeñan las instituciones, reglas y normas en el sistema socioeconómico.

\footnotetext{
${ }^{5}$ En el marco teórico del neoinstitucionalismo económico es importante distinguir entre instituciones y organizaciones. Las primeras constituyen el conjunto de normas creadas por la humanidad; mientras que las segundas son las modalidades de cooperación y coordinación que asumen distintos individuos de manera consciente para reducir la incertidumbre, alcanzar objetivos comunes específicos y maximizar sus beneficios, todo ello en función de las oportunidades del marco institucional establecido. Es decir, las organizaciones son los jugadores del juego.
} 
Para Espino (1992), la nueva economía institucional plantea que el mercado no se reduce a relaciones de precios y cantidades entre individuos (homo economicus) en las que la suma de todas las decisiones explica el funcionamiento del mercado (Villarreal, 1998) del pensamiento neoclásico, sino de acuerdo a North (1990) se requiere una "teoría de las instituciones [...], introducir en el mundo real con sus fricciones [...], los costos de transacción para iluminar los nudos ciegos que la miopía del modelo neoclásico les ha impedido observar" (North, 1990: 12).

North señala que "las instituciones son las reglas del juego en una sociedad o, más formalmente, son las limitaciones ideadas por el hombre que dan forma a la interacción humana. Por consiguiente, estructuran incentivos en el intercambio humano, sea político, social o económico. El cambio institucional conforma el modo en que las sociedades evolucionan a lo largo del tiempo, por el cual es la clave para entender el cambio histórico" (North, 1990: 13).

Las instituciones, en un sentido amplio, son las reglas, normas, costumbres de operación del sistema, y al mismo tiempo las redes que sirven para enlazar y encauzar institucionalmente las relaciones de intercambio económico, social y político entre los subsistemas o distintos componentes del sistema (Leone, 2003) ${ }^{6}$. Evidentemente un gobierno que se desenvuelve dentro de un marco de reglas claras, las cuales cobran vida a través de las instituciones, contribuye notablemente a generar un ambiente de mayor certidumbre en las sociedades.

Las instituciones son las reglas formales o informales, que definen los espacios autorizados o deseados dentro de los cuales se producen las interacciones entre actores. Estas reglas pueden ser interorganizaciones o intra-organizacionales. Así las leyes son instituciones, en particular, el estado de derecho, la constitución política constituye la regla de juego básica, ya que define la organización del Estado, los campos de regulación posible para todas las otras leyes emitidas por el Estado, establece el mercado, y define los deberes y derechos de los ciudadanos. Los valores - la confianza, la solidaridad, la equidad, la libertad, el respeto al medio ambiente, etc.- constituyen otro ejemplo de reglas de juego efectivas, aunque no escritas. El mercado constituye otra institución con sus reglas escritas y tácitas. Las políticas públicas y los conjuntos de instrumentos son también reglas de juego. Sin embargo, las agencias gubernamentales que ponen en práctica estas reglas son organizaciones.

Las organizaciones se clasifican en políticas, sociales y económicas, según estén orientadas a producir bienes públicos, colectivos o privados. Las vinculadas directamente con la provisión de soluciones cooperativas serían las políticas y las sociales y ambas pueden ser clasificadas en territoriales y funcionales. Mientras en las primeras prima el criterio de pertenencia a un territorio, las segundas se conforman en función de intereses diferenciados.

Las instituciones conforman no sólo la base de cualquier sistema político sino, además, es “innegable que afectan el desempeño de la economía [...] reducen la incertidumbre por el hecho de que proporcionan una estructura a la vida diaria. Constituyen una guía para la interacción humana" Leone, 2003: 14).

El nuevo institucionalismo destaca en primer lugar, como es natural, la importancia de las instituciones partiendo de que conforman el cemento de la sociedad; en segundo lugar, busca combinar las teorías económicas y de las instituciones para analizar las interacciones sistémicas entre ambas; en tercer lugar, pretende romper y trascender los límites más estrechos de los modelos tradicionales de Veblen, Commons y Mitchel que centran su atención en los individuos como agentes económicos con preferencias en la estructura social.

El nuevo institucionalismo integra desde la perspectiva histórica aspectos políticos, sociales y culturales, que se extiende en la actualidad como "un conjunto de reglas que determina los procesos de la reforma institucional a partir de los marcos de incentivos y restricciones impuestas a los comportamientos de los diferentes agentes y actores económicos, sociales y políticos para la formulación e implantación de políticas públicas, y que tienen un impacto en los resultados medidos en términos de crecimiento y desarrollo" (Hernández, 2005: 29).

\footnotetext{
${ }^{6}$ Entenderemos por intercambio toda relación o interacción entre individuos o entre individuos y entidades como empresas, compañías u oficinas gubernamentales. Y son las instituciones las encargadas de supervisar estas interrelaciones
} 
De esta manera, se está frente a un enfoque interdisciplinario que enriquece el debate y la investigación, convirtiéndose en el nuevo paradigma dominante del pensamiento de las ciencias sociales. Los estudiosos de este tema han elaborado una taxonomía básica de las instituciones que resulta de utilidad. Las instituciones - nos dicen- pueden ser formales como los sistemas legales, o informales, como los códigos de conducta, las costumbres y las convenciones, y pueden tener un carácter normativo o prescriptivo.

Las instituciones formales, por un lado, pueden cambiar súbitamente como resultado de indecisión judicial o de un cambio político; en cambio las instituciones informales, en tanto se manifiestan en sistemas de creencias, tradiciones, costumbres o códigos de conducta, son mucho más resistentes a las transformaciones repentinas. Por ejemplo, la diferencia entre las reglas formales y las informales es solo de grado.

\footnotetext{
"Imaginemos un continuo que va desde un tabú, pasando por las costumbres y las tradiciones, hasta llegar a las constituciones nacionales o internacionales, como en el caso del acta constitutiva de la Organización de las Naciones Unidas. Los esfuerzos por crear mejores gobiernos -es decir, instituciones-, como la infructuosa historia de la Constitución de la Unión Europea, son un buen ejemplo de las dificultades del proceso de institucionalización: las instituciones resultan provechosas sólo cuando las reglas sociales y los sistemas de creencias están listos para sustentarlas; de lo contrario son códigos huecos condenados al fracaso" (Elguea, 2008: 208).
}

Las reglas formales o instituciones formales incluyen reglas políticas y judiciales, reglas económicas y contratos entre particulares, y están ideadas para definir los límites de la acción, los beneficios garantizados y las obligaciones adquiridas, así como los castigos por infringirlas. Las reglas políticas, por ejemplo, definen la naturaleza del gobierno: sus principios, su estructura de decisiones y el control de su agenda. Las reglas económicas, por su parte, regulan aspectos como derecho de propiedad y las normas de intercambio. Las reglas sociales, por último, determinan los límites y las diferencias entre el comportamiento que es tolerado por una sociedad y el que es rechazado. Dentro de la jerarquía de las instituciones formales la parte más alta, es decir, las constituciones políticas, es siempre más difícil de modificar que la más baja, como en los casos de los acuerdos y los contratos individuales (Elguea, 2008: 207-208).

Williamson consideraba que "el neoinstitucionalismo trabaja en dos niveles: uno macro, constituido por el medio institucional o reglas de juego que constriñen las acciones de los agentes y las encausa, y un nivel micro, en el que operan las instituciones de gobierno sobre los agentes económicos, como los mercados, los cuasimercados y las estructuras jerárquicas de contratación (empresas y burocracias públicas)" ( Citado por Kalmanovitz, 2003: 192).

Elemento central de este enfoque es que la calidad de las instituciones, de sus leyes, sus ordenamientos, disposiciones y normas formales e informales se traducen en una determinada calidad de la economía que se mide por el nivel de los costos de transacción, restricciones de derechos de propiedad, costos de información, el análisis económico del derecho, de los incentivos, de la agencia, las fallas del mercado y las fallas del gobierno, etcétera.

El nuevo institucionalismo económico abreva de la teoría de la regulación económica, el papel de las estructuras jurídicas en el intercambio, problemas del principal y la agencia; de la escuela de los derechos de propiedad; de la economía de la información; de la economía de los costos de transacción; de la teoría de la gobernanza; teoría de la acción colectiva, de las cuales se tomarán algunos términos como el cambio institucional, los costos de transacción, la información incompleta y asimétrica, desempeño institucional, entre otros, para entender y valorar la gestión de las instituciones administrativas públicas.

Como se puede observar, el institucionalismo económico se preocupa más por el impacto de las instituciones en el comportamiento de los actores sociales, políticos y económicos y en su desempeño a través de instituciones. Así pues, para este enfoque el cambio institucional es un even to discreto y no un proceso permanente de ajuste y aprendizaje, lo que significa que el cambio en las instituciones ocurriría cuando la institución ha fracasado en su intento de satisfacer los requerimientos para los que se formó, es decir, el cambio institucional iniciaría cuando las instituciones son ineficientes en el momento de realizar su encomienda para la que fueron diseñadas y creadas. 
El nuevo institucionalismo presupone ser un enfoque sumamente dinámico en el estudio de las instituciones, de cambio institucional y de las diversas dinámicas que influyen en las instituciones y en los individuos, respectivamente. De ahí, que se parte de la premisa de que las instituciones son creación humana, por ende, evoluciona y son alteradas por los seres humanos. El que una institución sea estable no implica que acuse cambios. Por tanto, el cambio institucional es de gran importancia para el análisis institucional, porque explica los cambios incrementales a un conjunto de reglas y a sus propios mecanismos de sanción que se han dado en las últimas décadas en el sistema económico, político, social y administrativo, respondiendo al conjunto de incentivos que existen en los arreglos institucionales de la sociedad.

\subsubsection{Cambio institucional}

El nuevo institucionalismo es una teoría que explica la estabilidad de los procesos sociales a partir del conocimiento de las reglas y su contexto organizacional; partiendo también del hecho de que no considera a los agentes como personas autónomas e independientes, pues siempre están sujetos a una serie de transacciones en las que se manifiestan relaciones de poder, no por atributo simplemente sino por elementos de transacción (Crozier \& Erhard, 1990: 70-73).

De tal manera, que la estabilidad de los procesos sociales se explica a partir de dos ideas: 1) las organizaciones sólo cambian de manera incremental y concatenada, y 2) las normas y reglas en las instituciones influyen de forma determinante sobre el comportamiento de los individuos. Aunque cabe la posibilidad de la convención y el contrato como una vía de cambio institucional por actores que pueden llegar a ser protagónicos en momentos clave del desarrollo institucional (Perlman \& Pineda, 2006: 72). Como las instituciones cambian de manera incremental, también se supone que los actores pueden cambiar su comportamiento en el mismo contexto organizacional de manera incremental, es decir, poco a poco sobre plazos de tiempo relativamente largos y concatenados (North, 1990: 13-15).

Así, para el nuevo institucionalismo económico la estabilidad es el resultado de la obediencia al conglomerado de normas que regulan la actividad económica (Ayala, 1992: 50-93). Estas reglas pueden ser de dos tipos: formales o informales, su obediencia está garantizada debido a la amenaza de sanciones de quienes las transgredan. Al mismo tiempo porque son producto del acuerdo, del arreglo organizacional.

El cambio institucional ${ }^{7}$ consiste en ajustes marginales a esos conjuntos de reglas y a sus mecanismos de sanción (Verduzco \& Sánchez, 2000: 78-96). Los agentes de cambio son los individuos y la organización que existen en los arreglos institucionales. Para North (1990), el principal motor del cambio son las variaciones en los precios relativos, en virtud de que un cambio en esos indicadores crea un nuevo conjunto de incentivos para individuos y organizaciones, los cuales reaccionan intentando manipular las reglas institucionales de acuerdo con sus intereses en las nuevas circunstancias (North, 1990: 44-53). Es por ello que el cambio es incremental. Las distintas organizaciones negocian sucesivos ajustes a las reglas, de acuerdo con sus intereses; no obstante que ninguno de esos ajustes modifique radicalmente la naturaleza del arreglo institucional ${ }^{8}$.

De acuerdo con el argumento de North (1990), el cambio en las instituciones obedece a patrones racionales relativamente convencionales: actores racionales que intentan maximizar sus preferencias, respetando ciertas reglas del juego y que son capaces de calcular sus beneficios potenciales si se modifican algunos de los acuerdos. Estos actores son, además, capaces de movilizar recursos para luchar por las modificaciones que a ellos les resultan más convenientes (Pardo, 1986: $103-118)^{9}$.

\footnotetext{
${ }^{7}$ El cambio institucional es un elemento central para transitar hacia un modelo de desarrollo económico que identifica las potencialidades y limitaciones de los diferentes niveles organizacionales.

${ }^{8}$ La teoría de las instituciones de North está "edificada partiendo de una teoría de la conducta humana combinada con una teoría de los costos de negociación. Cuando se combinan esas teorías podemos entender por qué existen instituciones y qué papel desempeñan en el funcionamiento de las sociedades, y si se agrega una teoría de la producción podemos analizar las funciones de las instituciones en el desempeño de las economías" (1993: 44-53).

${ }^{9}$ Las reformas y cambios en los aparatos administrativos deben incluir como tarea prioritaria la consideración de la ciudadanía, de los usuarios de los servicios públicos. Eso quiere decir que el ciudadano no deberá entendérsele como administrado ni tampoco como cliente. La referencia en el primer caso esconde un tono paternalista y en el segundo mercantilista (Pardo, 1986).
} 
Esta concepción del cambio institucional sugiere una evolución hacia arreglos institucionales eficientes; empero, North señala que los mercados son imperfectos, la información incompleta y los costos de transacción elevados, lo que ocasiona una situación de relativa incertidumbre para el ejercicio del cálculo racional. En estas circunstancias, los actores recurren a ideologías, teorías y modelos determinados históricamente para tratar de interpretar la realidad. De tal forma que al final se tienen actores racionales atrapados en circunstancias definidas históricamente, con construcciones mentales subjetivas, que al actuar modifican de manera paulatina su contexto institucional (North, 1990: 51-53).

Para el nuevo institucionalismo sociológico el cambio institucional se concibe como respuesta de la interacción entre organización y medio ambiente ${ }^{10}$. Su argumento central es que el ritmo de las transformaciones en el medio ambiente es mucho más rápido de lo que pueden ser las transformaciones de las rutinas organizacionales de las instituciones. Por lo tanto, el cambio es consecuencia de las acciones de individuos y organizaciones (March \& Olsen, 1997) que, debido a nuevas características en el medio ambiente, se ven obligados a iniciar un proceso controlado de adaptación a las nuevas circunstancias (Vergara, 1997). Es lo que March y Olsen denominan reforma institucional, la cual puede ser entendida como un conjunto de acciones que aspiran a modificar de manera deliberada la estructura y cultura de una organización.

March y Olsen (1997) argumentan que la reforma institucional es un proceso de adaptación que ocurre con base en interacciones entre el medio ambiente e institución. Por una parte, tenemos la inercia de las rutinas y otras prácticas institucionales tendientes a la estabilidad; por otra, las presiones que el medio ambiente ejerce sobre la institución para que cambie. El medio ambiente como impulsor para generar condiciones de cambio lleva a considerar que, bajo determinados contextos, las organizaciones tienden a adoptar fórmulas institucionales aceptadas y consolidadas en su entorno de referencia; es decir, ya probadas por otras organizaciones que se consideran como referentes. A este proceso se le conoce como isomorfismo institucional.

Por su parte, Powell y DiMaggio destacan “tres tipos de isomorfismo institucional” (2001: 109-

1. Isomorfismo coercitivo: resultado de presiones formales e informales ejercidas por otras organizaciones para que se produzcan las estructuras y pautas de funcionamiento. Se asocia aunque no exclusivamente con los mandatos legales establecidos por el Estado. El entorno legal afecta a muchas organizaciones y, en especial, a las administraciones públicas.

2. Isomorfismo mimético: resultado de los procesos de imitación de referentes que se consideran líderes o ejemplos a seguir. Así, en entornos caracterizados por la ambigüedad en los objetivos, sin un claro criterio para evaluar resultados, con una importante presencia de elementos simbólicos, las organizaciones tienden a configurarse a partir de un referente que se considera más legítimo o exitoso.

3. Isomorfismo normativo: se refiere al impacto de los colectivos profesionales que definen aquello que es considerado como "mejores prácticas" y que, por lo tanto, se debe reproducir. La formación y la legitimación basada en conocimientos especializados, por un lado, y por otro, las redes de profesionales son los canales a través de los cuales tiene efecto este tipo de isomorfismo.

Desde esta perspectiva, las organizaciones públicas continuamente responden a fuerzas ambientales de naturaleza económica, política o social, con lo que se presenta un proceso de imitación de experiencias exitosas o con ciertos beneficios, mediante el cual diversos modelos organizacionales pueden ser difundidos, transferidos y adoptados.

\footnotetext{
${ }^{10}$ El término medio ambiente vinculado a las organizaciones será entendido como el conjunto de factores culturales, políticos, sociales, tecnológicos y legales que influyen en el comportamiento y en la definición de sus relaciones con otras organizaciones.
} 
Si bien es cierto que el nuevo institucionalismo sociológico concibe el cambio institucional como respuesta de la interacción entre la organización y el medio ambiente, también es verdad que para esa escuela el cambio es un proceso evolutivo pausado, ya que se parte del supuesto de un medio ambiente organizacional se va transformando con cierta lentitud. Bajo estas condiciones, el cambio institucional es una lenta evolución de las tradiciones y valores que nadie puede pronosticar ni controlar.

El cambio para Orozco (2010), es entendido como la transformación gradual que involucra la reconfiguración de modelos, resultados de un proceso de adaptación al medio ambiente en donde la influencia de los patrones externos empuja a las organizaciones a adoptar nuevas rutinas que, al incorporarse a un ambiente interno institucionalizado, da lugar a innovaciones limitadas.

Por otro lado, para Giddens (1995). el nuevo institucionalismo histórico-político parte de contextos organizacionales con relaciones intensas de los agentes, de la maximización de los beneficios y del entendimiento de que zonas de intercambio son también arenas en las que se lleve a cabo relaciones de poder, intercambio de intereses enmarcados en reglas y tradiciones que tienen su punto de partida en las rutinas organizacionales; de ahí que los actores las asuman porque representan mecanismos eficaces para moldear la realidad y coadyuvar en los procesos de elecciones que lleven a resultados óptimos.

El nuevo institucionalismo presupone ser un enfoque sumamente dinámico en el estudio de las instituciones, de cambio institucional y de las diversas dinámicas que influyen en las instituciones y en los individuos, respectivamente. De ahí, que se parte de la premisa de que las instituciones son creación humana, por ende, evoluciona y son alteradas por los seres humanos. El que una institución sea estable no implica que acuse cambios. Por tanto, el cambio institucional es de gran importancia para el análisis institucional.

\subsubsection{Costos de transacción}

El tema de los costos de transacción que determinan las instituciones es una de las contribuciones importantes de esta escuela. El propósito central es demostrar la importancia de la comparación de diferentes arreglos institucionales (transacciones, contratos, incentivos, jerarquía, gobierno y dirección) y esquemas de organización en los mercados para la selección de planes óptimos de producción más allá de los costos de insumos y las tecnologías como se conciben tradicionalmente.

Los costos de transacción son una variable que puede explicar los diferentes niveles de desempeño económico de la economía o los agentes, en términos de productividad, eficiencia y equidad. Éstos se pueden subdividir en tres órdenes de elementos: costos de información, costos de negociación y costos de vigilancia y ejecución (entendido como la fuerza necesaria para imponer el cumplimiento de los contratos).

Siguiendo las ideas de North, los costos de transacción son los costos de organización e integración humana, se puede decir, que son los costos de establecer y medir los atributos de la producción, de políticas o de los bienes y servicios en el mercado y los costos de la obligación al cumplimiento de acuerdos entre los participantes de una sociedad.

En las últimas décadas, la teoría económica neoclásica sólo se había preocupado por estudiar el costo de transformación o producción, ignorando o dejando a un lado el costo de transacción, los mismos eran considerados nulos, dentro de un entorno en donde la información era completa y perfecta, siendo de esta manera irrelevante asumir su existencia.

\footnotetext{
"Son los costos de transacción que explican, como dado, la capa institucional de la producción. Costos de producción determinan elecciones técnicas (de sustitución), pero costos de transacción determinan qué etapas del proceso de producción se asignan a la institución del sistema de precios y cuáles a la institución de la empresa. Los tipos de costos son lógicamente distintos; son ortogonales uno con el otro" (Citado por Gandlgruber, 2004: 27).
}

Ahora bien, los costos de transacción surgen de la transferencia de los derechos de propiedad, los mismos incluyen costos institucionales, tales como, costos de negociación, diseño, información, vigilancia, y cumplimiento de contratos y protección de los derechos de propiedad. Véase la figura 1.1. 
Hoy en día los institucionalistas han demostrado que los costos de transacción incluyen, entre otras cuestiones, la definición, protección e imposición de derechos de propiedad sobre los bienes o servicios: el derecho a usarlos, el derecho al ingreso que se derive de su uso, el derecho a excluir a los demás de este derecho, y el derecho de intercambiar este derecho por otro.

Figura 1.1 Costos de Transacción

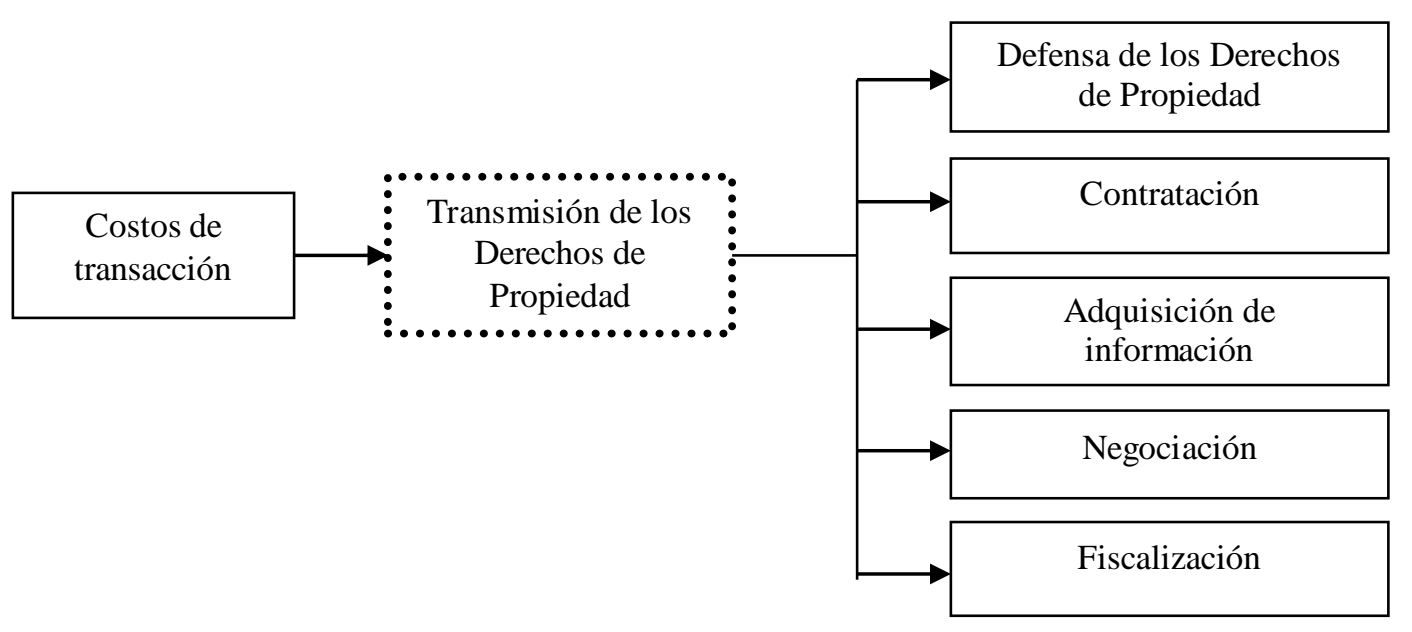

Fuente: Espino, J. A. (2011: 183) 2005: 5):

Como se puede observar, los costos de transacción están presentes en (Nienstaedt \& Zerpa,

- Búsqueda de información sobre precios, calidad, disponibilidad de insumos, como también de las condiciones del mercado.

- $\quad$ Regateo entre compradores y vendedores para fijar precios y cantidades, todo lo necesario para llegar a un acuerdo.

- $\quad$ Protección de los derechos de propiedad.

- Inicio de un nuevo negocio: permisos y licencias.

- $\quad$ Regulación de las empresas y marco legal.

De este modo, el papel que tienen las estructuras institucionales bien establecidas inciden directamente sobre el cumplimiento de los derechos de propiedad, la ecuanimidad de la aplicación en las leyes y normas, en fin, la puesta en práctica de una estructura formal e informal que garanticen la observancia efectiva de las instituciones, que generen incentivos aumentando la certidumbre y de una manera u otra abaratar los costos de transacciones.

Desde el punto de vista político y de acuerdo con Espino (2002), los costos de transacción se estudian en la elaboración de las políticas monetaria y fiscal para analizar los intercambios que ocurren en dicho proceso. Siendo necesario considerar los siguientes elementos:

i) La interacción política apreciada como un conjunto de relaciones contractuales.

ii) Las instituciones como las reglas del juego político influyen decisivamente en los incentivos de los agentes.

iii) Las estructuras de gobierno, los mecanismos y normas de organización son importantes en la relación instituciones-resultados.

iv) La noción de perspectiva intertemporal. Esto quiere decir que los incentivos que se generan en las transacciones políticas pasan por diferentes etapas para cada agente.

En la siguiente figura se ilustra la importancia que tienen las instituciones, ya que proporcionan la estructura de incentivos para incidir en los valores de los costos de transacción. 
Figura 1.2 Análisis Político de Costos de transacción: Secuencia lógica

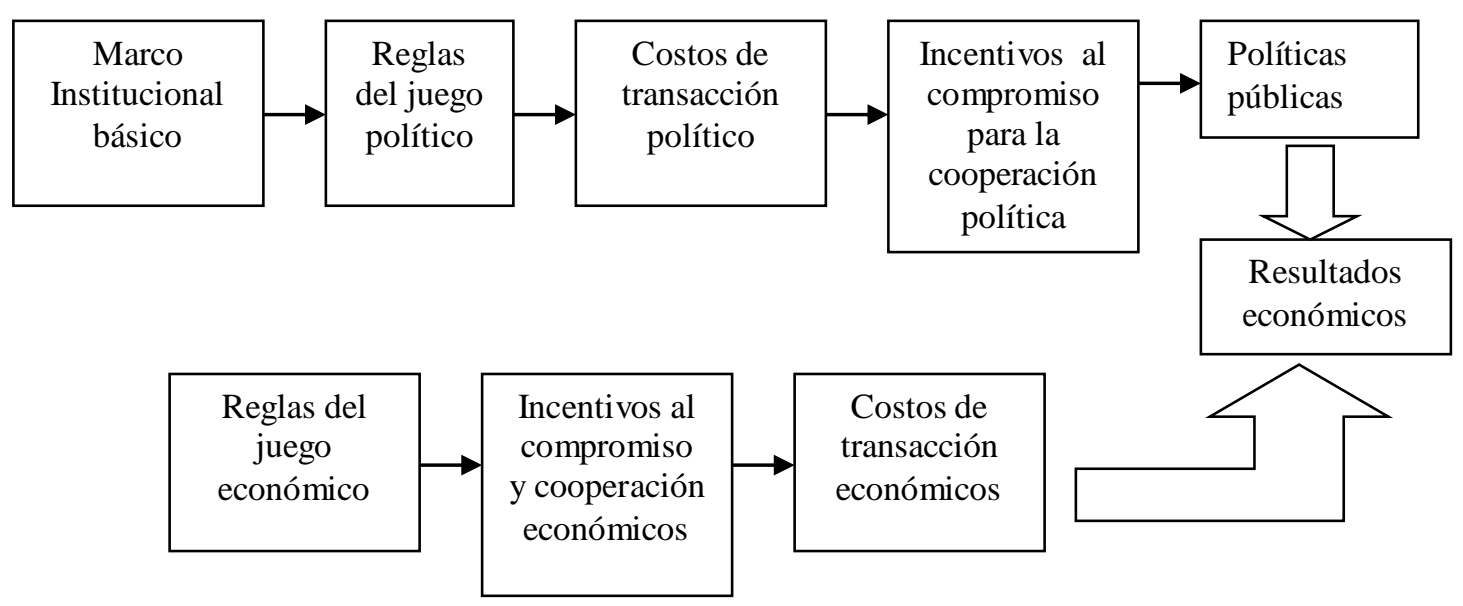

Fuente: C. Arias y Caballero (citado Nienstaedt \& Zerpa, 2005)

Se puede apreciar que el marco institucional es la base fundamental en la formación de costos de transacción y resultados económicos a los cuales los agentes llegan luego de haber realizado sus intercambios mediados, por las políticas públicas. De esta manera, los costos de transacción influyen en los mercados políticos y en el grado de eficiencia de las transacciones que en éstos se efectúan a la hora de diseñar una política fiscal y monetaria. Dándole así importancia a la estructura institucional que actúa como un conjunto de reglas que incentivan a la elección de los sujetos políticos, determinando así una salida política.

\subsubsection{Derechos de propiedad}

La teoría de los derechos de propiedad analiza las elecciones económicas de los agentes y postula que los derechos son instituciones estratégicas para inducir o bloquear la formación de estructuras de incentivos, para intercambiar activos, invertir, ahorrar, trabajar e incluso asignar recursos para innovar tecnologías (Treviño, 2002: 273).

En opinión de los economistas Armen Alchian, Ronal Coase y Harold Demsetz, los derechos de propiedad especifican las relaciones sociales y económicas que deben observar las personas al utilizar los recursos escasos, incluyendo no sólo los beneficios que se permiten disfrutar a los propietarios, sino también los daños a otros que se permite causar (Kamerman y Kahn, 1993: 41).

En este sentido, los derechos de propiedad representan una ventaja sobre la anarquía porque imponen un orden social frente a cualquier otro estado. Esto es así, porque las leyes o reglamentos restringen la conducta y elecciones egoístas de los individuos. Los agentes que incumplan los derechos de propiedad serán sancionados coercitivamente por el Estado.

Desde un punto de vista abstracto, Gary Becker define los derechos de propiedad como el derecho a usar, administrar al ingreso, consumir o destruir, modificar y transmitir. El alcance real de los derechos de propiedad va a depender de la interpretación y aplicación de la ley. La forma como el Estado defina y proteja los derechos de propiedad a través del tiempo puede crear perdurables instituciones formales que fortalezcan las organizaciones y así asegurar el uso eficiente de las metas que se establezcan las mismas (Nienstaedt y Zerpa, 2005: 55).

Para North, la presencia de instituciones formales e informales capaces de proteger la propiedad y garantizar el cumplimiento de los contratos explica en buena medida el éxito de los países desarrollados:

“[...] el mercado en su conjunto es un saco mezclado de instituciones; algunas aumentan la eficiencia y otras las reducen. No obstante, al contrastar el marco institucional en países como USA, Inglaterra, Francia, Alemania y Japón con países del tercer mundo o con los del pasado histórico de las naciones industrializadas, queda claro que este marco institucional es la clave del éxito relativo de las economías tanto en corte transversal como a lo largo del tiempo" (North, 1990: 44-53) 
En este sentido, los derechos de propiedad tienen ciertos atributos que los convierten en instituciones estratégicas porque (citado por Nienstadt \& Zerpa, 2005):

- Concentran peculiaridades que ninguna institución, restricción, derecho u obligación posee.

- Inducen o bloquean la formación de estructuras de incentivos para transar, invertir, ahorrar, innovar, entre otros.

En suma, el cumplimiento de los derechos de propiedad en una economía puede facilitar la comprensión sobre cómo se desenvuelven las decisiones de los agentes económicos en cuanto al desarrollo de actividades legales productivas. Para ello, resulta indispensable que exista un estatuto legal coherente y bien definido que exprese cuales han de ser los mecanismos de acción permisibles dentro del área en que se desenvuelven, generando el aumento de la credibilidad en los hacedores de política, por parte de la colectividad en general.

\subsubsection{Información incompleta y asimétrica}

A diferencia de la teoría neoclásica que parte del supuesto de que los agentes y las empresas tienen información perfecta, es decir, conocen todas las fuentes de utilidades o beneficios y los costos de éstas. El nuevo institucionalismo parte de la información imperfecta, o sea, el hecho de que diferentes individuos saben cosas distintas. Por ejemplo, el propietario de un coche lo conoce mejor que los posibles compradores.

En general, algunos agentes tienen información privada sobre las características de los bienes que intercambian con otros, es decir las transacciones ocurren en un contexto caracterizado por la presencia de información incompleta y distribuida asimétricamente, lo cual significa que la información es un recurso valioso y el conocimiento es poder (Espino, 2011: 137).

En tal sentido, la economía de la información parte del supuesto de que la producción, adquisición y procesamiento de la información es costoso, porque los mercados no la proporcionan adecuadamente. Aquí reside el origen de los problemas de la información (información incompleta y asimétrica) que influyen decisivamente en la conducta de los agentes (selección adversa, aversión al riesgo, riesgo moral y problemas para el agente y el principal). De tal suerte, que se incrementa la incertidumbre y el riesgo para los agentes.

La información incompleta se da porque un cierto tipo de información es difícil o incluso imposible de obtener en el mercado y/o los costos de adquisición son muy elevados. Esto tiene consecuencias sobre las posibilidades de coordinación de decisiones de los agentes, es decir, éstos están influidos por la incertidumbre, el riesgo y la carencia de incentivos para producir información tenderán a generar un ambiente muy poco cooperativo o en el cual la coordinación será poco probable, en consecuencia, sólo el Estado puede atenuar el problema de la información incompleta a través de la generación directa de información, la regulación económica y, en general, con el establecimiento de reglas (Espino, 2011: 141).

La información asimétrica se refiere a la distribución desigual de la información entre los agentes. Éstos tienen un acceso desigual a la información, todos los agentes son afectados, incluido el gobierno, pero sobre todo aquellos que tienen pocas posibilidades de adquirir información. Existe un problema de información asimétrica cuando un grupo de individuos involucrados en el intercambio de ciertos bienes tiene un acceso más fácil y barato a la información y, luego este grupo tendrá mayor poder de negociación de precios y cantidades, porque está mejor informado que su contraparte, y usará su ventaja para obtener mayores beneficios (Espino, 2011: 143).

El resultado típico de la información asimétrica es que en el intercambio o la transacción uno de los agentes tiene información pertinente que el otro agente desconoce, lo cual genera distorsiones relevantes en la toma de decisiones. La información asimétrica significa que la información se encontrará fragmentada, lo cual introduce incertidumbre y un margen mayor para que los agentes cometan errores de cálculo. 


\subsubsection{Desempeño económico}

Para Douglass North (1990), el desempeño económico hace referencia a diferentes conjuntos de instituciones como los derechos de propiedad, contratos, etcétera, pero también del resultado de los precios relativos de los factores (tierra, trabajo y capital). De tal suerte que para el nuevo institucionalismo económico el proceso de intercambio está sujeto a las restricciones institucionales, las cuales representan el conjunto de prohibiciones y permisos, desincentivos e incentivos, que constriñen el intercambio y las elecciones individuales y de grupo, de acuerdo a las características de las instituciones existentes; por ejemplo, los derechos de propiedad existentes, las diferentes modalidades de contratos; las características del poder judicial para obligar el cumplimiento, entre otras, inciden directamente en las elecciones y comportamiento de los agentes.

Esto es así, porque las instituciones (formales e informales) definen el arco de restricciones legales y extralegales (económicas, sociales, culturales, etc.) en medio del cual los individuos actúan, se organizan e intercambian. En este sentido, la calidad de las políticas públicas y de las instituciones, afirma M. Olson, es el factor decisivo en el crecimiento económico (Espino, 2011: 350). La presencia de instituciones malas o ineficientes (a pesar de los esfuerzos individuales, la dotación original de recursos, la ubicación geográfica, el capital humano y el capital social), no permiten alcanzar buenos resultados, es decir, la presencia de los anteriores elementos no necesariamente garantiza aprovechar el potencial existente.

Las distintas versiones del institucionalismo explican el cambio institucional a partir de las complejas interacciones de los elementos que determinarán el nivel del desempeño económico:

“ i) el propio agotamiento de las instituciones que no evolucionaron o se adaptaron al cambio técnico, político o social; ii) el cambio demográfico, en el sentido amplio - estratificación de la población por edades, sexo, raza, religión, etc.-, que influyen en la necesidad de nuevas instituciones; iii) cambios en la dotación de recursos: disminución de la relación de la tierra y capital con respecto a la fuerza de trabajo o población, y iv) la innovación tecnológica induce cambios en las instituciones” (Espino; 2011: 355-356).

El cambio institucional no ocurre en el vacío social, está restringido tanto por las instituciones existentes como por las restricciones sociales, políticas y económicas. El cambio institucional tiene como objetivo definir nuevos derechos, reducir costos de transacción, atenuar los problemas de información y la restructuración organizacional. El proceso de cambio está mediado por un proceso político que tiene dos caras: el aprendizaje y la internalización de las nuevas instituciones y, su operación y manipulación (Espino, 2011: 356).

En resumen, el desempeño económico depende de las restricciones institucionales existentes: a) el tipo de derechos de propiedad, las modalidades de los contratos, las características del poder judicial para obligar el cumplimiento de las instituciones; b) los costos de transacción derivados de la organización de las acciones individuales y colectivas relacionadas con la adquisición y procesamiento de información, el establecimiento y vigilancia de los contratos y los derechos de propiedad, y c) los procesos políticos involucrados en la acción y la negociación colectivas que facilitan o inhiben las elecciones públicas.

A lo largo del presente capítulo se puede apreciar cómo las corrientes sociológica y económica del nuevo institucionalismo hacen importantes aportaciones al estudio de las instituciones en referencia a los cambios que han experimentado los sistemas económico, político, social y administrativo; éste último aspecto a través de los términos gestión pública y gobernanza explica la instrumentación de capacidades administrativas e instituciones que acompañan la actuación de la administración pública la cual se presenta hoy como una disciplina que se orienta para dotar de un mayor grado de productividad y eficiencia a las organizaciones de gobierno, con la adopción de técnicas privadas y de una forma de gobernar asociado e interdependiente entre el poder público, organizaciones no gubernamentales y el sector privado. 


\section{Capítulo 2 El nuevo institucionalismo y la administración pública}

El estudio de las instituciones como revalorización de las ciencias sociales, incluida la administración pública, permite considerar a ésta como una pieza esencial para desarrollar la sociedad y mejorar el Estado. El nuevo institucionalismo a través de categoría cambio institucional permite explicar los cambios que se han dado en las últimas décadas en el sistema económico, político, social y administrativo. El cambio institucional coincide con algunas de sus premisas fundamentales para la adopción de acciones de gobierno como son el isomorfismo institucional, los derechos de propiedad, los costos de transacción, la certidumbre jurídica, la esencia de las organizaciones, la economía de la información, etcétera. Estas premisas son centrales para el diseño y funcionamiento de las instituciones que corresponden a la economía de mercado y la existencia de un Estado constitucional y democrático.

\subsection{La administración pública}

La administración pública ha experimentado cambios que van desde la acentuada y arraigada visión gubernamentalista, internalista del Estado a la construcción de una visión y práctica alternativa de la administración pública, donde se busca concretamente incorporar y validar la posición de que la extensión del gobierno y de la administración era (debía ser) algo constituido por el público ciudadano, y que los ciudadanos mismos, mediante sus organizaciones privadas, sociales, no gubernamentales, podían ser también los sujetos de la administración pública, haciéndose cargo de la gestión de los (varios, no todos) asuntos públicos en cooperación con el gobierno o con la presencia del gobierno. De esta manera, la administración pública ha ido recuperando progresivamente su espacio original incursionando en las políticas públicas, los asuntos públicos, la ciudadanía y la gobernabilidad (Caiden, 1996: 29), también entendida como la relación entre gobernantes y gobernados (Bobbio, 1986).

Desde la perspectiva liberal, la administración pública es la encargada de la conducción de las políticas públicas. Para que éstas sean consistentes con la sociedad a las que van dirigidas, deben atender a ciertos requisitos. En primer lugar, deben ser pragmáticas, lo que significa que deben ser orientadas a problemas; en segundo lugar, deben ser valorativas, lo que quiere decir que el fin último de la política debe ser el ser humano; en tercer lugar, deben ser interdisciplinarias, para lo cual deben reunir a diferentes técnicas, disciplinas y enfoques científicos; y por último, deben ser contextuales, lo que implica considerar integralmente factores políticos, económicos, culturales y sociales en la búsqueda de soluciones (Enríquez \& Ramírez, 1999: 133).

En este contexto, la administración pública como disciplina surge con el hombre mismo (González, 2001b: 21-56). Cuando las sociedades tienen un gobierno, la administración pública es la encargada de suministrar los servicios públicos, por ello se puede estudiar desde el desarrollo de sus diferentes actividades. Al respecto, algunas aportaciones que las antiguas civilizaciones hacen a la misma son la invención del papel y la tinta, los antiguos sistemas de reclutamiento chino, la recaudación de impuestos, la creación de leyes para la vida en sociedad fueron determinantes para el desarrollo de la disciplina.

La disciplina aparece cuando tiene un método y un objeto de estudio, como señala González "La Administración Pública se caracteriza porque se ocupa de los fines del Estado, la voluntad soberana, los intereses públicos y el derecho, que es el elemento coercitivo de la sociedad" (González, 2001b: 89), y luego menciona los términos en que se puede definir la administración pública:

“1) La administración pública es la actividad dinámica y en constante movimiento, que contribuye a alcanzar los fines del Estado; 2) Es el gobierno en acción, la parte más visible de su actividad pública, inicia donde termina la política y concluye donde la política comienza; 3) Es el poder ejecutivo con todos sus aparatos, órganos y dependencias públicas que lo constituyen, aunque relaciona de manera indirecta (complementaria) con los poderes legislativo y judicial; 4) Es un proceso dinámico que tiene como finalidad la satisfacción de las necesidades públicas reconocidas por el Estado; 5) Es la función que contribuye a que los ciudadanos, la sociedad y el Estado puedan alcanzar los objetivos concurrentes de estos tres factores; 6) Es un instrumento fundamental del Estado para realizar aquellas actividades que el mercado no puede o deja de hacer, pero que debido al interés público debe realizarse; 7) Como parte del gobierno que genera políticas públicas, se encuentra vinculada con toda clase de asuntos públicos, que se manifiestan de manera concreta en los servicios que realiza el gobierno, y 8) Es la ciencia social que se encuentra en gestación y desarrollo, que nació como un subcampo de la Ciencia Política, que tiene por objeto estudiar, analizar y sistematizar la actividad organizada por el Estado" (González, 2001b: 122). 
La administración pública, entendida como estructura y proceso de gobierno, como ejercicio profesional y disciplina académica, se presenta hoy como una disciplina que se orienta a dotar de un mayor grado de productividad y eficiencia a las organizaciones de gobierno, con la adopción de técnicas privadas.

“[...] la noción más fiel al significado de la administración pública consiste en la identificación con el gobierno. Con esta identidad queda puntualizada la naturaleza política de la administración pública [...]" (Orozco, 1981: 73).

Para Omar G. Orozco (1981), “[...] la administración pública es la acción a través de la cual la universalidad del Estado se individualiza en las particularidades de la sociedad civil. Los actos de la administración pública son actos particulares ejercidos por la sociedad, transformado por ese hecho lo general del Estado [...] en hechos concretos que causan un impacto en las clases sociales y en los individuos" (17).

Una administración, que va más allá de cumplir con el objetivo de proporcionar bienes y servicios, se preocupa por que se realice de manera eficaz y eficiente (Cardozo, 1983: 174) $)^{11}$, por lo que "la nueva administración se hace a cargo de la racionalidad (eficacia/eficiencia) de todo el marco del proceso decisorio: de la formulación e implementación de la política" (Villanueva, 1990: 170). Es así como su objetivo principal se amplía de proporcionar bienes y servicios optimizando los recursos disponibles a que estos han de ser de máxima calidad al menor costo posible para la sociedad. A la administración pública, le corresponde ser la base del gobierno que se conforma con la coordinación cooperativa de los individuos a través de la planeación, organización, dirección y control de la conducta para cumplir con los fines del Estado.

Ligada al marco del derecho, la administración pública se aprecia como el conjunto de normas sancionadas por el Estado, incluyendo los ideales, técnicas e instituciones que la conforman. Este cuerpo de proyectos tiene como objeto determinar los derechos y obligaciones de las personas y resolver cualquier tipo de controversia de acuerdo con lo establecido. La administración pública en este ámbito está orientada a crear una cultura política y administrativa respaldada por un gobierno democrático.

Omar G. Orozco (1985) menciona que la administración pública es un sistema organizado para transmitir y hacer eficaz el impulso del poder supremo, mediante la observación de leyes, por lo que no se concibe una administración pública descentralizada o independiente del poder supremo "[...] sin una administración subordinada no hay gobierno, porque no podrá expedir órdenes sino a lo sumo dar consejos" (Orozco, 1985: 35).

Para Orozco (1981:22), la administración pública es "un acto de dirección administrativa del Estado en la sociedad", es decir, la acción del Estado hacia la sociedad por medio del gobierno. ${ }^{12}$ En suma, es posible entender a la administración pública como un conjunto de instituciones y órganos de gobierno encaminados a procurar que los servicios públicos sean realizados eficientemente y satisfagan las necesidades de la sociedad oportunamente.

\subsection{Nuevo institucionalismo y administración pública}

Las organizaciones públicas y privadas están institucionalizadas cuando su comportamiento está señalado por reglas culturalmente condicionadas, las cuales se manifiestan en ciertas rutinas de acción y le dan significado a esas acciones, reflejan intereses, valores, opiniones, expectativas y recursos relativamente estables (Mena, Vega \& Mena, 2010: 86).

La instrumentación de capacidades administrativas e instituciones que acompañan a los cambios institucionales, es un elemento indispensable en la construcción de un orden democrático.

\footnotetext{
${ }^{11}$ En el sector público se considera eficiente el logro del conjunto de objetivos perseguidos con los mismos costos económicos, sociales y políticos [...]Se califica de eficaces las acciones que alcanzan los objetivos sin hacer ninguna medición sobre los costos en ellos impactados. Cardozo (1983: 170).

${ }^{12}$ Entiéndase por gobierno al proceso que conjunta, unifica y conduce el complejo institucional del Estado, en él se resumen la institución y acción del Estado político en el seno de la sociedad civil. (Orozco, 1980: 60).
} 
La actuación administrativa y política basada en reglas formales e informales, facultades extraordinarias y poderes discrecionales, explica la capacidad de implementar cambios en las reglas del juego, normas de conducta, expectativas, comportamientos, ubicaciones, recursos y relaciones entre los principales actores involucrados (Mena, Vega \& Mena, 2010: 87).

Sin duda, el diseño institucional de la administración pública es determinante para identificar su capacidad de coordinación, su modo de obrar y su misión con relación a otras estructuras de poder. En la sociedad moderna, la administración pública es producto de diseños institucionales que la conciben para dar cumplimiento efectivo a los objetivos compartidos y las tareas que se definen con alcance público-social. En este caso, la forma de Estado en la cual se organiza la vida de la administración pública es la que corresponde al Estado de derecho (Espino, 2001: 210).

En esta visión, el poder está sujeto a reglas que autorizan tanto competencias como las restricciones que debe obedecer. El poder se acepta y reconoce como atributo del Estado, pero se encuentra sometido a normas constitucionales (North, 1944: 232) y legales que dan sentido a su esencia y modo de obrar (Berrones, 2004a: 48).

En este sentido, la administración pública moderna está sujeta a la razón jurídica y la razón institucional. La primera, tiene su origen y sustento en los valores del constitucionalismo y el reconocimiento de las normas positivas del derecho que son la plataforma para la organización y atribuciones que le corresponden. Por su parte, la razón institucional se origina desde el momento en que su compromiso es con la sociedad, las reglas que deben cumplir tienen como característica que son universales, generales, abstractas e impersonales (Berrones, 2004a: 49).

La razón jurídica y la razón institucional organizan el ámbito de competencias de la administración pública, y éste se origina en el Poder Legislativo en cuanto institución que representa a la sociedad en el Estado. En consecuencia, la precisión o imprecisión sobre las atribuciones de la administración pública, no depende de ella misma, sino de la relación que guarda con el Poder Legislativo con el Poder Ejecutivo, y del tipo de régimen político que está vigente en la sociedad (Berrones, 2004a: 50). En esta perspectiva, se consuma la usurpación de funciones desde la instancia legislativa, provocando la debilidad institucional y política del presidente de la República, como bien lo ha explicado Emilio Rabasa (1981).

Si la institucionalidad significa capacidad de definir reglas, procedimientos y operaciones para atender y solucionar con efectividad las múltiples demandas de la sociedad, ello implica que con problemas en el diseño institucional, la administración pública carece de aptitudes idóneas para estabilizar problemas, articular los conflictos de interés y dar salida funcional a las demandas en competencia, mismas que se nutren con la pluralidad democrática (Berrones, 2004a: 51).

Las fallas en la institucionalidad repercuten directamente en el desprestigio de propia administración pública, porque tiene como objetivo la atención efectiva de los problemas sociales. Así, los movimientos y acciones de carácter administrativo son vitales para la construcción y consolidación de la institucionalidad estatal, pues sin ella, la autoridad pública da votos de censura y castigo que son el indicador más fehaciente de la desconfianza en las instituciones administrativas (Berrones, 2004a: 52).

En este contexto, el nuevo institucionalismo está tratando de resolver los graves problemas que sufren el sector público y sus organizaciones que están compuestos por actores interesados, en la búsqueda por racionalidad limitada, de evadir la incertidumbre en un juego que favorece a los intereses de los políticos y los burócratas, más que a la sociedad (Gault, 2010: 68-69).

El nuevo institucionalismo asume que el propio interés de los actores puede ser el móvil adecuado para encadenar racionalmente las decisiones con las acciones de los diferentes agentes sociales: políticos, buscando su carrera, con los incentivos correctos, pueden acabar preocupándose por la sociedad; los burócratas designados y de carrera, con los incentivos correctos, pueden, en el marco institucional adecuado, buscar racionalmente los mejores medios para la sociedad, y los grupos de interés, con la regulación apropiada, pueden influir sin capturar a organizaciones gubernamentales que administran tales incentivos correctos. 
De tal suerte, que la organización es vista entonces como un efecto de redes de incentivos y de las instituciones es un aparato complejo de juegos individuales y colectivos, pero nunca un mecanismo que escape del control racional.

Así, para Jocelyne Bourgon, la administración pública requiere la construcción de la capacidad colectiva para lograr resultados públicos evaluando tanto las tendencias del pasado como preservando las capacidades existentes. Es decir, esta capacidad colectiva va estar compuesta por: a) capacidad institucional, b) capacidad organizacional, c) capacidad anticipatoria y d) capacidad adaptativa (Bourgon, 2010).

La capacidad institucional significa que el Estado tiene la capacidad de hacer leyes y lograr que se cumplan; de establecer impuestos y gastar sin corrupción; de separar los poderes legislativos, ejecutivo y judicial; y rendir cuentas por el ejercicio del poder. La construcción de esta capacidad podría tomar años.

La capacidad organizativa genera las bases para lograr resultados públicos. Ello significa que se pueden entregar bienes públicos de alta calidad al menor costo posible para la sociedad; que los usuarios pueden realizar un proceso de retroalimentación que permita continuos mejoramientos e innovaciones en los servicios entregados de manera centralizada; y que se utilicen modernas tecnologías de información y comunicación, lo que permite reducir el número de intermediarios y empoderar a los usuarios a lo largo del proceso de suministro de servicios. Por su parte, la capacidad anticipatoria significa que los gobiernos tengan la capacidad de anticipar, detectar e intervenir proactivamente cada vez que sea necesario. También implica construir una capacidad colectiva para anticiparse, innovar y adaptarse.

Para enfrentar problemas de complejidad e incertidumbre, los gobiernos necesitan mejorar su capacidad para aprovechar la inteligencia colectiva de la sociedad que permita extraer el conocimiento y significado de los patrones y de las tendencias emergentes en el sistema social. Los ciudadanos y otros actores tienen invaluable información y perspectivas diversas que pueden proporcionar previsibilidad, dar formas a las decisiones e idear soluciones innovadoras.

Los gobiernos también pueden dar pasos para estimular la innovación social. Las redes sociales y las capacidades ciudadanas son haberes importantes para generar soluciones originales y perseguir cursos nuevos de acción hacia metas sociales. El gobierno puede apalancar el poder de las redes para conectar actores, problemas y soluciones como un medio para lograr resultados públicos. Estas acciones pueden ayudar al gobierno a avanzar desde una posición reactiva a una más adaptativa. Por sobre todo, ellas ayudan a construir capacidad anticipatoria e innovadora dentro y fuera del gobierno. La capacidad adaptativa se refiere a la capacidad del gobierno para construir y promover la capacidad colectiva de aprender y adaptarse y asegurar una distribución más equitativa de los riesgos, como una manera de mitigar los impactos negativos en las sociedades vulnerables.

En este sentido, las relaciones de poder se modifican dejando atrás las relaciones piramidales, las prácticas centralizadas, las políticas intervencionistas, el monopolio económico de las burocracias, la opacidad de las oficinas burocráticas, el interés público definido principalmente por la autoridad y la falta de espacios para que la organización de la sociedad tuvieran un margen de conducta en la definición de los asuntos colectivos.

Se trata de una nueva forma de gobernanza que enfatiza la vigencia de la administración pública no como estructura, programa u operaciones estandarizadas, sino como un conjunto de sistemas de gestión que se ocupa por la calidad de los resultados. La administración pública no es más la actividad en sí del Estado, sino también la administración de la sociedad con sentido de lo público.

\subsection{Cambio institucional y administración pública.}

Como se ha mencionado en párrafos anteriores el nuevo institucionalismo presupone ser un enfoque sumamente dinámico en el estudio de las instituciones, de cambio institucional y de las diversas dinámicas que influyen en las instituciones y en los individuos, respectivamente. De ahí, que se parte de la premisa de que las instituciones son creación humana, por ende, evoluciona y son alteradas por los seres humanos. 
El cambio institucional delinea la forma en que la sociedad evoluciona en el tiempo y es, a la vez, clave para entender el cambio histórico. En otras palabras, las instituciones son cambiantes, y nacen, funcionan, se transforman, declinan y desaparecen como en general, sucede con todas las realidades humanas.

El cambio institucional es un proceso complicado porque los cambios al margen pueden ser consecuencia de cambios en cuanto a normas, limitaciones informales y diversas clases de efectividad y observancia coercitiva. Además generalmente las instituciones cambian de un modo incremental, no de un modo discontinuo (González, 2009: 72). De acuerdo con Douglass North, cómo y por qué cambian incrementalmente y por qué razón inclusive los cambios discontinuos (revoluciones y conquistas) no son nunca totalmente discontinuos sino un resultado del encajonamiento de limitaciones informales en las sociedades (North, 1990: 17), se debe a que el cambio incremental proviene de las percepciones de los empresarios en organismos políticos y económicos que les indican que podrían redituarles más si alteraran en un cierto grado el marco institucional existente (González, 2009: 73).

Según March y Olsen, los altos funcionarios promueven reformas a la administración pública para luego abandonarlas. Las reformas a gran escala entendidas como "[...] esfuerzos sistemáticos y masivos destinados a transformar ciertas características de la organización y funcionamiento del estado a fin de dotarlos -como se dice tradicionalmente- de mayor eficiencia y eficacia. Durante la mayor parte del siglo fueron conocidas como "reformas administrativas" (Oszlak, 1999: 93). No obstante los cambios administrativos o la organización burocrática han sido parte del valor simbólico y la retórica porque expresan un afán y una voluntad transformadora, generalmente aceptada por la sociedad.

Para Mena, Vega y Mena (2010), la reforma administrativa dentro de un contexto de cambo político "representa un reto para el diseño institucional" (Mena, Vega \& Mena, 2010: 94). Y agregan

\footnotetext{
“[...] la eficiencia en los procesos administrativos determina el éxito de un sistema político. El proceso de reforma en la administración pública implica la rutinización que mas tarde se transforma en norma y convenciones, las cuales conforman la cultura organizacional. Pero para que una reforma de tal naturaleza sea efectiva debe incluir no solamente un cambio de estructuras y los procedimientos organizacionales sino en el comportamiento de los administradores orientado hacia el apego a la ley" (Mena, Vega \& Mena, 2010: 94).
}

En suma, el cambio institucional en la administración pública no sólo requiere de retórica sino de acciones efectivas para la transformación de la administración en su desempeño institucional y de gestión pública con apego a la legalidad.

\subsection{Desempeño institucional y gestión pública}

El desempeño de los gobiernos es de vital importancia, y por ende, de las administraciones públicas. No se limita al logro de la racionalidad formal -cumplimiento de las reglas y procedimientos autorizados conforme a las normas positivas- sino que se ubica en el universo de las aptitudes que se desarrollan para asegurar, a pesar de condiciones adversas, el cumplimiento de las metas colectivas. El desempeño institucional es la clave para identificar la aceptación o el rechazo de los gobiernos por parte de los ciudadanos (Berrones, 2004b: 12).

La articulación entre desempeño institucional y gestión pública se inscribe en la lógica del modo gobernar, es decir, en el modo de asegurar la dirección eficaz, la cual incluye la transformación de la sociedad. En este sentido, Prats (1995) señala: “gobernar deja de ser el cumplimiento de reglas y normas para convertirse en la gestión de la acción colectiva cuyos agentes manejan márgenes inevitables de libertad y en las fijación de los fines y resultados resulta tan problemática como la movilización de los recursos y la determinación de las consecuencias. El management deja de ser concebido principalmente como planificación y asunción de la responsabilidad por la acción colectiva" (Prats, 1995: 104).

La gestión del gobierno es asunto de instituciones e institucionalidad, por ello, la gestión pública no debe visualizarse como una simple expresión procedimental que responde al patrón de la racionalidad normativa que es fundamentalmente prescriptiva (Berrones, 2004b: 4). 
La gestión pública entendida como gestión de gobierno, se desenvuelve en la lógica de la racionalidad heurística y en los valores de la institucionalidad democrática (Berrones, 2004b: 4). En este sentido, la gestión pública es el núcleo de las capacidades de gobierno como objeto de creación, es decir, son producto de las habilidades, destrezas y conocimiento para conseguir los resultados favorables que demanda el saber técnico y tecnológico para ser aplicado en el universo de las instituciones. Por tanto, la gestión pública es la encargada de organizar la práctica de la administración pública tomando en cuenta las capacidades y los recursos de que dispone (Berrones, 2004b: 4-10).

La relación de correspondencia que guardan la administración pública y la gestión pública es producto de la armonización de compromisos, políticas y programas, pues la gestión pública en cuanto articulación de técnicas y tecnologías orientadas al incremento de la calidad de los resultados finales, debe tener en el control y la evaluación, los recursos que le permitan responder a la capacidad de respuesta que es propia de la administración pública (Berrones, 2004a: 65).

Desde el punto de vista técnico, el control y la evaluación son producto de decisiones institucionales, y de los arreglos entre los responsables de las decisiones; están comprometidos con los fines axiológicos de la administración pública y los valores teleológicos de la gestión pública (Berrones, 2004a: 65). Por tanto, la gestión pública es el comportamiento dinámico, diferenciado e intercomunicado de la administración pública, y se encarga de fortalecer la capacidad instalada que ésta tiene.

El reconocimiento desde la teoría de la gestión pública de que en sociedades de alta complejidad, diversidad, dinamismo e interdependencia, la eficacia y la eficiencia de la gestión ya no depende sólo de la acción del gobierno, sino de la capacidad para la creación y gestión de redes de actores. La gestión pública, según Metcalfe (1999), debe ser entendida:

\footnotetext{
“como gestión a nivel 'macro' relacionada con el ambiente con el cambio estructural a nivel de relaciones multiorganizacionales, mientras que la gestión privada funciona a nivel 'micro' centrándose en organizaciones específicas. Los problemas emergen cuando los reformadores intentan implementar técnicas de gestión micro en un espacio multiorganizacional 'donde no pueden suponerse ni el consenso en los fines ni la gestión por decisión de autoridad'. La gestión pública se refiere al cambio, no a nivel organizacional o micro -que la meta de la gestión del sector público y privado-, sino a nivel macro o estructural entendido como orientando la transición hacia un nuevo marco institucional" (12-53).
}

Metcalfe (1999) ve la diferencia entre los dos niveles de gestión similar a la que existe entre las reglas del juego y las estrategias de los actores. Es fácil reconocer que cambiar las reglas del juego (la gobernanza o la estructura institucional) es un cambio de naturaleza diferente al que implica cambiar las estrategias de los actores individuales (Prats, 2001: 116).

Por su parte, Christopher Hood y Michael Jackson (citado por Barzelay, 2001), reconocen a la nueva gestión pública como un argumento administrativo y como una filosofía administrativa. El primero, se refiere típicamente a un amplio espectro de problemas de diseño de la organización. La segunda, es un cuerpo de enseñanzas doctrinales que goza de una amplia aceptación en un lugar y momentos dados. Éstas afectan la agenda gubernamental en lo concerniente a cuestiones de diseño organizacional mediante el establecimiento de un clima de opinión relativo a dichas cuestiones (Barzelay, 2001: 2-5).

Mark H. Moore (citado por González, 2001a), expone una filosofía de la gestión pública, es decir, una idea de lo que los ciudadanos deben esperar de los gestores públicos, las responsabilidades éticas que asumen al tomar posesión de su cargo y lo que constituye una ejecución virtuosa. Identifica tipos de intervención que los gestores pueden realizar para explotar el potencial del contexto político y organizativo a fin de crear un valor público (González, 2001a: 154).

El autor afirma que muchas de las técnicas de la gestión privada son igualmente aplicables al sector púbico. Sin embargo, el sector público crea valor de una manera diferente al sector privado. El sector público crea valor en la provisión de determinados bienes y servicios que el sector privado no puede producir, fundamentalmente crea valor en la manera que produce dichos bienes, es decir, mediante el diálogo comunitario, la participación social y el respeto a los valores constitucionales y democráticos. 
En este sentido, el Centro Latinoamericano para el Desarrollo (CLAD), considera que la gestión pública debe ser esencialmente democrática, lo que garantiza el logro de los niveles de calidad y excelencia en el desempeño y resultados. Surge como paradigma social la búsqueda de una democracia plena, que soporte, entre otros, en el derecho de información, participación, asociación y expresión sobre lo público, es decir, un derecho genérico de las personas a participar colectiva e individualmente en la gestión pública (CLAD, 2009). De tal manera, la relevancia de la gestión pública tiene como sustento que sin resultados favorables de la acción de gobierno, no es posible que los ciudadanos tengan confianza en el mismo. Lo que un gobierno realiza o no, alude de modo directo a la gestión pública, ya que es el eje de las políticas públicas (Berrones, 2004b: 2).

\title{
2.5 Gobernanza
}

En respuesta a los problemas de eficacia directiva de los gobiernos, dos han sido las respuestas: la gobernabilidad y la gobernanza ${ }^{13}$. Ambos enfoques conceptuales y prácticos se relacionan con la acción del gobierno, hacen referencia al problema de la capacidad gubernativa o directiva del gobierno y buscan una solución, sin embargo, tienen un diverso planteamiento del problema y ofrecen una diversa respuesta (Villanueva, 2007).

Para Villanueva (2007), el problema de la capacidad y eficacia directiva de los gobiernos, se ha desplazado del sujeto de gobierno al proceso de gobernar y, en consecuencia, a la cuestión de la capacidad y eficacia directiva del gobierno, que incluye la administración pública como uno de sus componentes esenciales.

\begin{abstract}
"La democratización de los regímenes políticos y la instauración o restauración progresiva del Estado de derecho y, por ende, de la ley como marco vinculante de la acción de los poderes públicos y particularmente del gobierno ejecutivo se han resuelto razonablemente los dos cuestionamientos fundamentales al sujeto de gobierno: la legitimidad de su cargo y la legitimidad de su actuación. El sujeto de gobierno ha dejado de ser el problema, al reunir las características consideradas esenciales y correctas: elegido libremente entre opciones políticas en competencia, controlado por otros poderes públicos, sujeto al escrutinio ciudadano, sometido al imperio de las leyes, respetuoso de los derechos humanos y de las libertades políticas y civiles de los ciudadanos, transparente, rendidor de cuentas, conocedor además de los ingentes costos que acarrea a su legitimidad política, la inobservancia de la ley y el irrespeto a derechos humanos y ciudadanos" (Villanueva, 2007: 2).
\end{abstract}

El sujeto gobierno/la institución gobierno ha dejado ser el problema cognitivo y práctico, desplazándose al proceso de gobierno, a la gobernanza y, a la capacidad y eficacia directiva que el proceso de gobierno implica. Cuando se habla de un régimen democrático, se está hablando de Estado de derecho, un Estado que incluye dimensiones legales necesariamente implicadas por la existencia de un régimen (O’Donnell, 2008). En este sentido, el problema de la legitimidad o validez institucional ha dejado de ser el focus del problema, pues el gobernante ocupa legalmente el cargo y actúa conforme a las reglas jurídicas establecidas. Lo que se discute es su validez directiva, su competencia directiva (o su "legitimidad por resultados") (Villanueva, 2007). Las diferencias entre gobernabilidad y gobernanza se hacen presentes en la forma de abordar el problema de la acción de gobierno. Así, por gobernabilidad, se debe entender la posibilidad o probabilidad de que el gobierno gobierne a su sociedad, mientras que su opuesto, la ingobernabilidad, significa la posibilidad o probabilidad de que el gobierno deje de gobernar a su sociedad o no la gobierne.

\begin{abstract}
"El enfoque de la gobernabilidad es estrictamente gubernamental, se refiere a las condiciones y comportamientos del gobierno, no es un enfoque social, pues la premisa de su planteamiento es la consideración de que en la sociedad no existen o son irrelevantes las capacidades de autoorganización, autogobierno, autorregulación y de solución de problemas, en conformidad con el sujeto arraigado de considerar a la sociedad como problema, como realidad ingobernable por sí misma, intrínsecamente propensa al desorden, la inseguridad y el conflicto, por lo que para la sociedad pueda ser y existir debe reorganizarse en forma de Estado y ser gobernada por un agente externo a ella, dotado de capacidades y recursos para estar en aptitud de pacificarla y coordinarla. En este sentido, la gobernabilidad es una cuestión que se plantea sólo con referencia al gobierno y que no atañe a la sociedad, la cual es por definición ingobernable, destinada a conflicto y crisis" (Villanueva, 2007: 5).
\end{abstract}

\footnotetext{
${ }^{13}$ El término Gobernanza proviene de la lengua francesa gouvernance del siglo XIV, que después adopta la lengua inglesa governance y de acuerdo al Diccionario de la Real Academia Española de la Lengua, gobernanza es el arte o manera de gobernar, diferenciándose de la palabra gobierno (government) apegada a modelos de decisión pública predominantemente jerárquicos.
} 
Dos son las críticas que se hacen a la gobernabilidad, a saber: a) es un enfoque centrado en las capacidades de gobierno, las cuales no son más que probabilidades o potencialidades en acción, en vez de centrarse en las acciones de gobierno, que son justamente las que hacen que las capacidades sean reales, se manifiesten, se efectúen y sean efectivas; b) es un enfoque gubernamentalista en tanto sigue considerando que un gobierno bien equipado con los recursos y poderes apropiados es suficiente para dirigir a la sociedad, sin tomar en cuenta y en serio los hechos sociales, económicos y políticos, que han reducido su capacidad y autonomía decisoria o sin revisar el supuesto arraigado de que la sociedad es incapaz de gobernarse (Villanueva, 2010: 27).

En suma, el enfoque de gobernabilidad sigue siendo pensado y justificado como gubernamentalmente estructurado y dominado, que da por hecho que la sociedad económica y civil puede ser sólo objeto y destinatario del gobierno y la administración pública, pero en ningún modo sujeto.

Por su parte, la gobernanza es postgubernamental.

\begin{abstract}
"Apunta a la necesidad o conveniencia de un nuevo proceso directivo de la sociedad más que a la reproducción del proceso directivo estructurado por la acción del gobierno aun si dotado con la totalidad de las capacidades requeridas. Su supuesto básico es la noción de que en las actuales condiciones sociales el gobierno es un agente de dirección necesario pero insuficiente, aun si dotado con todas las capacidades requeridas y aun si sus acciones se aprovechan a cabalidad las muchas capacidades que le han sido otorgadas. Por consiguiente, se requieren y se valoran las capacidades sociales para una dirección satisfactoria" (Villanueva, 2007: 6).
\end{abstract}

En este sentido, "la gobernanza significa un cambio de proceso/modo/patrón de gobierno, que es bien entendido y formulado como el paso de un centro a un sistemas de gobierno ('governance system', PNUD), en el que se requieren activan y conjuntan los recursos del poder público, de los mercados y de las redes sociales" (Villanueva, 2010: 30).

Para Maynetz, la gobernanza moderna "significa una forma de gobernar más cooperativa, diferente del antiguo modelo jerárquico en el que las autoridades estatales ejercían un poder soberano sobre los grupos que constituían la sociedad civil" (Maynetz, 2001: 9).

El término gobernanza para la administración pública, según Guy Peters y Jon Pierre (2005), constituye un medio para elevar el contenido democrático de la conducción del Estado y la sociedad. En este sentido, la gobernanza puede estimular la participación y la confianza de la ciudadanía. La adopción del concepto de gobernanza como instrumento para la definición de las metas tiene varias implicaciones sobre el papel que desempeña la administración pública. En términos descriptivos el giro hacia la gobernanza significa que el gobierno ha dejado de ser parte de un Estado jerárquico y ordenador, que gobierna mediante su propia autoridad, para convertirse en parte de un Estado facilitador (Peters, 2004: 69).

Ahora bien, la gobernanza incluye a la gobernabilidad, en tanto requiere la acción de un gobierno capaz y eficaz, cuyas acciones, aportes y resultados son una condición esencial para que pueda haber dirección en la sociedad antes y ahora; pero el gobierno competente es sólo uno de los actores requeridos para una dirección exitosa de la sociedad. En este sentido, la gobernanza significa el cambio a un sistema de gobierno en el que se requieren y activan los recursos del poder público, de los mercados y de las redes sociales. Es el paso de un estilo de gobernar jerárquico centralizado a un estilo de gobernar asociado e interdependiente entre organismos gubernamentales, organizaciones privadas y civiles.

En términos de acción pública, el concepto de gobernanza responde a la cooperación y la interacción del Estado y los actores no estatales en el interior de las redes decisionales mixtas entre lo público y lo privado (Cabrero, 2005). La acción pública trata de entender la acción gubernamental local pero también intergubernamental; de entender la acción colectiva de los diversos actores sociales locales, así como de grupos específicos, coaliciones y conglomerados de intereses. De entender la relación entre los actores gubernamentales y no gubernamentales. Es decir, la acción pública se entiende como un continuo entre el Estado y la sociedad civil, en donde gobernar es conducir la acción colectiva la cual requiere de la construcción de la acción pública. 
Por otra parte, tanto la gobernabilidad como la gobernanza abrevan de las políticas públicas como de la nueva gestión pública con el propósito de restablecer su capacidad directiva debilitada y la gobernabilidad, o bien lo han hecho con el propósito o el resultado de dar forma a un nuevo proceso de gobierno más eficaz y acaso socialmente más aceptado, en tanto se practica con la participación de la sociedad: a una nueva gobernanza.

En este sentido, al utilizar el gobierno su poder para empoderar a otros que decidan y actúen, éste no está asumiendo un papel de laissez-faire, tampoco está reduciendo su posición relativa en relación con los otros actores de la sociedad. Lo que está haciendo es jugar una mezcla compleja de roles que es afirmativa del Estado como representante de lo colectivo (Bourgon, 2010: 9).

Una de las ideas principales que presentan los diversos autores que han escrito sobre la gobernanza es que implica un proceso de dirección de la sociedad (Villanueva, 2009: 80 y ss). Sin embargo, este proceso se desarrolla en ambientes complejos, donde el Estado tiene un papel importante, pero ya no es considerado el único actor involucrado en la solución de los problemas sociales, de tal manera que se incorporan actores no gubernamentales para buscar soluciones conjuntas (Strasser, 2003).

Según Jan Kooiman (2004: 173-174), las relaciones entre espacio social y político están definidas por tres características que tienen el origen en la teoría de sistemas: diversidad, complejidad y dinamismo. Kooiman argumenta que, si se toman estas tres características en conjunto, se puede comprender de mejor manera las interacciones existentes entre sistema político y social, es decir, entre Estado, mercado y sociedad.

A partir de estas características, se deduce que una ventaja importante del concepto de gobernanza es su aplicabilidad a diversos contextos. De esta manera, se puede utilizar para ejemplificar la interacción de los actores en diferentes niveles, ya sea vertical u horizontalmente. Por ejemplo, un proyecto que proporcione infraestructura básica a una pequeña comunidad marginada puede ser objeto de intervención de agencias gubernamentales ubicadas en distintos niveles de gobierno.

Las interacciones que llevan a cabo los actores necesariamente se ciñen a un entramado institucional. Las instituciones ofrecen el marco para manejar la diversidad, complejidad y el dinamismo de las relaciones entre el Estado, el mercado y la sociedad. Según Kooiman (2004: 188), la aportación de los estudios institucionales a un mejor entendimiento de la gobernanza tiene que ver con tres factores:

- $\quad$ Los actores interactúan en contextos colectivamente limitados.

- Algunas restricciones adoptan la forma de instituciones (modelos organizados de normas y roles construidos socialmente)

Las instituciones dan forma a los intereses de aquellos que interactúan y son, a su vez, influidos por ellos.

La gobernanza, entonces, identifica el nuevo balance de las relaciones entre el Estado y la sociedad, con énfasis en la cooperación de todos los actores sociales para solucionar sus problemas y dar dirección a la sociedad. Aunque recientemente se concede importancia a la participación de todos los actores sociales para la construcción de soluciones, en sociedades como la nuestra el papel del gobierno sigue siendo central en la implementación de cualquier estrategia que tenga como objetivo la resolución de problemas sociales (Vázquez, 2010: 14).

Guy Peters y Jon Pierre (2005) realizan un recuento de las variables que a su juicio han permitido que la gobernanza sea un concepto utilizado y promovido lo mismo por organizaciones internacionales que por académicos y gobiernos. Entre las más importantes se encuentran la crisis financiera del Estado, la globalización y el cambio de ideología hacia el mercado.

Para Stoker (citado por Villanueva, 2009: 133-134), el abanico de definiciones existente da lugar a las siguientes características comunes. La cita a continuación proviene del libro de Aguilar Villanueva, Gobernanza y Gestión Pública: 
1. Implica un conjunto de instituciones y actores que se encuentran dentro y fuera del gobierno.

2. Registra que las fronteras y las responsabilidades de lo público y lo privado son hoy permeables en el abordaje de los problemas económicos y sociales de una comunidad.

3. Reconoce la interdependencia (de poder, información, recursos) de las instituciones y los actores en la realización de sus objetivos.

4. Reconoce la existencia de redes sociales de actores autónomos que tienen capacidad de autogobierno en asuntos vitales para sus vidas y necesidad de la autoridad y mando de gobierno.

De lo anterior se deducen un par de conceptos clave para entender la gobernanza: cooperación y redes. La resolución de demandas sociales desde el enfoque de gobernanza implica que diversos actores sociales actúen en sintonía para procesarlas. De igual manera, se entiende mejor la cooperación si se conceptualiza como una red de actores que intentan resolver un problema en conjunto. El enfoque de las redes ha sido usado ampliamente para entender mejor -y solucionar- problemas complejos, ya que implica compartir información, recursos y habilidades para enfrentarlos de mejor manera.

La nueva gobernanza entendida como una gobernanza democrática implica que la importancia de las redes sea comprendida con base a los elementos siguientes: a) son punto de intermedio entre el mercado y las jerarquías; b) fortalecen las relaciones horizontales de los gobiernos; c) dan pauta para el trabajo interorganizacional; d) fortalecen la implementación de políticas públicas; e) tienen que reconocerse como estructuras interdependientes; f) son sistemas orgánicos de carácter informal y, g) son pautas de acción organizada (Berrones, 2009b: 61).

Ahora bien, para Rhodes (2005: 107) la gobernanza por redes sugiere que las redes estén autoorganizadas y esta misma autoorganización significa que una red es autónoma y se autogobierna. En tal sentido, la gobernanza como redes autoorganizadas es un reto para la gobernabilidad porque las redes se vuelven autónomas y resisten la dirección central.

Por otra parte, Rhodes (2005: 101-102) señala que la gobernanza entendida como gobernanza corporativa (corporate governance), tiene como objetivo asegurar la transparencia, la rendición de cuentas y la ética en el manejo del sector privado y público, para promover e incrementar la competitividad, las mejores prácticas comerciales, los mayores rendimientos y fomentar la inversión nacional e internacional. La gobernanza corporativa tiene resonancia cuando se discute la transparencia y la rendición de cuentas en la nueva gestión pública.

\subsection{Nueva gestión pública y gobernanza}

Con el análisis económico de la política, las burocracias son objeto de críticas por ser el centro en el cual la politización en el uso de los presupuestos, la relación asimétrica de la información, la maximización de los beneficios de los cargos administrativos, así como el control monopolios públicos en nombre del Estado, habían contribuido a que la gestión pública tuviera resultados no favorables (Berrones, 2009b: 61).

Surge así un nuevo patrón de gestión pública que, inspirado en la Nueva Gestión Pública (NGP) alienta la revisión y mejora empresarial de las administraciones públicas para superar los costos y externalidades negativas que tenían su origen en la ineficiencia, la corrupción y el descrédito de amplios aparatos públicos que habían consumido el excedente producido por los mercados y los sistemas económicos. Se impone, en consecuencia, el fortalecimiento de la ética, la transparencia y la rendición de cuentas para evitar que la discrecionalidad y la impunidad contribuyeran aún más al declive funcional y operativo de los Estados Latinoamericanos (Berrones, 2009b: 61).

La Nueva Gestión Pública también se refiere a las reformas de autonomía gerencial cuya idea principal es fortalecer el poder discrecional de los gerentes y brindar a los niveles subordinados, organizaciones y empresas paraestatales más libertad de acción (Laegreid, 2005: 705). Este incremento de la autonomía gerencial a las organizaciones y empresas paraestatales trae consigo una disminución de la capacidad del control político y de la rendición de cuentas en las organizaciones.

Ahora bien, un elemento para entender los procesos de reforma y sus efectos son las tradiciones culturales de un país, las reglas informales y los valores que sustentan a éstas. Tales tradiciones pueden contribuir a coartar el control político de líderes ejecutivos. 
Otro factor es el entorno: los ejecutivos políticos pueden ser vulnerables a las presiones externas, técnicas o institucionales, y su capacidad política también puede constreñirse según que tan fácil pueda resultar que el entorno admita sus esfuerzos por moldear la conducta de sus niveles subordinados, instituciones y actores, o influir en otros importantes actores, públicos o privados, para la toma de decisiones y la implementación de las políticas públicas (Laegreid, 2005: 707), las cuales se convierten en un verdadero campo de batalla.

En las reformas del sector público, se aprecia una visión instrumental donde la versión dominante es la jerárquica, en la que los ejecutivos son los responsables del proceso de reforma y sus resultados. La toma de decisiones se caracteriza por un firme control de los actores involucrados y un inequívoco pensamiento organizativo acerca de los cambios estructurales realizados. El firme control de los actores de la reforma se asegura con la participación de los líderes de esta o con la creación de mecanismos para controlar a los otros participantes, como una organización específicamente establecida para este propósito (Laegreid, 2005: 708).

Cuando los procesos de reforma jerárquicamente basados tienen problemas, normalmente se debe a la heterogeneidad. Los líderes políticos y administrativos pueden tener diferentes opiniones sobre el modo de continuar e implementar reformas, o puede haber turbulencias y discordancia entre los actores en el entorno. Esto modifica el control político y el cálculo racional.

Por su parte, mirar las reformas del sector público a través de una lente cultural significa enfocarse en el proceso de socialización en el que no sólo se debe aprender las normas formales de roles y tarea de la organización, sino también internalizar las normas y valores informales.

Los rasgos culturales o institucionales de las organizaciones públicas pueden llevar más allá o impedir las reformas instrumentales planeadas y por consiguiente el control político. Cuando las reformas contienen normas y valores que son altamente incompatibles con las normas y valores culturales tradicionales de los sistemas político-administrativos de países específicos, se dificulta la toma de decisiones de la reforma o su implementación, o la modificación de sus elementos. Sin embargo, igualmente las reformas pueden encajar en las normas y tradiciones de las culturas existentes y por consiguiente constituir una base para mayores esfuerzos reformadores (Laegreid, 2005: 709-710).

A este proceso de reforma se agrega la teoría de lo mitos en las organizaciones, la cual parte de una premisa: que cada organización tiene dos tipos distintos de ambiente, el técnico y el institucional. El ambiente técnico está relacionado con el intercambio de productos y servicios. En cambio, el ambiente institucional es por naturaleza inmaterial, contiene varios mitos generalmente aceptados y refleja una necesidad de reglas simples y empíricas para actuar en un mundo crecientemente complejo. Estos mitos se extienden alrededor del mundo a través de la imitación, primero dentro de ciertos países y organizaciones y luego entre ellos, produciéndose un isomorfismo, una similitud estructural (Laegreid, 2005: 710).

Uno de los límites principales en el proceso de reforma aun cuando se involucran los líderes políticos es que esta participación va disminuyendo debido a problemas de capacidad y atención. Esto hace que el proceso de reforma se caracterice hoy por negociaciones entre los líderes administrativos, de organizaciones y de empresas paraestatales, con una interferencia ocasional de líderes políticos ejecutivos.

El componente de la reforma que mina más el control político y la rendición de cuentas es la "autonomización" la autonomía gerencial que refleja un aumento vertical en la especialización interorganizativa. Un rasgo de esta tendencia es la creciente autonomía de las organizaciones, particularmente reguladoras.

Las organizaciones formalmente han ganado una mayor discrecionalidad, lo que hace difícil su control, aunque en parte esto haya sido una respuesta a la necesidad de mayor autonomía para su desarrollo profesional (Laegreid, 2005: 713).

El debilitamiento de control político, provocado por la autonomía gerencial, se ha agravado por los efectos de un aumento en la especialización horizontal, creando fragmentación y confusión. Aumentando los problemas de capacidad de los líderes políticos. 
A menudo los políticos prefieren resolver problemas a corto plazo y evitar obligaciones a largo plazo. Les gusta negociar, ser moderadores y anotarse puntos políticos mediante casos simbólicos y particulares. Son normalmente más reactivos e intuitivos que emprendedores y planeadores estratégicos. En síntesis, gustan naturalmente de ser/estar en el fragor político.

Sin embargo, en las reformas de la NGP se articula un rol político distinto para el líder ejecutivo, ya que según la NGP, los políticos deben pensar en una perspectiva a largo plazo, intentar evitar la intervención a corto plazo y las cambiantes metas y prioridades; debe existir una distinción clara entre la política y la administración; y los políticos deben establecer metas y prioridades, mientras los burócratas, en un estilo directivo, deben escoger la política instrumental e implementarla, manteniendo a los políticos a distancia.

Ahora bien, el control político decreciente de líderes políticos ejecutivos debido a la creciente autonomía gerencial, parece ser el resultado de una compleja combinación de factores estructurales, culturales y simbólicos. Entre las estrategias para que los ejecutivos políticos recobren capacidad política y control simplemente depende de dos condiciones: debe haber una coalición victoriosa a favor de recobrar el control, y los efectos negativos de la autonomía gerencial deben ser tan obvios que haya mucho que perder políticamente si no se hace nada al respecto.

Otra estrategia es que el centro político-administrativo puede fortalecerse de nuevo empleando a más personas para realizar las funciones de control; el control de organizaciones y compañías del Estado pueden fortalecerse; los contratos pueden prepararse para delinear claramente la responsabilidad de los líderes subordinados; y pueden lanzarse programas y proyectos para fortalecer la coordinación en una estructura gubernamental fragmentada.

En suma, el cambio institucional incorpora elementos de la nueva gestión pública y la gobernanza para superar los costos y externalidades negativas de la administración pública que tenían su origen en la ineficiencia, la corrupción y el descrédito de las organizaciones públicas. Se impone, en consecuencia, el fortalecimiento de la transparencia y la rendición de cuentas como mecanismos de gobernanza que adquieren resonancia en la nueva gestión pública para institucionalizar las tareas del quehacer público a través de las estrategias de la agenda de gobierno. 


\title{
Capítulo 3 El cambio institucional en la Agenda de Buen Gobierno
}

El diseño de una nueva estructura orgánica-funcional de la administración pública durante el mandato del presidente Vicente Fox, estuvo a cargo de la Oficina de Innovación Gubernamental, la cual a través de la implementación de las estrategias de la Agenda de Buen Gobierno buscó un cambio institucional incorporando elementos de la nueva gestión pública, que permitieran institucionalizar las tareas del quehacer público para responder de manera eficiente, eficaz y oportuna a la sociedad.

\subsection{El principio de la innovación gubernamental}

A principios del sexenio 2001-2006, el presidente Vicente Fox configuró un equipo de trabajo con alto perfil empresarial ${ }^{14}$, que sustituyera a la vieja estructura burocrática pública, bajo la idea del modelo estratégico para la innovación gubernamental, que se estableció en el Programa de Innovación Gubernamental, el cual señaló

\begin{abstract}
"Para poner al Gobierno a toda marcha, se hacen necesarias estructuras más planas, con menos niveles, con menos plazas, más sencillas. Para nadie es un secreto la excesiva obesidad de las estructuras de gobierno, la inutilidad de muchos procesos, la duplicidad de funciones, la pesada carga burocrática, la asignación de plazas por compromisos electorales o partidistas. No cabe duda que en este campo hay mucha tela de donde cortar" (OIG, 2001: 5).
\end{abstract}

\section{Asimismo, expuso}

“[...] [requerimos de] estructuras flexibles (reorganización). Nuestros organigramas son esquemas del pasado, de la revolución industrial. Ya no funcionan. Fueron diseñados para un entorno y una época que ya no existen. No podremos hacer política del cambio con los instrumentos y estructuras del viejo régimen" (OIG, 2001: 5).

La innovación de gobierno se inscribió en el libro de David Osborne y Ted Gaebler, intitulado Reinventing Government: How the Entrepreneurial Spirit is Transformining the Public Sector (1992), y de las posturas y principios de la Organización para la Cooperación y Desarrollo Económico (OCDE). La reinvención del gobierno se centra en el buen desempeño de la organización y el premio a la innovación y la calidad, en vez de centrarse en el individuo; aumenta la productividad al utilizar y administrar los recursos con más eficiencia; otorga más facultades a la ciudadanía mediante mecanismos de retroalimentación continua; el gobierno se ocupa del timón más que de los remos; está orientado a la misión y no a las reglas; en vez de prevenir, se anticipa; es participativo y no jerárquico; emprendedor en vez de rutinario.

Según la OCDE, el buen funcionamiento del gobierno está basado en varios aspectos, dentro de los que destacan el combate a la corrupción, la participación ciudadana en la elaboración de las políticas, la utilización de buenas prácticas, la motivación de los más altos niveles de conducta ética y la capacitación de los servidores públicos.

"Está comprobado que los gobiernos más eficientes requieren de funcionarios profesionales y competitivos, menos costos regulatorios y productividad de sus habitantes, lo que en gran medida, dará como resultado mayores inversiones internas y externas, mayor empleo, mayor riqueza y más bienestar para el país" (Delgado, 2009: 430).

En este contexto, el gobierno de Fox diseñó una nueva estructura orgánica-funcional de la administración pública, para responder supuestamente de manera eficiente, eficaz y oportuna, a las diferentes áreas del quehacer público y garantizar mantenerse cerca de la sociedad en un proceso de retroalimentación permanente.

\footnotetext{
${ }^{14}$ La composición del nuevo equipo de trabajo gubernamental estaba integrado por personas de alto perfil empresarial (Carlos Abascal, secretario de Trabajo; Fernando Canales, secretario de Economía; Javier Usabiaga, secretario de Agricultura; Raúl Muñoz Leos, director de Pemex, entre otros); algunos académicos de trayectoria reconocida como del extinto Adolfo Aguilar Zinser, ex embajador de México, ante la Comisión de Seguridad de la ONU -antes coordinador de Seguridad Nacional; Mariclaire Acosta, subsecretaria de Relaciones Exteriores; algunos expriístas como Florencio Salazar Adame, secretario de Reforma Agraria, en 2003, en sustitución de María Teresa Tello; Alfonso Durazo, secretario particular de Vicente Fox; algunos zedillistas, como Santiago Levy, director del IMSS. Equipo heterogéneo que en su mayoría presenta bajo perfil y escasa preparación en el manejo de la administración pública, pero en la cual predominan criterios de eficiencia y pragmatismo empresarial, así como, la aplicación de métodos y técnicas empresariales.
} 
En diciembre de 2000, se creó mediante acuerdo publicado en el Diario Oficial, la Oficina Ejecutiva de la Presidencia de la República, que en su artículo 2, refirió: "Para el estudio, planeación y despacho de los asuntos de su competencia, la Oficina Ejecutiva de la Presidencia de la República contará con las unidades administrativas" siguientes:

Jefe de la Oficina de Planeación Estratégica y Desarrollo Regional;

Jefe de Oficina de Políticas Públicas;

Jefe de Oficina para la Innovación Gubernamental;

Comisionado de Orden y Respeto;

Comisionado para el Crecimiento con Calidad;

Comisionado para el Desarrollo Social;

Comisionado para la Negociación para Chiapas;

Oficina de Representación para el Desarrollo de los Pueblos Indígenas;

Oficina de representación para la Promoción e Integración Social con Personas con

Discapacidad;

Oficina de Representación para Mexicanos en el Exterior y México-Americanos;

Dirección General de Administración y Secretariado Técnico.

Tabla 3.1 Rediseño de la Administración Pública

\begin{tabular}{|c|c|c|c|}
\hline $\begin{array}{l}\text { Comisionados de la } \\
\text { Oficinas de la } \\
\text { Presidencia }\end{array}$ & Crecimiento con Calidad & Desarrollo Social $^{1 /}$ & Orden y Respeto $^{1 /}$ \\
\hline 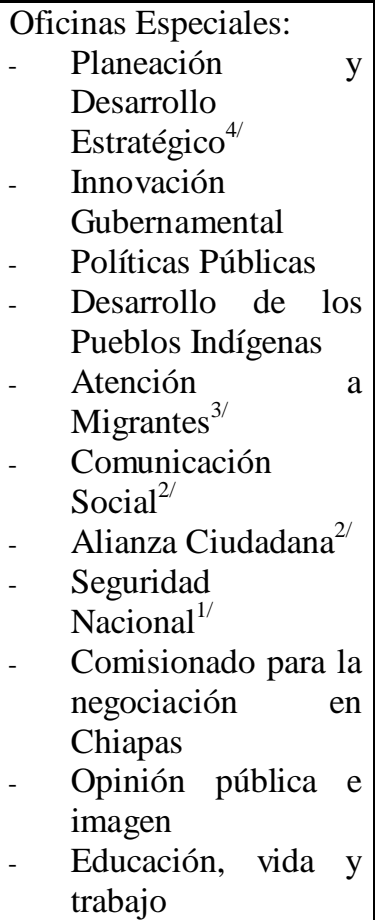 & $\begin{array}{ll}\text { - } & \text { Hacienda y Crédito } \\
& \text { Público } \\
\text { - } & \text { Energía } \\
\text { - } & \text { Turismo } \\
\text { - } & \text { Economía } \\
\text { - } & \text { Relaciones Exteriores } \\
\text { - } & \text { Comunicaciones y } \\
& \text { Transportes }\end{array}$ & $\begin{array}{ll}\text { - } & \text { Medio Ambiente y Recursos } \\
& \text { Naturales } \\
\text { - } & \text { Agricultura, Ganadería, Desarrollo } \\
& \text { Rural, Pesca y Alimentación, } \\
\text { - } & \text { Trabajo y Previsión Social } \\
\text { - } & \text { Educación Pública } \\
\text { - } & \text { Desarrollo Social } \\
\text { - } & \text { Salud }\end{array}$ & $\begin{array}{ll}\text { - } & \text { Gobernación } \\
\text { - } & \text { Contraloría y } \\
& \text { Desarrollo } \\
& \text { Administrativo } \\
\text { - } & \text { Reforma Agraria } \\
\text { - } & \text { Seguridad Pública } \\
\text { - } & \text { Defensa Nacional } \\
\text { - } & \text { Marina } \\
\text { - } & \text { Procuraduría } \\
& \text { General de la } \\
& \text { República }\end{array}$ \\
\hline
\end{tabular}

1/ La falta de articulación en términos de la administración pública, en cuanto a la poca claridad de las funciones específicas, como los instrumentos y las facultades reales que iban a tener las coordinaciones por área, derivó en las renuncias de Adolfo Aguilar Zinser (ex embajador de México ante la Comisión de Seguridad de la ONU), a la Comisión de Orden y Respeto, y a la Oficina de Seguridad Nacional; y de José Sarukhán, a la Comisión de Desarrollo Social, siendo desmanteladas por el propio presidente Fox, en el 2001.

2/ La Oficina de Alianza Ciudadana desapareció al ser nombrado su titular, Rodolfo Elizondo, vocero de la presidencia de la República, tras la renuncia de Martha Sahagún, como jefa de la Oficina de Comunicación Social, por su matrimonio con el presidente Fox en el año 2001. Después sería nombrado Secretario de Turismo.

3/ La oficina de Atención a los Migrantes, desapareció en el año 2002, tras la encomienda de otra tarea a su titular el México-estadounidense, Juan Hernández.

4/ En julio de 2003, Carlos Flores, jefe de la Oficina de Planeación Estratégica dejó la misma para ser nombrado embajador de México ante la Organización para la Cooperación y el Desarrollo Económico. En ese mismo año Ernesto Ruffo Appel, renunció a su cargo frente a la Comisión para Asuntos de la Frontera Norte.

Fuente: Elaboración propia con base a datos del Plan Nacional de Desarrollo 2001-2006, y El Financiero 6 y 8 de febrero de 2001 
Como se observa en la tabla 3.1, las secretarías de Estado estaban agrupadas en tres áreas principales, donde una especie de super-asesores o zares sectoriales, eran los encargados de atender los problemas regionales o nacionales, garantizando la debida coordinación entre diferentes niveles de gobierno o dependencias para cumplir con determinada meta u objetivo. Las unidades administrativas actuaban como un gabinete alterno, cuyas tareas incluían tanto las de apoyo, planeación estratégica y desarrollo regional, políticas públicas e innovación gubernamental, como las de vinculación con grupos sociales relevantes de la sociedad y seguimiento a las prioridades de este gobierno ${ }^{15}$. Bajo esta nueva estructura, el gobierno de Fox estableció compromisos por cada área responsable, y los programas y/o actividades de caracteres sectoriales, regionales y especiales, para su solución (OIG, 2001).

Para alcanzar los objetivos del programa de la administración Fox, el titular de la Oficina para la Innovación Gubernamental, Ramón M. Gutiérrez, presentó el Modelo Estratégico para la Innovación del Gobierno, elaborado por él; el cual partió para su construcción de una serie de premisas: 1) el mejor modelo es la realidad misma; 2) es un modelo de innovación social hacia el interior de la Administración Pública Federal (APF); 3) se centra en recuperar la confianza de los ciudadanos en el gobierno, así como en transformarlo en una institución competitiva de clase mundial; 4) no se pretende convertirlo en la palabra final; 5) se trata de una guía sólida y estructurada para la conducción del proceso de cambio, y se somete a revisión, respetando los principios básicos de los nuevos aprendizajes y desaprendizajes (OIG, 2001).

\subsection{Modelo Estratégico para la Innovación y la Calidad Gubernamental}

El modelo estratégico consideró la innovación del gobierno como un movimiento de carácter cultural y estructural, que buscó reformar radicalmente la orientación, la capacidad y velocidad de respuesta estratégica de la APF, revisualizándolo todo desde múltiples perspectivas (Gutiérrez, 2004: 138). De esta manera, se destacó la presencia de conceptos y definiciones que se establecían en el contexto internacional -innovación y calidad gubernamental, reingeniería de procesos, gestión estratégica y buen gobierno (gobernanza)-.

Figura 3.1 Modelo Estratégico para la Innovación y la Calidad Gubernamental

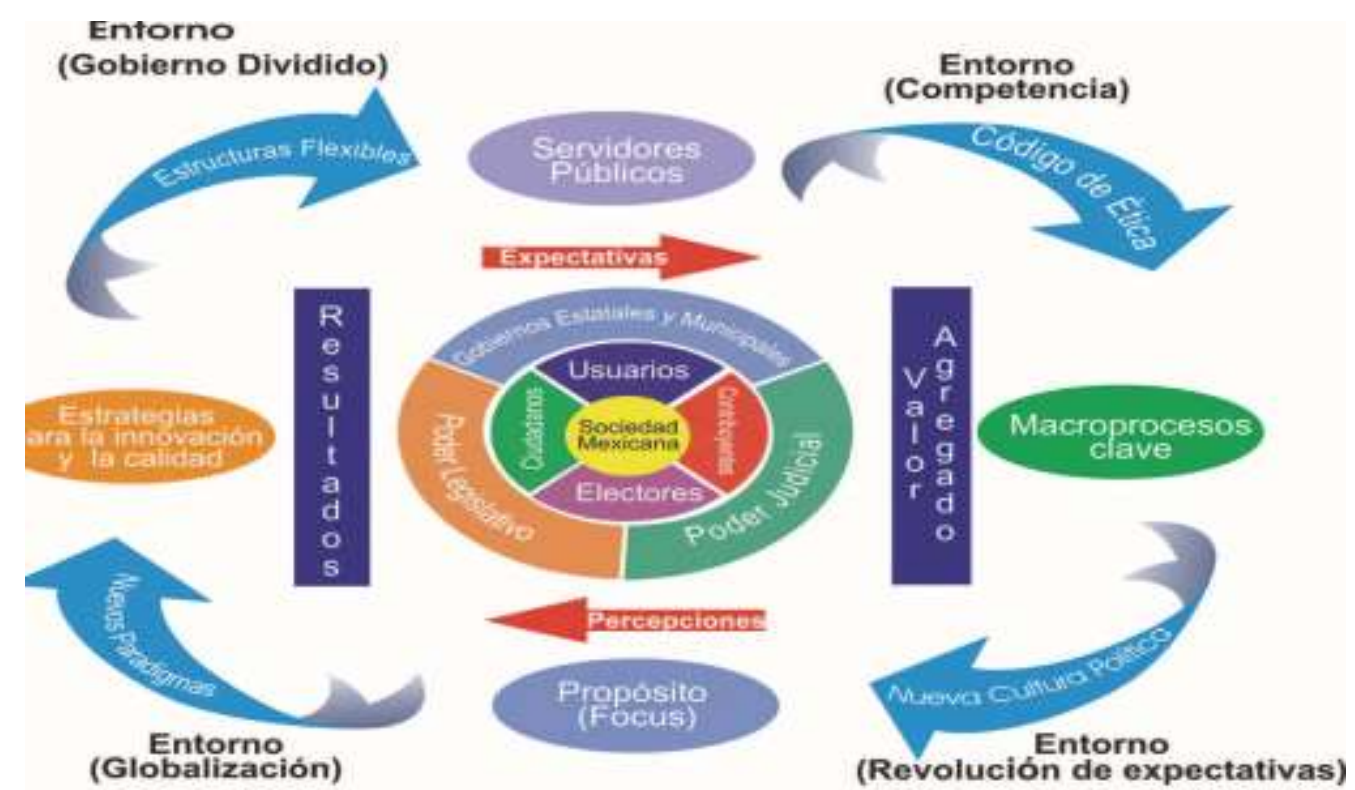

Fuente: Oficina de la Presidencia para la Innovación Gubernamental (2001). Modelo Estratégico para la Innovación Gubernamental

La innovación gubernamental en su génesis se basó en los principios relacionados con la new public management o nueva gestión pública (NGP), la cual se caracteriza por la incorporación de prácticas corporativas al gobierno cuya institucionalización alrededor del mundo se inicia entre mediados y finales de la década de los ochenta.

\footnotetext{
${ }^{15}$ Pocos meses después de creadas, dichas oficinas fueron cuestionadas por los propios colaboradores de Fox. En lugar de servir como mecanismos de coordinación del quehacer gubernamental, estas agencias sólo generaron diferencias con el gabinete de gobierno.
} 
Con el modelo de innovación se introdujo la innovación administrativa -haciendo a un lado la reforma y la modernización- como una estrategia para mejorar el aparato gubernamental (González, 2001: 178). Así, en el marco del Plan Nacional de Desarrollo 2001-2006, los objetivos que se presentaron bajo el modelo de innovación gubernamental fueron:

\footnotetext{
"1. Buen gobierno: Forjar un buen gobierno de clase mundial, competitivo, transparente, innovador, de calidad, honesto, participativo y proactivo, que trabaje mejor y cueste menos y genere, mayores beneficios a la sociedad.

2. Crecimiento económico: Crear las condiciones para un desarrollo económico sustentable y competitivo en el ámbito mundial, que impulse el progreso de todos los mexicanos.

3. Orden y respecto: Lograr que se viva permanentemente en un estado de derecho que garantice la seguridad, justicia, convivencia, participación y paz social.

4. Desarrollo humano y social: Lograr un desarrollo equilibrado, equitativo y participativo, donde sea prioritaria la ecuación y la salud de los mexicanos" (OIG, 2001: 30).
}

Para alcanzar los objetivos de la innovación gubernamental se tuvieron como elementos clave: a) concentrar a todos los servidores públicos en un propósito (focus); b) generar resultados que añadan valor al gobierno y la sociedad; y c) tomar en cuenta el entorno en el que participa, afecta e impacta a la administración pública federal. Para conseguir el propósito (focus), los objetivos y poner en marcha las estrategias (ver tabla 3.2), el modelo planteó construir una red de socios estratégicos. En esta red participarían: los oficiales mayores (cambiarán de denominación y su enfoque de trabajo); los responsables de las áreas de Recursos Humanos; Innovación y Calidad; las unidades de Desarrollo Administrativo de la Secretaría de Contraloría y Desarrollo Administrativo; del Servicio Civil de la Secretaría de Hacienda y Crédito Público, y los responsables de las áreas de Informática y Asuntos Jurídicos, entre otros.

Tabla 3.2 Estrategias del Modelo de Innovación Gubernamental

\begin{tabular}{|c|c|}
\hline Estrategias & ces \\
\hline 1. Administración por calidad & $\begin{array}{ll}\text { - } & \text { Establecer el Premio Nacional de Calidad } \\
\text { - } & \text { Establecer el sistema de administración de calidad (Intragob). } \\
\text { - } & \text { Cambiar el Premio Nacional a la Administración Pública por el Premio del Presidente a } \\
& \text { la Innovación y la Calidad. }\end{array}$ \\
\hline 2. Federalismo y municipalismo & $\begin{array}{l}\text { - } \quad \begin{array}{l}\text { Fortalecer la capacidad de respuesta estratégica de los gobiernos estatales y municipales } \\
\text { para servir mejor a los ciudadanos. }\end{array} \\
\end{array}$ \\
\hline 3. Tradición e innovación & $\begin{array}{ll} & \text { Cierre de dependencias. } \\
\text { - } & \text { Cancelación de programas. } \\
\text { - } & \text { Reducción de estructuras. } \\
\text { - } & \text { Necesario aprender como desaprender. }\end{array}$ \\
\hline $\begin{array}{ll}\text { 4. Gobierno abierto } & \\
\text { transparente } & \end{array}$ & $\begin{array}{ll}\text { - } & \text { Lograr un gobierno innovador y de calidad es vital democratizar la información. } \\
\text { - } & \text { El secreto está en convertir en una costumbre el rendirle a la sociedad cuentas claras. }\end{array}$ \\
\hline $\begin{array}{l}\text { 5. Reformas jurídicas } \mathrm{y} \\
\text { normativas }\end{array}$ & $\begin{array}{l}\text { - Los gobiernos cuyos paradigmas se basan en la innovación y la calidad y no en el } \\
\text { control, requieren de repensar y renovar sus marcos jurídicos y legales, ya que } \\
\text { responden a otra lógica. }\end{array}$ \\
\hline $\begin{array}{l}\text { 6. Unir la retaguardia con la } \\
\text { vanguardia }\end{array}$ & $\begin{array}{l}\text { - Construir reglas del juego, mecanismos de colaboración y espacios que permitan } \\
\text { compartir aprendizajes entre las distintas áreas, niveles y órdenes de gobierno. }\end{array}$ \\
\hline 7. Benchmarking & $\begin{array}{ll}\text { - } & \begin{array}{l}\text { Evaluar los procesos, servicios y resultados de las instituciones reconocidas como } \\
\text { representantes de las mejores prácticas. }\end{array} \\
\end{array}$ \\
\hline 8. Financiamiento emprendedor & $\begin{array}{l}\text { - Un gobierno debe ser capaz de allegarse recursos extragubernamentales, ya que los } \\
\text { presupuestos no alcanzan para financiar los proyectos estratégicos. }\end{array}$ \\
\hline $\begin{array}{l}9 . \quad \text { Informática } \\
\text { telecomunicaciones }\end{array}$ & $\begin{array}{l}\text { - El megaproyecto e-México, con sus productos: e-government -gobierno digital o } \\
\text { electrónico-; e-education -revolución de la educación soportada con tecnologías de } \\
\text { información-; e-commerce -negocios electrónicos, en otros, será la respuesta del } \\
\text { gobierno federal a tan estratégica oportunidad. }\end{array}$ \\
\hline 10. Subcontratación de servicios & $\begin{array}{l}\text { El gobierno debe dedicarse a dirigir, no a remar. El gobierno debe enfocarse a los } \\
\text { procesos estratégicos y sustantivos. Los procesos o servicios secundarios o adjetivos } \\
\text { pueden y deben ser subcontratados o cualquier otra modalidad jurídicamente permisible } \\
\text { y políticamente viable. }\end{array}$ \\
\hline 11. Encuesta valorativa & $\begin{array}{l}\text { - Se trata de un proceso generativo, lo que significa que es un blanco móvil y que la gente } \\
\text { que lo usa, lo crea y lo recrea. }\end{array}$ \\
\hline
\end{tabular}

Fuente: Realización propia con base a González (2004: 409) \& Gutiérrez, R. M. (2004: 153-154)

Con estas estrategias en el objeto de estudio se tenía como finalidad dar respuesta a las demandas y expectativas generadas por la sociedad que incluía una propuesta específica de rediseño de la administración pública que respondiera a la horizontalidad de la ciudadanía que se venía gestando. 
El modelo de innovación gubernamental contempló una serie de fases en las que el gobierno, en un escenario demasiado optimista, alcanzaría un nivel de clase mundial al finalizar el sexenio. De esta manera, los programas nuevos se interrelacionaron con las razones de la introducción de la innovación productiva empresarial en el sector público que son las mismas de la empresa privada, como el aumento de la eficiencia y la eficacia, la mejora de la imagen de la administración pública representándola como proactiva y moderna, venciendo resistencias en asuntos como: el casi monopolio público $^{16}$. En este sentido, la competencia entre organizaciones hace que éstas busquen sobrevivir al mínimo esfuerzo bajo la pretendida homogeneización con otras que han tenido éxito.

Figura 3.2 Fases de la Innovación Gubernamental

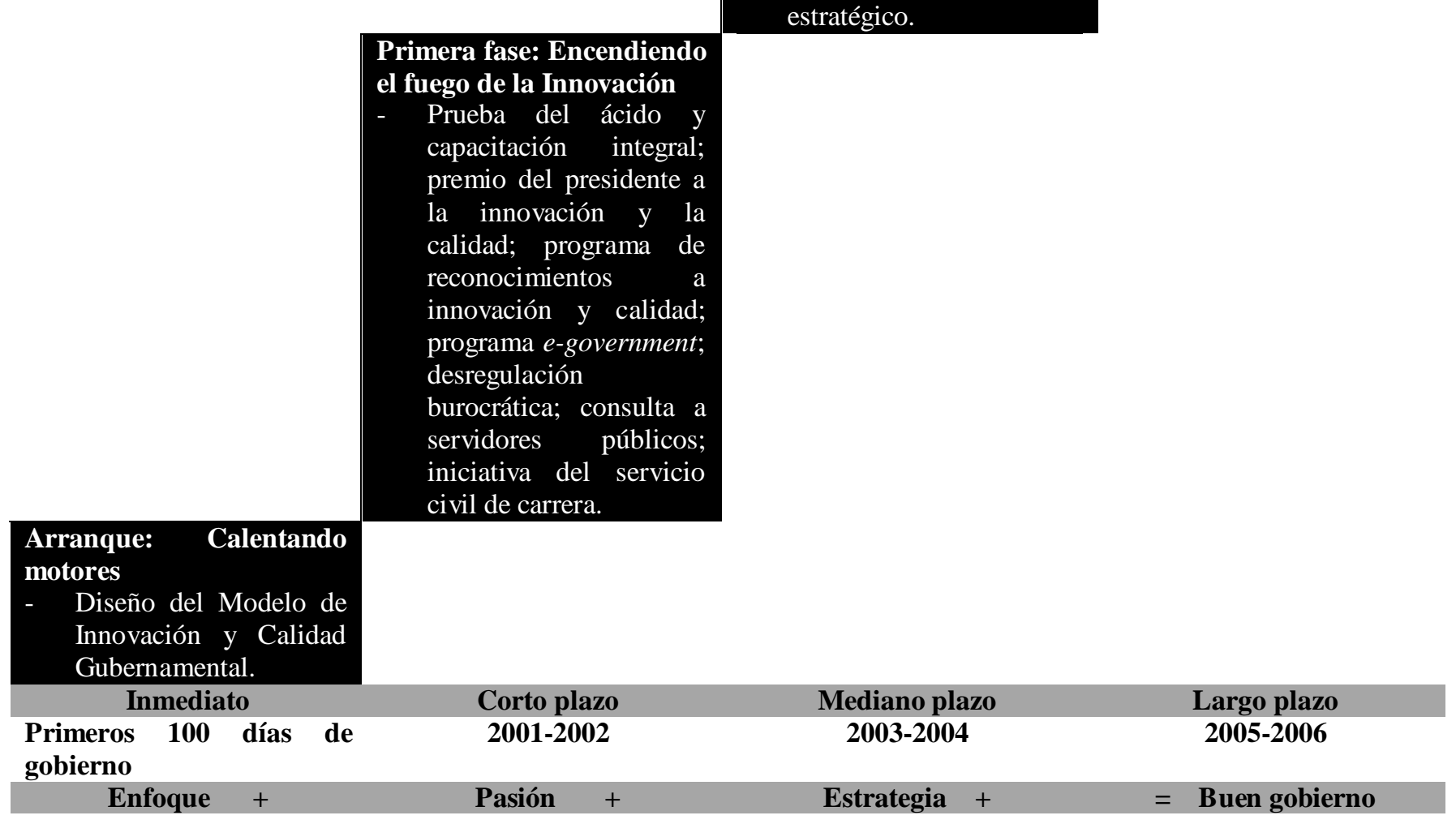


Significa que (en un lenguaje del institucionalismo sociológico) existen presiones para que las organizaciones se vuelvan isomórficas ${ }^{17}$.

La categoría de innovación abordada por Joseph Schumpeter en su clásico libro "Capitalismo, socialismo y democracia", publicado en 1942, es entendida formulando el principio "destrucción creadora", en la que el equilibrio del sistema económico capitalista se rompe por la acción de ciertos agentes innovadores que introducen cambios en los procesos productivos. Se trata de una ruptura intencional en el proceso productivo, en función de nuevas técnicas que permiten dar un salto y colocar a la empresa en una mejor situación de competencia dinámica; es decir, de competencia imperfecta. En otras palabras, la obsolescencia adquirida en las prácticas productivas precedentes implica un momento destructor de las prácticas anteriores, ampliando las innovaciones radicales, las cuales consisten en: introducción de nuevos cambios en los procesos productivos, la apertura de nuevos mercados, la generación de una nueva fuente de suministro u oferta de materias primas, cambios en la organización $\mathrm{o}$ en su proceso de gestión de la organización (Shumpeter, 2012) ${ }^{18}$. Sin embargo, las innovaciones radicales pierden tal carácter tan pronto su innovación se masifica, se vuelve rutinaria, es decir, tan pronto "pasa de moda" (Montoya, 2004).

La innovación, en otros casos, es de naturaleza "incremental" y puede ser entendida como un nuevo uso de las posibilidades y de los elementos preexistentes. Esta, modalidad -que ignora el pensamiento de Schumpeter- adquiere especial relevancia en ciertos sectores industriales más tradicionales y tienen gran importancia en los casos de los países menos desarrollados (Albornoz, 2009: 9-25).

Ambos tipos de innovación coexisten, se complementan y con frecuencia representan fases sucesivas de la difusión del conocimiento tecnológico. En este sentido las nuevas tecnologías de la información y la comunicación (TIC), son un ejemplo de innovación radical seguida de una posterior difusión incremental. La influencia de las TIC opera sobre todas las actividades económicas, sus ventajas directas de tipo económico reposan sobre el mejoramiento de la calidad, de la velocidad, de la generación, del almacenamiento y de la difusión de la información. Estas tecnologías son "radicales" por cuanto tienen la potencialidad de transformar profundamente el modo de producción. Al mismo tiempo, modifican la estructura organizacional de las empresas y repercuten sobre el empleo, la productividad y las capacidades básicas (Albornoz, 2009: 9-25).

En el sentido administrativo, la innovación se presenta como la mejora en programas. Las mejoras se refieren a bienes y servicios que al exterior se observan nítidamente. Al interior, es la forma como se organiza la administración para prestarlos, pero con el añadido de mejorar los tiempos con el uso de las TIC en que se realizan los trámites, se reciben los servicios y sus beneficios, y cómo los miembros de la burocracia, con sentido de la responsabilidad buscarán las causas de que lo anterior se cumple de manera expedita y en términos globales, eficientes (Martínez, 2009: 136).

Desde la perspectiva de González (2004: 66), el MEIG se aplica más a lo microadministrativo, antes que a la reforma y la modernización como una estrategia para mejorar el aparato gubernamental. En tal sentido, sostiene que:

\footnotetext{
"pareciera demasiado pretencioso promover una innovación gubernamental a escala federal, sin haber realizado antes diversas innovaciones específicas en los diversos ámbitos de la administración pública. La razón esencial es que la innovación surge por necesidades particulares de cada organización pública que difícilmente pueden repetirse o reproducirse en otras organizaciones con actividades diferentes [...] existen diversos niveles de innovación que algunas organizaciones pueden alcanzar como parte de las acciones para su mejoramiento administrativo, mientras que otros sólo podrán realizar algunas medidas innovativas, en parte por su carencia de capacidad administrativa, recursos y entorno en que se desenvuelven" (González, 2004: 66-67).
}

\footnotetext{
${ }^{17}$ Es un proceso compulsivo que obliga a una unidad en una población a asemejarse a otras que enfrentan el mismo conjunto de condiciones ambientales.

${ }^{18}$ Schumpeter (2012)) diferencia entre invención e innovación. La primera es el descubrimiento que pertenece al saber científico o técnico. La segunda es la introducción de nuevas combinaciones de los factores productivos. La invención es un acto de creatividad intelectual, sin importancia para el análisis económico. La innovación es una decisión económica: una empresa aplicando una invención.
} 
El diseño de este modelo de innovación gubernamental contempló varios componentes: el entorno y sus características; tener un propósito definido; quiénes serían los clientes externos y quiénes los clientes internos a los que se serviría, así como estrategias para impulsar el modelo en dos vertientes: la innovación, que permitiría mejorar la actividad pública generando un valor agregado. La vertiente de gobierno de calidad significaba también tener un gobierno eficiente y confiable cuyos procesos y servicios estarían avalados por la certificación de un sistema de gestión de calidad (Gutiérrez, 2004). En ambas vertientes, el desempeño del gobierno se daba bajo nuevas reglas ${ }^{19}$. Cabe aclarar que en este modelo de innovación se careció de mecanismos específicos y de evaluaciones sistemáticas para conocer la efectividad de los cambios en un mejor desempeño gubernamental (Gault, 2004: 129-133).

A la mitad del sexenio de Vicente Fox, con la finalidad de dar respuesta a las demandas y expectativas generadas por la sociedad, el gobierno, a través del MEIG estableció la Agenda de Buen Gobierno (ABG) (Villanueva, 1993: 29) ${ }^{20}$, que no sólo cuestionó el tamaño del gobierno sino su operación, la calidad de la gestión estatal, con base en el uso de lenguaje de la gestión privada que cada vez se hicieron más constantes en la administración pública términos como flexibilidad, productividad, competitividad, calidad y cliente (Gutiérrez, 2004: 42-43), ello tenía como objetivo transformar radicalmente los esquemas tradicionales del quehacer público, buscando generar cambios profundos, permanentes y reemplazando las viejas formas de los servidores públicos.

Con estructuras flexibles se pretendía pasar de la estructura vertical a la horizontal, matricial, de redes, virtual, por proyecto, para mejorar el desempeño gubernamental. Sin embargo, el enfoque empresarial (en el que prevalecían los empresarios-políticos) del modelo de innovación gubernamental no tuvo en cuenta la cultura y el contexto de la APF, porque no adecuaba su visión y formas de gestión al contexto gubernamental donde se desenvuelve el Estado mexicano (Pacheco, 2010: 53-113) ${ }^{21}$.

La productividad en el gobierno se entendía emulando a las empresas en la optimización de los recursos disponibles mediante sistemas adecuados para lograr eficiencia y ahorro. Ello permitiría competencia de mercado en los campos de la administración pública para la producción de bienes y servicios de mayor calidad que satisficieran las necesidades de los ciudadanos denominados "clientes",22.

Para llevar a cabo estas definiciones de productividad, competencia y calidad, el gobierno de Fox recurrió a las estrategias de benchmarking y la subcontratación de servicios. La primera se refiere a la evaluación de procesos, prácticas y resultados de las instituciones que son líderes por estar reconocidas como los mejores, con el propósito de reconocer esos procesos y prácticas para implementarlas en la propia organización. La segunda consiste en que el gobierno deje las funciones adjetivas en manos de empresas que se dediquen a tales servicios y que sólo pague por contratar la prestación de los servicios. "Entonces, se privatiza la parte adjetiva de la administración pública" (Ramos, 2008: 197).

\footnotetext{
${ }^{19}$ Para ello estableció una serie de líneas de acción identificadas como la filosofía del gobierno: administración por calidad, estructuras planas (reducción), estructuras flexibles (reorganización): administración cruzada, mejora en la capacidad de gobernar, visión y misión compartida, reposicionamiento, contribución a un nuevo orden mundial.

${ }^{20}$ De acuerdo a Luis F. A. Villanueva (1993: 29), por agenda de buen gobierno se entiende "el conjunto de problemas, de demandas, cuestiones, asuntos, que los gobiernos han seleccionado y ordenado como objetos de su acción y, más propiamente, como objetos sobre los que han 'decido que tienen que actuar" (1993: 29). Para Helena Ramírez (2012), la agenda política es una lista de temas o problemas a los que ponen atención en algún momento los oficiales del gobierno o gente fuera de gobierno relacionada con ellos. El proceso de definición de la agenda reduce el conjunto de posibles temas a aquellos que realmente se convierten en el cuadro de atención. Uno de los principales actores que definen la agenda es el gobierno que controla la legislación y el proceso de las políticas. El gobierno decide cuáles políticas deben ser revisadas, cambiadas o introducidas. Esta agenda tiene el propósito de anticipar los problemas o sus ramificaciones antes de que ocurra una crisis.

${ }^{21}$ Según Pacheco (2010: 57-113), un aspecto que impidió la creación y fortalecimiento del Marco Jurídico de la APF fue que el PAN tenía mayoría relativa en el Congreso; lo cual ante la falta de negociación y consenso por parte del Ejecutivo evitó la correcta gestión efectiva de leyes importantes para el desarrollo del país.

${ }^{22}$ Para el gobierno empresarial de Fox, el ciudadano era entendido como un cliente, el cual tenía que ser escuchado y atendido como en la iniciativa privada. Sin embargo, en esta investigación me ajustaré al término ciudadano, el cual se define como aquel que posee derechos y los ejerce para la toma de decisiones en la vida pública.
} 
Al final los resultados no fueron los esperados. La introducción de distintas estrategias para modernizar la APF en búsqueda de mayor eficiencia y eficacia, para mejorar el aparato gubernamental, no coadyuvaron a generar datos duros que reflejarán si la meta de mejorar la gestión se cumplió. Por ejemplo, escasa o nula disminución de la pobreza durante el sexenio de Fox, es una de las limitaciones que "se presentó en esta propuesta de cambio administrativo [la cual] se atribuye a que la cultura no ha cambiado en los funcionarios públicos mexicanos, [ello] se deriva de la escasa vocación de servicio del servidor público mexicano y del limitado liderazgo del Ejecutivo Federal de orientar su gobierno hacia impactos sociales de la realidad se deduce que es necesario reformar y modernizar al Estado mexicano" (Pacheco, 2010: 57-113, subrayado mío).

Si bien se reconoce en el modelo de innovación gubernamental que la "pobreza no podrá disminuir si no hay crecimiento económico [...]" (Gutiérrez, 2004: 55), se tiene que el PIB creció 2.3 por ciento entre 2000-2006, cifra que exhibe un pobre desempeño económico.

Por otra parte, la falta de claridad de la mejoría de los servicios y prestaciones que la administración pública ofrece a sus ciudadanos permite considerar que las decisiones frecuentemente se toman con la pretensión de que los usuarios serán los beneficiarios de tales decisiones. Empero, cambiar hacia nuevos esquemas se traduce en un reto de grandes complejidades que no siempre tienen como centro el bienestar de los ciudadanos y la eficiencia de la acción gubernamental (Pacheco, 2010: 57-113).

Así se tiene que los premios y reconocimientos a la innovación y la calidad, establecidos en el año 2002, cuya estrategia de desempeño del gobierno debió ser traducido en datos cuantitativos, sólo eran considerados si se reconocían los modelos de otros países por su buen desempeño y con base en ellos, definir un modelo que fuera semejante (Pacheco, 2010: 57-113) ${ }^{23}$. Sin embargo, su impacto no fue considerado en la medida que el ciudadano percibiera una mayor calidad en la gestión pública. Ello se deriva a que si bien, se basó la gestión pública mexicana en orientaciones internacionales de calidad, no se adaptaron al contexto prevaleciente en su momento en México.

\subsection{Reformas legales para el cambio democrático institucional}

Para acelerar el cambio institucional, el gobierno de Fox estableció tres acciones para un nuevo arreglo institucional entre los actores participantes -ciudadanos, servidores públicos y gobierno- en el ámbito de la administración pública. Estas tres acciones fueron: a) Ley Federal de Responsabilidades Administrativas de los Servidores Públicos (LFRASP), publicada el 13 de marzo de 2002; b) Ley de Transparencia y Acceso a la Información Pública Gubernamental (LTAIPG), publicada en el Diario Oficial de la Federación, el 11 de junio de 2002; esta ley derivó en la creación del Instituto Federal de Acceso a la Información Pública (IFAI), que comenzó a operar el 2 de julio de 2003; c) publicación de la Ley de Servicio Profesional de Carrera de la Administración Pública Federal (LSPCAPF), el 13 de abril de 2003, también se realizaron reformas a la Ley Orgánica de la Administración Pública Federal (LOAPF) y la Ley de Presupuesto, Contabilidad y Gasto Público, así como adiciones a la Ley de Planeación. Antes se creó la Secretaría de la Función Pública que a partir del $1^{\circ}$ de enero de 2003 sustituyó a la Secretaría de Contraloría y Desarrollo Administrativo (SECODAM); con el propósito de que fuera la encargada del desarrollo y profesionalización de las actividades de gobierno, y dirigiera el servicio profesional de carrera. En la tabla sinóptica 3.3 se muestran los cambios institucionales, las organizaciones encargadas de realizar dichos cambios y sus objetivos.

\footnotetext{
${ }^{23}$ El número de certificaciones de la norma ISO 9000, con las adaptaciones que establece la metodología mexicana, se lograron 429 centros de trabajo en la administración pública y 1,273 en el año 2004, se triplicó el número en un periodo de cuatro años. Idem.
} 
Tabla 3.3 Cambios institucionales en el gobierno de Vicente Fox

\begin{tabular}{|c|c|c|}
\hline Instituciones/Reformas & Organizaciones & Objetivos \\
\hline $\begin{array}{l}\text { Ley Federal de Responsabilidades } \\
\text { Administrativas de los Servidores } \\
\text { Públicos (LFRASP), } 13 \text { de marzo } \\
\text { de } 2002^{*} \text {. }\end{array}$ & $\begin{array}{l}\text { Secretaría de la Función Pública, } 1^{\circ} \text { de } \\
\text { enero de } 2003 \text {. }\end{array}$ & $\begin{array}{l}\text { Fortalecer las responsabilidades } \\
\text { administrativas de los servidores públicos } \\
\text { a través del establecimiento de } \\
\text { infracciones administrativas a todos } \\
\text { aquellos funcionarios que cometan actos } \\
\text { ilícitos. }\end{array}$ \\
\hline $\begin{array}{l}\text { Ley de Transparencia y Acceso a la } \\
\text { Información }\end{array} \begin{array}{l}\text { Pública } \\
\text { Gubernamental } \\
\text { junio de } 2002 .\end{array}$ & $\begin{array}{l}\text { Instituto Federal de Acceso a la } \\
\text { Información Pública, } 2 \text { de julio de } \\
2003 \text {. }\end{array}$ & $\begin{array}{l}\text { Garantizar el derecho al acceso de la } \\
\text { información; la protección de datos } \\
\text { personales; favorecer la rendición de } \\
\text { cuentas; mejorar la organización, } \\
\text { clasificación y manejo de lo } \\
\text { documentos, y contribuir a la } \\
\text { democratización de la sociedad mexicana } \\
\text { y la plena vigencia del Estado de derecho. }\end{array}$ \\
\hline 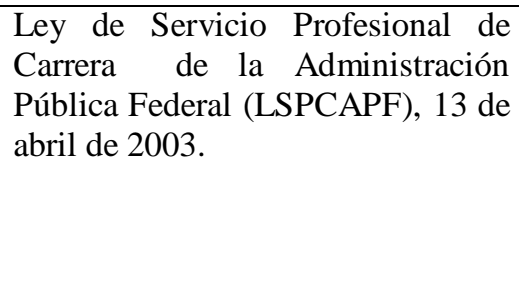 & $\begin{array}{l}\text { Secretaría de la Función Pública, } 1^{\circ} \text { de } \\
\text { enero de } 2003 \text {. }\end{array}$ & $\begin{array}{l}\text { Garantizar la igualdad de oportunidades } \\
\text { en el acceso a la administración pública } \\
\text { con base al mérito de los funcionarios } \\
\text { más aptos y capaces de ejercer su } \\
\text { función, privilegiando el interés público y } \\
\text { la profesionalización del servicio público } \\
\text { para beneficio de la sociedad. }\end{array}$ \\
\hline
\end{tabular}

*Responsabilidad administrativa. Conforme al Artículo 113 de la Constitución Política de los Estados Unidos Mexicanos (CPEUM) y los Artículos 7 al 16 de la Ley Federal de Responsabilidades Administrativas de los Servidores Públicos, las responsabilidades de los servidores públicos determinarán sus obligaciones a fin de salvaguardar la legalidad, honradez, lealtad, imparcialidad, y eficiencia en el desempeño de sus funciones, empleos, cargos y comisiones. La organización encargada de imponer sanciones por falta administrativa corresponde a la Secretaría de la Función Pública, el contralor interno y/o el titular del área de responsabilidades de la dependencia pública donde labore el servidor público que haya incurrido en la responsabilidad. Las sanciones por falta administrativa consistirán en: amonestación privada o pública; suspensión de empleo, cargo o comisión por un periodo no menor de tres días ni mayor a un año; destitución del puesto; sanción económica; e inhabilitación temporal para desempeñar empleos, cargos o comisiones en el servicio público.

Fuente: Elaboración propia

Como puede observarse, la vigencia de la Ley Federal de Responsabilidades Administrativas de los Servidores Públicos, la de Transparencia y Acceso a la Información Pública Gubernamental y la Ley de Servicio Profesional de Carrera de la Administración Pública Federal, son ejemplo conspicuo de la nueva institucionalizada que el país empezó a vivir. Define el cosmos de reglas que deben cumplirse para que los servidores públicos asuman conductas institucionales que respondan al imperativo de que en la visión del Estado de derecho (O’Donnell, 2007: 89-99) ${ }^{24}$, no hay ni puede haber la preeminencia de las personas sobre las normas.

Un acotamiento básico de la ley se refiere al modo en que el poder controla al poder, lo cual implica en la visión de la constitucionalidad y el derecho público, "que en la sociedad moderna el poder se organiza con base a reglas institucionales que son partes importantes para propiciar condiciones de certidumbre en beneficio de la vida privada, la vida pública y la vida política" (Berrones, 2003: 26).

La responsabilidad administrativa alude a la obligatoriedad que debe cumplirse para dar consistencia y eficacia a la función pública tomando en consideración los principios de legalidad, honradez, lealtad, imparcialidad y eficiencia del servicio público. De tal suerte, que la responsabilidad de la burocracia es consecuente con las instituciones que se han creado -rendición de cuentas, transparencia de recursos, servicio civil de carrera, derecho a la información, democratización de la sociedad- para limitar la práctica de los poderes discrecionales que dañan el espíritu y el contenido del Estado de derecho. "El apego a la norma y el cumplimiento de las tareas públicas son el epicentro que define el alcance de la efectividad burocrática" (Berrones, 2003: 26).

\footnotetext{
${ }^{24}$ Desde sus orígenes el concepto de Estado de derecho se basa en la idea de igualdad formal, por lo menos ante ciertos aspectos de vida social. Nos dice que todos somos iguales ante la ley y hay instituciones estatales, sobre todo pero no exclusivamente del poder judicial, que tienen a partir de ello la obligación de tratarnos como tales iguales. Esto es sólo posible de garantizar su efectividad bajo condiciones democráticas (O`Donnell, 2007).
} 
Por su parte, el acceso a la información es un requisito sine quo non para potenciar la participación ciudadana en las más variadas y diversificadas tareas que exige el desarrollo y la atención de los asuntos públicos. Una participación ciega sin bases y sin los fundamentos que da la información, es de pocos alcances y efectividad, en tanto que una participación debidamente apoyada en la información es evidentemente más eficaz.

De esta manera, la Ley Federal de Transparencia y Acceso a la Información Pública Gubernamental constituye el instrumento básico para incrementar la participación ciudadana e intensificar su corresponsabilidad en el desarrollo óptimo de los asuntos públicos.

Lo público en la democracia implica que la administración pública tenga controles ciudadanos para evitar que se convierta en un cuerpo extraño y ajeno a la sociedad. En cuanto categoría normativa, teórica, heurística y empírica, lo público es la pauta para diseñar un esquema de vigilancia y evaluación que garantice la interacción de los ciudadanos con la administración pública (Rabotnikof, 2000: 165).

La apertura de las instituciones es congruente con el poder democrático (Márquez, 1996: 5$54)^{25}$, porque la secrecía de los asuntos comunes corresponde más a los gobiernos autoritarios. Lo público frente a lo inaccesible, es un avance fundamental para que el gobierno de lo público sea la característica de las sociedades que han optado por la democratización del poder (Berrones, 2003), es decir, la democratización en las que se difunden e intensifican las prácticas democráticas en la toma de decisiones del gobierno y, por ende, de la administración pública.

En suma, las tres leyes objeto de análisis en este subapartado que fueron aprobados en el periodo 2000-2006, para los cambios democráticos institucionales en la administración pública; son claro ejemplo de cómo las instituciones pueden funcionar mejor cuando están sujetas a reglas que favorecen la certidumbre en democracia constitucional (Rawls, 1993) ${ }^{26}$, es decir, con el reconocimiento de los principios de justicia (derechos a las libertades e igualdades básicas), y "dejar abierta la puerta para que, mediante procedimientos bien descritos, los ciudadanos y sus representantes puedan emprender, y eventualmente culminar, actividades de cambio que mejoren el contenido y la estructura de los derechos, así como la del régimen constitucional en su conjunto" (Ugalde, 2010: 27).

La incorporación de los ciudadanos en los asuntos de gobierno revela la efectividad de los procesos democráticos, pues articula el ámbito de las libertades modernas con las atribuciones que los gobiernos tienen.

\subsubsection{Ley Federal de Responsabilidades Administrativas de los Servidores Públicos}

Al inicio del gobierno de Vicente Fox la demanda de que los servidores públicos se condujeran con responsabilidad abre el camino a una nueva ley que permitiera establecer en un solo ordenamiento jurídico la responsabilidad administrativa de los servidores públicos en aras de regular de manera integral las obligaciones que éstos tienen en el ejercicio de sus empleos, cargos o comisiones, así como las sanciones a las que podrán hacerse acreedores en caso de incurrir en un delito (González, 2012: 438).

\footnotetext{
${ }^{25}$ La democracia es una forma de gobierno compleja cuya comprensión se basa en el ejercicio del poder, el cual se refiere a cómo se gobierna ese poder, de qué manera se toman las decisiones, cómo se conocen sus actos, cuál es la estructura interna de ese poder, cuál es el espacio político del ciudadano.

${ }^{26}$ De acuerdo a John Rawls (1993), la democracia constitucional es aquella en que las leyes y estatutos deben ser consistentes con ciertos derechos y libertades fundamentales, por ejemplo, aquellos comprendidos por el primer principio de justicia -cada persona tiene el mismo derecho irrenunciable a un cuadro de igualdad de libertades básicas compatible con el mismo cuadro de libertades para los demás-. El segundo principio o principio de diferencia (leximin), dice que las desigualdades sociales y económicas deben satisfacer dos condiciones: primero estar vinculadas a los cargos y posiciones abiertas a cualquiera bajo condiciones de igualdad de oportunidad, y segundo, deben existir en beneficio de los miembros de la sociedad menos aventajados.
} 
Esta ley regula exclusivamente la materia de responsabilidad administrativa a diferencia de la anterior ley, que incluía también disposiciones sobre la responsabilidad política y penal ${ }^{27}$. Ello con el propósito de "[...] evitar confusiones sobre cuál era el ordenamiento supletorio que debía aplicarse cuando en la propia ley no hubiera una disposición específica para algún aspecto relativo al procedimiento de una responsabilidad administrativa" (SFP, 2005: 147).

De tal suerte, esta ley establece de manera expresa que en todas las relaciones relativas al procedimiento de responsabilidad administrativa y registro patrimonial de los servidores públicos, así como la apreciación de las pruebas, se observarán las disposiciones del Código Federal de Procedimientos Civiles, lo que le permite a las autoridades encargadas de aplicar la ley tener la certeza jurídica en el desarrollo del procedimiento administrativo de responsabilidades (González, 2012: 439).

El artículo $3^{\circ}$ define el espacio institucional para la aplicación de la ley que comprende los Tres Poderes de la Unión, y de modo específico se alude a: las Cámaras de Senadores y Diputados del Congreso de la Unión; La Suprema Corte de Justicia de la Nación; el Consejo de la Judicatura Federal; la Secretaría de la Función Pública; el Tribunal de Justicia Fiscal y Administrativa; los Tribunales de Trabajo y Agrarios; el Instituto Federal Electoral; La Auditoría Superior de la Federación; la Comisión Nacional de Derechos Humanos; el Banco de México y demás órganos jurisdiccionales.

El aprendizaje de la responsabilidad es cada vez más visible porque la democratización mexicana obliga a la apertura de las instituciones y a la evaluación que desde la sociedad civil y con diferentes medios -voto electoral, movilización ciudadana, opinión pública y comportamiento de los medios de comunicación- inciden de manera directa en el desempeño de los servidores públicos y en los directivos de primer nivel. Con la vigencia de la Ley Federal de Responsabilidades Administrativas de los Servidores Públicos se avanza en la configuración de un orden político y administrativo que sea más democrático (Berrones, 2003: 13).

Sin duda, la responsabilidad administrativa alude a la obligatoriedad que debe cumplirse para dar consistencia y eficacia a la función pública tomando en cuenta los principios de legalidad, honradez, lealtad, imparcialidad y eficiencia del servicio público.

\footnotetext{
${ }^{27}$ Responsabilidad penal. Conforme al Artículo 111 de la CPEUM y los Artículos 212 al 224 del Código Penal Federal, las sanciones penales se aplicarán de acuerdo con lo dispuesto en la legislación penal, específicamente en Título X. Delitos Cometidos por los Servidores Públicos, donde se tipifican algunos delitos comúnmente relacionados con actos corruptos, tales como ejercicio indebido de servicio público, abuso de autoridad, tráfico de influencias, cohecho, cohecho a servidores públicos extranjeros, peculado, enriquecimiento ilícito, entre otros delitos. La organización encargada de imponer sanciones por responsabilidad penal corresponde al Ministerio Público previas averiguaciones para proceder penalmente contra un servidor público; y a los jueces y tribunales determinar y aplicar las sanciones establecidas para cada delito. Tratándose de delitos por cuya comisión el servidor público obtenga un beneficio económico o cause daños o perjuicios patrimoniales, deberán graduarse de acuerdo con el lucro obtenido y con la necesidad de satisfacer los daños y perjuicios causados por su conducta ilícita, para los cual se impondrán multas económicas, destitución o inhabilitación para desempeñar cargos públicos, hasta prisión.

Responsabilidad política. Conforme al Artículo 110 de la CPEUM, en materia de responsabilidad política existe en México, el juicio político, un procedimiento que se activa para funcionarios de cierto nivel administrativo (como senadores, diputados, Jefe de Gobierno del D.F., Secretarios, Procurador, ministros de la Suprema Corte Justicia de la Nación, consejeros electorales, jueces y magistrados del Poder Judicial), cuando en el ejercicio de sus funciones incurran en actos u omisiones que redunden en prejuicio de los intereses públicos fundamentales o de su buen despacho. Para aplicación de las sanciones políticas, la Cámara de Diputados (previa declaración de mayoría absoluta) procederá a la acusación respectiva ante la Cámara de Senadores. Esta última se erigirá en Jurado de Sentencia y aplicará la sanción correspondiente (mediante la resolución de dos terceras partes de los miembros presentes en la sesión). Las sanciones consistirán en la destitución del servidor público y en su inhabilitación para desempeñar funciones, empleos, cargos o comisiones de cualquier naturaleza en el servicio público.

Responsabilidad resarcitoria. Conforme al Artículo 79 de la CPEUM y los Artículos 46 al 58 de la Ley de Fiscalización Superior de la Federación, señalan que a partir de la fiscalización superior a la Cuenta Pública Federal, la Auditoría Superior de la Federación puede imponer el procedimiento de Fincamiento de Responsabilidades Resarcitorias. La Auditoría Superior de la Federación puede imponer el financiamiento de responsabilidades resarcitorias aquellos servidores que causen daño a la Hacienda Pública Federal; y no rindan o dejen de rendir sus informes acerca de la solventación de los pliegos de observaciones realizadas por el órgano de fiscalización superior. Este tipo de responsabilidad implica resarcir al Estado y a los entes públicos, el monto de los daños y perjuicios estimables en dinero, ocasionados a la Hacienda Pública Federal y a su patrimonio, lo que se traduce en multas y sanciones pecuniarias.
} 


\subsubsection{La Ley de Transparencia y Acceso a la Información Pública Gubernamental}

La Ley de Transparencia y Acceso a la Información Pública Gubernamental garantiza el derecho de acceso a la información y protección de los datos personales, bajo tres principios:

1. La información de los poderes y organismos federales es pública, y debe ser accesibles para la sociedad, salvo que, en los términos de la propia ley, se demuestre en forma clara y debidamente sustentada que su divulgación puede poner en riesgo asuntos de interés general del país, como por ejemplo, la seguridad nacional, la seguridad pública, la defensa nacional, las relaciones internacionales, la estabilidad financiera, económica o monetaria, de acuerdo con el artículo 13.

2. El derecho de acceso a la información es universal, lo que significa que cualquier persona, sin distinción alguna, puede solicitarla sin necesidad de acreditar interés jurídico o exponer los motivos o fines de su solicitud.

3. Los datos de las personas que obran en las instituciones públicas son confidenciales y, por tanto, no deben divulgarse ni utilizarse para fines distintos para los que fueron recibidos o requeridos, de tal manera que se garantice el derecho a la intimidad y la vida privada, y al mismo tiempo sus titulares deben tener acceso a ellos cuando los soliciten (Gutiérrez, 2004: 82).

La LFTAIPG contempla en su artículo 33, la creación del Instituto Federal de Acceso a la Información (IFAI), el cual empieza a operar el 2 de julio de 2003. El IFAI está encargado de cumplir y hacer cumplir la LFTAIPG en el ámbito del Poder Ejecutivo Federal. Es la instancia encargada de promover y difundir el ejercicio del derecho de acceso a la información y de resolver la negativa de las autoridades a dar respuesta a las solicitudes de acceso a la información.

El IFAI es un órgano de la Administración Pública Federal que no está subordinado a ninguna secretaría de Estado. Tiene autonomía operativa, que le permite decidir sobre las reglas de organización y funcionamiento internas. Cuenta con autonomía presupuestaria que facilita definir sus necesidades financieras y le brinda la flexibilidad suficiente para la asignación interna y ejecución de los recursos bajo control normativo de la APF. Las funciones del IFAI se pueden clasificar en cuatro tipos (Gutiérrez, 2004: 84):

i. Las resolutivas y reguladoras son clave para garantizar el acceso a la información pública gubernamental y proteger los datos personales, por medio de la resolución de las negativas de acceso a la información, la interpretación de la ley y la expedición de los lineamientos.

ii. La función de vigilancia y de coordinación es esencial para impulsar avances en la transparencia del gobierno federal.

iii. La función de promoción es fundamental para fomentar y difundir los beneficios del derecho del acceso a la información e impulsar una cultura de transparencia y rendición de cuentas.

iv. Las funciones operativas y administrativas son necesarias para asegurar todo lo anterior.

En suma, el IFAI se erige en una institución que tiene las capacidades de vigilar, coordinar, fomentar, difundir, operar y administrar el derecho a la información de la sociedad impulsando una cultura de transparencia y rendición de cuentas de la gestión pública.

\subsubsection{Ley de Servicio Profesional de Carrera de la Administración Pública Federal}

La Ley del Servicio Civil de Carrera se puso en marcha el 2 de abril de 2004 con la expedición de su Reglamento. Tal como lo describe el artículo $2^{\circ}$ de la Ley: "el sistema del servicio profesional de carrera es un mecanismo para garantizar la igualdad de oportunidades en el acceso a la función pública para beneficio de la sociedad", mediante principios rectores como la legalidad, la eficiencia, la objetividad, la calidad, la imparcialidad, la equidad y la competencia por mérito.

Ésta es una ley dirigida a la Administración Pública Federal centralizada, es decir, sólo para dependencias y órganos desconcentrados. La rectoría, en la parte normativa recae en la Secretaría de la Función Pública, concretamente en la Unidad de Recursos Humanos y Profesionalización. 
No obstante esta rectoría, el esquema propuesto por la ley atiende a un sistema descentralizado, donde las dependencias y órganos desconcentrados son los que implementan el sistema de manera que en ellos se encuentran instituidos comités técnicos de Profesionalización y Selección que suman un total de 76. Como dato adicional, los puestos sujetos a la Ley del Servicio Profesional de Carrera van desde el nivel de director general, director general adjunto, director de área, subdirector, jefe de departamento y puestos de enlace para un número aproximado de 42944 servidores públicos de un total de 649 187, es decir menos del 10\% de servidores públicos de la Administración Pública Federal centralizada ( $6^{\text {to. }}$ Informe de Gobierno, 2006: 391), quedan fuera los puestos superiores y que corresponden a designación política (secretarios, subsecretarios y titulares de unidad), y los que por debajo, corresponden a puestos operativos o sindicalizados.

La Secretaría de la Función Pública conforme a la LOAPF que adiciona nuevas facultades al artículo 37 fracción VI bis, XVIII bis y XXVII; y modifica las fracciones XVIII y XXVI, tiene las siguientes funciones:

Tabla 3.4 Funciones de la Secretaría de la Función Pública

\begin{tabular}{|l|l|}
\hline Fracción & \multicolumn{1}{|c|}{ Función } \\
\hline VI bis & $\begin{array}{l}\text { Dirigir, organizar, y operar el Sistema de Servicio Profesional de Carrera en la Administración Pública } \\
\text { Federal en los términos de la ley de la materia, dictando las resoluciones conducentes en los casos de duda } \\
\text { sobre la interpretación y alcances de sus normas. }\end{array}$ \\
\hline XVIII & $\begin{array}{l}\text { Aprobar y registrar las estructuras orgánicas y ocupacionales de las dependencias y entidades de la } \\
\text { Administración Pública Federal y sus modificaciones, previo dictamen favorable de la Secretaría de } \\
\text { Hacienda y Crédito Público. }\end{array}$ \\
\hline XVIII bis & Establecer normas y lineamientos en materia de planeación y administración de personal. \\
\hline XXVI & Promover las estrategias necesarias para establecer políticas de gobierno electrónico. \\
\hline XXVII & Las demás que encomienden expresamente las leyes y reglamentos. \\
\hline
\end{tabular}

Fuente: González, J. J. S. (2004: 423)

La creación de la SFP representaría "una enorme aspiración de la administración pública, para darle la mayor prioridad a los asuntos de la función pública, su profesionalización, mejoramiento y modernización definitiva" (González, 2004: 422).

En síntesis, las tres acciones - nuevo marco legal de responsabilidades administrativas, transparencia y rendición de cuentas, servicio profesional de carrera y función pública- constituyeron un avance en el cambio institucional administrativo de nuestro país que sientan las bases para un estilo diferente de seleccionar, incluir, promover, capacitar y evaluar el desempeño de los servidores públicos.

\subsection{Agenda de Buen Gobierno}

En el marco del Plan Nacional de Desarrollo 2001-2006, el Modelo de Calidad Intragob ${ }^{28}$ contribuye a las estrategias de la Agenda Presidencial de Buen Gobierno: gobierno honesto y transparente; gobierno profesional; gobierno de calidad; gobierno digital; gobierno con mejora regulatoria y gobierno que cueste menos 29 .

\footnotetext{
${ }^{28}$ Son dos los componentes que constituyen el Modelo Intragob. El primero es el propio modelo que, bajo la inspiración de la serie ISO 9000 y de las experiencias internacionales, define ocho criterios que caracterizan un modelo de organización y gestión orientado a la calidad. El segundo componente es la premiación, que se divide en dos vertientes. La primera, dirigida a la calidad (basada en el modelo), y la segunda, orientada a premiar "prácticas innovadoras", es decir, no se premia en esta última a un modelo orientado a la calidad, sino a una práctica concreta, en esta modalidad también existe reconocimiento.

${ }^{29}$ En la lógica del enfoque empresarial-privado, un gobierno que cueste menos se refiere a un gobierno austero en el que se realice un ejercicio ordenado y sistemático de sus gastos de administración y de las funciones de apoyo con el fin de identificar las áreas de oportunidad en las que es posible reducir el gasto sin afectar el cumplimiento de sus programas sustantivos, mejorando con ello la eficiencia de las acciones gubernamentales. Entre los objetivos de un gobierno que cueste menos se encuentran: a) reducir el gasto burocrático que no agrega valor al ciudadano; b) aumentar el gasto de inversión en infraestructura y programas sociales de alto beneficio para la población; c) alcanzar los dos objetivos anteriores, en un marco de estabilidad macroeconómica y equilibrio financiero.
} 
Tabla 3.5 Estrategias de la Agenda de Buen Gobierno

\begin{tabular}{|l|l|}
\hline \multicolumn{1}{|c|}{ Objetivo } & \multicolumn{1}{c|}{ Descripción } \\
\hline $\begin{array}{l}\text { Gobierno honesto y } \\
\text { transparente }\end{array}$ & Para recuperar la confianza de la sociedad en su Gobierno \\
\hline Gobierno profesional & $\begin{array}{l}\text { Con las mejores mujeres y los mejores hombres en el servicio público, para garantizar que } \\
\text { la Administración Pública transite sexenalmente con el mínimo trastorno y la máxima } \\
\text { eficacia, asegurando que, siendo políticamente neutra, se convierta en un factor estratégico } \\
\text { de la competitividad del país. }\end{array}$ \\
\hline Gobierno de calidad & $\begin{array}{l}\text { Que satisfaga o incluso supere las expectativas de los ciudadanos en los servicios que se } \\
\text { les brindan. }\end{array}$ \\
\hline $\begin{array}{l}\text { Gobierno Digital } \\
\text { Gobierno con mejora }\end{array}$ & $\begin{array}{l}\text { Posibilitar que, desde la comodidad de su casa u oficina, los ciudadanos obtengan la } \\
\text { información de Gobierno y tengan acceso a los servicios que éste ofrece. } \\
\text { con facilidad, seguridad y a bajo costo. }\end{array}$ \\
\hline $\begin{array}{l}\text { Gobierno que cueste } \\
\text { menos }\end{array}$ & \begin{tabular}{l} 
Al reducir el gasto que no agrega valor para ofrecer mayores beneficios a la sociedad. \\
\hline
\end{tabular} \\
\hline
\end{tabular}

Fuente: Oficina de la Presidencia para la Innovación Gubernamental (2001: 1-48)

Como se observa, las estrategias de la Agenda Buen Gobierno se representaban en un esquema que se concebía como un estilo permanente de gobierno dentro de un mundo globalizado, no como un plan de un gobierno en particular, se pensaba como una reproducción tropical de los éxitos internacionales sin atender las singularidades del propio gobierno.

\subsubsection{Gobierno honesto y transparente}

Para recuperar la confianza de la sociedad en las acciones de gobierno, el $1^{\circ}$ de diciembre de 2000 , el presidente Vicente Fox, en un acto celebrado en el Auditorio Nacional, anunció el establecimiento de un Código de Ética para todos los funcionarios públicos que ese mismo día asumieron los miembros de los gabinetes legal y ampliado. Ello con el propósito de combatir la corrupción, la ineficacia y la falta de calidad de la gestión pública, como tema prioritario de la Agenda de Buen Gobierno. siguientes.

En este sentido, se estableció el Código de Ética que contempló los valores y compromisos

Tabla 3.6 Código de Ética para los Funcionarios Públicos

\begin{tabular}{|l|l|}
\hline \multicolumn{1}{|c|}{ Valor } & \multicolumn{1}{|c|}{ Compromiso } \\
\hline Procuración del bien común & $\begin{array}{l}\text { El servicio público es patrimonio de todos los mexicanos, y sólo se justifica y } \\
\text { legitima cuando se procura el bien común por encima de los intereses particulares. }\end{array}$ \\
\hline $\begin{array}{l}\text { Integridad de los funcionarios } \\
\text { públicos }\end{array}$ & $\begin{array}{l}\text { Las acciones y las palabras deben ser honestas y dignas de credibilidad, fomentando } \\
\text { siempre la cultura de confianza y verdad. }\end{array}$ \\
\hline Honradez & $\begin{array}{l}\text { El cargo público no es para obtener ganancias personales; no es ético aceptar } \\
\text { prebendas de personas u organizaciones que impliquen faltar a las responsabilidades } \\
\text { del bien común. }\end{array}$ \\
\hline Imparcialidad & El funcionario no debe privilegiar de manera indebida a personas u organizaciones. \\
\hline Justicia & Todo funcionario debe poner el ejemplo de apego y observancia de la ley. \\
\hline Transparencia & $\begin{array}{l}\text { La sociedad tiene derecho a conocer la información gubernamental sin más límite que } \\
\text { el interés público y los derechos de privacidad de particulares establecidos por la ley. }\end{array}$ \\
\hline Rendición de cuentas & $\begin{array}{l}\text { Participar en la mejora continua de la gestión gubernamental teniendo como } \\
\text { principios fundamentales la optimización de los recursos y la rendición de cuentas. }\end{array}$ \\
\hline Entorno cultural y ecológico & $\begin{array}{l}\text { Poner en práctica una clara voluntad de comprensión, respeto y defensa de entorno } \\
\text { cultural y ecológico del país. }\end{array}$ \\
\hline Generosidad & $\begin{array}{l}\text { Actuar siempre con una sensibilidad, compromiso y preocupación especiales por los } \\
\text { niños, las personas de la tercera edad, nuestras etnias y en general todas aquellas } \\
\text { personas que menos tienen }\end{array}$ \\
\hline Liderazgo & $\begin{array}{l}\text { Cada funcionario debe promover y apoyar estos compromisos con su ejemplo } \\
\text { personal }\end{array}$ \\
\hline
\end{tabular}

Fuente: Elaboración propia con base a Gutiérrez, R. M. (2004: 75-76). 
Tres días después de su toma de posesión, el 4 de diciembre de 2000, Fox Quezada emitió un acuerdo de creación de la Comisión Intersecretarial para la Transparencia y el Combate a la Corrupción $(\text { CITCC })^{30}$. Para febrero de 2001, la Secretaría Ejecutiva de la CITCC identificó 205 instituciones con áreas críticas ${ }^{31}$ de corrupción en la APF, con los siguientes resultados: 1914 unidades involucradas, 2 000 áreas críticas involucradas, 5328 probables conductas irregulares, 7118 medidas de mejoras propuestas, 206071 servidores en áreas críticas, 1253242 total de servidores públicos en estas instituciones y 16.4\% de total del personal se ubica en áreas críticas (SFP, 2006: 125).

Así, a través de los Programas Operativos para la Transparencia y Combate a la Corrupción (POTCC) se integraron y ejecutaron 7118 acciones de mejora relacionadas con las líneas estratégica de: desarrollo de recursos humanos y de la ética pública; mejora regulatoria; mecanismos de supervisión y control; participación ciudadana y rendición de cuentas e información pública $\left(2^{\circ}\right.$. Informe de Gobierno, 2002: 613).

En este sentido, el 22 de abril de 2002, se publicó en el Diario Oficial de la Federación el Programa Nacional de Combate a la Corrupción y Fomento a la Transparencia y el Desarrollo Administrativo (PNCTDA), cuyo propósito principal era sancionar las conductas ilícitas de los servidores públicos y, dar calidad y transparencia a la gestión pública. Así, para enero-junio de 2002 se amplió la cobertura de los POTCC mediante los cuales se detectaron 983 potenciales conductas irregulares, y se comprometieron 2771 acciones de mejora con las líneas de acción antes mencionadas (2॰. Informe de Gobierno, 2002: 613).

A partir de 2003, la evaluación de los programas operativos de transparencia y combate a la corrupción se realizaría por medio del Indicador de Seguimiento de Transparencia (IST) ${ }^{32}$. Sin embargo, este indicador recibía críticas por parte de los propios funcionarios que debían operar este programa, pues consideraban que se caía en la trampa debido a su diseño, de modificar varias décimas en seis años, lo cual minaba la atención de lo que las instituciones si podían hacer y que causaría su impacto, puesto que no se lograba una mejor calificación en el índice (Pardo, 2007: 902).

Para 2004, 161 instituciones del gobierno federal tenían programas de transparencia y combate a la corrupción, en ellas se realizaron más de cuatro mil acciones de mejora en 378 procesos y 655 áreas definidas como críticas, con impacto en más de 940 posibles conductas irregulares.

La CITCC continuó ampliando la cobertura de los Programas Operativos para la Transparencia y el Combate a la Corrupción (POTCC). Hasta julio de 2006 participaron 238 dependencias y entidades públicas, en las cuales se agrupó la mayor parte del presupuesto y personal del gobierno federal. En estos programas se identificaron 817 procesos críticos ${ }^{33}, 1095$ áreas críticas y 1839 posibles conductas irregulares. Con los programas generaron 3874 acciones de mejora orientadas a disminuir riesgos de opacidad y corrupción.

\footnotetext{
${ }^{30}$ Esta Comisión hizo públicos veinte acuerdos: 1. Implantación de un programa de reconocimiento de integridad a los servidores públicos. 2. Difusión de la información pública en Internet, en anticipación a la Ley de Transparencia y Acceso a la Información Pública Gubernamental. 3. Implantación de un programa de mejora regulatoria interna, 4. Implantación de la estrategia de Usuario Simulado. 5. Elaboración y difusión de un código de conducta. 6. Implantación de un programa de capacitación de valores. 7. Instrumentación de mecanismos rigurosos en la selección de personal. 8. Incorporación de batería de valores en el sistema de selección de personal. 9. Revisión de sueldos de áreas críticas. 10. Difusión de los Resultados del PNCTDA. 11. Difusión de las bases previas a la licitación. 12. Participación externa en la revisión de bases previas de licitación. 13. Realización de licitación vías electrónica. 14. Evaluación de usuarios de los procesos críticos. 15. Realización de compromisos para la Transparencia. 16. Mejoramiento de estándares de servicio y atención ciudadana. 17. Realización de trámites y servicios vía electrónica. 18. Creación de la Subcomisión de Acceso a la Información Pública Gubernamental. 19. Creación de la Subcomisión de Mejora de Índices de Percepción de Corrupción y Buen Gobierno. 20. Instrumentar medidas necesarias para solventar recomendaciones de la "Convención contra el cohecho de Servidores Públicos auspiciada por la OCDE. Las instituciones que integran de manera permanente la CITCC son las 18 secretarías de Estado, la Procuraduría General de la República, el Servicio de Administración Tributaria, Petróleos Mexicanos, Comisión Federal de Electricidad, Luz y Fuerza del Centro, Comisión Nacional del Agua, Instituto de Seguridad y Servicios Sociales de los Trabajadores del Estado, Instituto Mexicano del Seguro Social, Aeropuertos y Servicios Auxiliares, Caminos y Puentes Federales de Ingresos y Servicios Conexos, y la Lotería Nacional para la Asistencia Pública.

${ }^{31}$ Las áreas críticas son aquellas unidades operativas que participan en la ejecución de un proceso crítico.

${ }^{32}$ IST es una herramienta que mide el nivel de cumplimiento de las dependencias y entidades públicas en los POTCC y los Acuerdos de Transparencia. El IST utiliza una escala que va de 0 a 1000 puntos, en la cual los POTCC tienen una ponderación de 600 y los acuerdos de 400 .

${ }^{33}$ Un proceso crítico es un conjunto de procedimientos de gestión institucional en los que se presentan, presentaron, o pudieran presentar prácticas de opacidad o corrupción.
} 
El siguiente cuadro muestra el grado de avance de los POTCC, 2001-2005, cuyo indicador no refleja lo que las instituciones si podían hacer pues estaban más preocupados por lograr la meta y obtener una mejor calificación en el índice, sin considerar si la representación cuantitativa tenía su referente en la eficiencia y mejora de la gestión pública.

Tabla 3.7 Programas Operativos para la Transparencia y el Combate a la Corrupción 2001-2005

\begin{tabular}{|c|c|c|c|c|c|c|c|c|c|}
\hline Concepto & 2001 & 2002 & 2003 & 2004 & Meta & Observado & $\begin{array}{l}\mathbf{2 0 0 5} \\
\text { Variación } \\
\text { Avance \% } \\
\text { respecto a } \\
\text { la meta } \\
\text { anual }\end{array}$ & con re & ción a: \\
\hline $\begin{array}{l}\text { Instituciones } \\
\text { participantes }\end{array}$ & 117 & 149 & 155 & 161 & 214 & 236 & 110.3 & 101.7 & 46.6 \\
\hline Procesos críticos & 349 & 263 & 292 & 480 & n.a & 817 & n.a & 134.1 & 70.2 \\
\hline $\begin{array}{l}\text { Acciones } \\
\text { comprometidas }\end{array}$ & 3030 & 2650 & 3032 & 3715 & n.a & 3874 & n.a & 27.9 & 4.3 \\
\hline $\begin{array}{l}\text { Posibles conductas } \\
\text { irregulares }\end{array}$ & 1891 & 924 & 773 & 846 & n.a & 1839 & n.a & -2.7 & 117.4 \\
\hline $\begin{array}{l}\text { Áreas críticas } \\
\text { detectadas }\end{array}$ & 1339 & 427 & 550 & 708 & n.a & 1095 & n.a & -18.2 & 54.7 \\
\hline
\end{tabular}

Fuente: Secretaría de la Función Pública (2006: 136)

De enero a agosto de 2006 se aplicaron 3278 sanciones administrativas a 2455 servidores públicos, para suprimir y prevenir la comisión de irregularidades, así como restituir el orden y la disciplina en la función pública.

El total de sanciones impuestas fue de la siguiente manera: ocho apercibimientos, 1023 amonestaciones, 645 inhabilitaciones y 579 sanciones económicas por un monto de 586.5 millones de pesos, cifra inferior en 9.3 por ciento en términos reales para igual periodo de $2005\left(6^{\circ}\right.$ Informe de Gobierno, 2006: 383).

Gráfica 3.1 Sanciones Administrativas Impuestas y Servidores Púbicos Sancionados 2001-2006 ${ }^{1}$

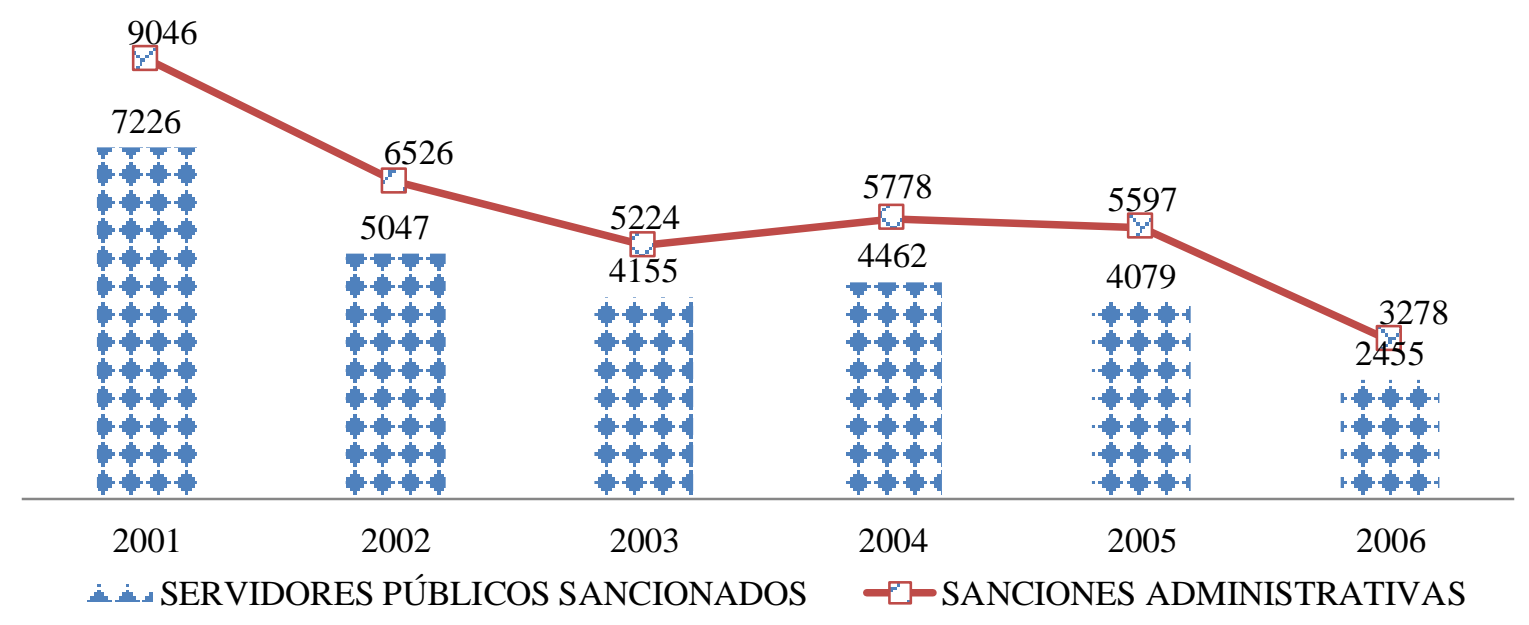

${ }^{1}$ Cifras correspondientes al periodo enero-agosto

Fuente: Sexto Informe de Gobierno (2006: 383)

Como se puede observar en la gráfica durante el periodo de análisis 2001-2006, las sanciones administrativas se redujeron en un $36 \%$ y los servidores públicos sancionados disminuyeron en un $33 \%$. 
Lo anterior se explica por la certidumbre que da la sujeción a las nuevas reglas por parte de las instituciones (LFRASP, LTAIPG, LSPCAPF), que introdujo el gobierno de Vicente Fox, a fin de ordenar jurídicamente la responsabilidad administrativa de los servidores públicos y, en consecuencia, disminuir la opacidad y corrupción de la APF. Sin embargo, los cambios institucionales no sólo se generan por la creación de nuevas leyes, son necesarias pero no suficientes, sino también se requiere de cambios internos en las rutinas de las organizaciones, en la concientización, capacitación y evaluación que incidan no sólo en las capacidades sino en los valores, en la ética profesional de los servidores públicos. Por ello, en contraste con los resultados positivos de la Secretaría de la Función Pública, otros estudios consideran que la corrupción en México sigue siendo su talón de Aquiles.

Según el Índice de Percepción de la Corrupción (IPC) ${ }^{34}$, de Transparencia Internacional que al igual que el Banco Mundial define la corrupción como el abuso de cargos públicos para beneficio de lo privado, poniendo en entredicho la disposición a respetar el orden legal vigente; México aparece como un país altamente corrupto por acercarse a " 0 ".

De acuerdo con el enfoque institucionalista, la corrupción tiene como relación causal en el diseño institucional lo siguiente: la corrupción tendrá lugar si las organizaciones públicas incentivan la deshonestidad; por ejemplo, por medio de trámites rigurosos y excesivos que invitan a los ciudadanos a corromper las autoridades; si la probabilidad de que el funcionario sea sancionado cuando se incurre en irregularidades es baja; y si los beneficios de desviarse de la función pública son mayores a la sanción. Desde la perspectiva institucionalista la corrupción no atiende a asuntos morales, sino a cálculos estratégicos (VII Congreso Internacional del CLAD, 2002) ${ }^{35}$.

Por ejemplo, las conductas de corrupción lesionaron a la administración de Vicente Fox: el financiamiento ilícito a su campaña presidencial por medio de los Amigos de Fox y el Pemexgate, en el caso de financiamiento al candidato del PRI, hasta acusaciones de malos manejos de los recursos públicos desde el principio hasta el final de su sexenio, tales como Toallagate y la Fundación Vamos México, las acusaciones de tráfico de influencia de los hijos de su esposa, Martha Sahagún. No hubo captura de "peces gordos", ni se revisó el ofensivo expediente del Fondo Bancario de Protección al Ahorro Bancario (FOBAPROA) que socializó las pérdidas por la crisis financiera durante el gobierno de Ernesto Zedillo.

Por otra parte, la transparencia y el acceso a la información son dos mecanismos de la rendición de cuentas (accountability), los cuales cobran presencia en la Ley Federal de Transparencia y Acceso a la Información Pública Gubernamental ${ }^{36}$. El 6 de diciembre de 1977, en el Diario Oficial de la Federación, se publicó el decreto que modificó 17 artículos constitucionales entre ellos el $6^{\circ}$ al que le fue adicionado una oración: "El derecho a la información será garantizado por el Estado". De esta forma nuestro país se incorporó a la comunidad internacional de garantizar el derecho a la información, que nació en 1948 con la Declaración de los Derechos del Hombre.

Sin embargo, tuvieron que pasar 25 años para que, en junio de 2002, se diera cuerpo legal al derecho a la información establecidos en los artículos $6^{\circ}$ y $7^{\circ}$ de la Constitución que reconocen, el derecho a la obtención de información gubernamental y el "derecho de petición" que facultad a cualquier ciudadano mexicano a realizar consultas relativas a las actividades gubernamentales (Gutiérrez, 2004: 81).

\footnotetext{
${ }^{34}$ El Índice de Percepción de la Corrupción es un índice compuesto que parte de múltiples encuestas de opinión a expertos y empresarios llevadas a cabo por determinadas instituciones independientes y acreditadas. Su cuantificación se realiza considerando una escala de 0 al 10, donde " 0 " es altamente corrupto hasta "10" que es altamente transparente.

${ }^{35}$ En términos de una ecuación, se podría expresar como $C=B+\operatorname{PrD}+\mathrm{S}$, donde $\mathrm{C}$ es frecuencia de actos de corrupción, $\mathrm{B}$ son los beneficios derivados de cometer actos de corrupción, $\mathrm{PrD}$ es la probabilidad de ser detectado en caso de incurrir en actos corruptos, y S es la magnitud de las sanciones. Si bien el enfoque institucionalista parece el más adecuado para el estudio de la corrupción, también enfrenta ciertos inconvenientes. Por ejemplo, los sociólogos resaltan que esta perspectiva sólo es útil cuando se aplica a sociedades con tendencias industriales; cuando se estudian sociedades tradicionales y patrimoniales, el enfoque pierde poder explicativo. De manera general, si se estudia una sociedad donde se sustituye el acatamiento de instituciones formales por convenciones informales, el institucionalismo ofrecerá un marco analítico limitado.

${ }^{36}$ La LFTAIPG garantiza el derecho de acceso a la información y la protección de los datos personales que obran en los Poderes Ejecutivo, Legislativo y Judicial, así como en los organismos constitucionales autónomos (IFE, CNDH, Banco de México)
} 
Ahora bien, existe una correspondencia entre el IFAI y el Gobierno Digital, la cual amplía las posibilidades de la solicitud de acceso a la información a través del Sistema de Solicitudes Información (SISI), que se puede ingresar por Internet en la dirección electrónica: http://www.informacionpublica. gob.mx.

En este contexto, en 2006, después de tres años de vigencia de la Ley de Transparencia y Acceso a la Información Pública Gubernamental, el IFAI a través del SISI había recibido en el primer semestre de ese año, 29741 solicitudes de información, un promedio mensual de aproximadamente cinco mil solicitudes (alrededor de 165 preguntas al día) y sólo 6.1 por ciento de ellas generaron cursos de revisión $\left(6^{\circ}\right.$ Informe de Gobierno, 2006: 386).

Gráfica 3.2 Número total de solicitudes recibidas, porcentaje de respuestas atendidas y de recursos de revisión presentados ante el IFAI, 2003-2006 ${ }^{1}$

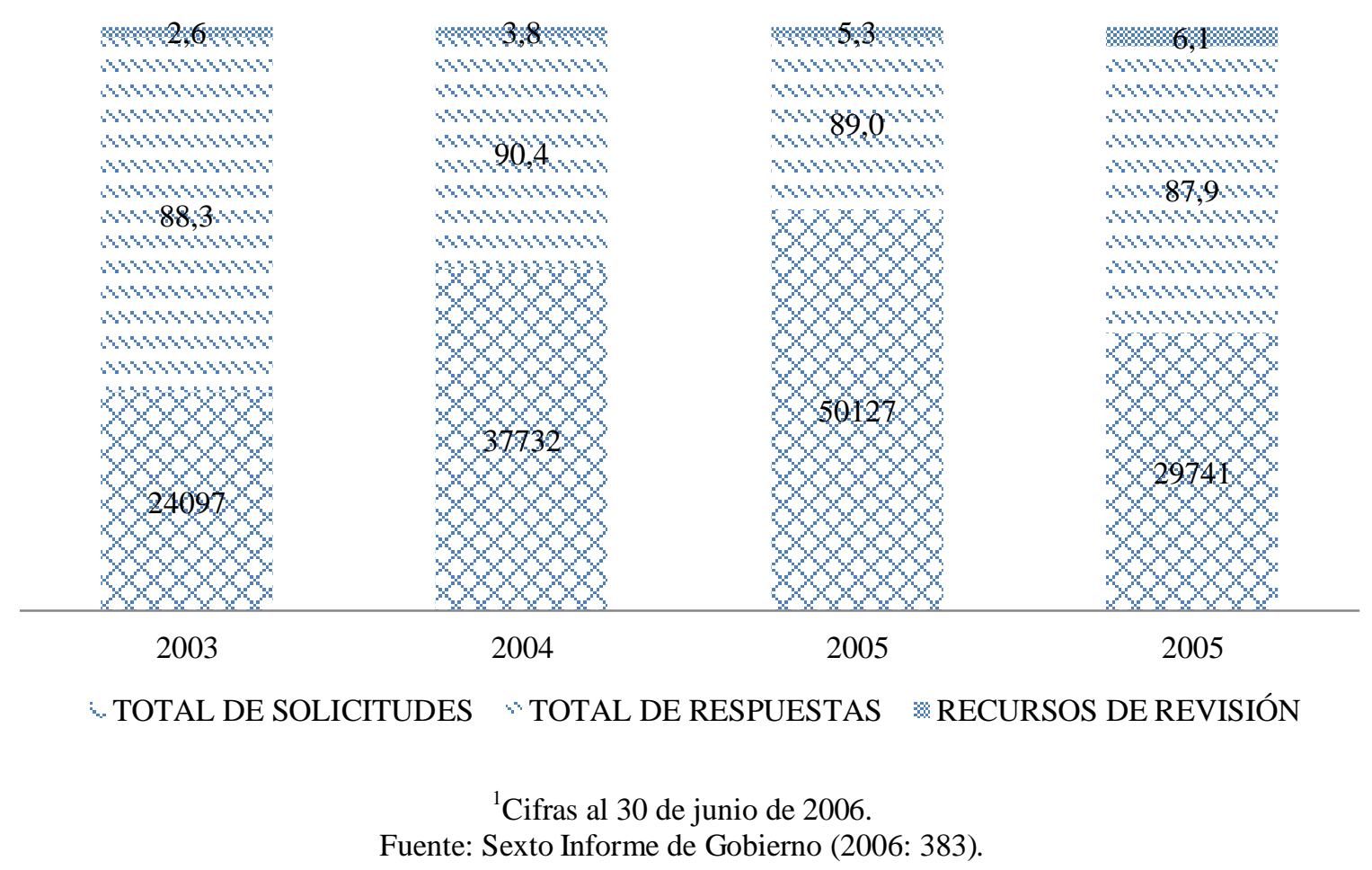

Las dependencias y entidades públicas con más solicitudes de información recibidas por el SISI en el periodo 2003-2006, fueron el Instituto Mexicano del Seguro Social, la Secretaría de Hacienda y Crédito Público, la Secretaría de Educación Pública y Secretaría del Medio Ambiente y Recursos Naturales (tabla 3.8). 
Tabla 3.8 Dependencias y entidades públicas con más solicitudes de información recibidas por el SISI, 2003-2006

\begin{tabular}{|c|c|c|c|c|c|c|c|}
\hline \multirow[b]{2}{*}{ Concepto } & \multicolumn{3}{|c|}{$\begin{array}{l}\text { Datos anuales } \\
\text { Observado }\end{array}$} & \multicolumn{4}{|c|}{ Enero-junio } \\
\hline & 2003 & 2004 & 2005 & Meta 2006 & 2005 & 2006 & $\begin{array}{l}\text { Variación } \\
\% \text { anual }\end{array}$ \\
\hline Total de solicitudes & 24097 & 37732 & 50127 & 57145 & 22640 & 29741 & 31.4 \\
\hline Instituto Mexicano del Seguro Social & 1114 & 2230 & 3825 & 4361 & 1641 & 2769 & 68.7 \\
\hline $\begin{array}{l}\text { Secretaría de Hacienda y Crédito } \\
\text { Público }\end{array}$ & 1570 & 2068 & 2247 & 2562 & 941 & 1116 & 18.6 \\
\hline Secretaría de Educación Pública & 1061 & 1413 & 2042 & 2328 & 874 & 1161 & 32.8 \\
\hline $\begin{array}{l}\text { Secretaría del Medio Ambiente y } \\
\text { Recursos Naturales }\end{array}$ & 779 & 1294 & 1823 & 2078 & 820 & 1131 & 37.9 \\
\hline Secretaría de la Función Pública & 696 & 1065 & 1659 & 1891 & 667 & 969 & 45.3 \\
\hline Procuraduría General de la República & 528 & 1138 & 1524 & 1737 & 568 & 790 & 39.1 \\
\hline Secretaría de Gobernación & 694 & 1011 & 1406 & 1603 & 621 & 739 & 19.0 \\
\hline $\begin{array}{l}\text { Secretaría de Comunicaciones y } \\
\text { Transportes }\end{array}$ & 636 & 964 & 1297 & 1479 & 539 & 735 & 36.4 \\
\hline Secretaría de Salud & 474 & 858 & 1312 & 1496 & 585 & 810 & 38.5 \\
\hline $\begin{array}{lll}\text { Servicio } & \text { de } & \text { Administración } \\
\text { Tributaria } & & \\
\end{array}$ & 354 & 751 & 1291 & 1472 & 489 & 846 & 73.0 \\
\hline Otras dependencias y entidades & 16191 & 24940 & 31701 & 36139 & 14895 & 18675 & 25.4 \\
\hline
\end{tabular}

${ }^{1}$ Cifras del 12 de junio al 31 de diciembre

Fuente. Sexto Informe de Gobierno (2006: 387)

Sin embargo, el avance no correspondió a las expectativas de la ciudadanía en la medida que en la agenda de gobierno honesto y transparente se hablaba mucho en el combate a la corrupción y, cuando había casos de corrupción notables se hacía poco. Por su parte, la rendición de cuentas como desempeño, llamada control de resultados, enfrentó dos problemas centrales. Primero, la dificultad para definir y medir los resultados en muchos ámbitos de la actividad gubernamental. Segundo, la resistencia en contra de medidas que limiten la discrecionalidad de los políticos clientelares en las decisiones relativas al personal (Somuano, 2009: 74-75). La Ley de Transparencia y Acceso a la Información, hasta cierto punto ha sido la estrategia más exitosa en materia administrativa del gobierno de Fox y sus efectos debieran tener importantes repercusiones en la ciudadanía, sin embargo, para que las ideas de la rendición de cuentas y transparencia gubernamental sean efectivas, se requiere una ciudadanía participativa.

\subsubsection{Un gobierno profesional}

La segunda línea de acción de la $\mathrm{ABG}$ se refiere a la profesionalización del sector público. Esta línea de acción se enfocó en la implementación del servicio profesional de carrera; la creación del @ Campus México para la capacitación de los servidores públicos a través de educación por medios electrónicos para el desempeño de sus funciones; la instalación de Comités Técnicos de Profesionalización y Selección en las Dependencias, y se desarrolló el Registro Único de Servidores Públicos (RUSP) ((6 ${ }^{\circ}$ informe de Gobierno, 2006: 89). Para la implementación del Servicio Profesional de Carrera, se aprobó y entró en vigor en 2002, la Ley respectiva (LSPC). Acerca de los Comités Técnicos de Profesionalización y Selección en las dependencias, en una primera etapa se constituyeron los Comités en las 15 dependencias sujetas a la LSPC, en su carácter de dependencias y coordinadora sectorial. Los resultados obtenidos por gobierno profesional antes de terminar el sexenio indicaban que las plazas que conforman la Administración Pública Federal centralizada ascendieron a $649187^{37}$, de las cuales 42 $944^{38}$ están sujetas al Servicio Profesional de Carrera en $75^{39}$ dependencias y órganos desconcentrados (6º Informe de Gobierno, 2006: 391) (gráfica 3.3 y gráfica 3.4).

\footnotetext{
${ }^{37}$ Incluye plazas del personal operativo y de mando superior, así como personal de las instituciones del sector central estén o no sujetas a la LSPCAPF.

${ }^{38}$ Considera a los servidores públicos de los niveles de director general, director general adjunto, director de área, subdirector de área, jefe de departamento y enlace de las dependencias en la APF y sus órganos desconcentrados. Es importante destacar que el número de puestos sujetos al SPC no es fijo, varía constantemente en el tiempo como resultado de tres factores principales: el número de instituciones sujetas a la Ley del SPC; los movimientos organizacionales que se realizan al interior de cada institución (renivelación y conversión); y aplicación de programas de separación individual (Retiro Voluntario). En este reporte se consideró el total de plazas del INEGI (existió un convenio para que se separara del SPC en octubre de 2006), así como a la Comisión Nacional de Fomento a la Vivienda que a partir del 28 de junio de 2006 se convirtió en Comisión Nacional de Vivienda y pasó a ser un organismo descentralizado.
} 
Gráfica 3.3 Registro de estructuras sujetas al Servicio Profesional de Carrera, 2004-2006¹

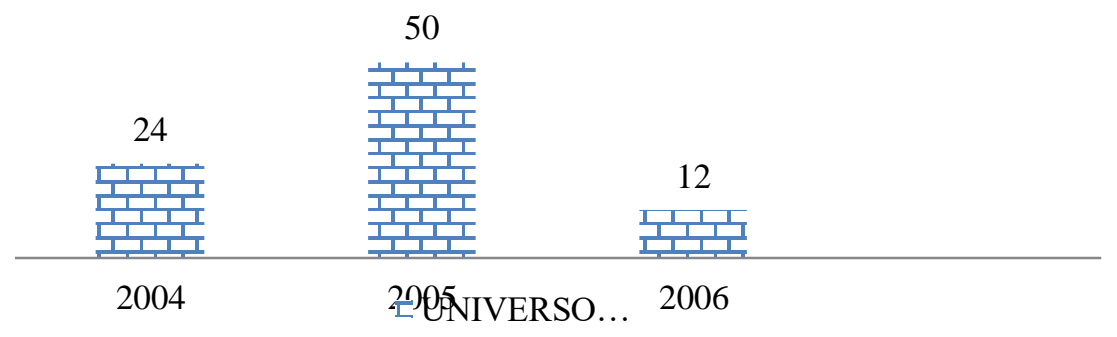

1/ Las cifras corresponden al periodo enero-junio

Fuente: Sexto Informe de Gobierno (2006: 392)

Gráfica 3.4 Registro de estructuras no sujetas al Servicio Profesional de Carrera, 2004-2006 ${ }^{1}$

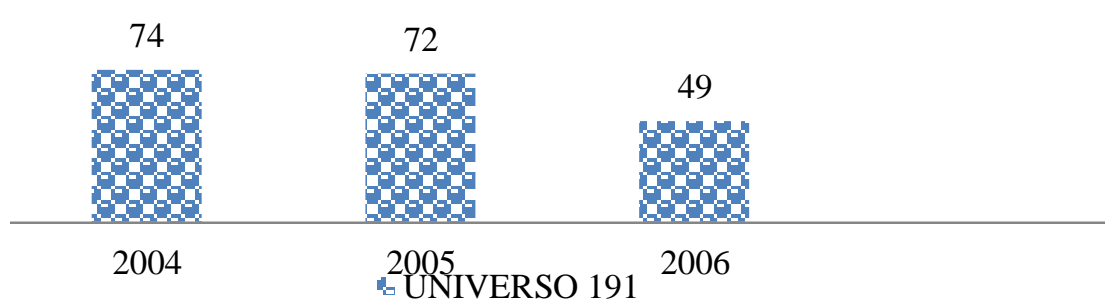

1/ Las cifras corresponden al periodo enero-junio

Fuente: Presidencia de la República (2006: 392)

Respecto a las convocatorias difundidas en el portal www.trabajaen.gob.mx, a mayo de 2006, se captó un total de 1334960 solicitudes y se registró a 188449 aspirantes. Se llevaron 4849 concursos, a través de los cuales el gobierno federal incorporó a 2496 servidores públicos de carrera. A pesar de ello, el portal www.trabajaen.gob.mx ha generado múltiples inconformidades pues "no se está evaluando como la ley establece, la posesión o no de las competencias laborales por medio de la medición de comportamientos, y por tanto, en muchos casos no están seleccionando a los candidatos idóneos para el puesto" (Méndez, 2009: 205). De ahí, el alto número de concursos que han sido declarados desiertos (1490) y 1319 no habían terminado su proceso.

Estos concursos declarados desiertos representaron el 30 por ciento, es decir, uno de cada tres concursos se declara desierto, con todo lo que ello implica en términos de efectos sobre la provisión continua y adecuada de servicios y el desperdicio de recursos públicos.

Para 2011, había 27364 servidores públicos de carrera, de los cuales 12017 fueron designados por concurso abierto y 15347 por certificación de competencias. El universo del servicio profesional de carrera si se considera que en ese año existía un total de 330632 empleados en la APF. Sin embargo, los puestos que abarca constituyen la esencia de la administración, pues son quienes establecen y operan la mayoría de las políticas públicas en nuestro país y reciben los salarios competitivos. Los demás puestos dentro la APF incluyen al personal administrativo y de prestación de servicios, y las designaciones políticas (OCDE, 2011: 165).

\footnotetext{
${ }^{39}$ El 1 de septiembre de 2005 se publicó en el DOF el decreto por el que se reformó el artículo $8^{\circ}$ de la Ley del Servicio Profesional de Carrera en la Administración Pública Federal, por lo que al 2 de septiembre de 2005, el número de instituciones en que aplicó dicha Ley eran 75, comprendidas 14 Secretarías de Estado, la Consejería Jurídica del Ejecutivo Federal y 60 órganos desconcentrados. El 7 de septiembre de 2005 se publicó en el DOF el decreto por el que se crea el órgano desconcentrado denominado Comisión Nacional de Bioética, aumentando a 76 el número de dichas instituciones. El 27 de junio de 2006 se publicó en el DOF el decreto por el que se expide la Ley de Vivienda, lo que implicó que la Comisión Nacional de Fomento a la Vivienda (CONAFOVI) modificara su naturaleza jurídica a organismo descentralizado, por lo que el número de órganos desconcentrados nuevamente quedó en 60, y el total y el número de instituciones en 75.
} 
El servicio profesional de carrera ha utilizado los concursos abiertos para establecer la transparencia y garantizar el nombramiento de la persona más competente para un empleo dado. Ello demuestra el compromiso del gobierno con la creación de una meritocracia. Sin embargo, existen dos grandes desventajas: $i$ ) este procedimiento no permite gestionar la planeación de la sucesión ni el desarrollo profesional; ii) es lento y costoso, lo que suma incentivos para que los ejecutivos realicen designaciones al amparo del artículo 34. El proceso está sujeto a la subjetividad y no hay salvaguardas para evitarlo. El hecho de que el superior jerárquico con poder de veto sea parte del comité de selección y responsable de diseñar los exámenes ha generado desconfianza en el proceso. En gran medida, permite reclutar tal como se hacía antes de adoptar el servicio profesional de carrera (OCDE, 2011: 182).

Los abusos cometidos en el uso del artículo 34 han llevado al público y a la comunidad académica a considerar que persiste la cultura del paternalismo y el clientelismo en la APF. Sin embargo, para Laguna, es difícil confirmar que todos los nombramientos hechos con el artículo 34 se hayan decidido por razones puramente políticas; empero, "[...] la discrecionalidad, las lealtades personales e incluso la afiliación partidista siguen influyendo mucho en las decisiones de contratación y ascenso" (Laguna, 2011: 51-73). La ley no deja clara las circunstancias imprevistas, lo que ha dado lugar a abusos. El informe de 2006 de la Auditoría Superior de la Federación concluyó que los lineamientos de la libre designación resultaban no sólo permisivos, sino vagos. Debido a los términos amplios en que se redactaron el artículo 34 y las reglas correspondientes, casi cualquier situación puede considerarse excepcional.

Por otra parte, el portal @ Campus a junio de 2006 brindó capacitación por medio de diversas instituciones educativas públicas y privadas ${ }^{40}$ que ofrecieron cursos y técnicas de aprendizaje, orientados a promover la posesión de capacidades. Empero, "la falta de equilibrio entre capacitación presencial y a distancia, así como la falta de técnicas de enseñanza-aprendizaje para promover las capacidades gerenciales generales" (Méndez, 2009: 207) generó importantes críticas al subsistema. Las fallas de diseño, las deficientes estrategias de implementación y las lagunas normativas han impedido el desarrollo de un sistema funcional de méritos, cuya cultura política residual aún se resiste a cambiar e intenta mantener el reparto de cargos entre partidarios políticos, el cual no respeta ni reconoce los beneficios de un sistema de meritocracia, sino que privilegia las lealtades personales.

\subsubsection{Un gobierno de calidad}

El gobierno de calidad ${ }^{41}$ se fundamentó en los conceptos y prácticas de calidad total, ello significaría un gobierno más eficiente y efectivo, enfocado en desarrollar programas que permitieran satisfacer las necesidades y expectativas de la ciudadanía; que hicieran transparente e incrementaran la calidad en los trámites y servicios de alto impacto ciudadano.

De tal suerte, que para lograr un gobierno de calidad se estableció el Modelo Intragob, que fue un sistema de gestión dirigido hacia la atención de tres aspectos prioritarios: la calidad de los servicios, la integridad de los servidores públicos y la percepción de la sociedad respecto a la confiabilidad y eficacia de la APF. En los tres primeros años del gobierno de Vicente Fox, se conformó para la operación del modelo (Méndez, 2009: 93):

- $\quad$ Una red en la que participaban 19 dependencias y 30 entidades de la APF.

\footnotetext{
${ }^{40}$ Universidad Nacional Autónoma de México, Instituto Politécnico Nacional, Universidad Iberoamericana, Santillana Formación, Enseñanza Programada e Ingeniería en Sistemas Educativos, Universidad Virtual Anáhuac, Creatividad en Capacitación, Instituto Tecnológico de Estudios Superiores Monterrey, Universidad La Salle, Consist-Harvard, Ingenia, Centro de Investigación en Educación Virtual, $B \& B$ Assessment, Jones University, Centro Ericksoniano de México, Edvantage y Escuela Net. Cabe señalar, que una institución se dio de baja en el primer semestre de 2006.

${ }^{41}$ Desde el inicio de su mandato, Vicente Fox se comprometió a incorporar a las tareas de gobierno los conceptos y prácticas de la cultura de la Calidad Total, dirigida a satisfacer las necesidades del cliente (ciudadanos, proveedores, comunidades y gobierno), y asegurar el desempeño interno (administrar, por medio de procesos, el desempeño del sistema de calidad de una organización). Ello significaría, en primer lugar, un gobierno eficiente y efectivo que contara con un modelo de dirección de calidad confiable y, en segundo lugar, con políticas, procesos y servicios, avalados por la certificación de sus sistemas de gestión de calidad en todas sus unidades administrativas con capacidad de autogestión y, en tercer lugar, que fuera un gobierno con resultados tangibles y mejorados, que evaluará permanente la gestión de sus recursos y el impacto de sus acciones y proyectos.
} 
El establecimiento de un Comité Directivo de Calidad en el 92 por ciento de las dependencias y el 65 por ciento de las entidades de la APF.

Para estimular los procesos de mejora dentro de la administración pública, se instituyeron los premios: a) el Premio a la Calidad Intragob, como reconocimiento a mejores prácticas en calidad total, y b) el Premio INNOVA y el reconocimiento a las mejores prácticas en innovación.

El Modelo Intragob lo constituyeron ocho criterios para establecer, desarrollar y mejorar programas de trabajo permanentes, que sustentaran la implantación de los sistemas definidos: 1) Satisfacción del cliente y del ciudadano; 2) Liderazgo; 3) Desarrollo del personal y del capital intelectual; 4) Administración de la información y de la tecnología; 5) Planeación; 6) Gestión y mejora de procesos; 7) Impacto en la sociedad y 8) Resultados, como se muestra en la siguiente figura.

Figura 3.3 Modelo de Calidad Intragob

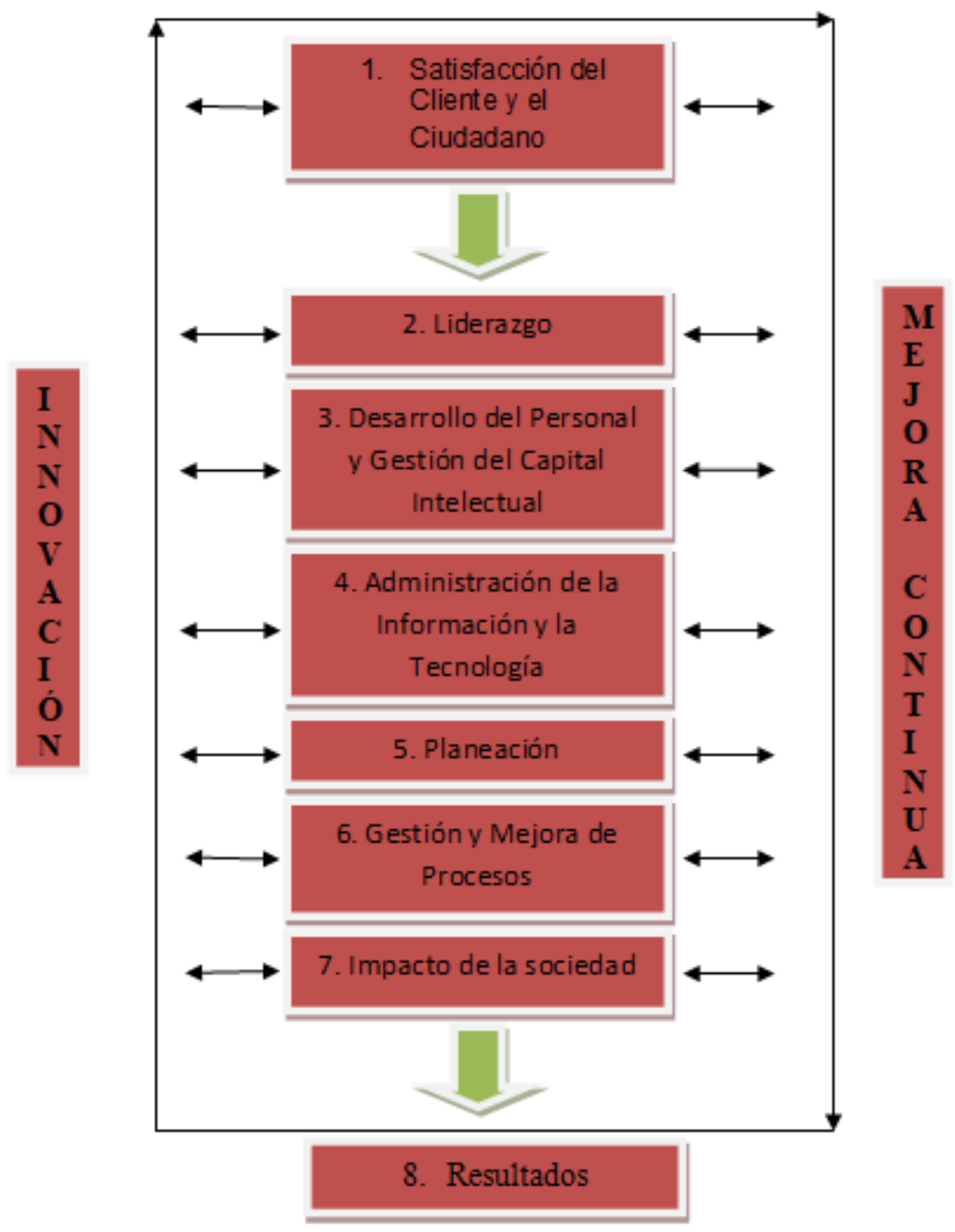

Fuente: Gutiérrez, R. M. (2004: 177)

De acuerdo con el ciclo de diseño e implantación de sistemas para la innovación y mejora continua de los criterios que integraban el Modelo de Calidad Intragob, se realizaba conforme a las etapas que se muestran en la figura 3.4. 
Figura 3.4 Ciclo de diseño, innovación y mejora de los sistemas aplicados al Modelo de Calidad Intragob

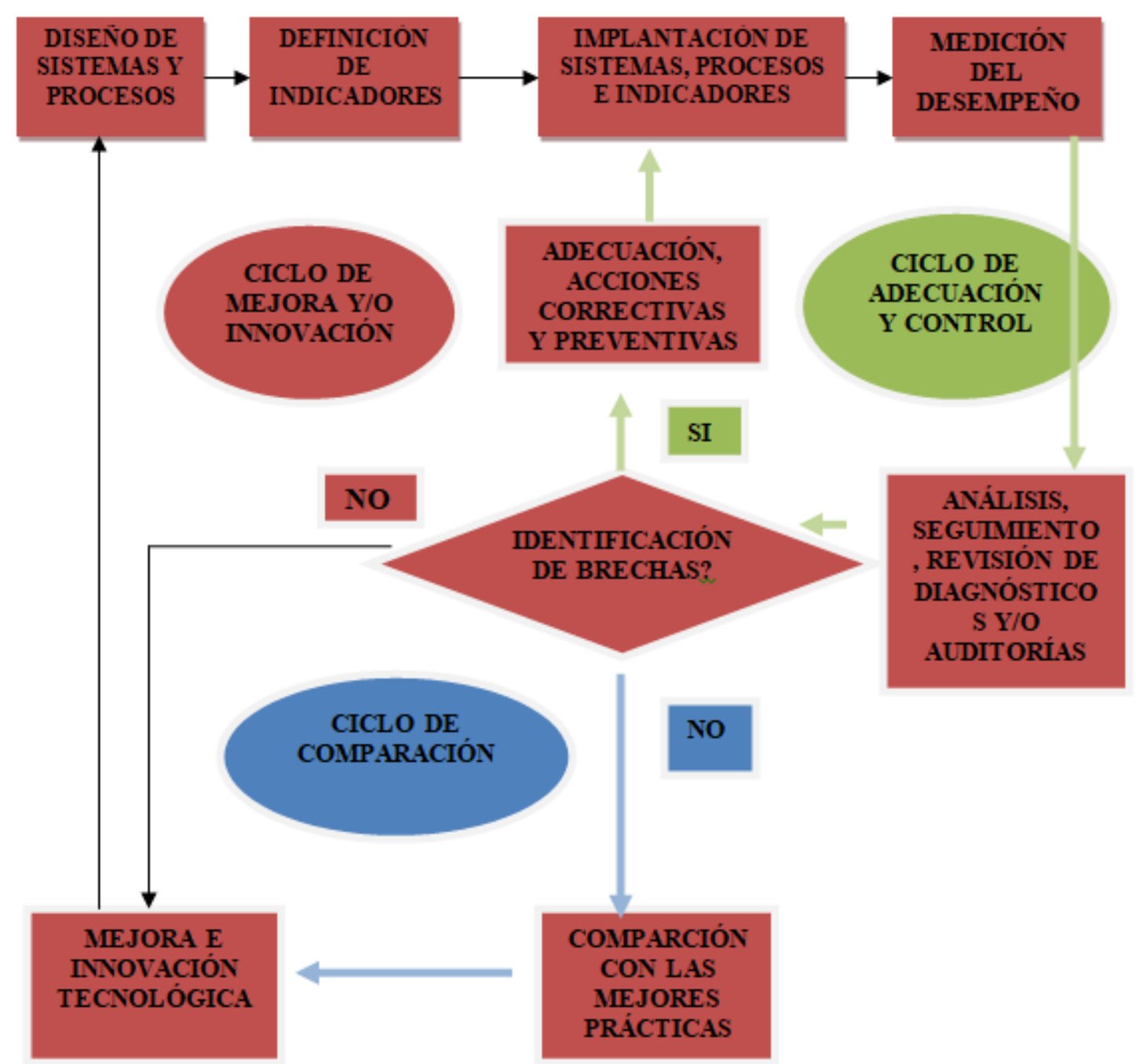

Fuente: Gutiérrez, R. M. (2004: 188)

Dos componentes constituyeron el modelo Intragob. El primero es el propio modelo que, bajo la inspiración de la serie ISO 9000 y de las experiencias internacionales definió ocho criterios que caracterizaban un modelo de organización de gestión orientado a la calidad. El segundo componente es la premiación, que se divide en dos vertientes: la primera, dirigida a la calidad (basada en el modelo), la segunda, la innovación (aplicación de ideas creativas) (Gutiérrez, 2004: 194-258) ${ }^{42}$.

\footnotetext{
${ }^{42}$ El reconocimiento Innova se entregaba a las entidades y dependencias de la Administración Pública Federal que se distinguieron por el desarrollo de servicios innovadores con un alto valor agregado para la ciudadanía. El reconocimiento a la innovación introdujo, a partir de 2004, la modalidad a través de la cual los ganadores del premio pasaban a una instancia especial en la que consideraban criterios adicionales de impacto al ciudadano, alcance regional y grado de innovación. Las prácticas de mayor puntaje recibían el Premio Nacional a la Innovación en la Administración Pública (Premio Innova). El premio consistía en el reconocimiento y orgullo de obtenerlo, al igual que en sus orígenes hacían los organizadores del Premio Deming a la calidad en Japón a través del izado de una bandera en la organización ganadora. Las dependencias e instituciones ganadoras del premio Innova durante el año 2000-2005 fueron la Secretaría de Relaciones Exteriores, por el ágil y confiable proceso de expedición de pasaportes; la Secretaría de Agricultura, Ganadería, Desarrollo Rural, Pesca y Alimentación, por la iniciativa de transparencia en el pago de apoyos para el campo a través de la tecnología de información; la Secretaría del Trabajo y Previsión Social, por los nuevos esquemas de información y vinculación laboral (Chambatel, Chambanet y Michamba); el Servicio de Administración Tributaria, por el nuevo esquema de pagos electrónicos; la Secretaría de la Defensa Nacional, por la implantación del sistema integral de administración; el Instituto del Fondo Nacional de la Vivienda para los Trabajadores, por las nuevas alternativas digitales de servicio Infonavit; la Procuraduría General de la República, por la creación de la Agencia Federal de Investigación; el Instituto Mexicano del Seguro Social, por la implementación del e-Gobierno y desarrollo tecnológico en el IMSS y la Secretaría de Comunicaciones y Transportes, por la primera red de conectividad digital satelital e-México. Para un mayor conocimiento de las dependencias e instituciones premiadas.
} 
Tabla 3.9 Criterios del Modelo de Calidad Intragob

\begin{tabular}{|ll|l|}
\hline 1. & Satisfacción del cliente y el ciudadano & \multicolumn{1}{c|}{$\begin{array}{c}\text { Descripción } \\
\text { Implica conocimiento de necesidades y expectativas del } \\
\text { cliente y ciudadano, comunicación y capacidad de respuesta } \\
\text { oportuna a sus quejas y reclamaciones. }\end{array}$} \\
\hline 2. $\quad$ Liderazgo & $\begin{array}{l}\text { Implementación de métodos y prácticas para impulsar el } \\
\text { liderazgo. }\end{array}$ \\
\hline 3. Desarrollo del personal y del capital intelectual & $\begin{array}{l}\text { Trabajo en equipo, profesionalización y desarrollo del } \\
\text { personal, capital intelectual, reconocimiento, mejoramiento } \\
\text { de la calidad de vida en el trabajo y ambientación } \\
\text { permanente para la calidad. }\end{array}$ \\
\hline 4. $\quad$ Administración de la información y la tecnología & $\begin{array}{l}\text { Administración de la información y de la tecnología para } \\
\text { impulsar la generación de conocimiento. }\end{array}$ \\
\hline $5 . \quad$ Planeación & \begin{tabular}{l} 
Planeación estratégica y planeación operativa \\
\hline $6 . \quad$ Gestión y mejora de procesos
\end{tabular} & $\begin{array}{l}\text { Desarrollo de servicios y procesos, implantación de sistema } \\
\text { de gestión y proveedores. }\end{array}$ \\
\hline 7. $\quad$ Impacto a la sociedad & $\begin{array}{l}\text { Mejoramiento del entorno promoviendo la cultura de calidad } \\
\text { yminimizando los impactos ambientales. }\end{array}$ \\
\hline $8 . \quad$ Resultados & $\begin{array}{l}\text { Valor creado para el personal y la dependencia o entidad, } \\
\text { clientes, ciudadanos y la sociedad, para una cultura de } \\
\text { calidad. }\end{array}$ \\
\hline
\end{tabular}

Fuente: Gutiérrez, R. M. (2004: 178-185)

Los resultados del gobierno de calidad si bien registran casos de éxito y, el otorgamiento de premios se puede convertir en un incentivo para mejorar la gestión pública, es difícil concluir que de ahí pueda derivarse necesariamente un desempeño cualitativamente mejor de la administración pública. Se requiere más que reconocimientos y premios, como concientización, capacitación y evaluación que incidan no sólo en las capacidades sino en los valores; ello exige cambios en la cultura política, escenario en el que, sin duda, no se trabajó con seriedad (Pardo \& Sánchez, 2009: 913).

\subsubsection{Un gobierno digital}

El presidente Vicente Fox, en su mensaje de posesión, dio instrucciones al Secretario de Comunicaciones y Transportes para iniciar el Sistema Nacional e-México, una de las primeras acciones del Sistema fue la organización de un Foro de Consulta Ciudadana que involucró a diversas entidades públicas y privadas para recopilar experiencias nacionales e internacionales sobre el uso de Tecnologías de Información y Comunicación en el sector público con el fin de integrarlas el PND 2001 $-2006^{43}$.

En 2002 se presentó la ABG en la que el desarrollo del gobierno digital o gobierno electrónico (e-government) era una prioridad y se señalaba que se debían "aprovechar al máximo las tecnologías de información y las telecomunicaciones, no sólo para reducir la corrupción y transparentar la función pública, sino también para hacerla más eficiente y proporcionar servicios de mayor calidad" (Gutiérrez, 2004: 94-95).

\footnotetext{
${ }^{43}$ El gobierno digital conocido como e-Gobierno, promovió el uso intensivo de sistemas digitales, en especial de Internet, como herramienta principal de trabajo de las unidades que conforman la APF, a través de siete líneas de acción: a) instalación y aprovechamiento de infraestructura tecnológica gubernamental, uso intensivo de redes de intranet gubernamental e Internet, para mantener integrada la actividad del sector público en todas las dependencias y entidades de la APF, e imprimir mayor precisión y oportunidad a la gestión de los servidores públicos; b) Promoción y aplicación de la administración del conocimiento y la colaboración digital, mediante sistemas y esquemas tecnológicos para adquirir, organizar y comunicar el conocimiento en la APF en sus distintas etapas, tales como aprendizaje, colaboración, evaluación y toma de decisiones; c) Mejora y rediseño de procesos con tecnologías de información para desarrollar, actualizar y consolidar los sistemas informáticos en las distintas áreas de la APF, así como facilitar la actualización informática de los procesos que operan las tareas adjetivas y sustantivas de las instituciones públicas; d) Mayor cobertura de los servicios y trámites electrónicos (e-Servicios) del gobierno federal que ofrece a la ciudadanía; e) Consolidación del Portal Ciudadano del Gobierno Federal para la creación de cadenas valor y un medio eficiente para la participación ciudadana, la transparencia y la rendición de cuentas; f) Ampliación de mecanismos como e-Democracia y participación ciudadana; g) Promoción de políticas de información, comunicación para el Gobierno Digital, dirigidas a conformar una red organizacional para la definición de planes rectores y políticas internas en materia de tecnologías de información, que sean congruentes con las metas de innovación gubernamental.
} 
Sin embargo, antes del lanzamiento de la ABG ya se habían emprendido acciones como la iniciativa de la Oficina de la Presidencia para la Innovación para modernizar y digitalizar el gobierno, la conformación del Consejo de e-México y la posterior puesta en funcionamiento del Programa Nacional e-México con la colaboración de la Secretaría de Educación Pública (SEP), la Secretaría de Desarrollo Social (SEDESOL), la Secretaría de Gobernación (SEGOB), la Secretaría de Salud y Asistencia (SSA) y la Secretaría de Economía (SE), así mismo se creó el Consejo Técnico del Fideicomiso e-México 2058 que fue el mecanismo mediante el cual varios proyectos de e-gobierno fueron financiados. En 2003 se creó la Unidad de Gobierno Electrónico y Política de Tecnologías de Información (UGEPTI) como parte de la SFP para darle a ésta responsabilidades en materia de desarrollo de las TIC en toda la $\mathrm{APF}^{44}$. En 2005, se emitió el Acuerdo para la creación de la Comisión Intersecretarial de Gobierno Electrónico que tenía como principal objetivo aprovechar estratégicamente las TIC para el buen gobierno. Además del marco legal directamente relacionado con el gobierno electrónico también se promulgaron la Ley Federal de Transparencia y Acceso a la Información Pública y la Ley del Servicio Civil de Carrera que afectaron indirecta, pero claramente el desarrollo del e-gobierno en México. En 2008, se estableció el Plan Estratégico de Tecnologías de la Información y Comunicación, y para enero de 2009, se creó la Agenda de Gobierno Digital (ver figura 3.5).

Figura 3.5 Mapa de ruta del e-Gobierno en México

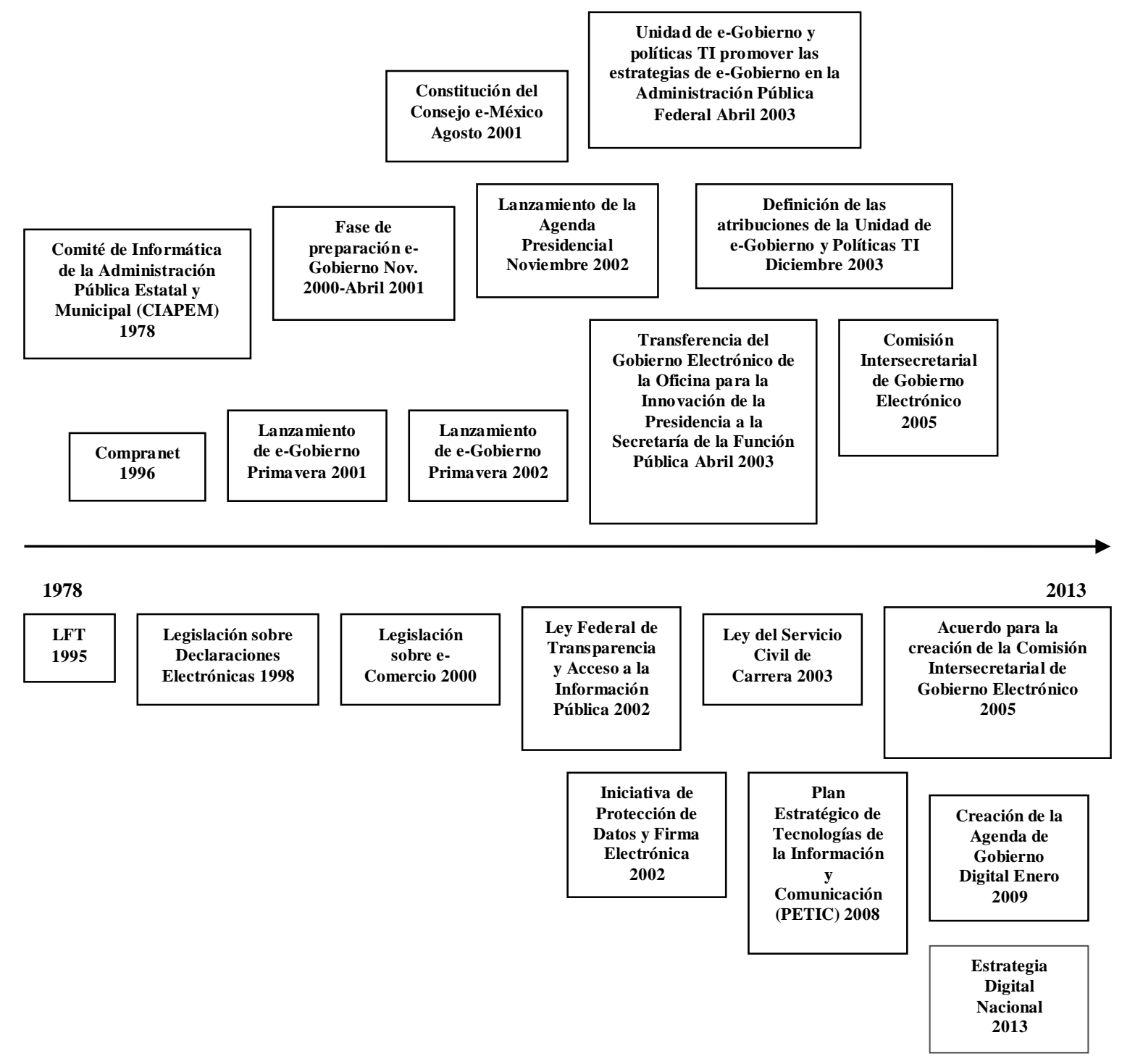

Fuente: Elaboración propia con base a Gil-García, Mariscal Avilés \& Ramírez Hernández (2008: 8), Estrategia Digital Nacional (2013)

Uno de los primeros portales electrónicos fue Compranet, creado en 1996, sus objetivos fueron mejorar las licitaciones y compras de gobierno federal, estandarizarlas y darles mayor transparencia al poner al alcance de los proveedores la información para participar de una manera más práctica.

\footnotetext{
${ }^{44}$ Anteriormente esta responsabilidad era compartida entre la SFP e INEGI.
} 
Sin embargo, la discrecionalidad en las adjudicaciones es todavía un gran reto que vencer. Los ámbitos de gobierno electrónico son muy variados; en el mismo portal e-gobierno, en el rubro de trámites y servicios de alto impacto, aparecieron, a su vez dieciséis portales ${ }^{45}$. En 2004, con fundamento en la Ley Federal de Procedimiento Administrativo, se estableció el Registro Único de Personas Acreditadas (RUPA), incorporando en el primer semestre de 2006, 35 dependencias y organismos descentralizados con 51 ventanillas en el Distrito Federal y 121 distribuidas en los 31 estados de la República. En ese mismo periodo, 1042 personas físicas y morales contaban con su número de identificación, lo que representó el 48.3 por ciento de la meta programada ese año.

De acuerdo con la información oficial en 2006 se podían realizar 1876 trámites y servicios electrónicos gubernamentales ${ }^{46}$. A través de los portales los usuarios tuvieron acceso a servicios como obtener la Clave Única de Registro de Población (CURP); trámites para empezar y operar un negocio; servicios y trámites para los extranjeros en el país, como la naturalización; el directorio de servidores públicos; declaración patrimonial; peticiones ciudadanas; capacitación; búsqueda de empleo; compras gubernamentales; pagos de impuestos; pago de servicios; búsqueda de vivienda; programación de citas médicas; trámite de pasaporte, por mencionar algunas (Maldonado, 2008: 180) ${ }^{47}$.

El gobierno digital contempló utilizar esta tecnología como plataforma para la operación de la Ley Federal de Transparencia y Acceso a la Información Pública Gubernamental, la cual determinó que los sujetos obligados a publicar información debían hacerlo, "a través de medios remotos o locales de comunicación electrónica" ${ }^{48}$, disponibles en cualquier lugar y en cualquier momento.

\footnotetext{
${ }^{45}$ Portal Ciudadano del Gobierno Federal, www.gob.mx; Sistema de Solicitudes de Información Instituto Federal de Acceso a la Información Pública, www.sisi.gob.mx; Compranet: Sistema Electrónico de Compras Gubernamentales, www.compranet.gob.mx; Declaranet: Sistema Electrónico para la Declaración de Bienes Patrimoniales de los Servidores Públicos de la Administración Federal, www.declaranet.gob.mx; Tramitanet; Registro Único de Personas Acreditadas, www.rupa.gob.mx; Capacitación en línea para los Servidores Públicos de la Administración Federal, www.campuasmexico.gob.mx; Portal de la Secretaría de Educación Pública (Enciclomedia), www.sep.gob.mx/wb2/sep/_Enciclomedia; Instituto Latinoamericano de la Comunicación Educativa, redescolar.ilce.edu.mx; Bolsa de trabajo de la Administración Pública Federal, www.trabajaen.gob.mx; Bolsa de trabajo del sector privado, www.chambatel.gob.mx; Base de conocimiento laboral (empleos/carreras), www.observatoriolaboral.gob.mx; Portal de la Sociedad de la Información e-México, www.e-mexico.gob.mx; Sistema de Administración Tributaria en línea [eSAT], www.sat.gob.mx; INFONAVIT: oportunidades para comprar casa, http://www.infonavit.gob.mx; Instituto Mexicano del Seguro Social, www.imss.gob.mx.

${ }^{46}$ Entre los resultados están los siguientes: el portalCiudadanowww.gob.mx, en el periodo de enero-junio de 2006 registró más de 20 mil visitas diarias.

${ }^{47}$ En materia de reconocimientos internacionales, el saldo podría decirse es bueno: El portal Ciudadanowww.gob.mx, ganó el Premio Reto Estocolmo (Stockholm Challenge Award) 2003-2004, en la categoría de gobierno electrónico; en septiembre de 2005, la Organización para la Cooperación y Desarrollo identificó a México, en cuatro años, como uno de los líderes en el mundo en materia de servicios gubernamentales en línea; la Organización de las Naciones Unidas entregó al Gobierno de México, a través de la Unidad de Gobierno Electrónico de la Secretaría de la Función Pública, en el marco del Día del Servicio, el 23 de junio de junio de 2005, el Premio de las Naciones Unidas al Servicio Público 2005 por la Estrategia de Gobierno Digital de la Agenda de Buen Gobierno. En tanto que el reporte Global sobre Aptitud de e-Gobierno 2005 de la Organización de las Naciones Unidas en el mes de diciembre de 2005, ubicó a México en el sitio 31 de entre 191 países evaluados. Además, lo coloca en el décimo primer lugar en materia de sofisticación y madurez de servicios gubernamentales en línea; en sexto lugar en e-Participación; y reconoce que México es una de las 10 naciones que ha progresado de manera más efectiva y rápida en sus estrategias de e-Gobierno (Sojo, 2005). De acuerdo con los diversos organismos y universidades evaluadores del tema en cuestión el gobierno digital de México ha logrado colocarse dentro de los primeros 50 países del mundo, (The Global Competitiveness Report 2007-2008, World Economic Forum, UN eGovernment Survey 2008, United Nations New York, 2008). A pesar de estos reconocimientos, según el Reporte Global de Tecnologías de la Información 2009-2010 publicado por el Foro Económico Mundial (WEF), México ocupa el lugar 78 de 133 en aprovechamiento de tecnologías, el mismo que el año pasado. Este reporte mide qué tan propensos son los países para explotar las oportunidades que ofrece la tecnología, a partir del gobierno, las personas y las empresas. Y con base en el sondeo e-Government, que realiza el Departamento de Asuntos Económicos y Sociales de las Naciones Unidas, Everis elabora el Índice de Desarrollo de e-Gov (IDEG), para medir qué uso les dan los gobiernos a las nuevas tecnologías, así como la capacidad de éstas para ser más transparentes y eficientes en la gestión pública. Corea del Sur, Estados Unidos y Canadá ocupan los tres primeros lugares en $e$-Gov en todo el mundo. Pakistán, Nigeria, la República Democrática del Congo y Níger son los más atrasados. México cayó 19 lugares, entre 181 países evaluados, al ubicarse en la posición 37 durante 2008, y ocupar la 56 en 2010. Abajo de países como Polonia, Uruguay, Chile y Colombia.

${ }^{48}$ De acuerdo con los artículos $7^{\circ}$ y $9^{\circ}$ de la Ley Federal de Transparencia y Acceso a la Información: "Los sujetos obligados deberán tener disposición de las personas interesadas equipo de cómputo, a fin de que estas puedan obtener la información, de manera directa o mediante impresiones. Asimismo, éstos deberán proporcionar apoyo a los usuarios que lo requieran y proveer todo tipo de asistencia respecto de los trámites y servicios que presten. Las dependencias y entidades deberán preparar la automatización, presentación y contenido de su información, como también su integración en línea, en los términos disponga que el reglamento y los lineamientos que al respecto expida el Instituto".
} 
Para ello, a fines del sexenio el gobierno informó que se instalaron más de 7500 centros comunitarios digitales e-México en todo el territorio nacional, ubicados en centros de desarrollo social y presidencias municipales, en dichos centros la información incluyó, además de español, inglés, francés y lenguas indígenas.

Las tecnologías de información y comunicación (TIC) se han convertido en parte de una nueva forma de organizar la gestión pública con el objetivo de incrementar la eficiencia, la transparencia, la accesibilidad y la capacidad de respuesta a las demandas de los ciudadanos y empresas. La modernización de la gestión pública, a través del uso de TIC, busca transformar un gobierno deficiente en un gobierno competitivo, ofreciendo a la población servicios públicos y acceso a la información de manera sencilla, oportuna y transparente. Sin embargo, los sitios electrónicos del gobierno siguen cometiendo los mismos errores: presentar información en formato pdf, ocultar datos relevantes debajo de muchas ligas (links), disfrazar las cifras con flash, imágenes flotantes o textos pequeños para distraer la atención de los usuarios y olvidarse del significado o contexto de la información, la práctica común de no colocar el nombre de quien publica la información ni la manera de contactarlos es un ejemplo de que la rendición de cuentas se realiza a medias, así como dificultar el compromiso de facilitar a los ciudadanos la información gubernamental.

\subsubsection{Gobierno con mejora regulatoria}

El gobierno con mejora regulatoria buscaba eliminar la normatividad excesiva de la gestión pública, a través de la consolidación de diversas herramientas y estrategias, en calidad, simplificación y mejora del marco jurídico de las instituciones del gobierno federal.

Entre las más sobresalientes se encuentran Comisión Federal de Mejora Regulatoria (COFEMER), creada en el año 2000 ante la reforma de la Ley Federal de Procedimiento Administrativo con lo cual se instituyó la política de mejora regulatoria. Para 2002 se creó la Normateca Federal. Durante el periodo septiembre 2002 a agosto de 2003, 17 instituciones instalaron normatecas internas. De septiembre 2003 a agosto 2004, se instalaron 34 de Comités de Regulatoria Interna de 44 comprometidos; para este mismo periodo, funcionaban las mesas de Simplificación Regulatoria, la metodología de Homologación Normativa y la iniciativa del Lenguaje Ciudadano.

La Cofemer junto con la SFP, emprendió tareas para mejorar los trámites con mayor impacto en las actividades productivas y en los ciudadanos. Identificaron 240 trámites que tenían ese perfil, de acuerdo con cinco criterios: a) frecuencia con la que el servicio fue tramitado, b) número de usuarios que realizaron el trámite, c) recurrencia de usuarios, d) ingresos generados y e) números de quejas o denuncias por corrupción.

La Normateca Federal a través de su portal www.normateca.gob.mx, registró en agosto de 2006, 694522 consultas, sumando un total de 1629302 a la fecha desde 2002. Con referencia a las normatecas internas, en agosto de 2006, se constituyeron 34, para un total de 78. Derivado de las evaluaciones realizadas a las instituciones que cuentan con normatecas internas, el índice de certeza jurídica se ubicó en 90.2 por ciento de avance en los programas de trabajo, desarrollo y actualización de las herramientas instaladas.

En el marco de los Comités de Mejora Regulatoria Interna en las Dependencias y Entidades ${ }^{49}$ (COMERIS), se estableció la racionalización en la emisión de disposiciones, la simplificación, la mejora y la desregulación de la normativa interna de cada dependencia o entidad, con el consecuente incremento en la calidad normativa. Apoyándose para ello, en la opinión de los usuarios de la norma con el fin de lograr mayor productividad y un proceso implícito de capacitación normativa (Mesta, 2009: 453). Así en agosto de 2006, los comités ascendieron a 73. Esta herramienta logró la simplificación y mejora de 11272 disposiciones y la eliminación de 9 322, para sumar un total de 20 594 disposiciones que han pasado por un proceso de mejora y calidad regulatoria.

\footnotetext{
${ }^{49}$ Esta herramienta integra a los emisores de las disposiciones y a sus usuarios, asesorados por los Órganos Internos de Control y las Unidades de Asuntos Jurídicos de cada institución. Ello ha permitido tener mayor control del marco normativo vigente, dictaminar la emisión de nuevos instrumentos, la administración de la Normateca Interna, así como la estandarización de los documentos normativos.
} 
Por su parte, las mesas de Simplificación Regulatoria integran, analizan y simplifican disposiciones de alto impacto y de aplicación general en la operación y funcionamiento de toda la APF. A partir del año 2004 y a la fecha, uno de los temas mayor importancia de la SFP es el Servicio Profesional de Carrera.

La herramienta Lenguaje Ciudadano buscó mejorar la interacción entre las instituciones y los ciudadanos por medio de una comunicación efectiva con el propósito de perfeccionar la transparencia, rendición de cuentas, productividad e incrementar la confianza de los ciudadanos en el gobierno. Así, entre los avances alcanzados por esta herramienta desde su inicio en 2004 a julio de 2006, sobresale la realización de 75 sesiones de capacitación en la materia con una participación de 2 mil servidores públicos, así como la realización de 19 conferencias con la asistencia de 2219 personas de los sectores públicos y privado, y la capacitación de 26510 servidores públicos en toda la APF.

A pesar de estos resultados, en los funcionarios públicos sigue existiendo una opinión generalizada de que hay sobrregulación en la actividad administrativa dada la contradicción existente entre ciertas líneas de acción de la ABG, como la desregulación y la certificación ISO 9000, esta última genera sobrerregulación interna en áreas gubernamentales que son difíciles de estandarizar (sobre todo en aquellas que no ofrecen servicios directos en ventanilla al público) (Somuano, 2009).

\subsubsection{Gobierno que cueste menos}

Para la administración Fox, un gobierno que cueste menos consistía en reducir el gasto burocrático que no agrega valor al ciudadano y en aumentar el gasto de inversión en infraestructura y programas sociales de alto beneficio para la población, y alcanzar estos dos objetivos en un marco de estabilidad macroeconómica y equilibrio macroeconómico.

De entre la serie de medidas en materia de desincorporación, racionalidad y austeridad presupuestaria para reducir el gasto burocrático destacaron: a) no otorgar incrementos salariales a los funcionarios públicos de mandos medios y superiores; eliminar las secretarías particulares en las unidades, coordinaciones y direcciones generales; b) ajustar la estructura de las dependencias a tres subsecretarías, salvo en los casos de excepción que se justifique; c) mantener una relación de tres directores generales adjuntos por unidad, coordinación y dirección general; d) fijar cuotas homogéneas para uso de telefonía celular, viáticos, pasajes y gastos de alimentación, que sean estrictamente necesarios para el desempeño de las funciones de los servidores públicos; e) racionalizar la contratación de estudios y asesorías; f) reducir el 15 por ciento los gastos de administración en las oficialías mayores y equivalentes, en las oficinas de comunicación social y enlace, representaciones en el extranjero y similares, delegaciones y representaciones estatales, y en las asesorías y oficinas de apoyo.

Respecto en aumentar el gasto de inversión en infraestructura y programas sociales de alto beneficio para la población, se consideraron las siguientes alternativas: i) un mayor endeudamiento a través de la ampliación del déficit público; ii) incremento de los recursos disponibles a través de mayor recaudación y liberación de recursos del gasto operativo. En este contexto, de 2001 al primer semestre de 2006, según datos oficiales, se alcanzó un ahorro total de 46130.6 millones de pesos, de los cuales 20792 millones corresponden a ahorro presupuestario, 15156.9 millones de pesos a ajustes al gasto y 984.8 son resultado de economías de comunicación social. Durante los seis años de gobierno disminuyó el número de funcionarios públicos. De 2001 a 2006 un total de 95347 servidores públicos concluyeron voluntariamente su relación laboral (Sexto Informe de Gobierno, 2006: 156) ${ }^{50}$.

El énfasis de la $\mathrm{ABG}$ en la obtención de resultados cuantitativos subordinó la obtención de resultados cualitativos que redundarán en beneficios claros para la sociedad. No obstante, de pugnar por una mayor participación de la ciudadanía se percibió a ésta como un conjunto de "clientes", a los que no se les consultó para conocer sus preferencias o sobre los beneficios que podrán derivar de las distintas propuestas.

\footnotetext{
${ }^{50} \mathrm{El}$ empleo del gobierno en general como porcentaje de la fuerza laboral total disminuyó de 10.9 por ciento en 2000 a 8.8 por ciento en 2007. México tiene una de las fuerzas laborales públicas más reducidas de los países miembros de la OCDE en comparación con el promedio del 15 por ciento de la organización. Cuando se incluye a los empleados de empresas públicas, el porcentaje asciende a 10 por ciento de la fuerza laboral total, que aún es bajo si se compara con el de otros países miembros (Australia 16\%, Turquía 13\%, Estados Unidos 14\%). OCDE (2011).
} 
Para algunos autores, el éxito de la ABG fue gerencial, no social. Dado que incorporó un número de acciones montadas en técnicas empresariales en cada dependencia, en concordancia con la eficiencia englobadas en la Nueva Gestión Pública, como el de calidad total, cuyos resultados debían evaluarse en el corto y mediano plazo.

A pesar de ello, las propuestas de la ABG sentaron ciertas bases para ir gradualmente cambiando -aunque sea de manera fragmentada-, a una nueva forma de asumir la responsabilidad y desempeño de las tareas públicas. Se reconocen cambios como la incorporación del Servicio Profesional de Carrera y la creación del IFAI (hoy INAI) ${ }^{51}$ en la Administración Pública Federal, que tienen todavía mucho camino por avanzar.

\subsection{Buena gobernanza}

El Plan Nacional de Desarrollo 2000-2006 señala la necesidad de medidas de "Buen gobierno". Unas corresponden a las "normas básicas de acción gubernamental" (gobernanza): apego a la legalidad, gobernanza democrática, transparencia y rendición de cuentas (Carrillo \& Cárdenas, 2004: 23).

El buen gobierno ${ }^{52}$ o buena gobernanza se reconoce por la forma en el ejercicio del poder en un país caracterizado por los rasgos de eficiencia, transparencia, rendición de cuentas, participación de la sociedad civil y estado de derecho. La conjunción de estos rasgos revela la importancia crucial del fortalecimiento de la capacidad de las instituciones del Estado y del gobierno, para resolver los problemas públicos.

En la medida que un Estado -o un gobierno- sea más eficiente, productivo, con capacidad de respuesta y capacidad de estimular la creatividad y respete la libertad, será más fuerte y, por ende, tendrá la determinación de utilizar los recursos a favor del desarrollo económico y social. Sin embargo, el riesgo de esta definición es que se confunda con uno de sus aspectos: la estabilidad (Camps, 1997) ${ }^{53}$. Un país puede dejarse gobernar por un gobierno que no gobierna, o que gobierna mal; el resultado puede ser un gobierno estable, con una gobernabilidad asegurada, en estrecho sentido, pero no un buen gobierno.

En este sentido, es necesario distinguir entre governance, good governance y buen gobierno. Governance alude a una forma de gobierno complementaria del régimen constitucional establecido. El término se ajustó a lo largo del tiempo, primero, haciendo referencia a la manera en que el gobierno conduce y, luego, a que mediante ella el gobierno incorpora - de un modo ahora menos jerárquico, más horizontal, como también más descentralizado, con voz y a veces votos-, a diversos sujetos y sectores u organizaciones aún privados, o no gubernamentales, en el proceso general y/o en distintos proceso determinados de formación, consenso, formulación e implementación de decisiones públicas (Strasser, 2003).

Por su parte, good governance (buena gobernanza) implica la existencia de gobiernos "realmente" legítimos, que dan espacio y permiten la participación social en la forma de un combinado de actores públicos gubernamentales y no gubernamentales, de consensos entre estas partes y con burocracias e instituciones que se administran de manera eficaz, eficiente y transparente (Strasser, 2003).

La noción de buen gobierno facilita un marco vertebral a los estudiosos y practicantes de la administración pública. Su aportación a la teoría consiste en que ayuda a proporcionar un mapa o guía del universo en mutación del gobierno. Detecta las pautas y hechos clave (Stroker, 1998).

\footnotetext{
${ }^{51}$ Con la aprobación de la Ley General de Transparencia y Acceso a la Información Pública en mayo de 2015, el Instituto Federal de Acceso a la Información y Datos Privados (IFAI), cambia su nombre por el de Instituto Nacional de Transparencia, Acceso a la Información y Protección de Datos Personales.

${ }^{52}$ La noción de buen gobierno (good governance) tiene su origen desde principios de los años noventa, década en que el Banco Mundial se refiere a ella especialmente asociada a la política de desarrollo.

${ }^{53}$ Según Victoria Camps (1997), si un gobierno tiene capacidad para tomar decisiones, de responder a los conflictos, gestionarlos, al tiempo que procura conservar su propio poder, sabe equilibrar a las demás fuerzas políticas, así como tener medianamente satisfechos a los sectores sociales más combativos, tiene algunos, pero no suficientes elementos de buen gobierno.
} 
De tal suerte que gobernar no sólo implica realizar actos de gobierno, también abarca la interacción de actores sociales, grupos y fuerzas con las organizaciones e instituciones públicas. Así, tomando en cuenta la relación continúa entre gobernantes y gobernados, un buen gobierno, en sentido pleno de la palabra, no es nada más un gobierno que permanece en el poder; es un gobierno que hace lo que se debe hacer.

Desde el punto de vista de su desempeño, los sistemas de gobierno son los que cumplen con tres objetivos: eficiencia, efectividad y legitimidad. La eficiencia es la relación entre los recursos empleados y los resultados obtenidos en la ejecución. La efectividad es la relación entre la acción y sus consecuencias. La legitimidad es el grado de aceptación de una autoridad por parte de quienes tienen que aceptar esa autoridad (Boukaert, 1994).

A decir de Victoria Camps (1997), la existencia de las tres cualidades resume las virtudes de un buen gobierno, sin dejar de reconocer que, si bien las dos primeras son medianamente verificables, la legitimidad encierra más ambigüedad y, por tanto, mayores espacios para la subjetividad.

En la actualidad se ha incrementado el interés por medir el desempeño de las instituciones gubernamentales. De acuerdo con Adeel Malik (2002), los trabajos iniciales de Stephen Knack y Philip Keefer para evaluar el desempeño institucional, tales como la International Country Risk Guide (ICRG) -Guía Internacional de Riesgo País-, pusieron de moda los indicadores de gobernanza en investigación económica y política. El propósito de estos indicadores desarrollados por las agencias de calificación de riesgo fue orientar a los inversionistas extranjeros sobre la eficiencia económica, política y administrativa en los países de interés. A medida que el concepto de gobernanza se fue ampliando, los indicadores para valorarlo también se diversificaron. En la actualidad existe un rango bastante amplio de indicadores que miden componentes de la gobernanza tan diversos como: corrupción, libertades civiles, estado de derecho, eficacia del poder judicial, en otros. A grandes rasgos los indicadores de gobernanza se dividen en dos grandes categorías: procesos y resultados. Los primeros analizan las acciones políticas, así como las condiciones institucionales (reglas del juego) que rigen estas acciones. Los segundos evalúan el impacto o resultados de las decisiones de política pública.

Una diferencia entre estos tipos de indicadores es la fuente de información usada en su construcción. Los indicadores de proceso se diseñan con base en creencias y valoraciones, mientras que los de resultados se elaboran con el empleo de estadísticas o datos censales (Paolo, 1997). De esta manera, existen indicadores basados en estadísticas internacionales, como los del Programa de Naciones Unidas para el Desarrollo (PNUD) y la Organización para la Cooperación y el Desarrollo Económico (OCDE). También hay indicadores que surgen de las opiniones de los actores y organizaciones no gubernamentales, por ejemplo, los del Foro Económico Mundial (Global Competitiveness Survey) o lo de Transparencia Internacional. Otros están basados en el análisis de expertos de instituciones académicas o bien se generan a partir de una combinación entre datos estadísticos y opiniones cualitativas; por ejemplo, los indicadores que proceden de las agencias calificadoras de riesgos. Finalmente, hay indicadores ya disponibles, como los del Banco Mundial (, 2004)

Para el caso de México, se analizan los resultados obtenidos por nuestro país en los indicadores que establece el Banco Mundial, en el periodo 1996-2016, especificando el espacio del objeto de estudio.

Los indicadores de gobernanza del Banco Mundial utilizan un método de agregación de múltiples variables que incluyen datos de estadísticas y de encuestas de percepción. El resultado de la agregación es un índice que evalúa las siguientes seis dimensiones: 1) Voz y rendición de cuentas (voice and accountability); 2) Estabilidad política y ausencia de la violencia (political stability); 3) Efectividad gubernamental (government effecgtiveness); 4) Calidad regulatoria (regulatory quality); 5) Control de la corrupción (control of corruption); y 6) Estado de derecho (rule of law). Estas dimensiones se sintetizan en la figura 3.6.

Por ejemplo, el estudio de Governance Matters VIII utiliza el método de agregación de múltiples variables individuales que da como resultado un indicador agregado para cada una de las seis dimensiones consideradas. 
La metodología de medición es compleja, pero existe una manera relativamente sencilla de interpretar los resultados: con la posición relativa que ocupa cada país en una clasificación por cuartiles $^{54}$. En 2009, la octava edición de los indicadores del Banco Mundial evalúa las seis dimensiones de gobernanza de 212 países para el periodo de 1996 a 2008 . A continuación, se presentan varias gráficas, las cuales revelan información sobre el estado de gobernanza en México.

Figura 3.6 Indicadores de Gobernanza

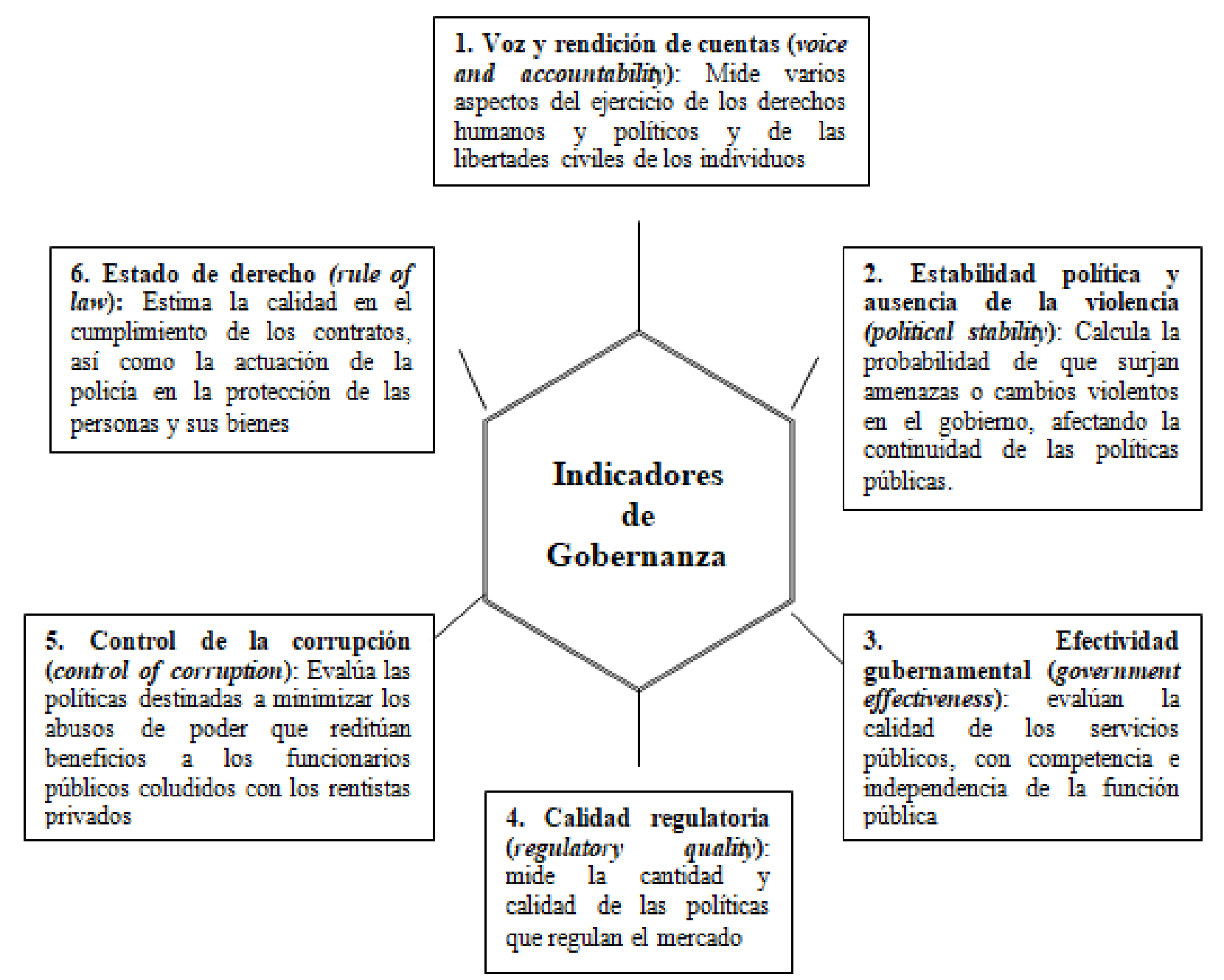

Fuente: Elaboración propia con base en Kaufmann, D., Kraay, A. \& Mastruzzi, M. (2009)

México, durante el periodo objeto de estudio no ha logrado posicionarse en el cuartil superior (de 75 a 100\%) en ninguna de las seis dimensiones de gobernanza. Las gráficas sugieren que las seis dimensiones en México han tenido un comportamiento de campana, es decir, iniciaron con puntajes bajos en los años de 1996 a 2000, pero incrementaron su calidad en el periodo 2000-2006; aunque cayeron nuevamente en los años 2006-2016.

Así se tiene que, en voz y rendición de cuentas, hubo avances entre 2000-2006. Resalta el ascenso pronunciado de la posición de México que pasó de 57.2\% en 2000 a $60.7 \%$ en 2003, empezando a descender en 2006 con 51.9\% (Ramírez \& Ramírez, 2018).

\footnotetext{
${ }^{54}$ En una distribución por cuartiles (proporciones iguales a 25\%), el mejor cuartil de ubicación es el superior al percentil de $75 \%$ (con la simulación de un tablero de control, el Banco Mundial clasifica el rango de $75 \%$ con color verde). El segundo mejor corresponde al mejor rango que va de 50 a $75 \%$ (color amarillo). El tercero va de 25 a $50 \%$ (color naranja), y el peor cuartil es el menor a $25 \%$ (color rojo). Por tanto, el objetivo general es que los niveles de gobernanza de los países se ubiquen en el cuartil superior a 75 por ciento.
} 
Gráfica 3.5 México 1996-2016. Voz y Rendición de Cuentas

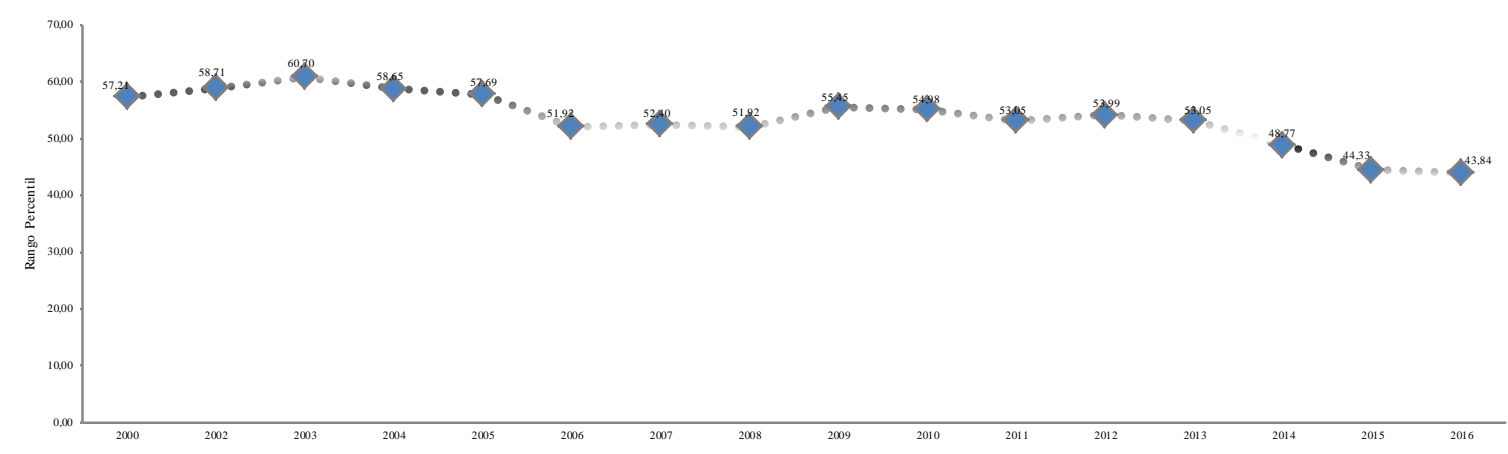

Fuente: Ramírez \& Ramírez (2018), con base en http://www. govindicators.org

En la estabilidad política y ausencia de violencia, el puntaje se ubicó en el cuartil más bajo de la clasificación del Banco Mundial. En 1996 tuvo un puntaje de 20.7\%, luego logró 45.5\% en 2002, para después caer con $26.5 \%$ en 2006, y en el cuartil más bajo con $20.0 \%$ en 2016.

Gráfica 3.6 México 1996-2016. Estabilidad Política y Ausencia de Violencia/Terrorismo

Gráfica 2. México 1996-2016. Estabilidad Política y Ausencia de Violencia/Terrorismo

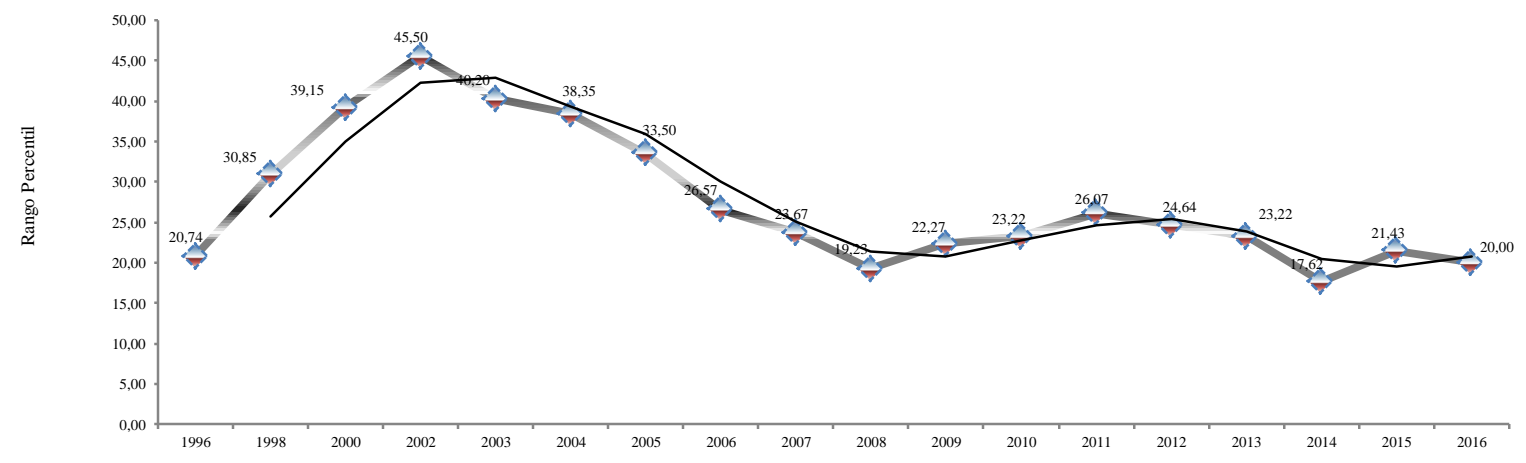

Fuente: Ramírez \& Ramírez (2018), con base en http://www. govindicators.org

En efectividad gubernamental, el puntaje no ha variado mucho en el periodo analizado, en 2000-2006 se mantuvo en promedio $61.5 \%$.

Gráfica 3.7 México 1996-2016. Efectividad Gubernamental

Gráfica 3. México 1996-2016. Efectividad Gubernamental

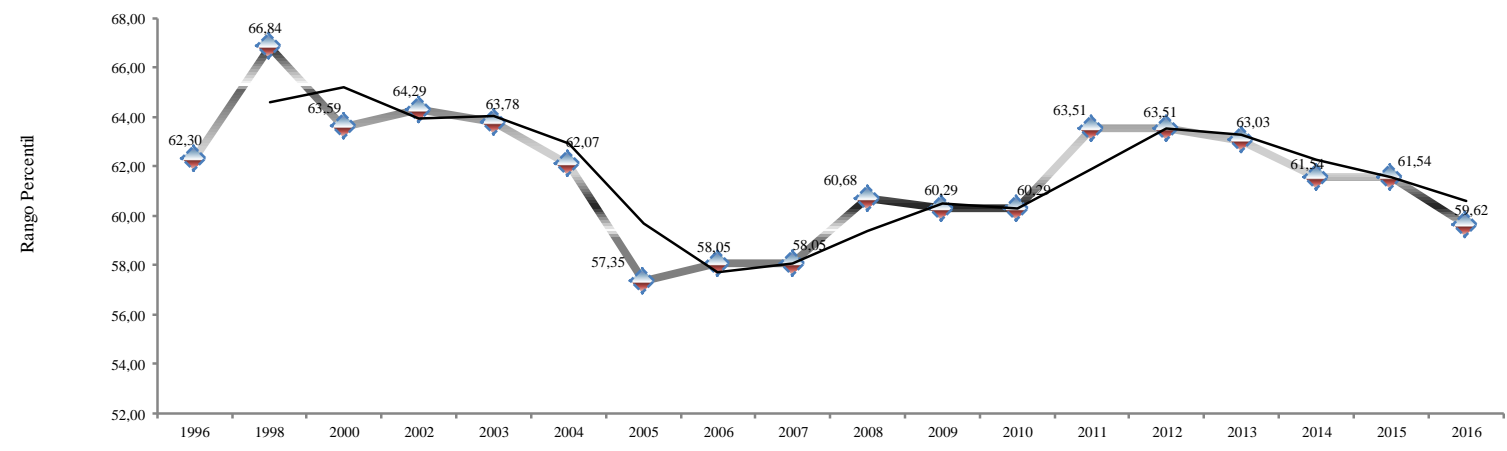


En calidad regulatoria se observó un cambio negativo de manera continua entre 1996 y 2008 al pasar de 72.2 a 65.2 por ciento.

Gráfica 3.8 México 1996-2016. Calidad Regulatoria

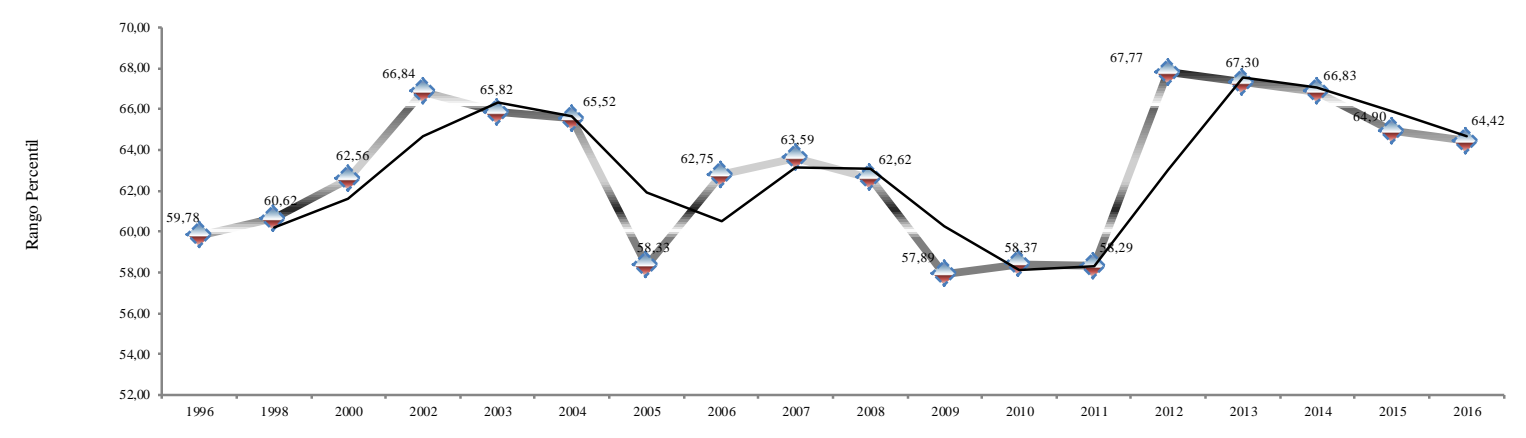

Fuente: Ramírez \& Ramírez (2018), con base en http://www. govindicators.org

El control de la corrupción tuvo su puntaje más alto en 2003 con 54.0\%, después en 2006, bajo a 47.3 por ciento. Para 2016 se encontró en un punto crítico en el cuartil más bajo $23.08 \%$.

Gráfica 3.9 México 1996-2016. Control de Corrupción

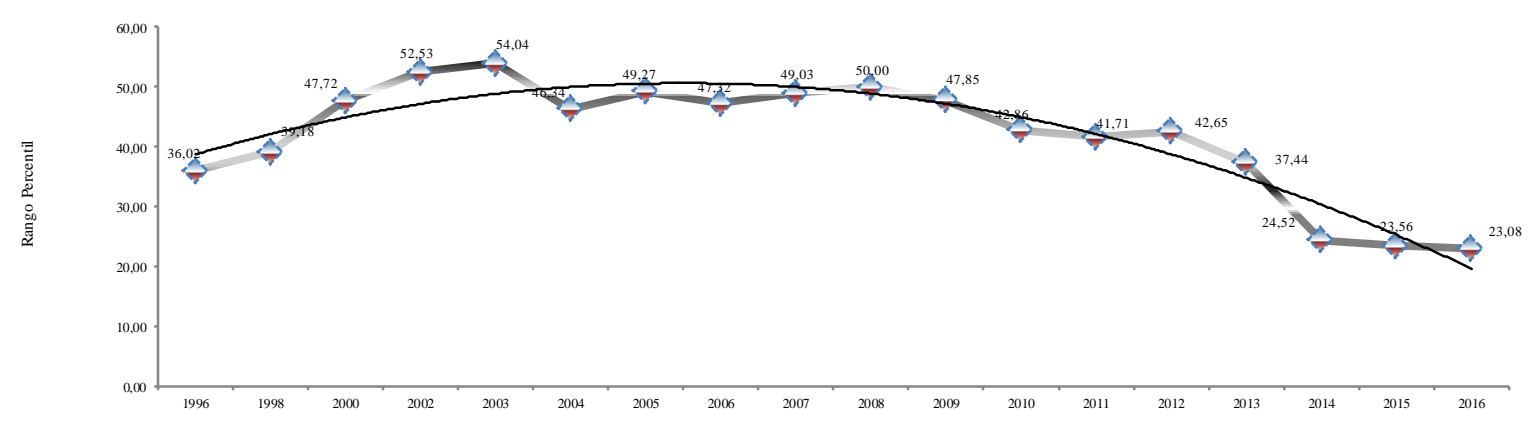

Fuente: Ramírez \& Ramírez (2018), con base en http://www. govindicators.org

Por último, la dimensión de Estado de derecho tuvo su puntaje más alto en 2002 con $44.0 \%$, para llegar en 2006 a 41.9 y descender $33.1 \%$ en 2016.

Gráfica 3.10 México 1996-2016. Estado de Derecho

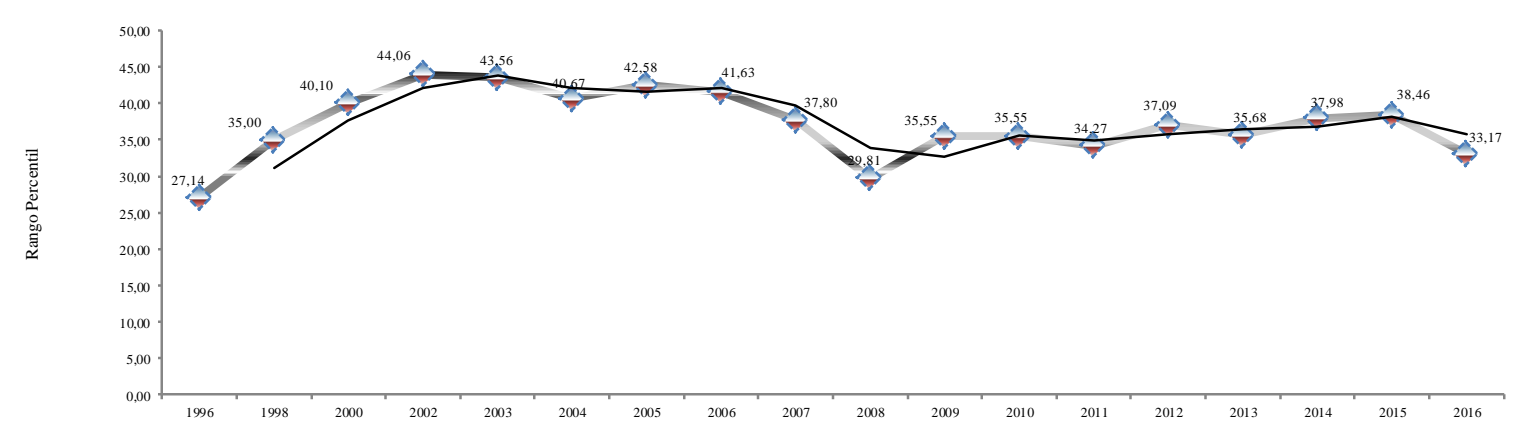

Fuente: Ramírez \& Ramírez (2018), con base en http://www. govindicators.org 
Como se puede observar, según los indicadores de gobernanza del Banco Mundial, México ha tenido una evolución negativa en los puntajes obtenidos en dichos indicadores. Por ejemplo, los indicadores estado de derecho y control de la corrupción, no han disminuido su calificación a lo largo del tiempo, esto se explica, en el primer caso, básicamente porque la ciudadanía percibe demasiada impunidad en la aplicación de las leyes. En cuanto al control de la corrupción su avance sigue siendo muy bajo y no ha logrado pasar del segundo cuartil. En estabilidad política está registró en 2006, $26.5 \%$.

Al final los resultados de la Agenda de Buen Gobierno no fueron los esperados. La introducción de distintas estrategias para innovar y modernizar la Administración Pública Federal buscando mayor eficiencia y eficacia en la mejora del aparato gubernamental, no coadyuvaron a generar mecanismos específicos y evaluaciones sistemáticas para conocer la efectividad de los cambios y si la meta de mejorar el desempeño gubernamental se cumplió.

La falta de claridad de la mejoría de los servicios y prestaciones que la administración pública ofrece a sus ciudadanos permite considerar que la toma de decisiones se caracterizó por un firme control de los actores involucrados y una inequívoca visión instrumental donde predominó la jerarquía del pensamiento organizativo empresarial acerca de los cambios estructurales realizados.

El impacto de la estrategia de desempeño del gobierno a través de la introducción de premios y reconocimientos a la innovación y calidad no fue considerado en la medida que el ciudadano percibiera una mayor calidad en la gestión pública, pues se basó en datos cuantitativos que sólo reconocían los modelos de éxito internacionales de calidad, sin adaptarse al contexto prevaleciente en su momento en México.

Las instituciones estaban más preocupadas por lograr la meta y obtener una mejor calificación para obtener premios y reconocimientos, sin considerar si la representación cuantitativa tenía su referente en la eficiencia y mejora de la gestión pública. Los nuevos arreglos institucionales de la administración pública tales como rendición de cuentas, transparencia de recursos, servicio civil de carrera, derecho a la información, responsabilidad de los servidores públicos, democratización de la sociedad, establecieron una nueva institucionalidad en el país, en la que el imperativo del cambio se organizó con base a reglas institucionales que son partes importantes para propiciar condiciones de certidumbre en beneficio de la sociedad.

A pesar de ello, los nuevos arreglos institucionales encontraron en su instrumentación un gran obstáculo para el desarrollo óptimo de los asuntos públicos. Prueba de ello, es la corrupción en la administración pública que violenta las reglas y transgrede los arreglos institucionales ya que contrariamente al ordenamiento jurídico de responsabilidad administrativa de los servidores públicos para la disminución de la opacidad y la corrupción, éstos continúan siendo grandes problemas.

En términos de gobernanza, los resultados del gobierno en el periodo 2000-2006, tuvieron un impacto entre regular y negativo en los indicadores voz y rendición de cuentas; estabilidad política y ausencia de violencia; efectividad gubernamental; calidad regulatoria; control de la corrupción y estado de derecho, pues ninguno de estos indicadores logró posicionarse en el cuartil superior (de 75 a $100 \%$ ) para una calidad buena de gobernanza, entendida como aquella en la que existe participación social amplia y sanciones efectivas en diferentes niveles y grados de transparencia, rendición de cuentas y combate a la corrupción.

De tal suerte, que el gobierno Foxista desde el punto de vista de su desempeño en materia de eficiencia y efectividad ha sido de una calidad regular a baja en la gobernanza entendida como aquella en la que hay una limitada o escasa participación social y sanciones selectivas, o bien sin sanciones efectivas por parte de las instituciones públicas a los casos de altos de corrupción.

En suma, el énfasis de la ABG en la obtención de resultados cuantitativos subordinó la obtención de resultados cualitativos que redundaran en beneficios claros para la sociedad. No obstante, de pugnar por una mayor participación de la ciudadanía se percibió a ésta como un conjunto de "clientes", a los que no se les consultó para conocer sus preferencias o sobre los beneficios que podrán derivar de las distintas propuestas. 
El éxito de la $\mathrm{ABG}$ fue gerencial, no social. Dado que incorporó un número de acciones montadas en técnicas empresariales en cada dependencia, en concordancia con la eficiencia englobadas en la nueva gerencia pública, como la innovación y calidad total, cuyos resultados debían evaluarse en el corto y mediano plazo.

A pesar de ello, las propuestas de la ABG sentaron ciertas bases para ir gradualmente cambiando -aunque sea de manera fragmentada-, a una nueva forma de asumir la responsabilidad y desempeño de las tareas públicas. Se reconocen cambios tales como -el nuevo marco legal de responsabilidades administrativas, transparencia y rendición de cuentas, el servicio profesional de carrera y la función pública-, los cuales constituyeron un avance en el cambio institucional administrativo de nuestro país sentando las bases para un estilo diferente de seleccionar, incluir, promover, capacitar y evaluar el desempeño de los servidores públicos.

Lo anterior ha permitido un avance gradual para que el gobierno de lo público sea la característica de las sociedades que han optado por la democratización del poder, es decir, la democratización en las que se difunden e intensifican las prácticas democráticas en la toma de decisiones del gobierno y, por ende, de la administración pública. 


\section{Capítulo 4 Análisis del desempeño del cambio institucional en la administración pública mexicana 2000-2006}

Los cambios institucionales analizados a través de la implementación de las estrategias de la Agenda de Buen Gobierno se han visto favorecidos por las reformas normativas, instituciones, estructuras y prácticas de gobierno, acordes con los nuevos paradigmas de la nueva gestión pública y la gobernanza, en función de los cuales se introducen mejoras e innovaciones para la modernización y mejor desempeño de la administración pública.

En este sentido, el presente capítulo tiene como objetivo analizar el cambio institucional de la administración pública mexicana en el periodo 2000-2006, que generó una nueva institucionalidad administrativa basada principalmente en el servicio civil de carrera, la transparencia, la rendición de cuentas y el combate a la corrupción, como parte de las acciones de gobierno (gobernanza) a fin de evaluar los resultados de su desempeño.

Con la creación de nuevas leyes como la Ley Federal de Responsabilidades Administrativas de los Servidores Públicos (2002), la Ley Federal de Transparencia y Acceso a la Información (2002) y la Ley del Servicio Profesional de Carrera de la Administración Pública Federal (2003), comienza un nuevo proceso de institucionalización de la transparencia, la rendición de cuentas, el combate a la corrupción y a la opacidad de los asuntos gubernamentales. Otra parte para acelerar el proceso de institucionalización es la participación ciudadana, de las organizaciones no gubernamentales y de actores de la sociedad civil para que utilicen estos instrumentos para transparentar los asuntos de gobierno.

La instauración del servicio profesional de carrera representó uno de los asuntos más importantes de la agenda político-administrativa mexicana. La institucionalización de la alternancia política, sin duda, permitió contar con "una burocracia profesional capaz de garantizar la continuidad de programas y políticas a través de una burocracia estable frente a los cambios de gobierno" (Vilchis, 2006: 458). Ello significó el diseño e implantación de un plan que ha apuntado a la transformación tanto de la propia administración pública como de su gestión de personal. Los cambios se experimentaron en los aspectos estructurales-organizacionales, presupuestales, tecnológicos y culturales.

\subsection{Transparencia}

La entrada en vigor de la Ley de Transparencia y Acceso a la Información Pública Gubernamental (2002) estableció que los sujetos obligados ${ }^{55}$ deben poner a disposición del público información sobre su estructura orgánica, las facultades, metas y objetivos de cada unidad administrativa, el directorio de servidores públicos, la remuneración mensual del puesto, los servicios y trámites que ofrecen, la información sobre el presupuesto asignado, los resultados de las auditorías al ejercicio presupuestal, el diseño, monto asignados y criterios de acceso a los programas sociales que establezca el Decreto del Presupuesto de Egresos de la Federación, las concesiones, permisos o autorizaciones otorgados, y las contrataciones que se hayan celebrado en términos de la legislación aplicable.

Desde una perspectiva descriptiva el concepto de transparencia aplicado al ejercicio gubernamental se entiende como un rasgo o característica de la actuación de las organizaciones públicas y de quienes las conforman y las hacen funcionar. Siguiendo a Jonathan Fox, la transparencia se refiere a la existencia o no de información -y de sistemas que la producen- sobre lo que son, hacen, utilizan y producen las dependencias de gobierno o, incluso, sobre los actos o productos de actores privados (es el caso de las información sobre el uso privado de recursos públicos, sobre la generación de riesgos potenciales a la salud y el medio ambiente, o sobre las características de bienes y servicios y su efecto en quienes los consumen, las etiquetas de prevención). Es, en esencia, el acceso público a datos o información (Fox, 2007: 663-671).

\footnotetext{
${ }^{55}$ Sujetos obligados según la Ley de Transparencia y Acceso a la Información son: El Poder Ejecutivo Federal, La Administración Pública Federal y la Procuraduría General de la República, el Poder Legislativo Federal integrado por la Cámara de Diputados, la Cámara de Senadores, la Comisión Permanente y cualquiera de sus órganos, el Poder Judicial de la Federal y el Consejo de la Judicatura Federal, los órganos constitucionales autónomos, los tribunales administrativos federales y cualquier otro órgano federal.
} 
En otras palabras, la transparencia gubernamental se refiere a la divulgación de información importante en redes de fácil y constante acceso. La transparencia no depende del derecho de los sujetos al acceso a la información, no requiere de una solicitud para darse, es un sistema que debe operar de forma que sea la propia mecánica de éste la que produzca los resultados esperados (Cossío, 2008).

Para Berrones (2011), la transparencia en sentido político y público forma parte de

\begin{abstract}
"los cambios institucionales que se impulsan para revalorar la importancia del Estado en los procesos de desarrollo económico y social por cuanto a los incentivos que aplica, las políticas que implementa y los resultados que consigue con relación a la sociedad, los mercados, la economía y la vida pública. La transparencia es parte de la estrategia del cambio institucional que se concibe para incluirla como pieza funcional en la relación del Estado con los ciudadanos" (Berrones, 2011: 15-29).
\end{abstract}

En términos de gobernanza, la transparencia está transformando el significado de la acción de gobernar hacia nuevas prácticas administrativas que ponen al alcance del ciudadano la posibilidad de vigilar lo que sucede dentro de la estructura administrativa de gobierno, permitiéndole participar como una medida de control externo sobre las acciones de los servidores públicos. De esta forma, la gobernanza nos ofrece una forma de pensar a la administración pública, guiados por la premisa de averiguar que actor gubernamental hace qué, cómo lo hace y con qué resultados.

La gobernanza implica también alentar la participación y confianza de los ciudadanos en las instituciones públicas, abriendo espacios de intervención que acrediten una nueva forma de gobernar, la cual tiene como elemento distintivo que la conducción de la sociedad no es piramidal, sino se reconoce por su carácter horizontal y multicentrado; de este modo, el patrón de la legitimidad conlleva a reconocer que la gobernanza democrática se ratifica con procesos de abajo hacia arriba (Berrones, 2007: 61).

La gobernanza se relaciona con la transparencia porque alude no sólo a la faceta pública del poder, sino también a la necesidad de que los gobernados, en un esquema horizontal de poder, tengan la oportunidad de conocer, identificar y valorar el desempeño de las instituciones públicas. El poder democrático abre la posibilidad de que los ciudadanos tengan el derecho a la información públicogubernamental, generada mediante el concurso de agentes, instancias y responsables de la burocracia (Berrones, 2007: 61).

Por lo tanto, el arquetipo del mando, control y la verticalidad es incompatible con la gobernanza democrática (Berrones, 2013: 21) ${ }^{56}$ dado que ésta valora y acepta la existencia de redes sociales y políticas que reclaman su derecho a participar e intervenir en la operación directa del Estado, destacando su autonomía frente a los poderes e instituciones del propio Estado. La categoría redes alude a condiciones en las cuales los procesos de apertura y accesibilidad se convierten en pilares de convivencia democrática del espacio público.

La gobernanza democrática también atiende los valores de la legalidad y la reglamentación, por lo que la transparencia es una condición necesaria para que el imperio de la ley y la rendición de cuentas sean una realidad, porque ayuda a identificar puntualmente por vía de la difusión de la información si las decisiones, acciones y políticas públicas se apegan a las normas legales correspondientes y si los gobernantes responden a sus gobernados, es decir, si guían sus decisiones en función de las necesidades y de los compromisos que asumieron frente a ella al tomar posesión de sus cargos (Peschard, 2007: 12).

Sin embargo, la divulgación de esta información plantea un dilema, pues parecería que el gobierno sólo busca mayor visibilidad pública sin modificar la forma en que se produce y utiliza la información, favoreciendo el secreto en los asuntos gubernamentales. En otras palabras, tiene el efecto perverso de que la verdadera oposición a la transparencia raras veces sea transparente. En este contexto, "los perdedores harán lo que tengan que hacer para limitarse a aparentar que cumplen con los requisitos de legales y los criterios civiles” (Fox, Haight \& Palmer, 2011: 5).

\footnotetext{
${ }^{56}$ La gobernanza democrática define el papel que le corresponde a las instituciones de gobierno en la estructuración y el funcionamiento de la vida colectiva.
} 
Aquí resulta pertinente la distinción conceptual de lo que podría llamarse "transparencia clara", en oposición a la transparencia "opaca" o "borrosa" (Fox, 2007). La transparencia clara refleja cómo se comportan realmente, en la práctica, las instituciones: que decisiones toman, cómo las toman, a dónde va a dar su dinero y cuáles son los resultados tangibles de sus acciones. "La transparencia clara arroja luz sobre el comportamiento institucional, lo que permite que los actores interesados en ese desempeño (como diseñadores de políticas públicas, líderes de opinión y beneficiarios de programas) puedan definir y desarrollar estrategias de mejora o cambio constructivo)" (Fox, 2007: 667).

Ejemplos de esta transparencia pueden ser aquellos documentos que definen de forma amplia los objetivos y los componentes de una política pública o un programa, y establecen las pautas y recursos que los responsables habrán de utilizar para lograr sus fines. Pueden ser también los informes de evaluación de instituciones, políticas, programas y presupuestos elaborados por dependencias públicas, por organizaciones civiles o por universidades.

En oposición, la transparencia opaca se refiere a la entrega de información disponible sólo nominalmente (accesible en teoría pero no en la práctica, datos cuya significación no es clara o información que se difunde pero que resulta no ser confiable (Fox, 2008), ejemplo de ello, son las innumerables estadísticas que se publican sobre el ejercicio del gasto público, o sobre las acciones individuales de funcionarios públicos y de programas, en periodos y áreas geográficas específicas (Sosa, 2011:23).

En este contexto, la divulgación de la información tiene un impacto directo sobre el desempeño institucional relativos a los insumos (como el gasto público o los contratos para construir escuelas, etcétera), los resultados (si se construyó o no la escuela) e impactos (si los niños lograron asistir a la escuela y si lograron aprender) (Sosa, 2011: 187).

Cuando se hace referencia al acceso público a la información acerca del desempeño del Estado, los instrumentos generalmente siguen dos caminos principales: la difusión proactiva y la divulgación responsiva. La difusión proactiva se refiere al acceso a un nivel mínimo de información acerca de las funciones y el desempeño oficial. La divulgación responsiva se refiere a un compromiso institucional que responde a demandas ciudadanas específicas que solicitan cierta documentación que, por otra, generalmente no se difunde (Sosa, 2011: 177).

Mauricio Merino (2008) identifica las siguientes conductas irregulares que se pueden presentar por falta de una política adecuada de transparencia:

1. Ocultar información pública para incrementar el patrimonio personal;

2. Utilizar información privilegiada para aumentar la influencia política propia;

3. Excluir a ciertos actores clave en el proceso de decisión;

4. Simular la documentación de un proceso de decisión que en realidad se llevó a cabo de una manera diferente, y

5. Demorar el flujo de información para la toma de decisiones oportunas.

En este sentido, cuando una política de transparencia no asume el valor estratégico de la información es inútil, cuando no logra cambiar las rutinas es burocrática (Merino, 2008). Esto es, como medio de mejora de la gestión pública, la transparencia tiene que integrarse y referirse a los objetivos, las metas, los procesos, las funciones y la cultura organizacional, por citar sólo los elementos más frecuentemente utilizados para describir una institución.

\footnotetext{
"Para lograr un gobierno transparente no es suficiente con un nuevo ordenamiento jurídico que reglamente las obligaciones de transparencia del gobierno, ni con la buena voluntad de los políticos y funcionarios de alto nivel. Estos elementos son necesarios, pero no suficientes. Es necesario, además, que las prácticas de transparencia se plasmen tanto en las rutinas y procedimientos de las organizaciones públicas como en el conjunto de valores (cultura organizacional) que influyen cotidianamente en los comportamientos de los actores organizacionales de todos los niveles" (Vergara, 2008: 9).
}

Es, por tanto, indispensable entender la dimensión organizativa que tiene la transparencia como rasgo de la gestión pública contemporánea, a partir de las nociones de transparencia activa y transparencia pasiva como señala Ferreiro (1999: 1-10). 
Desde el punto de vista organizativo, la transparencia pasiva y la transparencia activa pueden constituir extremos de un continuo que va de la simple publicación de datos y cifras a la elaboración de informes detallados sobre el uso de facultades legales, presupuestos públicos y resultados obtenidos. Su mayor o menor intensidad depende de la capacidad de ciudadanos y organizaciones para demandar información y hacer uso extensivo de ella y de la sensibilidad de las instancias gubernamentales para producir información útil y relevante.

La transparencia activa consiste en la difusión periódica y sistematizada de información acerca de la gestión estatal. Se trata de la obligación impuesta a los órganos del Estado para que con la periodicidad que la norma señale, publique toda la información que sea necesaria para una evaluación social de su desempeño. Esta información comprende, entre otras, la explicitación de las funciones, actividades, presupuesto, objetivos, indicadores de gestión, sistemas de atención al público, etcétera, y debe estructurarse de modo que permita la comparación entre un ejercicio y otro. Al efecto positivo de obligar al Estado poner en escrito sus compromisos de desempeño, así como sus datos y cifras más relevantes, se agrega la posibilidad de que la sociedad evalúe no sólo la información que se publique, sin el modo en que los datos evolucionan en el tiempo (Ferreiro, 1999: 1-10).

En oposición, la transparencia pasiva denota la obligación a que debe someterse el Estado para conceder, a los ciudadanos que los requieran, acceso oportuno a la información que obre en poder de los órganos públicos, salvo que medie razón legalmente establecida e imparcialmente acreditada, para justificar la reserva o secreto de determinado tipo de información (seguridad nacional, derechos de terceros, procedimientos en trámite cuya revelación anticipada perjudique el cumplimiento de una función pública, etc.) (Ferreiro, 1999: 9).

En este contexto, la cultura de la transparencia aquí se refiere a cambios en las creencias, prácticas y expectativas, insertas tanto en el Estado como en la sociedad, respecto al derecho del público a saber, implica que se requieren cambios actitudinales para que los servidores públicos acepten el derecho del público a saber, sobre todo porque, en la práctica el riesgo de sufrir sanciones tangibles por incumplimiento es mínimo (Fox, Haight \& Palmer, 2011: 48).

En México, los resultados del desempeño de la transparencia arrojan que en la práctica, haber confiado en la capacidad de la Secretaría de la Función Pública para aplicar sanciones en los casos de incumplimiento de las disposiciones del IFAI ha tenido resultados tangibles limitados. Ernesto Villanueva, en su artículo "Transparencia acotada" de la revista Proceso (2006) subraya este punto:

“[...del] análisis de las resoluciones de recurso de revisión del IFAI se desprende que, en 2004, sólo en nueve de los 465 casos atendidos ordenó procedimiento sancionador. En 2005, de mil 65 resoluciones, únicamente en 24 ocasiones se dio vista a la SFP para sancionar a quien hubiese incumplido el mandato de las resoluciones del IFAI. Se trata aproximadamente de 2 por ciento de los casos presentados en dos años $[\ldots]$.

Y señala,

[...] Pero si en dos años sólo en 33 casos el IFAI ha dado vista o solicitado a la SFP que sancione a los servidores públicos dentro de su ámbito de competencia, ésta ha procedido, de 2003 a la fecha, únicamente en ¡tres casos! [...]. Extrañamente, ninguno de los tres sancionados son mandos superiores, es decir, directores generales o de mayor categoría, sino mandos medios u operativos. Y esta circunstancia pone de relieve dos cosas: por una parte, que la SFP no cumple con la ley y sólo atiende menos de 10 por ciento de los casos reportados y, por otro, que al acatar mínimamente la ley la SFP se solaza con los integrantes del personal de las unidades de enlace, quienes, en realidad, sólo son mensajeros entre el solicitante de la información y quien tiene la autoridad para otorgarla" (Villanueva, 2007: 58).

La Secretaría de la Función Pública cumple pues selectivamente su función, en mucho menos del 10 por ciento de los casos y en perjuicio de los más débiles de la estructura gubernamental, quienes son sacrificados por cumplir instrucciones de sus superiores. Según lo dispuesto por el artículo $7^{\circ}$ de la LFTAIPG, en sus respectivos portales de transparencia, las dependencias deben dar a conocer cierta información básica, la cual monitorea el IFAI con el propósito de conocer en qué medida la información que se presenta en Internet está completa en términos de la disposición legal.

La siguiente tabla muestra los resultados de las evaluaciones, los cuales fueron dados a conocer públicamente. 
Tabla 4.1 Evaluaciones del IFAI del cumplimiento del Poder Ejecutivo Federal con el $7^{\circ}$ de la LFTAIPG

\begin{tabular}{|c|c|}
\hline Fecha & $\begin{array}{l}\text { Grado de cumplimiento general } \\
\text { (todas las dependencias) }\end{array}$ \\
\hline 23 de febrero al 12 de abril de 2004 & $62.8 \%$ \\
\hline A finales de 2004 & $80.6 \%$ \\
\hline A finales de 2005 & $95.9 \%$ \\
\hline Al 31 de diciembre de 2006 & $96.1 \%$ \\
\hline
\end{tabular}

Fuente: IFAI (2005: 33), Tercer Informe de Labores al H. Congreso de la Unión

Como muestra el cuadro 4.1, el grado de cumplimiento de las obligaciones de transparencia ha aumentado considerablemente. No obstante, la evaluación sólo verificó el contenido de los sitios de Internet según los criterios establecidos por la metodología de evaluación, sin considerar el formato en que se presentó la información, lo cual es un aspecto importante cuando se trata el tema de la transparencia. Debe señalarse que los niveles de cumplimiento bajo se deben, en algunos casos, a que las dependencias o entidades omitieron publicar ciertos elementos especificados en los criterios de evaluación como el presupuesto asignado, así como los informes de su ejecución, en los términos que establezca el Presupuesto de Egresos de la Federación, que son relevantes en la ejecución de los recursos públicos ${ }^{57}$.

A continuación, se presenta una tabla donde es posible apreciar el avance en el cumplimiento de las obligaciones de transparencia. A diciembre de 2006, 198 dependencias presentaron un grado de cumplimiento de 100 por ciento, sólo tres presentan un cumplimiento menor a 50 por ciento y otras cinco tienen un cumplimiento inferior a 60 por ciento como se observa en la tabla.

Tabla 4.2 Dependencias y entidades con cumplimiento debajo de 60 por ciento

\begin{tabular}{|c|c|c|}
\hline Entidad & $\begin{array}{l}\text { Porcentaje de } \\
\text { cumplimiento } \\
\text { actual }\end{array}$ & $\begin{array}{l}\text { Porcentaje de } \\
\text { cumplimiento } \\
\text { anterior }\end{array}$ \\
\hline Secretaría de Comunicaciones y Transportes & 58.2 & 100.0 \\
\hline Secretaría de Educación Pública & 58.0 & 63.0 \\
\hline Centro de Capacitación Cinematográfica & 56.9 & 40.0 \\
\hline Instituto Nacional de las Personas Adultas Mayores & 55.1 & 39.1 \\
\hline Secretaría de Gobernación & 53.5 & 86.0 \\
\hline Caminos y Puentes Federales de Ingresos y Servicios Conexos & 45.3 & 73.7 \\
\hline Instituto para el Desarrollo Técnico de las Haciendas Públicas* & 0.0 & 0.0 \\
\hline
\end{tabular}

*El Indetec argumenta ser un órgano del Sistema Nacional de Coordinación Fiscal, cuya naturaleza intergubernamental, al involucrar instancias federales y estatales, le determina una naturaleza que lo exceptúa para efectos de aplicación de la LFTAIPG, estando subordinado a su propia legislación (Ley de Coordinación Fiscal) y a sus órganos de gobierno como lo es la Comisión Permanente de Funcionarios Fiscales.

Fuente: IFAI (2006: 36), Cuarto Informe de Labores al H. Congreso de la Unión

El IFAI no puede sancionar directamente a las dependencias y entidades que no cumplan con las obligaciones de transparencia. En vez de ello, tiene que dirigirse a la Secretaría de la Función Pública y recomendarle que aplique las sanciones del caso.

\footnotetext{
${ }^{57}$ Dentro de las mismas organizaciones gubernamentales o incluso de otros sujetos obligados por la ley, la transparencia y la rendición de cuentas es muy opaca; es el caso de los fideicomisos -relación jurídica por medio de la cual una persona (fideicomitente) transfiere bienes a otra (fiduciaria) para que ésta los administre y realice con ellos algún fin licito específico o, en sus caso, los prepare para venderlos o transmitirlos, una vez cumplidos los fines establecidos en el contrato, a una tercera persona (fideicomisario)- que a lo largo de los años se han convertido en un blanco perfecto para el desvío inapropiado de recursos públicos. Existen fideicomisos públicos y privados. Los primeros están obligados a reportarse en el Presupuesto de Egresos de la Federación y en la Cuenta de la Hacienda Pública Federal, mientras que los segundos se quedan a la opacidad. Los fideicomisos públicos se desempeñan como entidades paraestatales (con estructura orgánica y obligados a rendir cuentas) aunque existen asimismo aquellos que no son considerados como entidades paraestatales y por ende no están obligados a rendir cuentas. El problema de los fideicomisos públicos es que son dolosamente mal utilizados pare el desvío de recursos públicos y gran cantidad de ellos se resisten a rendir cuentas a pesar de estar legalmente obligados. Algunos casos son: el FOBAPROA, el fideicomiso de apoyo para el rescate de autopista concesionadas (FARAC), Lotería Nacional a través de "Transforma México" y "Vamos México", Fideicomiso FONART entre muchos otros. (Fernández, 2010: 11-12).
} 
Esto, porque la ley de la transparencia prevé que las responsabilidades por incumplimiento se fincarán de acuerdo con los artículos 8, fracción IV y 13, de la Ley de Responsabilidades de los Servidores Públicos ${ }^{58}$.

\title{
4.1.1 La transparencia reduce costos de la asimetría de información
}

Hemos visto como la transparencia en la relación Estado-sociedad adquirió el carácter de defensa para conocer y, eventualmente, corregir las llamadas "fallas del Estado" (Ackerman, 2004), pero también para abordar e intentar solventar los efectos que producen en los gobiernos las asimetrías de información ${ }^{59}$ y la autonomía extrema de los agentes públicos (Vergara, 2008).

\begin{abstract}
"[...] un gobierno ejecutor del mandato ciudadano es el principal productor de la información concerniente a los problemas públicos, sus complejidades, las posibles soluciones y sus costos. También es quien posee la información necesaria para evaluar las políticas que ejecuta, por lo que es muy difícil para los ciudadanos saber si el gobierno está actuando eficientemente. Además, el gobierno es el único actor que tiene una visión completa de los problemas que enfrenta la nación, por lo que siempre será difícil rebatir la justificación de que, si la situación es mala, esto no se debe a una deficiente actuación del gobierno sino a factores externos sobre los que no se puede influir. En la medida en que todos los niveles de gobierno hagan disponible al público la información necesaria para juzgar la calidad de sus políticas, su nivel de desempeño y los resultados obtenidos, se reducirá la asimetría de información y será posible que la sociedad recupere control sobre sus gobiernos" (Vergara, 2008: 35).
\end{abstract}

Por supuesto que este escenario requiere de una sociedad organizada e interesada en los asuntos del quehacer gubernamental, exigiendo transparencia de la gestión pública. Una sociedad informada de lo que sucede en la vida pública de su país podrá expresar sus demandas y gestionar soluciones, ejerciendo influencia y participando en las decisiones públicas.

Cabe mencionar, que los cambios en la nueva relación entre la sociedad y el Estado están transformando el significado de la acción de gobernar. En la medida en que los ciudadanos tienen la capacidad de vigilar el desempeño de los funcionarios públicos e incidir así en los procesos y rutinas de las organizaciones públicas, se está ante un nuevo esquema analítico mejor conocido como la gobernanza.

En este sentido, la transparencia desde la gobernanza puede ser definida como un proceso de interacción entre la sociedad y el Estado, cuya intensidad da cuenta del grado de cohesión política en una red de instituciones, actores e intereses, permite pensar en nuevas prácticas administrativas para dirigir a una sociedad y alcanzar metas colectivas reemplazando al menos parcialmente las estructuras jerárquicas de gobierno por esquemas de gestión más dinámicas y de participación ciudadana más continua (Vergara, 2008: 38).

La transparencia pone al alcance del ciudadano la posibilidad de conocer y vigilar lo que sucede dentro de la estructura administrativa del gobierno, permitiéndole participar como una medida de control externo sobre las acciones de los funcionarios públicos, reduciendo, por ende, las asimetrías de la información. Sin embargo, nuestra cultura burocrática que tiende a comenzar en cada nuevo periodo gubernamental suele responder más a las formalidades exigidas por las reglas que cada órgano gubernamental debe cumplir, que al propósito deliberado de hacer más transparente la administración pública en su conjunto.

\footnotetext{
${ }^{58}$ Artículo 8. Todo servidor público tendrá las siguientes obligaciones: IV. Rendir cuentas sobre el ejercicio de las funciones que tenga conferidas y coadyuvar en la rendición de cuentas de la gestión pública federal, proporcionando la documentación e información que le sea requerida en los términos que establezcan las disposiciones legales Artículo 13. Las sanciones por falta administrativa consistirán en I. Amonestación privada o pública; II. Suspensión del empleo, cargo o comisión por un período no menor de tres días ni mayor a un año; III. Destitución del puesto; IV. Sanción económica, e V. Inhabilitación temporal para desempeñar empleos, cargos o comisiones en el servicio público. Cuando no se cause daños o perjuicios, ni exista beneficio o lucro alguno, se impondrán de seis meses a un año de inhabilitación. Cuando se impongan como consecuencia de un acto u omisión que implique beneficio o lucro, o cause daños o perjuicios, será de un año hasta diez años si el monto de aquéllos no excede de doscientas veces el salario mínimo general mensual vigente en el Distrito Federal, y de diez a veinte años si excede dicho límite. Este último plazo de inhabilitación también será aplicable por conductas graves de los servidores públicos. En el caso de infracciones graves se impondrá, además, la sanción de destitución.

${ }^{59} \mathrm{La}$ asimetría de la información se refiere a la distribución desigual de la información entre los agentes. Éstos tienen un acceso desigual a la información, todos los agentes son afectados, incluido el gobierno, pero sobre todo aquellos que tienen pocas posibilidades de adquirir información.
} 
Así, los servidores públicos son los principales agentes de cambio por sus conocimientos de la cultura burocrática y representan el punto de partida para cualquier análisis de implementación y cambio cultural, así como para conocer los obstáculos al cumplimiento de una norma, sus interpretaciones subjetivas sobre la apertura apropiada de información pueden tener gran significado en el éxito o fracaso de la ley de transparencia y acceso a la información. Por ejemplo, a un año de entrada en vigor la ley de transparencia y acceso a la información, Juliet Gill y Sallie Hughen, en Bureaucratic Compliance with Mexico's New Access to Information Law (2005) realizaron un estudio de las percepciones de los funcionarios mexicanos y la implementación de la LFTAIPG, en el que se observaron los siguientes resultados (citado por Luna, 2008) ${ }^{60}$.

En 2004, cerca de $75 \%$ de los servidores públicos encuestados respondieron que la ley causaría cierta carga adicional para sus oficinas, lo que no significaba que los funcionarios estuvieran dispuestos a evadir la ley. Sobre el conocimiento de la norma, un tercio de los encuestados ese año respondió que no habían recibido capacitación aún. Asimismo, manifestaron que las tendencias hacia el secretismo interferían con el cumplimiento cabal de la ley. En 2004, los encargados de comunicación social afirmaron, en un $96 \%$ que la información gubernamental debía ser siempre o casi siempre pública. Sin embargo, cuando se les hicieron preguntas más específicas, más de dos tercios de los encuestados respondieron que ellos reservarían documentos relacionados con temas como la seguridad nacional (90\%), la seguridad económica (78\%), las investigaciones judiciales en curso (70\%) y los nombres de las víctimas de crímenes (66\%). En contrario, se obtuvieron respuestas a favor del acceso a la información en documentos sobre el proceso de toma de decisiones, incluyendo los borradores (66\%), minutas internas y notas (88\%), los correos electrónicos de los servidores públicos (90\%) y sobre los procesos de responsabilidad administrativas de los funcionarios públicos $(80 \%)$.

Cuando se les preguntó a los encuestados de Gill y Hughen en forma general si ellos pensaban que los servidores públicos cumplirían la ley de transparencia totalmente, parcialmente o para nada, el $52 \%$ respondió que creían que los burócratas cumplirían totalmente con la ley; el restante $48 \%$ respondió que parcialmente, y ningún servidor expresó que la ley no se cumpliría para nada ${ }^{61}$. No obstante, los servidores públicos mostraron miedo a ser acreedores a las sanciones formales de las nuevas leyes de transparencia y responsabilidades administrativas, y las informales que sus jefes pudieran propinar.

Para la autoras, las respuestas obtenidas en la variable de incentivos indican una mezcla de estos o una falta de voluntad políticas en la cúpula burocrática que inhibe el cumplimiento por las razones siguientes: "por falta de conocimiento, negligencia y presiones"; "creo que dependerá de los intereses de cada una de las instituciones y departamentos"; "la administración de la información es subjetiva; siempre recae en la toma de decisiones subjetiva"; "habrá muchos matices en la administración de la información. Esto dará a los servidores públicos espacio para maniobrar y reservar mucha información"; "existen muchos miedos acerca de los deberes de la administración pública". Estas razones dan cuenta de un modo de extralegal y con matices políticos de jerarquía de poderes (Luna, 2008: 7).

El concepto de transparencia transciende el ámbito de la ley de acceso a la información. Un número relevante de servidores públicos no percibe a la ley de transparencia y acceso a la información como uno de los elementos más importantes para un gobierno transparente. Para ellos, la transparencia se logra mejor con el trabajo de la Auditoría Superior de la Federación como órgano fiscalizador de las acciones de los servidores públicos con facultades de sanción por faltas administrativas, así como denunciando actos de corrupción directamente a las autoridades competentes (Luna, 2008: 10-11). En suma, no es de esperarse que la ley de transparencia por sí sola sea un catalizador del cambio institucional.

\footnotetext{
${ }^{60}$ Hicieron una muestra que abarcaba el Ejecutivo Federal, el Ejecutivo Estatal del Distrito Federal, y Delegaciones Políticas, donde en total contactaron a 152 entidades de las cuales respondieron 37, el equivalente a 50 respuestas.

${ }^{61}$ Entre las respuestas directas sobre el cumplimiento parcial de la ley de transparencia y acceso a la información se encuentran: "porque así siempre se ha hecho"; "se van a requerir mucha capacitación y disposición de cada uno de los servidores públicos para que esto sea alcanzado"; "probablemente le pongan a temas 'sustanciales'"; "tenemos que crear una nueva cultura de transparencia para este trabajo. Tomará su tiempo"; "en general el apego a la legalidad en México es muy deficiente"; "debido a la carencia de una cultura ética"; "en algunas oficinas, la burocracia y la pereza sigue reinando"; "por la cultura política del país".
} 
De no haber una motivación de parte de los altos mandos, un compromiso de gobierno adquirido y una conciencia en todos los niveles de llevarlo a cabo, las obligaciones que imponen las leyes pasan a ser percibidas cargas pesadas e innecesarias de trabajo, y si a eso se agregan procedimientos largos y onerosos, puede esperarse un incumplimiento seguro propiciado por la falta de interés de la burocracia en el tema de la transparencia. No obstante, lo cierto es que la ley de transparencia y acceso a la información representa un valor constitucional democrático toda vez que es un derecho fundamental de las personas y mejora la gestión gubernamental, coadyuvando a reducir los costos de asimetría de la información.

\subsection{De la transparencia a la rendición de cuentas}

La ley de transparencia otorga a los ciudadanos el derecho a solicitar y obtener de forma rápida y sencilla cualquier documento e información de las instituciones estatales, vuelve de dominio e interés públicos los asuntos gubernamentales y contribuye a reducir las formas de impunidad y corrupción. Este derecho a conocer y supervisar las acciones de funcionarios y gobernantes, el uso de los recursos públicos y los resultados obtenidos marcó un inicio entre el Estado, las organizaciones no gubernamentales, la sociedad civil, en la cual los ciudadanos pueden desempeñar un papel fiscalizador a través de la exigencia de rendición de cuentas de la actuación de las organizaciones públicas.

En este sentido, la transparencia sin rendición de cuentas es inocua y la rendición de cuentas sin transparencia impide la necesaria contrastación de opiniones y posturas ante evidencias que pueden ser cuestionables (Sosa, 2011: 26). Luego entonces, la estrecha relación entre transparencia y rendición de cuentas parece configurarse en la necesidad de los beneficios que cada una ofrece, para abordar de manera integral los desafíos de la gobernanza contemporánea (Villanueva, 2009).

Aunque hay algunos autores que afirman que el concepto de accountability ${ }^{62}$ es intraducible y ajeno a las tradiciones administrativas nacionales, lo cierto, es que varias de las primeras instituciones creadas en el México colonial fueron instituciones que buscaban asegurar la rendición de cuentas, tales como, los juicios de residencia a los conquistadores (que comenzaron con Hernán Cortés), los tribunales de cuentas instituidos por Felipe III, y los visitadores que, en representación del monarca, viajaban a las colonias para exigir cuentas (Cejudo \& Sour, 2007: 204). Con la independencia, la rendición de cuentas se refirió a justificar las cuentas del dinero público ante el legislativo. Empero, por la inestabilidad y la discontinuidad legal, la efectividad de los mecanismos legales diseñados para la rendición de cuentas estuvo severamente limitada. A pesar de ello, el diseño basado en una Contaduría Mayor vinculada al Congreso sería la que impondría y que, con cambios mínimos, funcionaría hasta casi finales del siglo XX (Cejudo \& Sour, 2007: 204-205). Sin embargo, cabe mencionar que tanto en el periodo colonial como en el de independencia la rendición de cuentas era de carácter vertical, jerárquica, para el control y fiscalización de las élites que conformaban el poder, el cual no contemplaba a los ciudadanos.

El proceso de democratización que inició en la década de los sesenta se volvió irreversible por diversas movilizaciones sociales y presiones políticas, que dieron lugar a la construcción de instituciones de transparencia y rendición de cuentas. De acuerdo con la definición de Schedler, la rendición de cuentas se puede desagregar en dos dimensiones básicas: a) la obligación de los políticos y los funcionarios de informar sobre sus decisiones y justificar sus actos (answerability) (Schedler, 2011: $80)^{63}$, y b) la capacidad para imponer sanciones negativas a los funcionarios públicos y representantes que violen ciertas normas de conducta (enforcement) Schedler, 2011: 83) ${ }^{64}$.

\footnotetext{
${ }^{62}$ Como otros conceptos políticos en inglés, se trata de un término que no tiene un equivalente preciso en español, ni una traducción estable. A veces se traduce como control, como fiscalización y otras como responsabilidad. Sin embargo, la traducción más común y la más cercana es la rendición de cuentas. Tenemos que el significado de la palabra anglosajona accountability, en inglés significa "el estado de ser sujeto a la obligación de reportar, explicar o justificar algo; [...] ser responsable de algo (liable) [...] ser sujeto y responsable para dar cuentas y responder a preguntar (answerable). Accountability se deriva de account, que significa "descripción oral o escrita de eventos o situaciones particulares [...] explicación de una conducta a un superior [...] razones, sustentos [...] balance de ingresos y gastos [...] registros financieros [...]". The Random House Dictionary of the English Languaje.

${ }^{63}$ Answerability, en español se intenta dar significado con el neologismo respondabilidad y se define como la capacidad de asegurar que los funcionarios públicos respondan por sus acciones.

${ }^{64}$ Enforcement, es otro término inglés que no tiene equivalente preciso en español y que describe un conjunto de actividades orientadas hacia la observación de la ley, a través de la imposición de sanciones. En el mismo sentido que Schedler, March y Olsen consideran que las bases de la rendición de cuentas son la información y las sanciones.
} 
Para Schedler, answerability implica el derecho ciudadano de recibir información y obligación de los funcionarios de proveerla, asimismo, implica contar con los mecanismos para supervisar los actos de gobierno. Por su parte, enforcement implica hacer cumplir la ley y sancionar a los gobernantes, representantes y funcionarios que incumplen con sus obligaciones a fin de que paguen las consecuencias de sus actos y se active el mecanismo de control preventivo que disuada a potenciales infractores de la ley.

La suma de obligación de responder con la posibilidad de aplicar sanciones refleja una buena parte del pensamiento del nuevo institucionalismo respecto de las condiciones para crear instituciones efectivas (North, 1995). Según esta corriente, para que las reglas sean efectivas deben ir acompañadas de mecanismos de supervisión que prevengan que su eventual violación pase inadvertida (función informativa de la rendición de cuentas). Pero también debe incluir mecanismos de aplicación que brinden la posibilidad y los incentivos para que los actos ilegales sean sujetos de castigo (la dimensión punitiva de la rendición de cuentas).

La rendición de cuentas implica así tres mecanismos diferentes, pero interrelacionados de control de poder: a) la obligación de ejercerlo de manera transparente; b) la obligación de justificar los actos derivados de su ejercicio, y c) sujetar a quienes lo ejercen a una gama de posibles sanciones (Ayllón \& Ruiz, 2007: 107). Respecto al criterio de rendición de cuentas los servidores públicos pueden ser sujetos de rendición de cuentas de diversas maneras como se establece en la clasificación de Ayllón y Ruiz (2007).

Tabla 4.3 Criterios de la rendición de cuentas

\begin{tabular}{|l|l|}
\hline \multicolumn{1}{|c|}{ Rendición de cuentas } & \multicolumn{1}{|c|}{ Criterio } \\
\hline Política & $\begin{array}{l}\text { Evalúa tanto las políticas sustantivas y sus procesos de creación como las } \\
\text { cualidades personales de los actores políticos. }\end{array}$ \\
\hline Administrativa & $\begin{array}{l}\text { Revisa que los actos burocráticos sean expeditos y sus procedimientos } \\
\text { correctos. }\end{array}$ \\
\hline Profesional & $\begin{array}{l}\text { Se refiere a los criterios éticos de la conducta, tales como el profesionalismo de } \\
\text { los jueces, abogados o periodistas. }\end{array}$ \\
\hline Presupuestaria & $\begin{array}{l}\text { Sujeta el uso de los recursos públicos por parte de los servidores públicos a } \\
\text { reglas de eficiencia, austeridad o propiedad. }\end{array}$ \\
\hline Legal & $\begin{array}{l}\text { Analiza la observancia de las reglas jurídicas y evalúa los actos y decisiones } \\
\text { sean congruentes con ellas. }\end{array}$ \\
\hline
\end{tabular}

Fuente: López \& Ruiz (2007: 109)

En México, a partir de la creación de la Auditoría Superior de la Federación (ASF) en sustitución de la Contaduría Mayor de Hacienda, hecho que ocurrió con las reformas constitucionales de 1999, que otorgaron a la ASF, entre otras atribuciones: autonomía técnica de gestión en su labor revisora; mayores facultades especialmente para el fincamiento de responsabilidades administrativas, y una coordinación más eficiente con el Congreso por medio de la Comisión de Vigilancia.

En este sentido, la fiscalización de la gestión pública iba acompañada de manera inexorablemente de la rendición de cuentas. De tal suerte, que las auditorías públicas sobre el desempeño gubernamental se incrementaron gradualmente de 2001 a 2008. En 2001, la ASF practicó 30 auditorías al grado de cumplimiento de los objetivos a los programas gubernamentales. En el ejercicio 2008 practicó 228. Las auditorías del desempeño representaron el $8.5 \%$ en 2001, en tanto que en 2008 representaron 23.1\% (Ramírez, 2010: 21-30).

Respecto de las atribuciones de responsabilidades y sanciones el número de observaciones emitidas por la ASF se incrementó en un factor de 2.9 veces entre 2002 y 2008 . Los datos disponibles indican que pasó de 5 acciones sancionatorias en 2002 a 1,111 acciones en 2008 (véase tabla 4.4). Sin embargo, por denuncia penal, el resultado se desmorona, puesto que las acciones de fincamiento de responsabilidad, el número de denuncias y querellas no rebasó el número de 10. Estos datos revelan de manera concluyente la baja la calidad del enforcement y, por lo tanto, de la rendición de cuentas existente en México (Ramírez, 2010: 30-31). 
Tabla 4.4 Acción Fiscalizadora y Rendición de Cuentas, Auditoría Superior de la Federación 20022008

\begin{tabular}{|l|r|r|r|r|r|r|r|}
\hline Concepto & 2002 & 2003 & 2004 & 2005 & 2006 & 2007 & 2008 \\
\hline Auditorías & 336 & 338 & 424 & 627 & 754 & 962 & 987 \\
\hline Observaciones & 2584 & 2638 & 3424 & 4505 & 7182 & 9557 & 7745 \\
Acciones promovidas & 3410 & 3437 & 4013 & 5182 & 8131 & 10873 & 8751 \\
\hline Administrativas sancionatorias & 5 & 31 & 342 & 431 & 555 & 1632 & 1111 \\
\hline Denuncias o querellas & - & 1 & 3 & 2 & 4 & 2 & 10 \\
\hline
\end{tabular}

*Datos de la ASF. Informes del Resultado de la Fiscalización Superior de la Cuenta Pública 2002, 2003, 2004, 2005, 2006, 2007 y 2008.

Fuente: Ramírez, J. L. J. (2010: 31)

Para la mayoría de los autores la capacidad para castigar forma una parte integral de la rendición de cuentas. Quienes piensan en la centralidad de las sanciones insisten que la exigencia de cuentas es un asunto que compete a dos actores: el principal y el agente, los cuales se sitúan en un eje asimétrico de autoridad formal.

\subsubsection{La rendición de cuentas en el modelo principal-agente}

La teoría de la agencia formulada por Michael Jensen y William Meckling en "Theory of the Firm: Managerial Behaviour, Agency Cost and Ownership Structure, (1976), ofrece un modelo explicativo de las relaciones de un contrato de agencia en el que un sujeto (Principal) delega parte de su autoridad o la gestión de una actividad a otra persona (Agente) ${ }^{65}$. En el ámbito de la administración pública y en el de la ciencia política el modelo principal-agente se utiliza para estudiar el espectro de la influencia burocrática. En estas áreas el principal tiende a estar personificado por la legislatura (y políticos en general), mientras que el agente es representado por la burocracia (Gault, 2004: 13).

La teoría del principal-agente tiene como objetivo mostrar la relación entre estos dos actores a partir del juego de intereses que se conjugan en las asimetrías de información dado que el agente tiene sus propios intereses y que el principal tiene escasa capacidad para monitorear las acciones del agente y para ejercer su poder y disciplinarlo, si fuera preciso (North, 1995). De tal suerte, que los objetivos del principal dependen de las acciones que realice el agente, las cuales se ven afectadas por la información preferente que este último posea.

El problema de la agencia surge de la asimetría de la información y el conflicto de intereses. Es decir, si el principal conociese exactamente todas las acciones del agente (o toda la información que posee), éste último no actuaría a favor suyo y en contra de los intereses del primero. Por tanto, no habría problemas de agencia si fuese posible realizar un seguimiento de las acciones del agente a un costo razonable. Pero esto, obviamente es imposible en muchas ocasiones debido a que el agente tiene acceso a una información que se encuentra fuera del alcance del principal y le induce a actuar en un sentido que pasará inadvertido a este último.

En la información asimétrica el agente siempre tiene más información que su principal del negocio, oficio o profesión que desempeña. A esta situación se le denomina problema de información oculta (hidden information) o selección adversa (adverse selection). Por ejemplo, el Congreso mexicano atribuye al Ejecutivo la autoridad para ejercer el presupuesto anual de egresos, pero una vez que la delegación se ha realizado y el gasto se ha ejercido, el Ejecutivo cuenta con los detalles y las minucias de ejercicio de ese presupuesto, mientras que el Congreso en su carácter de principal sólo dispone de información parcial y limitada (Ugalde, 2002a: 19).

En cuanto al conflicto de intereses, la teoría de la agencia constata que en general existe una falta de concordancia entre el interés del principal y el agente, debido a que ambas partes se disputan la optimización de sus propios intereses en torno a la distribución de un recurso (dinero, presupuesto, etc.) o al cumplimiento de un servicio.

\footnotetext{
${ }^{65}$ La teoría principal-agente fue utilizada originalmente para estudiar la relación entre el dueño de una empresa (principal) y sus administradores (agente), cuando aquel cede a éste el control de la misma.
} 
Es decir, el agente tiene incentivos para desviarse del mandato del principal en beneficio propio debido a las características intrínsecas al acto de delegar, pues cuentan con intereses personales que no siempre coinciden con los de su superior jerárquico, en estas circunstancias se habla de riesgo moral (moral hazard).

En la administración pública este conflicto se interpreta de la manera siguiente:

\begin{abstract}
"El agente (burocracia) carece de la autoridad formal; sin embargo, tiene conocimientos estratégicos, elemento que le permite diseñar el conjunto de alternativas. Por su parte, el principal (políticos) tiene autoridad formal pero sus conocimientos son escasos. Su único papel es el de hacer la elección final. Dado este contexto, las burocracias o el agente tienen preferencias programáticas y su cometido prioritario es el de manipular la agenda del principal para aumentar la probabilidad de que se seleccione su programa preferido. Por su parte, los políticos o el principal han de intentar que la selección del programa a implementar sea el que garantice el mejor beneficio para su status político. Visto lo anterior, el conflicto de intereses puede visualizarse como una consecuencia de la relación existente entre la autoridad formal que emana de la jerarquía institucionalizada y la autoridad real, determinada por la estructura de información" (Arellano, Alamilla \& Campos, 2004: 14).
\end{abstract}

Con la lógica del principal-agente se asiste de alguna u otra manera a la institucionalización racional del interés particular y el engaño, en la que ambos actores racionalmente pueden mentir o actuar de manera racional con "dolo" (hidden information, adverse selection o moral hazard), lo cual en la esfera de lo público tiene importantes consecuencias, como resultados no óptimos para la sociedad producto de actos racionales individuales o colectivos, que en su combinación generan ineficiencia.

Cuando se alude a la burocracia pública se está en presencia de una particular manera de afrontar el dilema organizativo de la administración pública: ordenar el interés propio de los individuos que componen la burocracia y el sistema político, de tal manera que sus acciones individuales no se reduzcan sólo a un entramado de costos de transacción, dónde el cálculo de beneficios y el manejo oportunista de información termina englobando de manera prácticamente general la racionalidad política de los actores de una sociedad particular; sino que sus acciones individuales generen eficiencia social como efecto (si no como intención) a través del desempeño y los resultados. En la medida que se crean sistemas (empoderamiento del ciudadano) que reducen la capacidad de la burocracia para aprovechase de su ventaja de información, lo mismo puede decirse de la relación entre políticos y sociedad. En esta conciencia de la sociedad sobre la vigilancia y control sobre el gobierno y sus instituciones, se debe entender la relación compleja sociedad-políticos-burocracia.

Ante los intereses divergentes e información asimétrica algunos autores proponen para superar estos problemas, contar con sistemas de rendición de cuentas que, por un lado, obliguen al agente a reportar detalladamente al principal de sus actos y resultados, y, por otro lado, doten al principal de mecanismos para monitorear el desempeño del agente (Ugalde, 2002a: 21).

En este sentido, la definición de rendición de cuentas siguiendo a Ugalde (2002b: 9) es la obligación permanente de los mandatarios o agentes para informar a sus mandantes o principales de los actos que llevan a cabo como resultado de una delegación de autoridad que se realiza mediante un contrato formal o informal y que implica sanciones en caso de incumplimiento. Ahora bien, la rendición de cuentas establece la distinción entre rendición de cuentas vertical y rendición de cuentas horizontal, propuesta por Guillermo O'Donnell, que se analizarán en los siguientes subapartados.

\title{
4.2.2 Rendición de cuentas vertical
}

La rendición de cuentas vertical se refiere a los mecanismos que permiten a los ciudadanos dar a conocer sus demandas sociales a los funcionarios públicos (electos o no) y denunciar a dichos funcionarios por actos ilegales que pudieran cometer (O`Donnell, 1998: 113). Esta rendición describe una relativa subordinación, que se refiere a un actor "superior" que obliga a un "inferior" a rendirle cuentas, o viceversa. El concepto es bidireccional y puede ser "de arriba hacia abajo" o bien "de abajo hacia arriba". Un ejemplo "de arriba hacia abajo" es la burocrática, en la cual los servidores públicos de alto rango tratan de controlar a los funcionarios subordinados. En cambio, un ejemplo "de abajo hacia arriba", se da en la democracia representativa en la que los ciudadanos juzgan el desempeño de sus representantes a través de las elecciones. 
La rendición de cuentas vertical tiene una serie de limitaciones pues las elecciones sólo afectan a quienes poseen cargos electivos y no al conjunto de la burocracia estatal; el acto de elección es siempre complejo ya que la falta de información de la plataforma de los partidos políticos y, en general, por el desapego entre ciudadanos y sus representantes, no es fácil considerarlas premio o castigo ni puede derivarse de ellas una clara idea de las preferencias ciudadanas en materia de política pública. Además, el voto puede ser objeto de prácticas clientelistas. Por su parte, la acción de los medios de comunicación es importante pero relativa, dado el control que sobre ellos ejerce la clase política. Ahora bien, el gobierno puede ignorar estas presiones dado que legalmente no está obligado a atenderlas. Por ejemplo, el problema de la rendición de cuentas vertical a la luz del sufragio electoral encuentra parte de su respuesta. El ciudadano elige a un gobierno para que lo represente y opere a favor de su bienestar, sin anteponer sus intereses individuales a los de la colectividad. Si el gobierno actúa irresponsablemente, de manera discrecional, ocultando las acciones y la información en la que se desarrolla su gestión, el elector tiene la facultad de sufragar por otro partido para gobernar en el siguiente periodo. Sin embargo, la actuación de los ciudadanos es más bien marginal, porque únicamente puede sancionar a los políticos cuando acuden a las urnas. La otra vertiente de la rendición de cuentas vertical "de abajo hacia arriba" requiere la participación de agentes sociales activos ${ }^{66}$ con conocimientos técnicos para evaluar el desempeño de la agencia y con la capacidad para influir en otras agencias horizontales o en los representantes políticos. A este mecanismo de rendición de cuentas, Enrique Peruzzotti \& Catarina Smulovitz (2002), lo llaman rendición de cuentas social (societal accountability), la cual se define como:

\begin{abstract}
"[...] un mecanismo de control vertical, no electoral, de las autoridades políticas basado en las acciones de un amplio espectro de asociaciones y movimientos sociales, así como también en acciones mediáticas [...] [la rendición de cuentas] social puede canalizarse tanto por vías institucionales como no institucionales [...] [así] a diferencia de los mecanismos electorales, la [rendición de cuentas] social puede ejercerse entre elecciones y no depende de calendarios fijos. Se 'activa a pedido' y puede dirigirse hacia el control de temas, políticas o funcionarios particulares. Tal como sucede con los horizontales, los mecanismos sociales pueden supervisar la legalidad de los procedimientos seguidos por políticos y funcionarios públicos" (Peruzzotti \& Smulovitz, 2002: 10).
\end{abstract}

Se trata de un control indirecto de los actores e instituciones políticas, basado en la vigilancia, el estudio, la protesta, el escándalo, la denuncia; que utilizan los movimientos sociales y asociaciones diversas (Rivera, 2009) ${ }^{67}$, desde organizaciones no gubernamentales hasta grupos empresariales para imponer "costos reputacionales" a los políticos que se corrompen o abusan de su poder.

\footnotetext{
${ }^{66}$ En la década de los noventas y con la alternancia política en el 2000, organizaciones de la sociedad civil han intervenido en el espacio público en la vigilancia del ejercicio de gobierno, la defensa de los derechos humanos, la seguridad pública, la pobreza, derechos de las mujeres, políticas de salud, entre otros. Organizaciones de la Sociedad Civil (OSCs), como Fundar, Centro de Servicios Municipales Heriberto Jara (CESEM), Alianza Cívica, Incide Social; Equipo Pueblo (DECA, Equipo Pueblo), Centro Nacional de Comunicación Social (CENCOS),entre otras, han desarrollado modelos de evaluación de un campo de la política pública o nivel de gobierno. Es el trabajo de Fundar en materia de presupuestos públicos y en el ámbito de la transparencia del Poder Legislativo, asimismo, el CESEM ha denunciado la falta de transparencia y de acceso a la información en diversos municipios del país. Incide Social desarrolla varios proyectos, pero su Observatorio de Derechos Humanos y Política Social es un ejemplo de contraloría social desde el ámbito civil. Véase Olvera (2009: 27-37). En los últimos diez años, el crecimiento promedio del universo asociativo pasó de 180 organizaciones por año -hasta el año 2002a las 405 en el 2002, a las 1216 en el 2004, es decir, dos años después de la promulgación de la Ley Federal de Transparencia y Acceso a la Información Pública y a las 1814 en el 2008 (lo cual coincide también con la reforma al artículo $6^{\circ}$ Constitucional de 2007, sobre el derecho a la información de toda persona). El directorio de Donatarias Autorizadas del Servicio de Administración Tributaria registra 5,300 organizaciones. El Registro Federal de OSCs cuenta con 15 mil organizaciones. Véase OCDE (2011).

${ }^{67}$ Cabe mencionar que, en muchos casos, las acciones civiles han resultado poco efectivas en términos de impulsar cambios en las políticas públicas. La falta de articulación entre el gobierno y sociedad además de la ausencia de homogeneidad entre las normas e instituciones en los tres niveles de gobierno, contribuyen a una creciente complejidad de acciones gubernamentales lo cual hace difícil la participación ciudadana en los procesos de política pública. Si a ello se suma la cantidad de trámites y recursos que se requieren para crear una organización social así como el marco fiscal vigente para las aportaciones voluntarias, no favorecen la vitalidad del asociacionismo. Por ejemplo, la Ley sobre el Impuesto sobre la Renta es la que define qué organizaciones pueden ser donatarias autorizadas, es decir, organizaciones susceptibles de recibir donativos con beneficios fiscales para los donantes, no contempla explícitamente la posibilidad de que una organización sin fines de lucro pueda especializarse en exigencia de rendición de cuentas. Por el contrario, exige que se abstengan en actividades destinadas a influir en la legislación (Artículo 97, fracción II de la Ley del Impuesto sobre la Renta) estableciendo como excepción a esta disposición la publicación de análisis o de investigaciones a pedido sin que sea vinculante en la legislación. Sólo algunas organizaciones como Alternativas y Capacidades, Incide Social, Dejemos de Hacernos Pendejos, Fundar, Centro de Análisis e Investigación, Fundación Este País, Género y Desarrollo, Acción Ciudadana para la Justicia y la Democracia Ririki-Intervención Social, participan con la Comisión de Hacienda de la Cámara de Diputados para mejorar el marco normativo y fiscal de las organizaciones sociales. (Rivera, 2009: 27-37).
} 


\subsubsection{Rendición de cuentas horizontal}

Las limitantes de la rendición de cuentas vertical, siguiendo a O’Donnell, activan los mecanismos de la rendición de cuentas horizontal que se refiere a aquellas acciones orientadas a controlar o sancionar acciones u omisiones por parte de agentes o agencias de Estado que puedan ser calificadas como ilegales. Según esta perspectiva, los mecanismos horizontales se activan cuando hay una intromisión ilegal por parte de una agencia estatal con respecto a la autoridad apropiada de otra o en casos que involucran la corrupción de funcionarios públicos. De ahí, que O’Donnell restringe el concepto de accountability horizontal a ese conjunto de controles e intercambios intraestatales que están orientados hacia la imposición de la sanción legal.

En el caso de México, lo anterior se explica porque si bien las primeras señales de apertura política fueron las reformas electorales iniciadas en la década de los setenta y los triunfos opositores de finales de los ochenta, los efectos de la competencia electoral en la rendición de cuentas no fueron significativos sino hasta que los partidos de oposición tuvieron presencia suficiente en el Congreso para incidir en la labor de fiscalización y vigilancia del Poder Ejecutivo (Cejudo \& Sour, 2007: 208).

Estos primeros avances en la dimensión horizontal de la rendición de cuentas significaron un límite importante a las prácticas autoritarias en el sistema político mexicano. Sin embargo, como explica Erika Moreno, Brian Crisp \& Matthew Shugart, en "The Accountability Deficit in Latin America" (2003), las instituciones horizontales sólo pueden funcionar efectivamente como complemento de los mecanismos verticales, nunca como substituto (Moreno, Crisp \& Shugart, 2003: 79-131). De poco servía que la constitución obligara al gobierno federal a enviar sus cuentas para que el legislativo las revisara, o que el presidente cumpliera con el rito de informar cada año sobre "el estado que guarda la nación", si los incentivos políticos -cuando no las normas legales- prevenían de cualquier posibilidad de exigir más información de la que el Ejecutivo estaba dispuesto a ofrecer y descartaban la posibilidad de cualquier sanción real (Cejudo \& Sour, 2007: 208).

Es a partir de 1997, con la creación del sistema electrónico de compras gubernamentales, mejor conocido como Compranet, que todas las dependencias y entidades tuvieron en este sistema innovador la información sobre sus procedimientos de licitación pública. Así, a finales del sexenio una parte importante de las adquisiciones del gobierno federal y de varios gobiernos estatales estaban automatizados en Compranet, lo cual no sólo incrementó la transparencia, sino que también redujo los costos de las adquisiciones gubernamentales e incrementó el número de proveedores (Cejudo \& Sour, 2007: 210$)^{68}$.

En 1999, la creación de la Auditoría Superior de la Federación a iniciativa presidencial en términos de la rendición de cuentas horizontal se encarga de vigilar el ejercicio de los recursos públicos. Después, en diciembre de 2000 se aprobó la ley reglamentaria (Ley de Fiscalización Superior de la Federación), con lo cual entraba en operación el mecanismo de rendición de cuentas para controlar la legalidad y el buen uso del dinero público en el quehacer gubernamental.

Finalmente, con el triunfo de la oposición en las elecciones de 2000, se complementan los mecanismos horizontales de rendición de cuentas. Así, en 2002 se emite la nueva Ley Federal de Responsabilidades Administrativas de los Servidores Públicos, la cual integra disposiciones para prevenir conductas ilícitas y establece normas para desarrollar y aplicar valores éticos en la función pública.

\footnotetext{
${ }^{68}$ En su segunda versión, Compranet 3.0 tenía capacidad para el registro de las entidades y dependencias, siempre y cuando éstas contaran con Internet y un buen equipo de cómputo. Igualmente, los proveedores que querían registrarse debían instalar módulos especiales en sus equipos. La participación en los primeros años era reducida, únicamente alrededor de 12 mil empresas utilizaban la herramienta. En 2010, la participación de las empresas ha aumentado, se estima que 41 mil proveedores y contratistas están registrados en el sistema. En junio de 2010, se liberó una versión más actualizada del sistema Compranet 5.0, con la cual, la plataforma dejó de ser sólo un sistema transaccional. En esta nueva versión, la herramienta permite el suministro de información, la descarga de documentación sobre las convocatorias, la liberación automática de anuncios, y la gestación de la comunicación entre proveedores y autoridades. Véase Prieto, Stankiewicsz \& Cuatlayol (2011: 57).
} 
La aprobación y publicación de la Ley de Transparencia y Acceso a la Información Pública Gubernamental y con ello la creación del Instituto Federal de Acceso a la Información Pública (IFAI); así como, la publicación de la Ley de Servicio Profesional de Carrera de la Administración Pública Federal, son quizá, los cambios institucionales más importantes del sexenio 2000-2006, enfocados en el control de la administración pública como mecanismos de rendición de cuentas horizontal.

No obstante, la rendición de cuentas horizontal enfrenta problemas que tienen que ver con: la falta de transparencia en su funcionamiento; la falta de legitimidad de las agencias de control frente a la ciudadanía, que son meras extensiones administrativas del gobierno; el carácter limitado de las sanciones, que son impuestas a individuos sin atender a instituciones; la incapacidad de las agencias de control para conectarse con la ciudadanía. A pesar de ello, debe reconocer que en este nivel puede haber aplicación de la ley y, por tanto, resultados tangibles.

Considerando los resultados de negativas de los organismos a proporcionar información a los ciudadanos, en los que las resoluciones del IFAI como dependencia de rendición de cuentas horizontal, a favor de los ciudadanos fue del 17.5 por cientos de los casos (2003-2008) y, que el organismo de aplicar las sanciones por el incumplimiento de mandatos del instituto, la Secretaría de la Función Pública, es también una de las secretarías federales que más se resiste a responder las solicitudes de información de los ciudadanos, así como una de las más renuentes acatar los mandatos del IFAI.

La rendición de cuentas horizontal encuentra en los propios muros de las dependencias gubernamentales el mayor número de quejas por no cumplir las resoluciones del instituto, como se observa en la tabla siguiente.

Tabla 4.5 Los diez organismos con mayor número de quejas por no cumplir resoluciones del IFAI que les ordenaban divulgar información 2003-2008*

\begin{tabular}{|l|c|c|c|}
\hline \multicolumn{1}{|c|}{ Dependencia } & $\begin{array}{c}\text { Total de } \\
\text { quejas } \\
\text { acumuladas }\end{array}$ & $\begin{array}{c}\text { Total de } \\
\text { resoluciones } \\
\text { del IFAI con } \\
\text { instrucciones }\end{array}$ & $\begin{array}{c}\text { Porcentaje del total de } \\
\text { resoluciones del IFAI que } \\
\text { involucran instrucciones a } \\
\text { una dependencia y que dan } \\
\text { por resultado una queja } \\
\mathbf{2 0 0 4 - 2 0 0 8}\end{array}$ \\
\hline Secretaría de Educación Pública & 46 & 357 & 12.9 \\
\hline Procuraduría General de la República & 34 & 249 & 13.7 \\
\hline IMSS & 30 & 420 & 7.1 \\
\hline Secretaría de la Función Pública & 29 & 251 & 11.6 \\
\hline Secretaría de Relaciones Exteriores & 24 & 185 & 9.4 \\
\hline Secretaría de Hacienda y Crédito Público & 22 & 233 & 15.6 \\
\hline Oficina de la Presidencia & 19 & 227 & 7.8 \\
\hline Pemex, Exploración y Producción & 19 & 122 & 13.6 \\
\hline Secretaría de Comunicaciones y & 18 & 232 & \\
\hline Transportes & 17 & 125 & \\
\hline Comisión Nacional del Agua & & & \\
\hline
\end{tabular}

*Para 2003 no se registraron quejas por incumplimiento.

Fuente: Solicitudes de información números 0673800076508 y 0673800064109 . Fox, Haight \& Palmer (2011: 41)

Las dependencias que tienen la proporción más alta de quejas por hacer caso omiso de las resoluciones del IFAI incluyen Pemex, la SEP, la PGR y, de manera destacada la Secretaría de la Función Pública. Cuando se toma asimismo las escasas respuestas satisfactorias de esta última institución a las solicitudes de información (34.2\%), así como la alta tasa de quejas por negativas $(92.3 \%)$ proporcionar información, surge un patrón de comportamiento institucional.

Un ejemplo, que involucra diferentes tipos de rendición de cuentas es el caso de Provida: 
En el año 2002, la Cámara de Diputados aprobó el incremento de 600 millones de pesos para programas nacionales de salud. Entre las modificaciones ocurridas tras este incremento, destacó la cancelación de un fondo de alrededor de 30 millones de pesos para el combate del VIH-SIDA, que se asignó, en cambio, a la organización Comité Nacional Provida. A partir de ese mismo año, una serie de organizaciones de la sociedad civil, entre las que destacó Fundar, Centro de Análisis e Investigación A.C., realizaron una revisión de la forma en que Provida había utilizado los recursos otorgados. Durante el proceso encontraron serias irregularidades, como el pago a organizaciones ficticias, importantes gastos no vinculados a programas de salud y excesivos gastos de publicidad. Las organizaciones que dieron seguimiento al caso Provida solicitaron reunirse con el encargado de la Secretaría de Salud en turno, pero esta solicitud no prosperó. Se decidió entonces emprender una campaña de medios nacionales para llamar la atención sobre el caso. Esta acción la llevaron a cabo en alianza con numerosas organizaciones civiles que presentaron una petición al gobierno para investigar oficialmente el caso. Lo anterior, motivó la intervención de la Secretaría de la Función Pública con sanciones de carácter monetario. Adicionalmente, Jorge Serrano Limón, quién estaba a cargo de Provida fue inhabilitado por 15 años de cualquier cargo público. Ésta fue la primera vez que la Ley Federal de Responsabilidades Administrativas de los Servidores Públicos, se aplicó a personas que no son servidores públicos, pero que son responsables del uso de fondos públicos. En agosto de 2010, un juez en materia civil ordenó devolver la totalidad de los fondos otorgados a dicha organización, pagar la sanción impuesta y ser excluida de la recepción de fondos públicos por 15 años. La suma total para devolver a los fondos públicos ascendió a 14 millones 188 mil pesos, más intereses acumulados, lo que suma un total de aproximadamente 22 millones de pesos (Gozzo, 2006, Fuentes, 2010, Velasco, 2011: 32).

A este caso de Provida de rendición de cuentas se suman otros tales como Toallagate (2001), Escalera Náutica o Proyecto Mar de Cortés (2001), Pemexgate (2002), Fundación Vamos México (2001), desvío de fondos de Lotería Nacional (2001), Fondo de Desastres Naturales (FONDEN) (2002), Mega Biblioteca José Vasconcelos (2003), ropas de la pareja presidencial (2003), Emprendedores con Discapacidad (ECODIS) (2005), Ley Televisa (2006), entre otros.

Como se puede observar, la rendición de cuentas sigue siendo opaca. Esto en términos de gobernanza se explica en ocasiones en una rendición de cuentas caracterizada en algunos casos por una gobernanza débil, en la que predominan las instituciones públicas sin sanciones efectivas, o bien en una gobernanza limitada, en la que puede existir una participación social ampliada y aplicación selectiva de sanciones.

\subsection{La institucionalización del servicio profesional de carrera}

La implementación del servicio profesional de carrera en la Administración Pública Federal responde a la necesidad de establecer la profesionalización de la función pública incorporando nuevas prácticas de gestión tales como sistemas de evaluación del desempeño poniendo énfasis en los resultados, mecanismos de control y evaluación del sistema de gestión de recursos humanos, mejor capacidad técnica de gestión mediante nuevas tecnologías de la información, entre otros. Todo ello, para mejorar la eficiencia del funcionamiento de las organizaciones públicas.

Desde el enfoque del nuevo institucionalismo la transformación de la propia administración pública como de la gestión de personal, incorpora al análisis cómo determinados valores o procesos se refuerzan mutuamente y se sostienen en normas formales e informales, creando un entramado que difícilmente puede modificarse tan sólo parcialmente algunos de sus ingredientes. En esta perspectiva, el diseño del servicio profesional de carrera implica no sólo la aplicación del concepto normativo sino también aquellos aspectos no tangibles, referidos a la cultura, a los valores y a las normas y procesos no formalizados pero que contribuyen a explicar el funcionamiento de las administraciones públicas.

Así, "el tipo de actividades desarrolladas en el ámbito de la gestión de los recursos humanos en las administraciones públicas se ve limitado por la normativa explícita, pero también de los valores y reglas informales que establece qué es aquello que puede modificarse y hasta qué punto puede 'legítimamente' alterarse" (Salvador, 2010: 21). De esta manera, la institución tiende a ofrecer resistencia a determinadas acciones en materia de gestión de personal.

Las resistencias de los servidores públicos a la evaluación del desempeño que forma parte del sistema del servicio profesional se manifiestan principalmente con la esquizofrenia generada por la falta de un cambio en la cultura organizacional de las rutinas, hábitos y costumbres laborales de las personas. Precisamente en las normas informales es donde se reflejan más claramente algunos de los valores que caracterizan el sistema de gestión de los recursos humanos. Estos valores son uno de los componentes del sistema más importantes en cuanto a institución. 
La conformación de una cultura organizativa resulta ser un elemento clave para anticipar el encaje, tanto de la propia iniciativa de cambio, como de la estrategia seguida para su impulso (Salvador, 2010: 22).

En su dimensión de institución, la interrelación de normas, valores, reglas, rutinas, procesos y estructuras que se dan en el sistema de gestión de personal establece los parámetros para el desarrollo de la actividad de los distintos agentes implicados. Así, el proceso de institucionalización en el diseño del servicio profesional de carrera cobra vida a través de la ley y demás normas, como por el cambio en las estructuras, procedimientos, valores, reglamentaciones, rutinas y hábitos de las personas.

Con la institucionalización de la profesionalización, el servicio de carrera pretende dotar de técnicas requeridas para obtener los fines de las dependencias. Para Alvarado (2007), ello implica un cambio en la gestión pública en aspectos como:

1. Los procesos de profesionalización de los servidores públicos en su formación y actualización profesional.

2. Los programas institucionales que representan modificar los derechos laborales de los servidores públicos, que implican también modificar las formas de reclutamiento, selección y permanencia en las instituciones, con base a la meritocracia.

3. Mayor legitimidad de las instituciones de gobierno ante la población usuaria, pues la profesionalización pretende cambiar su imagen burocrática.

El servicio profesional de carrera se organizó en siete subsistemas que respondía al siguiente diseño institucional, como se observa en la tabla 4.6.

Tabla 4.6 Subsistemas del Servicio Profesional Carrera

\begin{tabular}{|l|l|}
\hline \multicolumn{1}{|c|}{ Subsistema } & \multicolumn{1}{c|}{ Función } \\
\hline Planeación de Recursos Humanos & $\begin{array}{l}\text { Identificar necesidades de contratación con las } \\
\text { dependencias y órganos desconcentrados. }\end{array}$ \\
\hline Ingreso & $\begin{array}{l}\text { Regular los procesos de reclutamiento y de selección } \\
\text { de candidatos, así como los requisitos para incorporar } \\
\text { aspirantes al sistema. }\end{array}$ \\
\hline Desarrollo Profesional & $\begin{array}{l}\text { El funcionario podría trazar su plan de carrera } \\
\text { incluyendo movilidad y acceso a la administración } \\
\text { pública. }\end{array}$ \\
\hline Evaluación del Desempeño & $\begin{array}{l}\text { Desarrollar herramientas que permitieran la } \\
\text { profesionalización de los funcionarios. }\end{array}$ \\
\hline Separación & $\begin{array}{l}\text { Establecer mecanismos de medición y evaluación de } \\
\text { los servidores públicos de carrera para ascensos, } \\
\text { promociones, premios y estímulos. }\end{array}$ \\
\hline Control y Evaluación & $\begin{array}{l}\text { Establecer mecanismos de separación del cargo con } \\
\text { garantía de respeto y transparencia. }\end{array}$ \\
\hline
\end{tabular}

Fuente: Elaboración propia con base al sistema del Servicio Profesional de Carrera, 2004.

Es importante señalar que autores como David Arellano pusieron el acento en los riesgos de un servicio civil, sobre todo a los referentes a su instrumentación. Especialmente en el riesgo de que la Secretaría de la Función Pública se convirtiera en la práctica en una entidad centralizadora, sobrerreguladora y, peor aún operadora, cuando la ley establece claramente un marco descentralizado de operación, donde las dependencias seleccionan y operan los instrumentos específicos del servicio y la SFP establece la normatividad general, promueve el servicio mediante estrategia de cambio cultural, además de por supuesto supervisar $\mathrm{y}$, en caso de detectar desviaciones significativas, corregir la operación. Todo lo contrario, lo que prevaleció fue un esquema centralizado que con los años comenzó a mostrar serias deficiencias y se convirtió en un problema. 
En este contexto, la experiencia mexicana de la profesionalización de la administración pública enfrentó problemas graves de implementación debido a los siguientes elementos: a) factores de carácter estructural por el rezago existente en el registro de estructuras de organización, la inadecuación de estructuras en relación con funciones y plazas, el exceso de niveles jerárquicos y de normas, así como de duplicidades; b) la existencia de una buena cantidad de técnicas obsoletas en materia de administración de recursos humanos, que se traducían en la inexistencia de mecanismos adecuados para la selección, inducción y sobre todo para la evaluación y la eventual "certificación” (Vilchis, 2006: 457-483), y c) el diseño de la propuesta enfrentó problemas desde su aplicación, por la ausencia de una clara definición de lo que se esperaba con el sistema, que exige un compromiso ético con sus presupuestos básicos, como respeto a la legalidad y fomento de la neutralidad, donde no tiene cabida vacilaciones, ni menos aún tentaciones para utilizarlo con fines políticos.

Desde una visión normativa, el servicio profesional de carrera tiene como principal objetivo evitar que la administración se partidice y favorecer la estabilidad al operar bajo el principio de separación entre administración y política; con ello se busca impedir que los partidos que acceden al poder asuman como un botín los cargos públicos. Sin embargo, operar bajo un esquema de reglas que impriman certeza y control genera siempre resistencias puesto que, por definición, la administración pública se compone de escenarios de incertidumbre y movilidad. Siguiendo a David Arellano, las nuevas reglas entran en competencia con un mundo excesivamente normado, obligando a los sistemas de carrera a buscar mecanismos que impidan la violación de las reglas escritas y resten legitimidad a la separación entre política y administración; de ahí su casi inevitable tendencia a volverse rígidos (Gault, 2000: 135-150).

El informe de evaluación de la Auditoría Superior de la Federación a la SFP en 2005 destacó los resultados obtenidos por ésta en el establecimiento de las bases de organización, funcionamiento y desarrollo del sistema del SPC para garantizar la legalidad, la eficiencia, la objetividad, la calidad, la imparcialidad, la equidad y la competencia por mérito en la administración pública; la verificación de los 168, 439.5 miles de pesos reportados en la Cuenta Pública de 2005, con base en los registros presupuestarios de la SFP, así como los 243,109.7 miles de pesos erogados en la implementación del sistema del servicio profesional de carrera reportado por la SHCP y 74 dependencias y órganos desconcentrados.

Asimismo, se revisaron 204 (7.0\%) expedientes de los 2,930 concursos realizados en 2005, (80 en la SFP, 65 en la SHCP y 59 en la SEMARNAT), ya que en estas dependencias se localizó el 16.2\% $(6,942)$ de las 42,944 plazas sujetas a la LSPCAPF en 2005; 208 (13.6\%) registros electrónicos de las evaluaciones de 1,524 concursos declarados ganados; así como 45,123 registros de los 26,771 servidores capacitados, y 49 expedientes de inconformidades y recursos de revocación.

En cuanto al presupuesto ejercido la Auditoría Superior de la Federación constató que los 243,109.7 miles de pesos representaron el 19.8\% de 1,229,102.5 miles de pesos por la SFP en la Subfunción 03 "Función Pública”, y significó que por cada plaza del SPC se ejercieran en promedio 5.9 miles de pesos, esto es, $18.8 \%$ más que lo previsto por el Consejo Consultivo del SPC. De los 243,109.7 miles de pesos erogados en 2005, con la implementación y operación del SPC, la SFP erogó $170,402.8$ miles de pesos $(70.1 \%)$ y las dependencias y órganos desconcentrados $72,706.9$ miles de pesos $(29.9 \%)$, como se detalla en la tabla siguiente.

Tabla 4.7 Recursos erogados en la implementación y operación del SPC en la Administración Pública Federal centralizada, 2005. (Miles de pesos)

\begin{tabular}{|l|r|r|}
\hline \multicolumn{1}{|c|}{ Concepto } & Presupuesto ejercido & Participación (\%) \\
\hline SFP & $170,402.8$ & 70.1 \\
\hline Conducción, dirección y seguimiento del SPC & $168,439.5$ & 69.3 \\
\hline Capacitación de los servidores públicos adscritos a la secretaría & $1,963.3$ & 0.8 \\
\hline 74 dependencias y órganos desconcentrados & $72,706.9$ & 29.9 \\
\hline Reclutamiento y selección & $2,274.1$ & 0.9 \\
\hline Capacitación & $55,326.9$ & 22.8 \\
\hline Certificación & $1,915.2$ & 0.8 \\
\hline Infraestructura tecnológica & $13,190.1$ & 5.4 \\
\hline Total & $243,109.7$ & 100.0 \\
\hline
\end{tabular}


En promedio, se determinó que cada dependencia erogó 982.5 miles de pesos en la implementación y operación del servicio, monto menor en 980.6 miles de pesos (49.9\%) que el ejercido por la SFP para cubrir las erogaciones del personal que se capacitó (1,963.3 miles de pesos). Con base a la revisión de los registros presupuestarios proporcionados por la SFP para el ejercicio fiscal 2005, la ASF verificó que la entidad fiscalizada erogó, con cargo en la Actividad 003 "Prevenir y abatir prácticas de corrupción e impunidad, e impulsar la mejora de la calidad en la gestión pública", 168,439.5 miles de pesos en la implementación del SPC.

En conclusión, la SFP en 2005 ejerció el $66.5 \%$ (168,439.5 miles de pesos) de los 253,459.8 miles de pesos aprobados en el Presupuesto de Egresos de la Federación para el Ejercicio Fiscal 2005 y el 98.9\% (170,246.9 miles de pesos) del presupuesto modificado en el transcurso del año, a efecto de cumplir con sus objetivos y metas contenidos en sus programas, según lo establecido en el artículo 39 del Reglamento de la Ley de Presupuesto, Contabilidad y Gasto Público Federal (ASF, 2007: 872). La siguiente tabla sinóptica muestra los resultados de la evaluación de la Auditoría Superior de la Federación al servicio profesional de carrera de la Administración Pública Federal centralizada, 2005.

Tabla 4.8 Evaluación del Servicio Profesional de Carrera de la Administración Pública Federal Centralizada, 2005

\begin{tabular}{|c|c|}
\hline Subsistema & Resultados \\
\hline Planeación de Recursos Humanos & - $\quad 90.0 \%$ de los puestos descritos, valuados, perfilados y registrados \\
\hline Ingreso & $\begin{array}{l}\text { - La SFP estableció el sistema "trabajaEn" para regular el proceso de } \\
\text { reclutamiento de candidatos al SPC, mediante el que } 59 \text { (76.6\%) de } \\
\text { las } 77 \text { dependencias efectuaron las convocatorias públicas para } 2,930 \\
\text { concursos. } \\
\text { - En los } 2,930 \text { concursos, las } 59 \text { dependencias recibieron } 766,587 \\
\text { solicitudes de aspirantes para ocupar } 2,509 \text { plazas, en promedio } 305 \\
\text { candidatos por plaza. } \\
\text { De las 2,509 plazas, } 86.2 \%(2,163) \text { se concursaron una sola vez y } \\
13.8 \% \text { (346) se concursaron más de una ocasión mediante } 767 \\
\text { concursos, } 2 \text { concursos por plaza en promedio. } \\
\text { Para la ASF no fue posible determinar el número de plazas vacantes } \\
\text { registradas en 2005 en las 77 dependencias y órganos } \\
\text { desconcentrados sujetos a la Ley del Servicio Profesional de Carrera } \\
\text { en la Administración Pública Federal, a efecto de verificar que } \\
\text { fueran concursadas. } \\
\text { En el sistema "trabajaEn", la ASF no pudo identificar, en forma } \\
\text { automática, a los aspirantes que siendo servidores públicos } \\
\text { concursaron para pertenecer al SPC, a fin de verificar que se } \\
\text { garantice el principio de "competencia por mérito". } \\
\text { En las tres dependencias revisadas por la ASF (SFP, SHCP y } \\
\text { SEMARNAT) no se establecieron mecanismos para comprobar la } \\
\text { legalidad de la documentación presentada por el aspirante. } \\
\text { De una muestra de } 208 \text { concursos ganados la ASF constató que el } \\
\text { 38.0\% (79) el ganador no resultó ser el mejor evaluado en el sistema } \\
\text { "trabajaEn". }\end{array}$ \\
\hline Desarrollo Profesional & $\begin{array}{l}\text { - } 60.0 \% \text { de servidores públicos de carrera con Planes Individuales de } \\
\begin{array}{l}\text { Carrera fueron aprobados por el Comité Técnico de } \\
\text { Profesionalización. }\end{array}\end{array}$ \\
\hline $\begin{array}{l}\text { Capacitación y Certificación de } \\
\text { capacidades }\end{array}$ & $\begin{array}{l}\text { - Con la evaluación la ASF determinó que de las } 77 \text { dependencias y } \\
\text { órganos desconcentrados, el } 3.9 \% \text { (3) capacitó al } 100.0 \% \text { de sus } \\
\text { servidores públicos del SPC; el } 24.7 \% \text { (19) no presentó actividades } \\
\text { de capacitación de servidores públicos del SPC, que probablemente } \\
\text { fueron capacitados en 2004; el } 48.0 \% \text { (37) presentó niveles de } \\
\text { cobertura de } 47.6 \% \text { y } 0.1 \% \text { de sus servidores públicos; el } 18.2 \% \text { (14) } \\
\text { capacitó entre el } 50.4 \% \text { y } 96.3 \% \text { de sus servidores públicos; y el } \\
2.6 \% \text { (2) capacitó a sus servidores públicos y no contó con plazas del } \\
\text { SPC y el } 2.6 \% \text { (2) no registró ninguna actividad. } \\
\text { La ASF verificó que para } 2005 \text { la SFP no contó con una metodología } \\
\text { e indicadores de desempeño que permitieran evaluar si la á } \\
\text { capacitación otorgada a los servidores públicos les permitió } \\
\text { desarrollar, complementar, perfeccionar o actualizar los } \\
\text { conocimientos y habilidades necesarios para el eficiente desempeño } \\
\text { de su carrera o cargo. }\end{array}$ \\
\hline & - Para iniciar el proceso de certificación en las capacidades \\
\hline
\end{tabular}




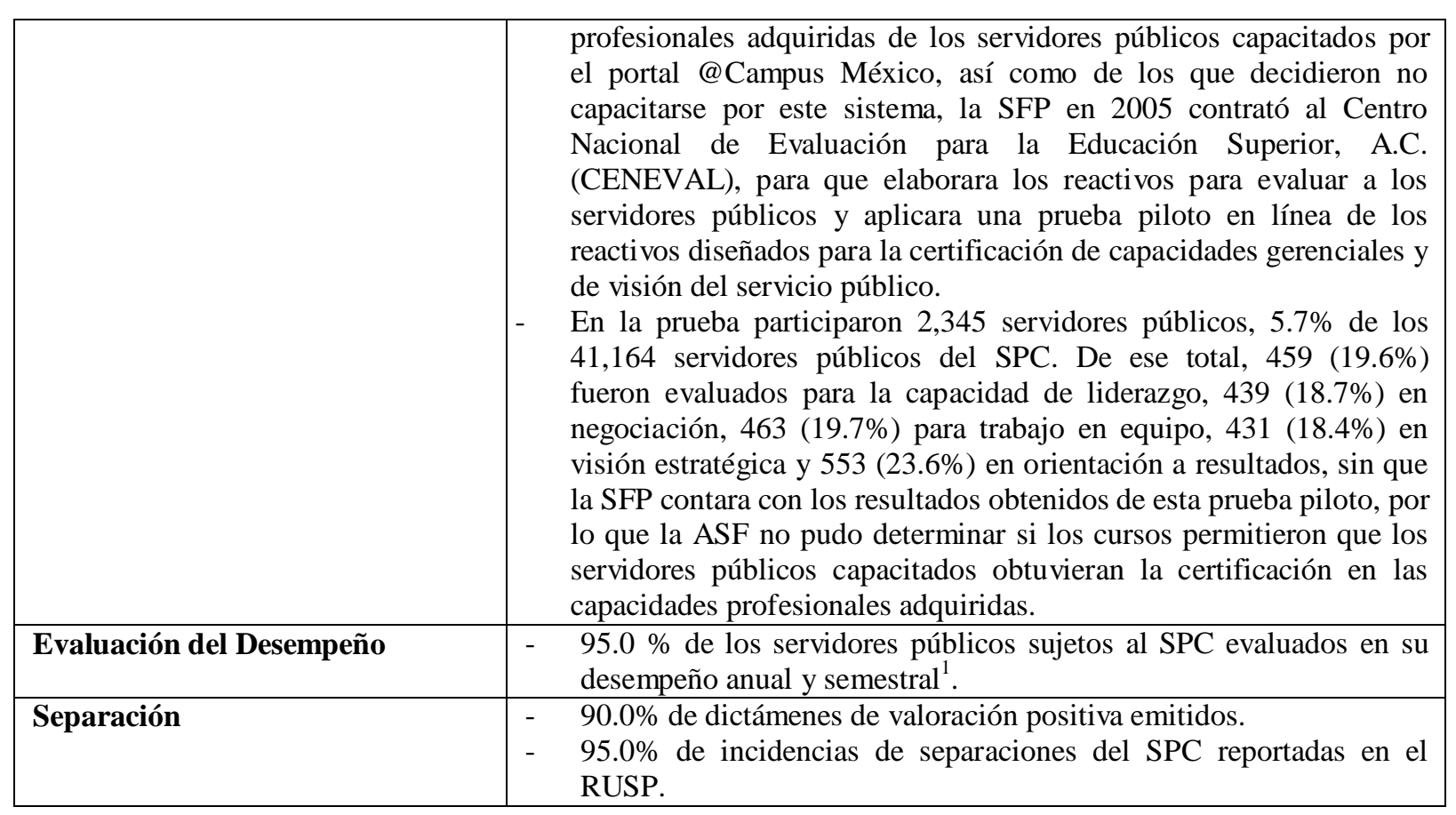

${ }^{1}$ En 2005 sólo se reportaron las evaluaciones del desempeño de aquellos servidores públicos que hubieran ingresado a través del proceso de ingreso del sistema del SPC a partir del 1 de abril de 2004 y hasta el 1 abril de 2005.

DGRH: Dirección General de Recursos Humanos.

CTP: Comité Técnico de Profesionalización.

USPRH: Unidad del Servicio Profesional y Recursos Humanos.

RH: Recursos Humanos.

Fuente: Elaboración propia con base a la Auditoría Superior de la Federación (2007: 659-879)

Por otra parte, la experiencia internacional muestra que los países con altos niveles de desarrollo tales como Gran Bretaña y Estados Unidos, tuvieron el cuidado de seleccionar a los funcionarios de carrera evaluando sus capacidades y la congruencia entre éstas y las necesidades del puesto, y no por su filiación partidista. Asimismo, ejemplifica cómo los servicios civiles limitan el uso discrecional de los recursos públicos al orientarlos hacia la consecución de igualmente públicos. Favorecen la profesionalización como la rendición de cuentas, y fortalecen los esquemas competitivos y democráticos (Pardo, 2007: 907).

El servicio profesional de carrera no es un sistema acabado y no está exento de problemas por lo que se tiene que insistir en el proceso de cambio institucional con métodos y técnicas que consideren las relaciones y el comportamiento de los actores implicados. El servicio profesional es, probablemente, el servicio más complejo no sólo porque abarca un número de servidores públicos (42 944) sino porque abarca 77 dependencias y órganos desconcentrados de la Administración Pública Federal centralizada, cada uno con diversos fines institucionalizados y, por lo tanto, necesidades diferenciadas de recursos humanos.

Las 42944 plazas del SPC representaron el 15.6\% del personal de las ramas sujetas al servicio profesional y el 55\% del personal de confianza de la administración pública (ASF, 2007: 688-691), es decir, 55\% de los servidores públicos que formulan las principales políticas públicas del país. Según los resultados de la auditoría realizada por el órgano de fiscalización del Poder Legislativo (Auditoría Superior de la Federación), en 2007 al servicio profesional de carrera, arrojaron 38 observaciones que derivaron en 25 recomendaciones sobre el funcionamiento del servicio profesional y sus diferentes líneas de trabajo. Entre las recomendaciones propuestas por la ASF se encuentran las siguientes: a) aplicar los principios rectores del servicio profesional de carrera (legalidad, eficiencia, objetividad, calidad, imparcialidad, equidad, competencia por mérito y equidad de género) a través de un programa anual y de mediano plazo; b) crear metas sobre las bases jurídicas del SPC que señalen su nivel de flexibilidad, descentralización, gradualidad y eficiencia; c) elaborar y emitir la norma faltante, así como la expedición de manuales de organización y procedimientos.

En términos generales, una primera aproximación a los problemas indica que la Ley del Servicio Profesional de Carrera, es adecuada pero su reglamentación, implementación y operación no fue la más correcta, registrándose problemas como los siguientes: 
a) excesiva descentralización en la operación de la SFP y su entidad experta; b) limitado énfasis en el desarrollo profesional; c) reglamentación restringida para la separación de servidores públicos, y d) participación limitada de los Órganos Internos de Control (entidades que tienen a su cargo la fiscalización interna de la administración pública). En el mismo sentido, se llegó a la conclusión de que el sistema fue implantado de manera compleja y poco flexible, lo cual observa problemas particulares de la siguiente forma: e) el registro de estructuras es difícil y largo; f) los exámenes son iguales para todos; g) las ponderaciones de las evaluaciones son complejas; h) la movilidad es limitada para los servidores públicos; i) el sistema de evaluación del desempeño es complaciente, un dato relevante señala que más del $80 \%$ de los servidores públicos son evaluados como sobresalientes; j) falta de regulación del artículo 34, y por ende, uso indiscriminado en la ocupación de puestos de forma temporal y sin concurso; y k) elevado número de concursos desiertos en los procesos de ingreso y selección (Martínez, 2009: 9). Como consecuencia, se planteó trabajar como se observa en el cuadro.

Tabla 4.9 Recomendaciones de la Auditoría Superior de la Federación al Servicio Profesional de Carrera, 2007

\begin{tabular}{|c|c|}
\hline Periodo & Recomendaciones \\
\hline Corto plazo & $\begin{array}{l}\text { - Emitir un nuevo reglamento y la normativa secundaria con el fin de ajustar la operación actual } \\
\text { a las recomendaciones de la Auditoría Superior de la Federación, considerando esencialmente: } \\
\text { a) Cuidar la estricta observancia de los principios de la Ley. } \\
\text { b) Construir indicadores de desempeño que permita evaluar el SPC. } \\
\text { c) Verificar el real funcionamiento del SPC con base en lo alcanzado en los indicadores de } \\
\text { programa anual y de mediano plazo. }\end{array}$ \\
\hline Mediano plazo & $\begin{array}{l}\text { - Mejorar el sistema para lograr procesos de ingreso eficaz y acorde a los requerimientos de } \\
\text { ocupación reales de las dependencias, que permitan valorar experiencia y otros méritos. } \\
\text { - } \quad \text { Evaluación del desempeño rigurosa. } \\
\text { - } \quad \text { Capacitación efectiva, y procesos de separación apegados a la legalidad. }\end{array}$ \\
\hline Largo plazo & $\begin{array}{l}\text { - Consolidar el Servicio Profesional de Carrera y contribuir al proceso de profesionalización de } \\
\text { organismos no sujetos al mismo, enfatizando el logro de resultados mediante el desarrollo del } \\
\text { capital humano, así como en otros órdenes de gobierno. }\end{array}$ \\
\hline
\end{tabular}

Fuente: Treviño (2007)

Estas recomendaciones todavía son vigentes ante la falta de consolidación del servicio profesional de carrera y del proceso de profesionalización de organismos no sujetos al mismo y de ampliar la cobertura de profesionalización a las administraciones estatales y municipales, dando lugar a un servicio profesional de carrera nacional.

\subsection{El combate a la corrupción}

La corrupción ${ }^{69}$ es un mal endémico que permea en la vida pública de México, es decir, los espacios de la política, la economía, la administración, la cultura y el ámbito social, son escenarios de un mal que carcome sus entrañas y deja sin defensas a la sociedad (Ramírez, 2016: 10). Está comprobado que la corrupción inhibe el desarrollo, económico, político y social, generando así la agudización de la pobreza y la marginación. Por ello, en 2002, el diagnóstico que realizó la SECODAM, hoy Secretaría de la Función Pública, concibió a este problema de gran magnitud, pues representó el 9\% de la PIB nacional, según estimaciones del Banco Mundial (SECODAM, 2002: 6). Además de una fundada percepción en la opinión pública de que existe corrupción y que ésta genera ineficiencias en la actividad pública y servicios de baja calidad. Por ejemplo, datos de la SECODAM en el año 2000 establecen que recibió 7 mil quejas y denuncias de irregularidades de la APF (SECODAM, 2002: 10), que van de la violación de leyes y normas presupuestales, abuso de autoridad, cohecho y extorsión, negligencia administrativa e incumplimiento en procesos de contratación.

En este contexto, el Ejecutivo Federal estableció como prioridad fundamental enfrentar la corrupción que existe en los distintos órdenes de la administración pública.

\footnotetext{
${ }^{69}$ La palabra corrupción proviene del adjetivo corruptus, que en latín significa descomposición, podredumbre o desintegración. De acuerdo al Diccionario de la Lengua Española, corrupción en las organizaciones públicas es la práctica consistente en la utilización de las funciones y medios de aquellas en provecho, económico o de otra índole, de sus gestores.
} 
Con fundamento en los artículos 29 y 32 de la Ley de Planeación ${ }^{70}$, se sustenta legalmente el Programa Nacional de Combate a la Corrupción y Fomento a la Transparencia y Desarrollo Administrativo, que entró en vigor el 22 de abril de 2002. Así, el decreto emitido por el presidente de la República por el que se aprueba el PNCTDA, ratifica en su artículo II, la obligatoriedad de este programa para las dependencias y entidades de la APF.

Desde esta perspectiva, el PNCTDA establece como objetivos: a) prevenir y abatir prácticas de corrupción e impunidad e impulsar la mejora de la calidad gestión pública; b) sancionar las prácticas de corrupción e impunidad; c) dar transparencia a la gestión pública y lograr la participación de la sociedad; d) administrar con pertinencia y calidad el patrimonio inmobiliario federal. Y a partir de la década de los noventa se han creado instrumentos para medir los niveles de transparencia o de corrupción y fortalecer los mecanismos institucionales de la rendición de cuentas.

La transparencia está íntimamente ligada con los conceptos de ética, claridad, moral pública, honestidad, exposición e información de otros, más aún cuando el responsable directo es el funcionario público. La democracia se consolida y garantiza cuando se fortalecen permanentemente los sistemas de transparencia y de responsabilidades, principalmente en el sector público. "Si un estado no lo garantiza, y el ciudadano no tiene acceso a una información fidedigna y adecuada; si no existen normas y mecanismos que puedan exigir tanto a las autoridades políticas como técnicas una rendición total y clara de las cuentas públicas, entonces se corre el riesgo de incurrir en actos de corrupción. Así, se puede observar que el término de transparencia se relaciona opuesta y directamente con el concepto de corrupción" (Del Castillo, 2003: 13).

Para Ayala Espino (2011: 88), un Estado sin sentido de lo público es entendido como un sitio de ventajas y privilegios los cuales se multiplican en la medida que la corrupción avanza de manera vertical y horizontal en sus oficinas administrativas y burocráticas. En este sentido, varios autores han definido la corrupción como un tipo de relación entre Estado y sociedad, estableciendo la diferencia entre corrupción "política" y corrupción "burocrática". Otra clasificación muy general sobre corrupción distingue entre corrupción "funcional" y "disfuncional". Algunas otras veces, el propósito ha sido relacionar el concepto de corrupción con otros fenómenos o procesos importantes. Por ejemplo, recientemente se ha incluido la lucha contra la corrupción como elemento clave en los procesos de democratización (Del Castillo, 2000: 15).

De acuerdo con esta distinción, la corrupción política puede verse como el uso indebido de un servicio y autoridad públicos en la formulación de políticas, y a la ejecución de dichas políticas como corrupción administrativa, es decir, la autoridad pública es ejercida por los funcionarios electos (políticos) y designados (burócratas) que desempeñan respectivamente funciones de creación y ejecución de políticas públicas. Aunque no siempre es fácil distinguir la corrupción política de la administrativa, puede decirse que los actores principales de los actos corruptos son, en la primera, los políticos y, en la segunda, los burócratas (Del Castillo, 2000: 15).

En cuanto a la corrupción funcional es aquella en la que existen prácticas corruptas que pueden ayudar a las estructuras políticas y burocráticas a moverse, en cambio la corrupción disfuncional es aquella que francamente obstaculiza y vulnera la gestión de los bienes públicos y la impartición de justicia. Esta distinción pone énfasis en el grado de desarrollo de las sociedades. Para Shah y Schacter, la corrupción se enlista en tres grandes tipos: a) corrupción burocrática o pequeña corrupción administrativa -un amplio número de funcionarios públicos abusan de su oficina exigiendo sobornos y comisiones, desviando fondos públicos, o concediendo favores a cambio de consideraciones personales-; b) corrupción mayor -el robo o abuso de una cantidad considerable de fondos públicos por un número relativamente pequeña de funcionarios-, y c) "captura del estado" o "captura regulatoria" colusión entre agentes públicos y privados, para beneficio privado- (Shah \& Schacter, 2004).

\footnotetext{
${ }^{70}$ Artículo 29 de la Ley de Planeación.- El Plan y los programas regionales y especiales deberán ser sometidos por la Secretaría de Hacienda y Crédito Público a la consideración y aprobación del presidente de la República.

Artículo 32 de la Ley de Planeación.- Una vez aprobados el Plan y los programas serán obligatorios para las dependencias de la Administración Pública Federal en el ámbito de sus respectivas competencias.
} 
En el debate actual corrupción suele ser entendida en términos generales como el abuso de cargos públicos para beneficio de lo privado, en otras palabras, la corrupción involucra una conducta por parte de los funcionarios del sector público, que pueden ser servidores políticos o civiles, en donde éstos se enriquecen a sí mismos o a gente cercana a ellos de forma impropia o ilegal, a través del abuso del poder público que les fue encomendado.

Sin embargo, esta definición resulta tan amplia que es poco operable. Entendida de esta manera, el término corrupción puede incluir una gran variedad de actos ilícitos, como el soborno, nepotismo, extorsión, fraude, tráfico de influencias, cohecho, favoritismo, lavado de dinero, etcétera. Todos estos son actos ilegales que, ciertamente, pueden ser considerados manifestaciones distintas de la corrupción, pero no son iguales en su extensión, ni en sus causas, ni efectos.

Si consideramos al soborno y la extorsión ${ }^{71}$, como formas específicas pero comunes de corrupción en el país en los tres niveles de gobierno, junto a la definición de corrupción propuesta por Transparencia Internacional. Se tiene que la corrupción consiste en la violación de una obligación de un funcionario público (burócrata) o representante popular (político) con el objeto de obtener un beneficio personal, en forma de dinero o regalos, de la persona que lo soborna o a quien extorsiona (Del Castillo, 2003: 17$)^{72}$.

Desde esta perspectiva, se puede argumentar que la corrupción puede aparecer cuando existen ciertas condiciones estructurales que la hacen más propicias, a partir de lo que se ha llamado "ecuación básica" de la corrupción, como se expresa: Corrupción = Monopolio de la decisión pública más Discrecionalidad de la decisión pública menos Responsabilidad (en el sentido de obligación de dar cuentas) por la decisión adoptada.

De acuerdo con esta ecuación fundamental, la corrupción encuentra su terreno mejor abonado cuando las decisiones públicas se toman en régimen de práctico monopolio (personal u organizacional), con amplias facultades discrecionales y sin criterios acotados de decisión, y sin mecanismos que obliguen a la rendición de cuentas. Por el contrario, cuando el agente decisor es plural o el poder es consensuado, los criterios de decisión objetivos tasados, y la fiscalización y rendición de cuentas muy estricta, la corrupción se halla en un medio ambiente mucho más hostil.

Una administración sin vigilancia, controles y penalización es motivo para alentar las conductas indeseables, así como la reproducción de la cultura burocrática que tiende a consumir los recursos públicos de manera desordenada y con incentivos perversos que tienen incidencia en la gestión fiscal y presupuestal del Estado. La degradación de la administración pública tiene que evitarse con medios legales y conciencia ciudadana. Si la corrupción administrativa tiende a crecer, significa que la vida pública no tiene la garantía de que los procesos productivos y sociales sean transparentes ni eficientes, situación que conduce a que el desempeño del sistema económico y social sea magro (Berrones, 2012: 19).

La corrupción administrativa es producto de ilegalidades, omisiones, imprecisiones, arreglos y, sobre todo, de fallas de diseño de los marcos institucionales donde se gesta y desarrolla. Por ejemplo, malversación del presupuesto público hacia objetivos distintos al que consigna el presupuesto en ejecución; favoritismo del funcionario público a alguien allegado para la contratación de una obra pública; enriquecimiento ilícito por el provecho de bienes públicos, entre otros.

\footnotetext{
${ }^{71}$ De acuerdo con el Diccionario de la Lengua Española en su edición de 2001, la extorsión es la "amenaza por parte del funcionario público al ciudadano de una medida lesiva para éste si no realiza un contraprestación o pago irregular a beneficio del funcionario". Por su parte, soborno, es "una suma de dinero u otro favor que se ofrece a una persona que ocupa una posición de poder o de autoridad pública, a fin de influir en sus asuntos de vista o comportamiento".

72 Esta forma de entender el concepto corrupción tiene la ventaja además de establecer vínculos estrechos con las definiciones de rendición de cuentas y transparencia apuntadas anteriormente. Al igual que en el caso de la rendición de cuentas, un modelo conceptual útil para analizar la corrupción es el modelo agente-principal. Una autoridad o un principal, como la Secretaría del Medio Ambiente, emplea a un agente como inspector de medio ambiente. El agente interactúa en representación del principal con un cliente como, por ejemplo, una empresa que solicita una licencia para desempeñar una actividad considerada perjudicial para el medio ambiente. En tal caso, un agente será corrupto cuando a su juicio, los beneficios de corromperse superen los posibles riesgos de ser sorprendido en el ilícito. De igual manera, un cliente participará en el soborno o en la extorsión cuando los beneficios que obtenga sean mayores que los costos implicados. (Del Castillo, 2003: 17).
} 
Esto implica que la ejecución de las normas del derecho público no tiene el ambiente idóneo para ser efectivas, más cuando la voluntad de hacerlas cumplir es un conjunto de claroscuros, es decir, la combinación de elementos de certeza formal, pero a la vez de tendencias hacia la discrecionalidad (Berrones, 2012: 18).

Conviene recordar que la vigencia plena de la ética de la responsabilidad en la administración pública y el servicio público es condición necesaria para desactivar las diversas formas de corrupción como el soborno, la extorsión, la ineficiencia, los privilegios, el despilfarro y las prebendas que violan las reglas normativas, dado que tiende a controlar los esquemas de trabajo con criterios personales, no institucionales (Berrones, 2012: 19).

Desde el inicio, en 2001, de la medición del Índice Nacional de Corrupción y Buen Gobierno $\left(\mathrm{INCBG}^{73}\right.$, elaborado por Transparencia Mexicana ${ }^{74}$, México ha mantenido calificaciones entre 8.5 y 10.6 puntos. En 2001 se registró la calificación más alta con 10.6 puntos, mientras que en 2003 se registró una calificación de 8.5. En 2010 la calificación fue de 10.3 puntos por encima de la calificación de 2007 (SFP, 2012).

Las evaluaciones de Transparencia Mexicana han mostrado que en el periodo 2003-2010, los actos de corrupción se duplicaron, al pasar de 101 millones de actos de corrupción en 2003 a 200 millones en 2010, mientras que su costo se triplicó, de 10 mil 600 millones de pesos en el primer año a poco más de 32 mil millones de pesos en el segundo, lo que significa que los pagos irregulares para realizar trámites o evadir el cumplimiento de alguna disposición normativa ha crecido en una proporción de dos a uno respecto del número de actos indebidos (SFP, 2012: 187).

Para los hogares mexicanos, los actos de corrupción costaron en 2010 un promedio de 165 pesos, 58 pesos más que en 2003, lo cual representa el $14.0 \%$ de ingreso de las familias a este rubro en 2010. Los trámites con mayor susceptibilidad a la corrupción, según Transparencia Mexicana, se presentan en evitar el pago de infracciones de tránsito, arrastre de grúas y sacar el auto del corralón; pago a franeleros por estacionarse en la vía pública; evitar trámites en la aduana y la detención de un ministerio público o agilizar seguimiento a algún expediente; obtener servicio de una pipa de agua, y vender en la vía pública. En cambio, los servicios con menor índice de corrupción en el periodo 20012010 fueron: el pago predial, solicitar una beca para algún tipo de estudios; recibir correspondencia, y obtener la cartilla militar.

De los 35 trámites incluidos en el INCBG cinco son de carácter federal: recibir correspondencia; obtener la cartilla militar/exentar el servicio militar; obtener o acelerar el pasaporte en la Secretaría de Relaciones Exteriores; conexión o reconexión de luz a domicilio; y pasar sus cosas en alguna aduana, retén, garita o puerto fronterizo. Estos trámites se ubican en las posiciones 3, 4, 10, 13 y 32 de los 35 servicios evaluados, respectivamente, lo cual significa que de éstos, el de "pasar sus cosas en alguna aduana, retén, garita o puerto fronterizo" es el servicio federal que tiene la peor calificación con 28.3 puntos, en la escala de cero a 100.

Según el INCBG, los trámites que redujeron sus índices de corrupción se explican porque el gobierno federal o bien algunos gobiernos locales o municipales han hecho uso de tecnologías de la información como medios auxiliares, lo que permite realizar pagos ya no sólo en ventanillas de tesorería sino también en sucursales bancarias, supermercados e incluso por medio de internet, coadyuvando con esto a reducir los índices de corrupción y eficientar los procesos administrativos.

\footnotetext{
${ }^{73}$ El índice registra la corrupción en 35 trámites y servicios públicos ofrecidos en los tres órdenes de gobierno (Federal, estatal y municipal) y por empresas particulares. El índice por servicio se obtiene al dividir el número de veces que se obtuvo un servicio mediante un soborno entre el número de veces que se utilizó el mismo servicio. Utiliza una escala de 0 a 100, donde 0 representa menor corrupción y 100 mayor corrupción. El INCBG para 2010 incluyó una muestra de 15,326 hogares en el territorio nacional, y se utilizó la misma estructura urbano-rural que la del Conteo de Población y Vivienda de INEGI 2010, con una margen de error para resultados nacionales menor que el $1 \%$.

${ }^{74}$ Transparencia Mexicana (TM) es una organización no gubernamental que analiza el problema de la corrupción desde una perspectiva integral para generar cambios concretos en el marco institucional y en la cultura de la legalidad en México. Fue fundada en 1999 por diversos académicos, intelectuales y ciudadanos que deseaban entender y enfrentar mejor los problemas de corrupción del país Entre los miembros de su consejo rector se encuentran Sergio García Ramírez, José Sarukhán, David Ibarra, Olga Pellicer y Federico Reyes Heroles, quien dirige la organización.
} 
Sin embargo, se puede observar en la tabla 4.10, cómo durante el desempeño del gobierno de la alternancia, el estado de la corrupción se mantiene incólume; es por demás evidente que, bajo la gestión de Vicente Fox, no se verifica mejoría alguna; antes bien, de 2001 a 2006, se conserva el Índice de Percepción de la Corrupción, disminuyendo -inclusive- en los dos últimos años de su administración, lo que significa un incremento de la percepción de la corrupción en la sociedad mexicana.

El Índice de Percepción de la Corrupción en el año 2006, de una lista de 90 países, ubicó a México en el lugar 70, con una puntuación de 3.3, por debajo de Chile, ubicado en el lugar 20 (7.3 puntos), Uruguay en el lugar 28 (6.4) y Costa Rica, ubicado en el lugar 55 (4.1 puntos) (SFP, 2012: 187).

Tabla 4.10 Índice de Percepción de la Corrupción (Escala 0-10) ${ }^{1}$

\begin{tabular}{|l|c|c|c|c|c|c|}
\hline \multicolumn{1}{|c|}{ Concepto } & $\mathbf{2 0 0 1}$ & $\mathbf{2 0 0 2}$ & $\mathbf{2 0 0 3}$ & $\mathbf{2 0 0 4}$ & $\mathbf{2 0 0 5}$ & $\mathbf{2 0 0 6}$ \\
\hline Índice de percepción de la corrupción & 3.7 & 3.6 & 3.6 & 3.6 & 3.5 & $\mathbf{3 . 3}$ \\
\hline Posición de México & $\mathbf{5 1}$ & $\mathbf{5 7}$ & $\mathbf{6 4}$ & $\mathbf{6 4}$ & $\mathbf{6 5}$ & $\mathbf{7 0}$ \\
\hline
\end{tabular}

${ }^{1}$ Mientras 10 significa "altamente limpio", 0 implica "altamente corrupto”.

Fuente: Transparency International (The Global Coalition Against Corruption); en http://www.transparency.org/

En cuanto a las sanciones a servidores públicos de la APF de 1983-2012, la Secretaría de la Función Pública y los Órganos Internos de Control impusieron 158,352 sanciones, el 87.8\% $(138,976)$ fueron administrativas, y $12.2 \%$ (19,376) fueron económicas, por un monto de 67,922.9 millones de pesos. El número de sanciones creció 10 veces en los periodos que se analizan, al pasar de 5,389 en el primer periodo a 53,296 sanciones en el último periodo (SFP, 2012: 171), como se puede apreciar en la tabla siguiente.

Tabla 4.11 Sanciones impuestas por la SFP y los OIC, 1983-2012

\begin{tabular}{|l|c|c|c|c|c|c|}
\hline \multicolumn{7}{|c|}{ Periodos } \\
\hline Sanciones & $\mathbf{1 9 8 3 - 1 9 8 8}$ & $\mathbf{1 9 8 9 - 1 9 9 4}$ & $\mathbf{1 9 9 5 - 2 0 0 0}$ & $\mathbf{2 0 0 1 - 2 0 0 6}$ & $\mathbf{2 0 0 7 - 2 0 1 2}$ & Total \\
\hline Total & 5,389 & 27,891 & 37,275 & 34,501 & 53,296 & 158,352 \\
\hline Administrativas & 4,709 & 25,828 & 31,383 & 28,674 & 48,382 & 138,976 \\
\hline Part. (\%) & 3.4 & 18.6 & 22.6 & 20.6 & 34.8 & 100.0 \\
\hline Amonestación Privada & 1,696 & 4,459 & 4,023 & 2,322 & 13,106 & 25,606 \\
\hline Amonestación pública & 149 & 3,168 & 4,667 & 7,552 & 11,597 & 27,133 \\
\hline Suspensión & 1,833 & 7,347 & 8,505 & 7,370 & 13,584 & 38,639 \\
\hline Inhabilitación & 66 & 4,032 & 7,106 & 7,894 & 7,723 & 26,821 \\
\hline Otras & 965 & 6,822 & 7,082 & 3,536 & 2,372 & 20,777 \\
\hline Económicas & 680 & 2,063 & 5,892 & 3,536 & 4,914 & 19,376 \\
\hline $\begin{array}{l}\text { Monto (Millones de } \\
\text { Pesos) }\end{array}$ & $1,104.1$ & $9,189.6$ & $5,699.8$ & $19,578.4$ & $32,351.0$ & $67,922.9$ \\
\hline
\end{tabular}

Fuente: Auditoría Superior de la Federación (2012: 171).

De las 158,352 sanciones, el $87.8 \%(138,976)$ fueron administrativas, y $12.2 \%(19,376)$ fueron económicas, por un monto de 67,922.9 millones de pesos. El número de sanciones creció 7 veces en los cuatro primeros periodos, al pasar de 5,389 en el primer periodo a 34,501 sanciones en el cuarto periodo y creció 10 veces al pasar a 53,296 sanciones en el último periodo.

Dos terceras partes (68.3\%) 94,880 de las sanciones administrativas que se impusieron de 1983 a 2012 fueron no graves, en tanto que la otra tercera parte (31.7\%) sí se considera grave. Las sanciones no graves se distribuyeron de la manera siguiente: el $40.7 \%(38,639)$ correspondieron a suspensiones; el $28.6 \%(27,133)$, a amonestaciones públicas; $27.0 \%(25,606)$ a amonestaciones privadas; y el $3.7 \%$ $(3,502)$ a apercibimientos. En el caso de las sanciones graves, el $60.8 \%(26,821)$ correspondieron a inhabilitaciones, y el 39.2\% (17,275), a destituciones. Cabe destacar que los tipos de sanción administrativa que más se incrementaron de 1983 a 2012 fueron graves, específicamente las inhabilitaciones las cuales pasaron de 66 en el periodo 1983-1988 a 7,894 en el periodo 2001-2006. 
Las sanciones económicas se incrementaron 5.2 veces, al pasar de 680 en el periodo 1983-1988 a 3,536 en el periodo 2001-2006, y 7.2 veces al pasar a 4,914 en el periodo 2007-2012. El monto de las sanciones económicas aumentó 17.7 veces al pasar de 1,104.1 millones de pesos en el primer periodo a 19,578.4 miles de pesos en el cuarto periodo, y 29.3 veces, al pasar de 1,104.1 millones de pesos en el primer periodo a 32,351.0 miles de pesos en el último periodo. Como se puede observar, la corrupción continúa siendo un mal endémico que violenta y transgrede tanto las reglas como los arreglos institucionales de la administración pública. A pesar de las acciones realizadas por el gobierno para combatir la corrupción, tales como las reformas legales para precisar las responsabilidades de los servidores públicos, mejorar mecanismos de control interno, establecer el servicio profesional de carrera, entre otros, no han sido suficientes para mejorar la percepción de la sociedad respecto de la corrupción en las instituciones públicas.

\subsubsection{Corrupción y costos de transacción}

La corrupción administrativa incrementa los costos de transacción desde el momento en que los trámites y servicios a cargo de las oficinas burocráticas son retrasados, triangulados y costosos. De acuerdo con José Ayala, los costos de transacción surgen, en primer lugar “...de la transferencia de los derechos de propiedad en cualquiera de sus modalidades", en segundo lugar, "... son los problemas de información incompleta, información asimétrica, aversión al riesgo, daño moral y selección adversa". En tercer lugar los costos de transacción son resultado de “...cambios en los términos de intercambio especificados en las instituciones, por ejemplo, cambios en las negociaciones, los contratos, los derechos de propiedad y del sistema legal existente, porque estos cambios implican renegociar, recontratar y aceptar el nuevo ordenamiento legal" (Espino, 2011; 187) ${ }^{75}$.

La corrupción en la contratación pública ocasiona una serie de consecuencias altos y graves costos con repercusiones no sólo de carácter económico, sino político y social, debido a las diversas formas en que este puede manifestarse. La autoridad cuenta con dependencias gubernamentales que realizan una serie de procesos; los cuales implican la contratación y gestión de recursos humanos (aparato burocrático), adquisición de materiales e insumos (compras públicas), gestión de recursos financieros (gasto público) y entrega de bienes y/o servicios producidos. Para que la autoridad gubernamental administre estos recursos se plantean zonas de interacción público-privadas y/o públicopúblico, en las cuales hay probabilidad de prácticas ilícitas y deshonestas.

Las secuelas negativas de la corrupción distorsionan la economía, especialmente en variables macroeconómicas. Así se reduce la inversión tanto doméstica como extranjera como en la aplicación de nuevas ideas e innovaciones tecnologías y, por tanto, disminuye el crecimiento económico (Mauro Paolo, 1995). Una consecuencia directa está relacionada con los mayores costos de transacción originados en los pagos extraoficiales realizados por los agentes públicos en los procesos de compras estatales; estas irregularidades en los procesos de contratación sumadas a las pérdidas de incumplimiento generan costosos traslados a un mayor precio de los bienes y servicios transados. La corrupción aumenta los costos de transacción debido a que incrementa la ineficiencia administrativa como resultado de la introducción de demoras y requerimientos innecesarios para forzar el pago de sobornos. Por ejemplo, el estudio único denominado Índice de Honestidad y Eficiencia en la Generación de infraestructura Pública ${ }^{76}$, elaborado por la empresa CEI Consulting \& Research, presenta un análisis del costo que el gasto público ejerció para generar infraestructura pública en México abarcando un periodo de 30 años, de 1973 a 2003, publicado en agosto de 2005, y analiza el Distrito Federal y los 31 estados de la República Mexicana.

\footnotetext{
${ }^{75}$ La teoría de los costos de transacción ha sido desarrollada esencialmente por Oliver Williamson en su obra The Economics Institutions of Capitalism (1985), a partir de los planteamientos pioneros de Ronald Coase en su obra seminal la Naturaleza de la empresa (1937). Williamson sostiene que la teoría de los costos de transacción es una perspectiva interdisciplinaria que busca estudiar la organización económica desde un punto de vista institucional comparado con el fin de minimizar los costos de transacción que surgen en los intercambios que se producen en el sistema económico.

${ }^{76}$ La metodología del estudio se basó en datos del INEGI, CFE, SENER, PEMEX, SEDESOL, SCT, SEP, BANXICO, Secretaría de Salud, así como de la Cuenta de la Hacienda Pública Federal, Estatal y de los Informes presidenciales; además, se calcula a partir de la diferencia entre dos subíndices: a) el acervo de infraestructura cuantifica la infraestructura física existente, la cual se estandarizó, y se agregan los datos para normalizarlos posteriormente. Aquellos datos compuestos por una sola clase se promediaron aritméticamente, y aquellos que contienen más de una clase se promediaron geométricamente; b) el acervo de capital público ejercido es la cuantificación histórica acumulada del precio pagado por el gobierno en sus tres niveles para la inversión en infraestructura pública. Se emplea el método econométrico de Inventarios Perpetuos, en el cual se estandarizan los datos para calcular los activos de capital a precios constantes.
} 
El tema central del estudio es la diferencia entre la infraestructura existente y el gasto público ejercido, los cuales representan recursos desviados en fraudes, malversación de fondos, despilfarro o mala administración. Los resultados oscilan entre 0 y 6. Los valores más cercanos a 0 presentan una mejor calificación en el ejercicio de sus recursos en infraestructura: Michoacán (0.149), Jalisco (0.328) y Baja California (0.434). Los valores cercanos a 6 reflejan la peor posición: el Distrito Federal, Campeche y Tabasco con 5.793, 3.238 y 2.355, respectivamente (ASF, 2012: 29).

En estos datos existe la percepción de que los gobiernos municipales, estatales y federal ejercen un mayor gasto de los que realmente valen las obras en puentes, carreteras, escuelas y hospitales, entre otras; sin embargo, no se ha podido estimar el costo efectivo que representa el dispendio de recursos públicos ha tenido en la generación de infraestructura.

Otra consecuencia económica directa es que, al introducir irregularidades en los procesos de contratación, se permite o se fomenta la reducción en la calidad de los productos o servicios, promoviendo la desigualdad en las condiciones de competencia. Por ejemplo, el Diagnóstico sobre el Impacto del Fraude y Corrupción en las Pymes en México, elaborado por CEI Consulting \& Research, tiene como objetivo medir el efecto económico y administrativo de la corrupción en las pequeñas y medianas empresas, las cuales en 2004 generaron 315 mil empleos y el 42.0\% del PIB nacional (ASF, 2012: 67).

Los resultados del estudio se presentan a continuación: a) 867 empresas (63.0\%) han sido víctimas de cuando menos un fraude y $83.0 \%$ lo percibe como una seria amenaza para su estabilidad y rentabilidad; b) El fraude representa la tercera causa más importante de la desaparición de las Pymes, con $23.0 \%$, y es superada por la falta de organización (34.0\%) y la falta de experiencia en el ramo (27.0\%); c) Las pérdidas por fraudes que han registrado las Pymes ascienden a 205 millones de pesos; d) El $43.0 \%$ de las Pymes realiza ocasionalmente pagos extraoficiales a servidores públicos, mientras que el $35.0 \%$ lo hace de forma consuetudinaria; e) Por sector, las empresas que más reportaron tener ese problema fueron: manufactura $(38.0 \%)$, construcción $(27.0 \%)$, comercio $(24.0 \%) \mathrm{y}$, finalmente, servicios (11.0\%) (ASF, 2012: 67-69).

La corrupción también influye negativamente en la composición y en las rentas del gobierno, aumentando el gasto y reduciendo la recaudación de impuestos, profundizándose el déficit fiscal y haciendo menos productivo el gasto público. En consecuencia, se puede concluir que la corrupción influye directa e indirectamente en forma negativa sobre el crecimiento económico y en el desarrollo de un país, estrangulando la economía y erosionando el patrimonio social (ASF, 2012: 67-69).

Adicionalmente, se producen desviaciones de recursos generando desigualdad en términos redistributivos y restringiendo las posibilidades de ciudadanos para alcanzar niveles de vida superiores, al impedir que el uso de los recursos públicos sea óptimo en beneficio de la sociedad. De igual manera, y como resultado de lo anterior, la corrupción puede hacer más cruda y persistente la pobreza, al permitir e incrementar la desigualdad en el ingreso y hacer que cada vez más personas pasen a engrosar las filas de la extrema pobreza.

Según la Encuesta de Gobernabilidad y Desarrollo Empresarial $2005^{77}$, el $20 \%$ de las empresas reconocieron haber realizado pagos extraoficiales para influir en el contenido de nuevas leyes, políticas y regulaciones; asimismo el $13 \%$ de las empresas encuestadas admitió haber pagado algún soborno para influir en los funcionarios públicos a nivel federal. La encuesta calculó que dichas empresas gastaron en promedio $6 \%$ de sus ingresos en la corrupción burocrática administrativa con el gobierno federal.

En este contexto, el desarrollo y la competitividad de la nación no se incrementó. La prueba de lo anterior se observa con el crecimiento del PIB, el cual en los tres primeros años del sexenio, cayó en términos reales $1.5 \%$ en $2001,0.7 \%$ en 2002 y $0.2 \%$ en 2003 . En conjunto, el PIB por persona cayó a una tasa media anual de casi 1 por ciento. Para 2004, la economía creció. El PIB por persona, en términos reales, fue de $2.7 \%$ mayor que el año anterior, en 2005 creció $1.6 \%$ y para 2006, la Secretaría de Hacienda reportó un crecimiento del $4.8 \%$.

\footnotetext{
${ }^{77}$ El Centro de Estudios Económicos del Sector Privado, A. C., realizó una encuesta única sobre gobernabilidad y desarrollo empresarial 2005.
} 
A pesar de ello, el crecimiento económico a lo largo de todo el sexenio fue magro. En competitividad, México disminuyó 22 lugares, estando posicionado en el lugar 55 de 117 países.

En suma, la corrupción violenta los arreglos institucionales y las reglas de las organizaciones públicas generando desigualdad en términos redistributivos y restringiendo las posibilidades de ciudadanos para alcanzar niveles de vida superiores, al impedir que el uso de los recursos públicos sea óptimo en beneficio de la sociedad. 


\section{Conclusiones}

Como resultado de la presente investigación intitulada Administración Pública y Gobernanza en México. Análisis del Cambio Institucional en la Agenda de Buen Gobierno, se encontró que las estrategias implementadas por el gobierno de Vicente Fox buscó diseñar una nueva estructura orgánicafuncional de la administración pública sustentada en conocimientos teóricos-empíricos provenientes de la nueva gestión pública, la cual se enfoca en la parte técnico-instrumental de la organización para lograr una estructura flexible con personal especializado, que logrará la eficiencia, eficacia y calidad en la realización de sus productos; buscando además establecer formas dinámicas de participación social en la búsqueda de posibles alternativas de solución a las decisiones de gobierno en cuanto transparencia, rendición de cuentas y combate a la corrupción. A continuación, se exponen las conclusiones más importantes derivadas del cambio institucional en la Agenda de Buen Gobierno.

1. El nuevo institucionalismo a través de categoría cambio institucional permite explicar los cambios que se han dado en el país, desde la década de los noventa en el sistema económico, político, social y administrativo. El cambio institucional coincide con algunas de sus premisas fundamentales para la adopción de acciones de gobierno como son el isomorfismo institucional, los derechos de propiedad, los costos de transacción, la certidumbre jurídica, la esencia de las organizaciones, la economía de la información, entre otras. Estas premisas son centrales para el diseño y funcionamiento de las instituciones que corresponden a la economía de mercado y la existencia de un Estado constitucional y democrático.

2. Con el análisis económico de la política, las burocracias son objeto de críticas por ser el centro en el cual la politización en el uso de los presupuestos, la relación asimétrica de la información, la maximización de los beneficios de los cargos administrativos, así como el control de monopolios públicos en nombre del Estado, habían contribuido a que la gestión pública tuviera resultados no favorables.

3. La administración pública mexicana ha experimentado cambios que van desde los esquemas administrativos tradicionales que favorecieron patronazgos, clientelismos, conducción centralizada, entre otros comportamientos, que se evidenciaron de muchas maneras, particularmente en el momento de cambiar las administraciones. En esta lógica de cambio, la administración busca concretamente incorporar y validar la posición de que la extensión del gobierno y de la administración era (debía ser) algo constituido por el público ciudadano, y que los ciudadanos mismos, mediante sus organizaciones privadas, sociales, no gubernamentales, podían ser también los sujetos de la administración pública, haciéndose cargo de la gestión de algunos asuntos públicos en cooperación con el gobierno o con la presencia del gobierno.

4. El cambio político en el año 2000 permitió al Ejecutivo Federal emprender un ambicioso programa de innovación gubernamental en la administración pública mexicana buscando devolver a la ciudadanía la credibilidad en el gobierno. Para alcanzar los objetivos del programa de innovación se creó el Modelo Estratégico para la Innovación del Gobierno cuyos principios gerenciales basados en la nueva gestión pública buscó mayor grado de productividad, eficacia y eficiencia a través de resultados en las organizaciones de gobierno, con el propósito de sustituir a la vieja estructura burocrática pública.

5. Con la aplicación del modelo gerencial trataron de establecer cómo reducir el poder a la burocracia, a través de reglas de mercado, eficiencia y competencia; contratos por desempeño; sistemas de incentivos, en otros, para romper el sentido de la colectividad, por ejemplo, el servicio profesional de carrera introduce la evaluación del desempeño individual, la competitividad individual, como señalan las reglas del mercado.

6. Para el Modelo Estratégico para la Innovación del Gobierno una administración que vaya más allá de cumplir con el objetivo de proporcionar bienes y servicios se preocupa porque se realice de manera eficaz y eficiente, es por eso por lo que la nueva administración se hizo a cargo de la racionalidad (eficacia/eficiencia) de todo el marco del proceso decisorio: de la formulación e implementación de la política. Es así como su objetivo principal se amplió de proporcionar bienes y servicios optimizando los recursos disponibles a que estos fueran de máxima calidad al menor costo posible para la sociedad. 
7. En este contexto, los cambios institucionales analizados por las vías de las estrategias de la Agenda de Buen Gobierno se vieron favorecidos por las reformas normativas, instituciones, estructuras y prácticas de gobierno, acordes con los nuevos paradigmas de la nueva gestión pública, en función de los cuales se introducen mejoras e innovaciones para la modernización y mejor desempeño de la administración pública.

8. Para acelerar el cambio institucional, el gobierno de Fox estableció tres acciones para un nuevo arreglo institucional entre los actores participantes - ciudadanos, servidores públicos y gobiernoen el ámbito de la administración pública. La vigencia de la Ley Federal de Responsabilidades Administrativas de los Servidores Públicos, la de Transparencia y Acceso a la Información Pública Gubernamental y la Ley de Servicio Profesional de Carrera de la Administración Pública Federal, son ejemplo conspicuo de la nueva institucionalidad que el país empezó a vivir. Define el cosmos de reglas para dar consistencia y eficacia a la función pública que limite la práctica de los poderes discrecionales y avanzar en la configuración de un orden político y administrativo más democrático.

9. Estas leyes son clave para abrir el gobierno al escrutinio ciudadano para una mejor rendición de cuentas, así como, la apertura de espacios nuevos e importantes para el control y la participación ciudadana en asuntos gubernamentales.

10. Sin embargo, los resultados de la Agenda de Buen Gobierno en general fueron limitados. La introducción de distintas estrategias para innovar y modernizar la APF buscando eficiencia y eficacia en la mejora del aparato gubernamental, no coadyuvaron a generar mecanismos específicos y evaluaciones sistemáticas para conocer la efectividad de los cambios y si la meta de mejorar el desempeño gubernamental se cumplió. Por ejemplo, el impacto de la estrategia del gobierno por medio de la introducción de premios y reconocimientos a la innovación y calidad de la administración no fue considerado en la medida que el ciudadano percibiera una mayor calidad en la gestión pública, pues se basó en datos cuantitativos que sólo reconocían modelos de éxito internacionales de calidad, sin adaptarse al contexto prevaleciente en su momento en el país.

11. Lo anterior se tradujo en otra dificultad pues imitar o basarse en el mito de si a un gobierno diferente le resultó exitosa una estrategia, entonces hay que usarla y aplicarla. La nueva gestión pública receta los mismos remedios para atender las causas de los problemas que aquejaban a las distintas administraciones públicas deviniendo en un isomorfismo institucional, sin adaptarse por ello a la realidad de nuestro país. Por ejemplo, no toda política prescriptiva resuelve en sí el complejo entramado de dificultades tales como la corrupción, la desregulación administrativa, el servicio profesional de carrera, la transparencia y la rendición de cuentas.

12. Si bien el gobierno de Fox realizó un diagnóstico de los rezagos importantes en la administración pública, el problema de este residía en la reducción economicista a través de los costos en que inciden las fallas de la administración, como si por antonomasia, esta reducción de costos condujera per se a la eficacia y eficiencia de la acción de gobierno. La experiencia práctica demostró justo lo contrario, por ejemplo, en la implementación y operación del servicio profesional de carrera, la Secretaría de la Función Pública erogó 170,402.8 miles de millones de pesos $(70.1 \%)$ y las dependencias y órganos desconcentrados 72,706.9 miles de pesos (29.9\%), sin que por ello se alcanzara la eficiencia.

13. En cuanto a garantizar el derecho a la información y protección de los datos personales el gobierno creó el Instituto Federal de Acceso a la Información como organismo descentralizado con autonomía operativa, presupuestaria y de toma de decisiones. Sin embargo, aún no convence a la mayoría ciudadana de que esto significa un cambio sustancial en el quehacer de la administración pública ante todo porque sus efectos prácticos no se manifiestan como tangibles y decisivos. Los resultados del desempeño de la transparencia arrojan que en la práctica haber confiado en la capacidad de la Secretaría de la Función Pública para aplicar sanciones administrativas a través de las OIC en los casos de incumplimiento de las disposiciones del IFAI han sido notoriamente limitados. 
En 2005, de 1,065 resoluciones, únicamente en 24 ocasiones se dio vista a la SFP para sancionar a quien hubiese incumplido el mandato de las resoluciones del IFAI. Se trata aproximadamente de 2\% de los casos presentados entre 2004-2005.

14. La estadística pública si bien presentó algunos éxitos en relación con el número de sanciones administrativas a servidores públicos, multas económicas, procesos de inhabilitación del sector púbico, entre otros indicadores; la persistencia de escándalos ligados al dispendio de recursos públicos, el tráfico de influencias en algunos servicios públicos no ha permitido comunicar avances certeros en el combate a la corrupción en el país. La calificación del Índice de Percepción de la Corrupción (2006), de Transparencia Internacional ubicó a México en el lugar 70 de 90 países con una puntuación de 3.3. De tal suerte, que mientras el gobierno no logre comunicar que desde la administración pública se vela por el interés público, no habrá normas, ni instituciones ni sanciones suficientes para cambiar la percepción de los mexicanos respecto al combate a la corrupción.

15. La existencia de leyes en materia de transparencia, de normas presupuestarias, la creación de nuevos órganos de control de la gestión y la construcción de un sistema de rendición de cuentas no han sido suficientes para generar una percepción diferente entre la ciudadanía. El problema está principalmente en la efectividad, no en la existencia per se de instituciones anticorrupción. Si bien los órganos encargados de la lucha contra la corrupción poseen autonomía presupuestal, técnica y de gestión (ASF, SFP) en el caso mexicano el arreglo institucional no garantiza una autonomía constitucional para que cuenten con mayores facultades en el sistema de fiscalización y hacer que sus recomendaciones y observaciones sean atendidas por los entes auditados con mayor celeridad y oportunidad.

16. Respecto de las atribuciones de responsabilidades y sanciones el número de observaciones emitidas por la ASF se incrementó en un factor de 2.9 veces entre 2002 y 2008. Los datos disponibles indican que pasó de 5 acciones sancionatorias en 2002 a 1,111 acciones en 2008 . Sin embargo, por denuncia penal, el resultado se resquebraja, puesto que las acciones de fincamiento de responsabilidad, el número de denuncias y querellas no rebasó el número de 10. Estos datos revelan de manera concluyente la baja la calidad del enforcement y, por lo tanto, de la rendición de cuentas existente en México.

17. Dentro del gobierno, la determinante fundamental en las prácticas reales de transparencia y rendición de cuentas son las leyes e instituciones de orden horizontal, es decir, aquellas que provienen del equilibrio de poderes y de los órganos de control internos, las cuales han sido instituidas en lo fundamental en los tiempos del régimen autoritario. Por tanto, de las prácticas instituidas en esa época están también vigentes. Por ello, los mecanismos de rendición de cuentas horizontal no funcionan adecuadamente debido a que la cultura de la participación, la creación de instancias efectivas para ello, y del adecuado diseño legal e institucional correspondiente, no son tareas que puedan llevarse a cabo por medio de medidas administrativas. Una reforma institucional que contemple la autonomía constitucional a las contralorías y órganos de fiscalización y la creación, dentro de estas instancias, de espacios de participación ciudadana, permitiría un mayor control y mejor desempeño del gobierno.

18. En términos de gobernanza, la evolución de la voz y rendición de cuentas que mide varios de aspectos del ejercicio de los derechos humanos, políticos y de las libertades civiles de los individuos tuvo un mejor desempeño en el gobierno de Vicente Fox, al incrementarse el número de organizaciones de la sociedad civil en espacio público para vigilar el ejercicio del gobierno, el cual pasó de 180 organizaciones por año -hasta el año 2002- a las 1216 en el 2004. Pero, la falta de autenticidad de la gran mayoría de los espacios de participación en el país ha convertido al concepto de empoderamiento ciudadano en una palabra vacía. Sólo algunas OSC's como Fundar, Incide Social, Alianza Cívica, participan desarrollando modelos de evaluación de un campo de la política pública o nivel de gobierno, así como en la Comisión de Hacienda de la Cámara de Diputados para mejorar el marco normativo y fiscal de las organizaciones sociales. Recuperar las instancias de participación como espacios reales de intercambio democrático entre Estado y ciudadanos es una labor fundamental de la democratización de la vida pública. 
19. Cabe destacar que las acciones civiles han resultado poco efectivas en términos de impulsar cambios en las políticas públicas. La falta de articulación entre el gobierno y sociedad además de la ausencia de homogeneidad entre las normas e instituciones en los distintos niveles de gobierno, contribuyen a una creciente complejidad de acciones gubernamentales lo cual hace difícil la participación ciudadana en los procesos de política pública. La participación ciudadana se ha convertido en un discurso que no corresponde con una práctica democrática en México.

20. La gobernanza entendida por la administración Fox como aquella que incorpora mecanismos de transparencia, rendición de cuentas, servicio profesional y ética en el manejo del sector privado y público, para promover e incrementar la competitividad, las mejores prácticas comerciales, los mayores rendimientos y fomentar la inversión nacional e internacional, tiene resultados mixtos que van de lo regular a lo negativo, tales son los casos de los indicadores estado de derecho y control de la corrupción que tuvieron una evolución negativa en el periodo 20002006, mientras que el indicador de calidad regulatoria ofreció un mejor desempeño. Sin embargo, ninguno de estos indicadores que comprende la gobernanza logró posicionarse en el cuartil superior (75 a 100\%), lo cual infiere que se estuvo lejos de la calidad de buena gobernanza entendida como aquella en la que existe participación social amplia y sanciones efectivas en diferentes niveles y grados de transparencia, rendición de cuentas y combate a la corrupción, para fortalecer el proceso de democratización.

21. En materia de mejora regulatoria el gobierno de Fox buscaba eliminar la normatividad excesiva de la gestión pública, a través de la consolidación de diversas herramientas y estrategias en calidad, simplificación y mejora del marco jurídico de las instituciones del gobierno federal. No obstante, entre los funcionarios públicos existía una opinión generalizada de que había sobrerregulación en la actividad administrativa dada la contradicción existente entre ciertas líneas de acción de la ABG, como la desregulación y la certificación ISO 9000, esta última generaba sobrerregulación interna en áreas gubernamentales que eran difíciles de estandarizar (sobre todo en aquellas que no ofrecen servicios directos en ventanilla al público).

22. La implementación del servicio profesional de carrera en la administración pública a través de concursos abiertos para establecer la transparencia y garantizar el nombramiento de la persona más competente para un empleo dado, demostró el compromiso del gobierno con la creación de una meritocracia. Empero, existen dos grandes desventajas: a) este procedimiento no permite gestionar la planeación de la sucesión ni el desarrollo profesional; b) es lento y costoso, lo que suma incentivos para que los ejecutivos realicen designaciones al amparo del artículo 34. El proceso está sujeto a la subjetividad y no hay salvaguardas para evitarlo. El hecho de que el superior jerárquico con poder de veto sea parte del comité de selección y responsable de diseñar los exámenes ha generado desconfianza en el proceso. En gran medida, permite reclutar tal como se hacía antes de adoptar el servicio profesional de carrera.

23. Los abusos cometidos en el uso del artículo 34 han llevado al público y a la comunidad académica a considerar que persiste la cultura del paternalismo y el clientelismo en la APF. El informe de 2006 de la Auditoría Superior de la Federación concluyó que los lineamientos de la libre designación resultaban no sólo permisivos, sino vagos. Debido a los términos amplios en que se redactaron el artículo 34 y las reglas correspondientes, casi cualquier situación puede considerarse excepcional.

24. El alcance de la legislación en materia de servicio profesional de carrera en el periodo analizado se limitó a un grupo más bien reducido, aunque crucial, de servidores públicos (42 944 plazas). Otros miembros del personal de sectores clave como los maestros o los trabajadores del sector salud, al igual que gran parte del personal de menor nivel (los trabajadores de base sindicalizados) estaban sujetos a las regulaciones anteriores y a una legislación más bien proteccionista en el gobierno de Fox.

25. Las fallas de diseño, las deficiente estrategias de implementación y las lagunas normativas han impedido el desarrollo de un sistema funcional de méritos, cuya cultura política residual aún se resiste a cambiar e intenta mantener el reparto de cargos entre partidarios políticos, el cual no respeta ni reconoce los beneficios de un sistema de meritocracia, sino que privilegia las lealtades personales. 
26. Para la administración Fox, un gobierno que cueste menos consistía en reducir el gasto burocrático que no agrega valor al ciudadano y en aumentar el gasto de inversión en infraestructura y programas sociales de alto beneficio para la población, y alcanzar estos dos objetivos en un marco de estabilidad macroeconómica y equilibrio macroeconómico.

27. Con Fox en el gobierno se demostró que se tenía una concepción del Estado económico en términos de la gerencia (eficacia y eficiencia) que deviniera en un Estado gerencial, que no debía ser propietario sino impulsor de la iniciativa privada, que debía garantizar que no se generaran conflictos en las relaciones sociales que obstaculizarán el desarrollo económico y resquebrajaran la armonía social. De tal suerte, que la administración pública quedó sometida a un Estado gerencial y jerárquico. Por tanto, la agenda de buen gobierno fue gerencial, no social. Prueba de ello, es la persistencia de la pobreza al permitir e incrementar la desigualdad en el ingreso que inciden de forma negativa sobre el crecimiento económico y en el desarrollo del país.

28. A pesar de los resultados limitados de la Agenda de Buen Gobierno, los cambios institucionales han generado una nueva relación entre la sociedad y el Estado transformando el significado de la acción de gobernar. En la medida en que los ciudadanos tengan la capacidad de vigilar el desempeño de los funcionarios públicos e incidir así en los procesos y rutinas de las organizaciones públicas, se está ante una nueva gobernanza.

29. En suma, las propuestas de la ABG colocaron ciertas bases para ir gradualmente cambiando aunque sea de manera fragmentada-, una nueva forma de asumir la responsabilidad y desempeño de las tareas públicas. Se reconocen cambios como -el nuevo marco legal de responsabilidades administrativas, transparencia y rendición de cuentas, el servicio profesional de carrera y la función pública-, los cuales constituyeron un avance en el cambio institucional administrativo de nuestro país que sentaron las bases para un estilo diferente de seleccionar, incluir, promover, capacitar y evaluar el desempeño de los servidores públicos.

30. Desde la perspectiva del nuevo institucionalismo, la administración pública mexicana experimentó cambios de manera incremental y adaptativa a través de un conjunto de arreglos institucionales que establecieron una nueva institucionalidad en el país, en la que el imperativo del cambio se organizó con base a reglas institucionales que son partes importantes para propiciar condiciones de certidumbre en beneficio de la sociedad.

31. Con base a las conclusiones planteadas la mejora de la transparencia, la rendición de cuentas y el combate a la corrupción en el sector público del país se recomienda la observancia y cumplimiento del estado de derecho entre las instituciones de gobierno y las organizaciones privadas y sociales. La evaluación del desempeño gubernamental periódicamente mediante un control interno robusto con autonomía de la autoridad y una gestión administrativa y financiera consolidada. La participación de la sociedad a través de un gobierno abierto, que propicie mejores políticas públicas. Así como, el comportamiento de los servidores públicos acorde con los valores y principios éticos institucionales de buen gobierno.

32. El fortalecimiento de la gobernanza deberá observar en las instituciones del poder ejecutivo y en los otros poderes cuando menos los siguientes principios: integridad, acceso a la información pública, rendición de cuentas, responsabilidad, eficiencia, eficacia, legalidad e informes de gestión, que mejoren las prácticas en todos los ámbitos institucionales, y que sean visibles al escrutinio público para evitar simulaciones de apertura gubernamental con vacío social.

33. Un mejor desempeño del gobierno debe contemplar una reforma institucional que articule la autonomía constitucional de los órganos de fiscalización con plena independencia de los tres poderes que permitan un mayor control de las actividades y el manejo de los recursos públicos con estricto apego a un estado de derecho y a la democracia. 


\section{Referencias}

Ackerman, J. (2004). Sinergia Estado-sociedad en pro de la rendición de cuentas: lecciones para el Banco Mundial. Washington, Banco Mundial (documentos de trabajo del Banco mundial, 31, 1-49.

Albornoz, M. (2009). Indicadores de innovación: las dificultades de un concepto en evolución. Revista CTS, 13(5), 9-25.

Alvarado, O. A. C. (2007). El servicio civil de carrera y los cambios en las gestión pública de México. Tesis Doctoral, México: UNAM.

Arias y Caballero (2005). Instituciones, costes de transacción y políticas públicas; un panorama. Departamento de Economía Aplicada, Universidad de Vigo, España.

Aoki, M. (2001). Toward a Comparative Institutional Analysis. MIT Press, Boston.

Auditoría Superior de la Federación (2012). Perfil de México a través de indicadores clave. México: ASF.

Auditoría Superior de la Federación (2011). Informe de actividades 2010. México: Cámara de Diputados.

Auditoria Superior de la Federación (2007). Informe del Resultado de la Revisión y Fiscalización Superior de la Cuenta Pública 2005. Tomo IX, 1. México: ASF.

Barzelay, M. (2001). La nueva gerencia pública. Un ensayo bibliográfico para estudiosos latinoamericanos (y otros). Revista del CLAD Reforma y Democracia, 19, 1-35.

Berger, P. (2003). La construcción social de la realidad. Buenos Aires: Amorrortu.

Berrones, R. U. (2013). Las políticas públicas en el arquetipo de la gobernanza democrática. En Ochman, M. \& Rodríguez-Oreggia, E. (coords.). Análisis e incidencias de las políticas públicas en México. En busca de un gobierno eficiente. México: EGAP, Gobierno y Política Púbica Tecnológico de Monterrey, Miguel Ángel Porrúa, 13-35.

México. México: IAPEM, 9-25.

(2012). Presentación. En Sánchez González, José Juan. La corrupción administrativa en (2011). Fundamentos de la transparencia en el Estado Democrático de Derecho. En Berrones, R. U. (coord.). Rumbos de la transparencia en México. México: UNAM, 15 -29.

(2009). Gestión de redes institucionales. En Revista Convergencia XVI Aniversario, Facultad de Ciencias Políticas y Administración Pública, Universidad Autónoma del Estado de México.

(2007). Gobernabilidad, transparencia y reconstrucción del Estado. En Revista Convergencia, 14 (45), 47-74.

(2004a). El control y la evaluación en la administración pública”, en Revista Mexicana de Ciencias Políticas y Sociales, XLVI(192), 43-70.

(28), $1-29$.

(2004b). El valor institucional de la gestión pública. Revista Venezolana de Gerencia, 9

(2003). Visión contextual de la Ley de Responsabilidades Administrativas de los Servidores Públicos. En Leyes para el cambio democrático de la Administración Pública Federal (DOF). México: Orden Jurídico Nacional, Secretaría de Gobernación.

Bobbio, N. (1986). El futuro de la democracia. México: FCE. 
Bourgon, J. (2010). Propósito público, autoridad gubernamental y poder colectivo. Revista Reforma y Democracia, 46, 1-23.

Boukaert, G. (1994). Governance Between Legitimacy and Efficiency: Citizen Participation in the Belgian Fire Services. En Kooiman, J. (coord.). Modern Governance. Londres: Sage, 156-177

Cabrero, E. M. (2005). Acción pública y desarrollo regional. México: Fondo de Cultura Económica.

Caiden, G. (1996). Revitalización de la administración pública. Revista de Administración Pública. Ensayos sobre la Nueva Administración Pública. 91, 29-49.

Camps V. (1997). Ética del Buen Gobierno. En Giner, Salvador y Sarasa, Sebastián (eds.). Buen Gobierno y Política Social. España: Ariel, 19-24.

Cardozo, M. B. (1983). La evaluación de las políticas públicas: Problemas, metodologías, aportes y limitaciones. Revista de Administración Pública, 84, 167-197.

Casillas, S. V. (2008). Rendición de cuentas, transparencia y combate a la corrupción. Revista de Administración Pública. Número Especial, Nueva Época, XLIII. México.

Castro, A. C. \& Cárdenas, G. H. C. (2004). La reforma administrativa en México desde la perspectiva de la formación de funcionarios públicos. Revista de Administración Pública "La Agenda Actual de la Administración Pública: Una visión Iberoamericana”, Nueva Época 110, XXXIX(1), 19-29.

Cejudo, G. M. \& Sour, L. (2007). ¿Cuánto cuesta vigilar al gobierno federal?. Revista IAPEM, 66, 201-235.

CLAD (2009). Carta Iberoamericana de Participación Ciudadana en la Gestión Pública. Portugal.

CLAD (2002). VII Congreso Internacional del sobre la Reforma del Estado y de la Administración Pública, Lisboa, Portugal, 8-11.

Cossío, J. R. (2008). Transparencia y Estado de Derecho. en Ackerman, J. M. Más allá del acceso a la información. México: Siglo XXI.

Crawford, S.E.S. \& Ostrom, E. (1995). A grammar of institutions. The American Political Sciences Review, 89(3), 582-600.

Crozier, M. \& Erhard, F. (1990). El actor y el sistema. Las restricciones de la acción colectiva. México: Alianza.

Del Castillo, A. (2003). Medición de la corrupción: Un indicador de la rendición de cuentas. Serie Cultura de la Rendición de Cuentas 5. México: Auditoría Superior de la Federación.

Delgado, J. M. (2009). Agenda de Buen Gobierno en México. En Pardo, M. \& Sánchez, E. V. La Gerencia Pública en América del Norte. Tendencias actuales de la reforma administrativa en Canadá, Estados Unidos y México. México: El Colegio de México, Instituto de Administración Pública de Nuevo León, 429-455.

Echebarría, K. (2004). Objetivar la gobernanza: funciones y metodologías. Ponencia presentada en el IX Congreso Internacional del CLAD sobre Reforma del Estado y de la Administración Pública. Madrid, España.

Elguea, J. (2008). Razón y desarrollo. El crecimiento económico, las instituciones y la distribución de la riqueza espiritual. México: El Colegio de México. 
Enríquez, G. \& Ramírez, J. M. (1999). La gobernabilidad mexicana en una transición federalista. En Pineda, J. Enfoques de políticas públicas y gobernabilidad. México: Colegio Nacional de Ciencias Políticas y Administración Pública, Instituto Tecnológico Autónomo de México, Universidad Anáhuac, 88-108.

Espino, J. A (2011). Instituciones y economía. Una introducción al neoinstitucionalismo económico. México, Fondo de Cultura Económica.

\section{Economía.}

(2002). Fundamentos institucionales del mercado. México: UNAM, Facultad de

(2001). Políticas de Estado y arreglos institucionales para el desarrollo en México. Revista Instituciones y Desarrollo, 8-9, 203-228.

(1996). Mercado, elección pública e instituciones. Una revisión de las teorías modernas del Estado. México: Facultad de Economía, UNAM.

(1992). Límites del Mercado. Límites del Estado. México: INAP.

Espinosa, E. T. \& Guadarrama, J. P. (2009). Reforma institucional en México. Avances y asignaturas pendientes. México: UNAM.

Fernández, G. A. (2010). Hacia un México Transparente: Alcances y límites de la Ley Federal de Transparencia con respecto a los sujeto obligados. 1-55.

Ferreiro A. Y. (1999). Dinero, política y transparencia: el imperativo democrático de combatir la corrupción. Ponencia presentada en la 9th International Anti-Corruption Conference. Durban, Sudáfrica, 8-9.

Fox, J. (2008). Transparencia y rendición de cuentas. En John Ackerman (coord.). Más allá del acceso a la información: Transparencia, rendición de cuentas y Estado de derecho. México: Siglo XXI, 174198.

Fox, J. (2007). The Uncertain Relationship between Transparency and Accountability. Development in Practice. JSTOR, 17(4/5), 663-671.

Fox, J., Haight, L. \& Palmer-Rubin, B. (2011). Proporcionar transparencia ¿Hasta qué punto responde el gobierno mexicano a las solicitudes de información?. Gestión y Política Pública, XX(1), 3-6.

Fox, J. \& Haight L. (2006). Las reformas a favor de la transparencia: teoría y práctica. Derecho a saber. Balance y perspectivas cívicas, 29-64.

Fuentes, Víctor ( 15 de agosto de 2010). Deberá Provida pagar 22 mdp. Reforma.

Gandlgruber, B. B. (2004). Abrir la caja negra: teorías de la empresa en la economía institucional. Análisis Económico, XIX (41), 19-58.

Garza-Aldape, E. S. (2005). De la alternancia al desarrollo. Políticas públicas del Gobierno del Cambio. México: FCE.

Gault, D. A. (2010). El enfoque organizacional en la política y la gestión públicas. Entendiendo las organizaciones gubernamentales. En Merino, Mauricio \& Cejudo, Guillermo (comps.). Problemas, decisiones y soluciones Enfoques de política pública. México, FCE, CIDE, 61-92.

(2004). Comentario. En Pardo, María del Carmen. De la administración pública a la gobernanza. México: El Colegio de México, 129-133.

(2000). Aspectos organizacionales de los sistemas de servicio civil: dimensiones y puntos críticos para la experiencia mexicana. Revista de Ciencias Sociales y Humanidades, 48, 135 -150. 
Gault D. A., Alamilla C. M. \& Campos G. A. (2004). ¿Sólo innovación gerencial? La nueva gestión pública, los cuasi-mercado y el esquema principal-agente? Documento de Trabajo, 156, México: CIDE.

Gozzo, G. (2006). El caso Provida: Cuentas pendientes en la transparencia y la justicia. México: Fundar, Centro de Análisis e Investigación, A.C.

Giddens, Anthony (1995). La construcción de la sociedad. España: Amorrurtu.

Immergut, E. M. (2006). El núcleo teórico del nuevo institucionalismo. En Alarcón, V. O. (coord.). Metodologías para el análisis político. Enfoques, procesos e instituciones. México: UAM-Iztapalapa, Plaza y Valdés editores, 387-424.

Gil-García, J. R., Mariscal, J. A. \& Ramírez, F.H. (2008). Gobierno electrónico en México. México: CIDE, 214, 1-57.

González, J. J. S. (2012). La corrupción administrativa en México. México: IAPEM.

González, J. J. S. (2001a). Gestión Pública y Governance. México: IAPEM. Plaza y Valdés.

(2001b). La Administración Pública como ciencia, su objeto y su estudio. México: INAP,

(2004). Reforma, modernización e innovación en la historia de la administración pública en México. México: IAPQROO, Miguel Ángel Porrúa.

(2009a). El cambio institucional en la reforma y modernización de la administración pública mexicana. Revista Gestión y Política Pública, XVIII(1), 67-105.

(2009b). La administración pública de Vicente Fox: del Modelo Estratégico de Innovación Gubernamental a la Agenda de Buen Gobierno. Revista Espacios Públicos, 2 (24), 8-31.

(2010). La propuesta de modernización administrativa del gobierno de Felipe Calderón. Revista de Administración Pública 123, Nuevas Visiones del Servicio Público, XLV(3), 31-56.

Gutiérrez, R. M. (2004). Innovación Gubernamental. El paradigma de Buen Gobierno en la administración del presidente Vicente Fox. México: FCE.

Herbert, S. A. (1992). El comportamiento administrativo. Madrid: Aguilar.

Hernández, J. G. V. (2005). Emergencia del nueva cultura institucional: impacto en la transformación del escenario de la transformación económica. Economía, Sociedad y Territorio, v(17), 27-61.

Immergut, E. M. (2006). El núcleo teórico del nuevo institucionalismo. En Alarcón, V. O. (coord.). Metodologías para el análisis político. Enfoques, procesos e instituciones. México: UAM-Iztapalapa, Plaza y Valdés editores, 387-424.

INEGI (2011). Encuesta Nacional de Calidad e Impacto Gubernamental. México: INEGI.

Instituto Federal de Acceso a la Información y Protección de Datos (2012). Información de Rendición de Cuentas 2006-2012. México: IFAI.

Instituto Federal de Acceso a la Información (2006). Cuarto Informe de Labores al H. Congreso de la Unión.

Instituto Federal de Acceso a la Información (2005). Tercer Informe de Labores al H. Congreso de la Unión.

Jensen, M. \& Meckling W. (1976). Theory of the Firm: Managerial Behaviour, Agency Cost and Ownership Structure. Journal of Financial Economics, 3(4), 305-360. 
Jepperson, R. L. (2001). Instituciones, efectos institucionales e institucionalismo. En Powell, W. \& DiMaggio, P. J. (comps.). El Nuevo Institucionalismo en el análisis organizacional. México: Fondo de Cultura Económica, Colegio Nacional de Ciencias Políticas y Administración Pública, UAEM, 193215.

Kalmanovitz, S. (2003). El neoinstitucionalismo como escuela. Revista de Economía Institucional, 5(9), 189-212.

kamerman, S. B. \& Kahn, A. [comps.] (1993). La privatización y el Estado benefactor. México: Fondo de Cultura Económica.

Kaufmann, D., Kraay, A. \& Mastruzzi, M. (2009). Governance Matters VIII. Agergate and Individual Governance Indicators 1996-2008. Documento de Trabajo, No. WPS4978, Banco Mundial, Washington, D.C.

Kooiman, J. (2004). Gobernar en Governance. En Cerillo, A. (coord.), La gobernanza hoy: diez títulos de referencia. Madrid: Instituto Nacional de Administración Pública, 57-81.

Kuhn, S. T. (1982). La estructura de las revoluciones científicas. México: Fondo de Cultura Económica.

Laegreid, P. (2005). Los políticos y la reforma de la administración pública en la era de la Nueva Gestión Pública: el caso Noruego. Revista Foro Internacional, XLV(4),705-733.

Laguna, M. D. (2011). The Challenges of Implementing Merit-based Personnel Policies inLatin America: Mexico's Civil Service Reform Experience. Journal of Comparative PolicyAnalysis: Research and Practice, 13(1), 51-73.

Leone, J. A. R. (2003). El neoinstitucionalismo y la revalorización de las instituciones. Reflexión Política, 5(9), 37-46.

Ley Federal de Responsabilidades Administrativas de los Servidores Públicos (2002). México.

Ley de Transparencia y Acceso a la Información Pública Gubernamental (2002). México.

Ley de Servicio Profesional de Carrera de la Administración Pública Federal (2003). México.

Lourau, R. (1994). El análisis institucional. Buenos Aires: Amorrurtu.

Luna, I. P. (2008). Aspectos culturales de la implementación del acceso a la información en México. Revista del CLAD Reforma y Democracia, 48, 211-234.

Majone, G. (2005). Evidencia, argumentación y persuasión en la formulación de políticas. México: Colegio Nacional de Ciencias Políticas y Administración Pública, FCE.

Malik, A. (2002). State of the Art in Governance Indicators. Documento de apoyo para el Informe de Desarrollo Humano 2002. Poverty Eradication and Democracy in the Developing World, Programa de Naciones Unidas para el Desarrollo, Washington, D.C.

Maldonado, M. Y. (2008). Tres miradas al gobierno de Fox: el gabinete, la agenda de gobierno y la corrupción. En Gamboa, H. Z. (coord.). Transición política, alternancia y proceso de gobierno en México 2001-2006. UNAM-FCPyS, México: Gernika, 153-198.

March, J. \& Olsen, J. P. (1997). El redescubrimiento de las instituciones. La base organizativa de la política. México: Fondo de Cultura Económica, Colegio Nacional de Ciencias Políticas y Administración Pública, A.C., Universidad Autónoma de Sinaloa.

March, J. \& Olsen, J. P. (1984). The New Institutionalism: Organizational Factors in Political Life. American Political Science Review, 78, 734-749. 
Mariscal, J. (2010). Nuevo institucionalismo y regulación. En Merino, M. y Cejudo, G. (comps.), Problemas, decisiones y soluciones Enfoques de política pública. México: FCE, CIDE, 179-206.

Márquez, J. J. S. (1996). Esferas de la democracia. En Cuadernos de Divulgación de la Cultura Democrática 9. México: IFE, 5-54.

Martínez, F. M. (2009). Reforma y modernización de la administración pública del siglo XXI ¿Cambio de paradigma? México: IAPEM.

Marsh, D. \& Stoker, G. (eds.) (1995). Teorías y métodos de la ciencia política. Madrid: Alianza editorial.

Maynetz, R. (2001). El Estado y la sociedad civil en la gobernanza moderna. Revista del CLAD Reforma y Democracia, 21, 1-8.

Medrano M. J.(2000). Instituciones, política y gobernabilidad, VI (9), 61-84.

Mena, J. E., Vega, M. F. \& Mena, J.L. R. (2010). Cambio político y nuevo institucionalismo en la administración pública. México: IAPEM.

Méndez, J. L. (2009). El servicio profesional de carrera en México y Godot llegó, pero... ¿Para quedarse? En Pardo, M. \& Sánchez, E. V (coord.). La gerencia pública en América del Norte. Tendencias actuales de la reforma administrativa en Canadá, Estados Unidos y México. México: El Colegio de México, INAP, 195-210.

Merino, M. (2008). La transparencia como política pública. En Ackerman, J. (coord.). Más allá del acceso a la información: Transparencia, rendición de cuentas y Estado de derecho. México: Siglo XXI, 240-262.

Metcalfe, L. (1999). La Gestión Pública: de la imitación a la innovación. En Losada, C. ¿De Burócratas a Gerentes? Las Ciencias de la Gestión Aplicadas a la Administración del Estado. Washington: Banco Interamericano de Desarrollo, 47-68.

Montoya Suárez, Omar (2004). Schumpeter, innovación y determinismo tecnológico. En Scientia et Technica, X (25), 209-213.

Moreno, E., Crisp B. F. \& Shugart, M. (2003). The Accountability Deficit in Latin America", en Mainwaring, S. y Welna, C. (eds.). Democraty Accountability in Latin America. Oxford: University Press.

Nienstaedt, M. \& Zerpa, D. (2005). El marco institucional del Banco Central de Venezuela. Eumed.Net

North, D. C. (1994). Estructura y cambio en la historia económica. Madrid: Alianza editorial.

(1990). Instituciones, cambio institucional y desempeño económico. México: Fondo de Cultura Económica.

(1995). Instituciones, cambio institucional y desempeño económico. México: Fondo de Cultura Económica.

O’Donnell, G. (2008). Democracia y Estado de derecho. En John Ackerman (coord.). Más allá del acceso a la información. Transparencia, rendición de cuentas y Estado de derecho. México: Editorial Siglo XXI, 89-99.

126.

(1998). Horizontal Accountability in New Democracies. Journal of Democracy, 9(3), 112-

OCDE (2011). Hacia una gestión pública más efectiva y dinámica en México. OECD Publishing. 
Oficina de Innovación Gubernamental de la Presidencia de la República (2001). Programa de Innovación Gubernamental.

Oficina de la Presidencia para la Innovación Gubernamental (2001). Modelo Estratégico para la Innovación Gubernamental.

Orozco, L. C. (2010). La calidad en la gestión como factor de cambio institucional en las organizaciones gubernamentales del Estado de México. Revista de Ciencias Sociales Convergencia, 53, 285-310.

Orozco, O. G. (1985). Introducción a la administración pública. México: Editorial Harla.

(1980). Diccionario de Política y Administración Pública. México: Colegio de Licenciados de Ciencias Políticas y Administración Pública.

(1981). La administración pública en el estado capitalista. Barcelona: Editorial Fontamara.

(1992). El Estado en la Era de la Modernización. México: Plaza y Valdés.

Osborne, D. \& Gaebler, T. (1994). Un nuevo modelo de gobierno. Cómo transforma el espíritu empresarial al sector público. México: Gernika.

Oszlak, O. (1999). De menor a mejor. El desafío de la Segunda Reforma del Estado. Nueva Sociedad, 160, 1-18.

Pacheco, A. V. (2010). El Sistema de Evaluación del Desempeño (SED) en México: Una propuesta para los Gobiernos Locales. Premio del Instituto Nacional de Administración Pública. México.

Pardo, M. (2007). La gerencialización de la administración pública. Foro Internacional, XLVII(4), 895925.

Pardo, M. \& Sánchez, E. V (2009). La Gerencia Pública en América del Norte. Tendencias actuales de la reforma administrativa en Canadá, Estados Unidos y México. México: El Colegio de México, Instituto de Administración Pública de Nuevo León.

Paolo M. (1997). The effects of corruption on growth, investment and government expenditure: a cross-country analysis. En Williot, K. (coord.). Corruption and the Global Economy. Institute for International Economics, Washington, D.C., 87-107.

Parra, J. F. (2005). Liberalismo: nuevo institucionalismo y cambio institucional. Política y Cultura, 24, 31-61.

Plan Nacional de Desarrollo 2000 - 2006. México: PND

Peruzzotti, E. \& Smulovitz, C. [eds.] (2002). Controlando la política. Ciudadanos y medios en las nuevas democracias latinoamericanas. Buenos Aires: Temas

Peschard, J. (2007). Transparencia y partidos políticos. México: IFAI, Cuadernos de Transparencia 08.

Prieto, J. P., Stankiewicsz, M. V. \& Cuatlayol, M. M. J. (2011). Rendición de cuentas y compras del gobierno. Cuadernos de Rendición de Cuentas 05. México: Secretaría de la Función Pública.

Perlman B. J. \& Pineda, J. (2006), Nuevo institucionalismo e institucionalidad en México. Universidad Autónoma del Estado de México, The University of New México.

Pesqueux, Yvon (2009). Institución y Organización. Cuadernos de Administración, 41, 7-25.

Peters, B. G. (2003a). El nuevo institucionalismo. Teoría institucional de la ciencia política. Barcelona: Editorial Gedisa. 
Peters, G. B. (2003b). La capacidad para gobernar ¿retrocediendo hacia el centro? Revista de Administración Pública, 27, 1-15.

Peters, G. B. (2004). Cambios en la naturaleza de la Administración Pública: De las preguntas sencillas a las respuestas difíciles. En Pardo, M. (comp.). De la Administración Pública a la Gobernanza. México: El Colegio de México.

Peters, G. B. \& Jon, P. (2005). ¿Por qué ahora el interés por la gobernanza?. En Cerrillo, A. (coord.), La gobernanza hoy: diez títulos de referencia. Madrid: Instituto Nacional de Administración Pública, 37-56.

Powell, W. \& DiMaggio, P. J. [comps.] (2001). El Nuevo Institucionalismo en el análisis organizacional. México: Fondo de Cultura Económica, Colegio Nacional de Ciencias Políticas y Administración Pública, UAEM.

Prast, J. (1995). Derecho y Management en las administraciones públicas (Notas sobre la crisis y renovación de los respectivos paradigmas. Revista del CLAD Reforma y Democracia, 3, 1-15.

(2001). Gobernabilidad democrática para el desarrollo humano. Marco conceptual y analítico. Revista de Instituciones y Desarrollo, 10, 103-148.

Presidencia de la República (2006). Sexto Informe de Gobierno. México.

Presidencia de la República (2002). Segundo Informe de Gobierno. México.

Puón, R. M. (2006). Alcances y resultados del Servicio Profesional de Carrera en México. Un ejercicio de evaluación a tres años de su implementación. Gestión y Política Pública, XV(2), 457-483.

(2009). La nueva fisonomía del servicio profesional de carrera en México. Revista del CLAD Reforma y Democracia, 43, 1-17

Rabasa, E. (1981). La constitución y la dictadura. México: Editorial Porrúa.

Rabotnikof, N. (2000). Heurística y espacio púbico. En Velasco, Ambrosio. El concepto de heurística en las ciencias sociales y las humanidades. México: Siglo XXI, UNAM.

Ramírez, R. P. \& Ramírez, D. J. F. (2018). La administración pública y su desempeño a través de los indicadores de gobernanza. En López, E. D \& Villarreal, E. (coords.). Las ciencias sociales y la agenda nacional. Reflexiones y propuestas desde la Ciencias Sociales. IV. Políticas públicas y gobernanza. México, San Luis Potosí: Consejo Mexicano de Ciencias Sociales, A. C., Facultad de Ciencias Sociales y Humanidades de la UASLP, Colegio de San Luis, A. C., 341-361.

Ramírez, R. P. (2016). Corrupción y costos de transacción en la administración pública. Revista Iberoamericana de las Ciencias Sociales y Humanísticas, 5, 10, 1-27.

Ramírez, H. (2012). Definición de la agenda de políticas. Disponible en http://www.slidefinder.net/d/definici_n_agenda_pol_ticas/pres22/984958

Ramírez, J. L. J. (2010). El problema de la efectividad del control externo del Sector Público ante la dinámica actual del cambio institucional. Décimo Certamen Nacional de Ensayo de Fiscalización sobre Fiscalización Superior y Rendición de Cuentas, 1er. Lugar, 21-30.

Ramos, M. A. S. (2008). La política gubernamental administrativa. En Vázquez, F. R. (coord.). El gobierno panista de Vicente Fox. La frustración del cambio. México: UNAM, 173-205.

Rawls, J. (1993). Liberalismo político. México: FCE. 
Rhodes, R. A. (2005). La nueva gobernanza: gobernar sin gobierno. En Cerrillo, Agustí (coord.). La gobernanza hoy: diez títulos de referencia. Madrid: Instituto Nacional de Administración Pública, 99122 .

Riojas, C. (2010). Adaptaciones institucionales en la época neoliberal. Revista Política y Cultura, 34, 131-157.

Rivera, A. J. O. (2009). La Rendición de Cuentas en México: Diseño Institucional y Participación Ciudadana. Cuadernos sobre Rendición de Cuentas 2. México: Secretaría de la Función Pública.

Romero, J. J. (2001). Estudio introductorio. En Powell, W. \& DiMaggio, P. J. [comps.] (2001). El Nuevo Institucionalismo en el análisis organizacional. México: Fondo de Cultura Económica, Colegio Nacional de Ciencias Políticas y Administración Pública, UAEM, 7-29.

Salvador, M. (2010). Perspectivas analíticas en torno a la institucionalización del servicio público. Revista de Administración Pública 123, XLV(3), 17-29.

Sánchez, E. V. (2011). Gestión Pública y Rendición de Cuentas: ¿Un enfoque basado en cumplimiento a uno basado en resultados? Cuadernos sobre Rendición de Cuentas. México: Secretaría de la Función Pública

Sosa, J. (2011). Transparencia y rendición de cuentas: un ensayo introductorio. En Sosa, J. (comp.). Transparencia y rendición de cuentas. México: Siglo XXI.

Somuano, M. F. (2009). Comentario. En Pardo, M. \& Sánchez, E. V. (coord.). La gerencia pública en América del Norte. Tendencias actuales de la reforma administrativa en Canadá, Estados Unidos y México. México: El Colegio de México, INAP, 71-76.

Schedler, A. (1999). Conceptualizing Accountability. En Schedler, A., Diamond, L. \& Plattner. M. F. (eds.). The Self-Restraining State: Power and Accountability in New Democracies. Boulder: Lynne Reinner, 14-15.

Schumpeter, J. (2012). Teoría del desenvolvimiento económico. México: FCE.

Shah, A. \& Schacter, M. (2004). Combating Corruption: Look Before Leap. The World Bank.

Stoker, F. (1998). El Buen Gobierno como Teoría: Cinco Propuestas. Revista Internacional de Ciencias Sociales, 155.

Strasser, C. (2003). América Latina: participación cívica, instituciones democráticas, buen gobierno. Los obstáculos y las cuestiones. En Sojo, C. (coord.), Desarrollo social en América Latina: temas y desafíos para las políticas públicas. Costa Rica: Banco Mundial/Flacso, San José de Costa Rica, 383 456.

Secretaría de Contraloría y Desarrollo Administrativo (2002). Programa Nacional de Combate a la Corrupción y Fomento a la Transparencia y Desarrollo Administrativo. México: SECODAM.

Secretaría de la Función Pública (2006). Informe de Rendición de Cuentas de la Administración 20002006. México: SFP.

Secretaría de la Función Pública (2005). Transparencia: Buen gobierno y combate a la corrupción en la función pública. México: FCE.

Secretaría de la Función Pública (2008). Programa Especial de Mejora de la Gestión en la Administración Pública 2008-2012. México: SPF.

Secretaría de la Función Pública (2010). Menos reglas, mejores resultados. México: SFP. 
Secretaría de la Función Pública (2012). Consolidación de la Estrategia de Mejora de la Administración Pública Federal 2008-2012. México: SFP.

Secretaría de la Función Pública (2012). Informe del Resultado de la Fiscalización Superior de la Cuenta Pública 2011. México: SFP.

Suárez, O. M. (2004). Schumpeter, innovación y determinismo tecnológico. Scientia et Technica, $\mathrm{X}(25), 209-213$.

Transparency International (The Global Coalition Against Corruption). Disponible en http://www.transparency.org/

Treviño, D. (2007). El nuevo Reglamento de la Ley del Servicio Profesional de Carrera en la Administración Pública Federal. Servicio Profesional de Carrera, 8.

Treviño, L. C. (2002). Teorías económicas de la innovación tecnológica. México: IPN-CIECAS-ESEUNAM.

Ugalde, F. V. (2010). La regla ausente. Democracia y conflicto constitucional en México. México: FLACSO, UNAM, Editorial Gedisa.

Ugalde, L. C. (2002a). Rendición de cuentas y democracia. El caso de México. México: IFE. (2002b). La rendición de cuentas en los gobiernos estatales y municipales. México: Auditoría Superior de la Federación.

Vázquez, J. M. (2010). La gobernanza y las relaciones intergubernamentales. En Los indicadores de buen gobierno en México y el trabajo legislativo. México: Reporte CESOP, 37, 11-1.

Verduzco, B. \& Sánchez, A. (2000). Cambio institucional, Coordinación Económica y Desarrollo Local. Gestión y Política Pública. México: CIDE, 78-96.

Vergara, R. (2008). La transparencia como problema. Cuadernos de Transparencia 05. México: IFAI.

Vergara, R. (1997). Estudio Introductorio. En March, J. \& Olsen, J. El redescubrimiento de las instituciones. La base organizativa de la política. México: Fondo de Cultura Económica, Colegio Nacional de Ciencias Políticas y Administración Pública y Universidad Autónoma de Sinaloa, 9-40.

Vilchis, J. M. (2006). Estudio introductorio. En Perlman J. B. \& Pineda, J. (coords.). Nuevo institucionalismo e institucionalidad en México. México: UAEMex, University of New México, 23 -45.

Villanueva, E. (2007). Transparencia acotada. Revista Proceso, 1557, 58.

Villanueva, L. F. A. (2010). Gobernanza: el nuevo proceso de gobernar. México: Fundación FriedrichNaumann.

(2009). Gobernanza y gestión pública. México: FCE.

(2007). El aporte de la política pública y de la nueva gestión pública a la gobernanza. Revista del CLAD Reforma y Democracia. 39, 1-15.

(1993). Problemas públicos y agenda de buen gobierno. México: Miguel Ángel Porrúa, Antologías de las políticas públicas.

(1990). Políticas Públicas. Revista del Colegio, 4, 233-255.

Villarreal, R. (1998). Hacia una nueva economía de mercado, Institucional y participativa. México: Ediciones Castillo. 


\section{Siglas}

\begin{tabular}{|c|c|}
\hline ABG & Agenda de Buen Gobierno \\
\hline AP & Administración Pública \\
\hline APF & Administración Pública Federal \\
\hline CURP & Clave Única de Registro de Población \\
\hline COMERIS & Comités de Mejora Regulatoria Interna en las Dependencias y Entidades \\
\hline COFEMER & Comisión Federal de Mejora Regulatoria \\
\hline CITCC & Comisión Intersecretarial para Transparencia y el Combate a la Corrupción \\
\hline CPEUM & Constitución Política de los Estados Unidos Mexicanos \\
\hline ECODIS & Emprendedores con Discapacidad \\
\hline ENCIG & Encuesta Nacional de Calidad e Impacto Gubernamental \\
\hline FARAC & Fideicomiso de Apoyo para el Rescate de Autopista Concesionadas \\
\hline FOBAPROA & Fondo Bancario de Protección al Ahorro \\
\hline FONDEN & Fondo de Desastres Naturales \\
\hline IST & Indicador de Seguimiento de Transparencia \\
\hline IPC & Índice de Percepción de la Corrupción \\
\hline INCBG & Índice Nacional de Corrupción y Buen Gobierno \\
\hline IFAI & Instituto Federal de Acceso a la Información Pública \\
\hline INAI & Instituto Nacional de Acceso a la Información Pública \\
\hline ICRG & International Country Risk Guide \\
\hline LTAIPG & Ley de Transparencia y Acceso a la Información Pública Gubernamental \\
\hline LSPCAPF & Ley de Servicio Profesional de Carrera de la Administración Pública Federal \\
\hline LFRASP & $\begin{array}{l}\text { Ley Federal de Responsabilidades Administrativas de los Servidores } \\
\text { Públicos }\end{array}$ \\
\hline LOAPF & Ley Orgánica de la Administración Pública Federal \\
\hline MEIG & Modelo Estratégico para la Innovación del Gobierno \\
\hline NGP & Nueva Gestión Pública \\
\hline OCDE & Organización para la Cooperación y Desarrollo Económico \\
\hline OIC & Órganos Internos de Control \\
\hline PMG & $\begin{array}{l}\text { Programa Especial de Mejora de la Gestión en la Administración Pública } \\
\text { Federal }\end{array}$ \\
\hline PNUD & Programa de Naciones Unidas para el Desarrollo \\
\hline PETIC & Plan Estratégico de Tecnologías de la Información y Comunicación \\
\hline PND & Plan Nacional de Desarrollo \\
\hline PNCTDA & $\begin{array}{l}\text { Programa Nacional de Combate a la Corrupción y Fomento a la } \\
\text { Transparencia y el Desarrollo Administrativo }\end{array}$ \\
\hline POTCC & Programas Operativos para la Transparencia y Combate a la Corrupción \\
\hline RUPA & Registro Único de Personas Acreditadas \\
\hline RUSP & Registro Único de Servidores Públicos \\
\hline SECODAM & Secretaría de Contraloría y Desarrollo Administrativo \\
\hline SEDESOL & Secretaría de Desarrollo Social \\
\hline SE & Secretaría de Economía \\
\hline SEP & Secretaría de Educación Pública \\
\hline SFP & Secretaría de la Función Pública \\
\hline SEGOB & Secretaría de Gobernación \\
\hline SHCP & Secretaría de Hacienda y Crédito Público \\
\hline SEMARNAT & Secretaría del Medio Ambiente y Recursos Naturales \\
\hline SSA & Secretaría de Salud y Asistencia \\
\hline SED & Sistema de Evaluación del Desempeño \\
\hline SISI & Sistema de Solicitudes de Información \\
\hline TIC & Tecnologías de la Información y la Comunicación \\
\hline UGEPTI & Unidad de Gobierno Electrónico y Política de Tecnologías de Información \\
\hline
\end{tabular}


Agradecimiento

$\uparrow$ A mi hermana Clotilde por todas sus alegrías, amor y comprensión. 


\section{[Título de Libro en Times New Roman y Negritas No.14 en Español e Inglés]}

Apellidos (EN MAYUSCULAS), Nombre de $1^{\mathrm{er}}$ Autor $\dagger^{*}$, Apellidos (EN MAYUSCULAS), Nombre de $2^{\text {do }}$ Autor, Apellidos (EN MAYUSCULAS), Nombre de $3^{\text {er }}$ Autor y Apellidos (EN MAYUSCULAS), Nombre de $4^{\text {to }}$ Autor

Institutional Affiliation of Author including Dependency (No.10 Times New Roman and Italic)

International Identification of Science - Technology and Innovation

ID $1^{\text {er }}$ Autor: (ORC ID - Researcher ID Thomson, arXiv Author ID - PubMed Autor ID - Open ID) y CVU $1^{\text {er }}$ autor: (Becario-PNPC o SNI-CONACYT) (No.10 Times New Roman)

ID $1^{\text {er }}$ Coautor: (ORC ID - Researcher ID Thomson, arXiv Author ID - PubMed Autor ID - Open ID) y CVU $2^{\text {do }}$ autor: (Becario-PNPC o SNI-CONACYT) (No.10 Times New Roman)

ID $2^{\text {do }}$ Coautor: (ORC ID - Researcher ID Thomson, arXiv Author ID - PubMed Autor ID - Open ID) y CVU $3^{\text {er }}$ autor: (Becario-PNPC o SNI-CONACYT) (No.10 Times New Roman)

ID $3^{\text {er }}$ Coautor: (ORC ID - Researcher ID Thomson, arXiv Author ID - PubMed Autor ID - Open ID) y CVU $4^{\text {to }}$ autor: (Becario-PNPC o SNI-CONACYT) (No.10 Times New Roman)

Institución de Afiliación del Autor incluyendo dependencia (en Times New Roman No.12)

Correo institucional (Times New Roman No.12)

\section{Resumen (En Español, 150-200 palabras)}

Objetivos

Metodología

Contribución

Indicar 3 palabras clave en Times New Roman y Negritas No. 12 (En Español)

\section{Resumen (En Inglés, 150-200 palabras)}

Objetivos

Metodología

Contribución

Indicar 3 palabras clave en Times New Roman y Negritas No. 12 (En Inglés)

Indica área de investigación (CONACYT) (Time New Roman No. 12)

Área:

Campo:

Disciplina:

Subdisciplina:

Indicación si corresponde a celebración de año conmemorativo o festejo institucional 


\section{Introducción}

Texto redactado en Times New Roman No.12, espacio sencillo.

Explicación del tema en general y explicar porque es importante.

¿Cuál es su valor agregado respecto de las demás técnicas?.

Enfocar claramente cada una de sus características.

Explicar con claridad el problema a solucionar y la hipótesis central.

Explicación de las secciones del Capítulo.

Desarrollo de Secciones y Apartados del Capítulo con numeración subsecuente

[Título en Times New Roman No.12, espacio sencillo y Negrita]

Desarrollo de Capítulos en Times New Roman No.12, espacio sencillo.

\section{Inclusión de Gráficos, Figuras y Tablas-Editables}

En el contenido del Capítulo todo gráfico, tabla y figura debe ser editable en formatos que permitan modificar tamaño, tipo y número de letra, a efectos de edición, estas deberán estar en alta calidad, no pixeladas y deben ser notables aun reduciendo la imagen a escala.

[Indicando el título en la parte Superior con Times New Roman No.12 y Negrita, señalando la fuente en la parte Inferior centrada con Times New Roman No. 10]

Tabla 1.1 Título

\begin{tabular}{|l|l|l|}
\hline \multicolumn{1}{|c|}{ Variable } & \multicolumn{1}{|c|}{ Descripción } & \multicolumn{1}{c|}{ Valor } \\
\hline$P_{1}$ & Partición 1 & 481.00 \\
\hline$P_{2}$ & Partición 2 & 487.00 \\
\hline$P_{3}$ & Partición 3 & 484.00 \\
\hline$P_{4}$ & Partición 4 & 483.50 \\
\hline$P_{5}$ & Partición 5 & 484.00 \\
\hline$P_{6}$ & Partición 6 & 490.79 \\
\hline$P_{7}$ & Partición 7 & 491.61 \\
\hline
\end{tabular}

Fuente de Consulta:

(No deberán ser imágenes, todo debe ser editable)

Figura 1.1 Título

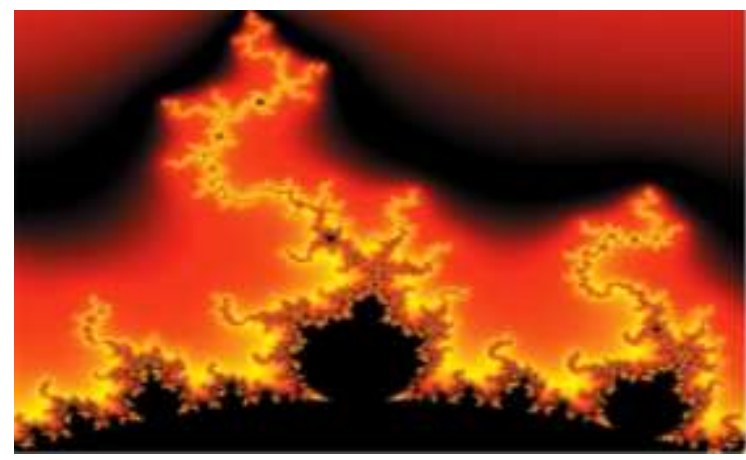

Fuente de Consulta:

(No deberán ser imágenes, todo debe ser editable) 
Gráfico 1.1 Título

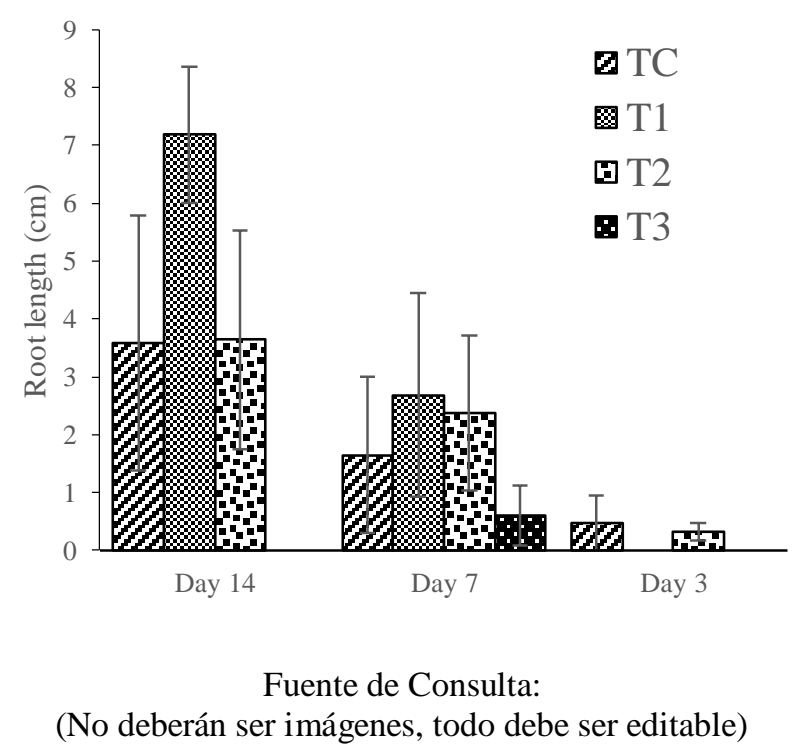

Cada Capítulo deberá presentar de manera separada en 3 Carpetas: a) Figuras, b) Gráficos y c) Tablas en formato .JPG, indicando el número en Negrita y el Titulo secuencial.

Para el uso de Ecuaciones, señalar de la siguiente forma:

$\int_{\lim ^{-1}}^{l i m}=\int \frac{\lim ^{1}}{\lim ^{-1}}=\left[\frac{1(-1)}{\lim }\right]^{2}=\frac{(0)^{2}}{\lim }=\sqrt{\lim }=0=0 \rightarrow \propto$

Deberán ser editables y con numeración alineada en el extremo derecho.

\section{Metodología a desarrollar}

Dar el significado de las variables en redacción lineal y es importante la comparación de los criterios usados.

\section{Resultados}

Los resultados deberán ser por sección del Capítulo.

\section{Anexos}

Tablas y fuentes adecuadas.

\section{Agradecimiento}

Indicar si fueron financiados por alguna Institución, Universidad o Empresa.

\section{Conclusiones}

Explicar con claridad los resultados obtenidos y las posibilidades de mejora.

\section{Referencias}

Utilizar sistema APA. No deben estar numerados, tampoco con viñetas, sin embargo, en caso necesario de numerar será porque se hace referencia o mención en alguna parte del Capítulo. 


\section{Ficha Técnica}

Cada Capítulo deberá presentar en un documento Word (.docx):

Nombre del Books

Título del Capítulo

Abstract

Keywords

Secciones del Capítulo, por ejemplo:

1. Introducción

2. Descripción del método

3. Análisis a partir de la regresión por curva de demanda

4. Resultados

5. Agradecimiento

6. Conclusiones

7. Referencias

Nombre de Autor (es)

Correo Electrónico de Correspondencia al Autor

Referencias

\section{Requerimientos de Propiedad Intelectual para su edición:}

-Firma Autógrafa en Color Azul del Formato de Originalidad del Autor y Coautores -Firma Autógrafa en Color Azul del Formato de Aceptación del Autor y Coautores 


\section{Reserva a la Política Editorial}

ECORFAN Books se reserva el derecho de hacer los cambios editoriales requeridos para adecuar la Obra Científica a la Política Editorial del ECORFAN Books. Una vez aceptada la Obra Científica en su versión final, el ECORFAN Books enviará al autor las pruebas para su revisión. ECORFAN® únicamente aceptará la corrección de erratas y errores u omisiones provenientes del proceso de edición de la revista reservándose en su totalidad los derechos de autor y difusión de contenido. No se aceptarán supresiones, sustituciones o añadidos que alteren la formación de la Obra Científica.

\section{Código de Ética - Buenas Prácticas y Declaratoria de Solución a Conflictos Editoriales}

Declaración de Originalidad y carácter inédito de la Obra Científica, de Autoría, sobre la obtención de datos e interpretación de resultados, Agradecimientos, Conflicto de intereses, Cesión de derechos y distribución.

La Dirección de ECORFAN-México, S.C reivindica a los Autores de la Obra Científica que su contenido debe ser original, inédito y de contenido Científico, Tecnológico y de Innovación para someterlo a evaluación.

Los Autores firmantes de la Obra Científica deben ser los mismos que han contribuido a su concepción, realización y desarrollo, así como a la obtención de los datos, la interpretación de los resultados, su redacción y revisión. El Autor de correspondencia de la Obra Científica propuesto requisitara el formulario que sigue a continuación.

Título de la Obra Científica:

El envío de una Obra Científica a ECORFAN Books emana el compromiso del autor de no someterlo de manera simultánea a la consideración de otras publicaciones seriadas para ello deberá complementar el Formato de Originalidad para su Obra Científica, salvo que sea rechazado por el Comité de Arbitraje, podrá ser retirado.

- Ninguno de los datos presentados en esta Obra Científica ha sido plagiado ó inventado. Los datos originales se distinguen claramente de los ya publicados. Y se tiene conocimiento del testeo en PLAGSCAN si se detecta un nivel de plagio Positivo no se procederá a arbitrar.

Se citan las referencias en las que se basa la información contenida en la Obra Científica, así como las teorías y los datos procedentes de otras Obras Científicas previamente publicados.

- Los autores firman el Formato de Autorización para que su Obra Científica se difunda por los medios que ECORFAN-México, S.C. en su Holding México considere pertinentes para divulgación y difusión de su Obra Científica cediendo sus Derechos de Obra Científica.

Se ha obtenido el consentimiento de quienes han aportado datos no publicados obtenidos mediante comunicación verbal o escrita, y se identifican adecuadamente dicha comunicación y autoría.

El Autor y Co-Autores que firman este trabajo han participado en su planificación, diseño y ejecución, así como en la interpretación de los resultados. Asimismo, revisaron críticamente el trabajo, aprobaron su versión final y están de acuerdo con su publicación.

No se ha omitido ninguna firma responsable del trabajo y se satisfacen los criterios de Autoría Científica.

Los resultados de esta Obra Científica se han interpretado objetivamente. Cualquier resultado contrario al punto de vista de quienes firman se expone y discute en la Obra Científica. 


\section{Copyright y Accesso}

La publicación de esta Obra Científica supone la cesión del copyright a ECORFAN-Mexico, S.C en su Holding México para su ECORFAN Books, que se reserva el derecho a distribuir en la Web la versión publicada de la Obra Científica y la puesta a disposición de la Obra Científica en este formato supone para sus Autores el cumplimiento de lo establecido en la Ley de Ciencia y Tecnología de los Estados Unidos Mexicanos, en lo relativo a la obligatoriedad de permitir el acceso a los resultados de Investigaciones Científicas.

Título de la Obra Científica:

\begin{tabular}{|l|c|}
\hline \multicolumn{1}{|c|}{ Nombre y apellidos del Autor de contacto y de los Coautores } & Firma \\
\hline 1. & \\
\hline 2. & \\
\hline 3. & \\
\hline 4. & \\
\hline
\end{tabular}

\section{Principios de Ética y Declaratoria de Solución a Conflictos Editoriales}

\section{Responsabilidades del Editor}

El Editor se compromete a garantizar la confidencialidad del proceso de evaluación, no podrá revelar a los Árbitros la identidad de los Autores, tampoco podrá revelar la identidad de los Árbitros en ningún momento.

El Editor asume la responsabilidad de informar debidamente al Autor la fase del proceso editorial en que se encuentra el texto enviado, así como de las resoluciones del arbitraje a Doble Ciego.

El Editor debe evaluar los manuscritos y su contenido intelectual sin distinción de raza, género, orientación sexual, creencias religiosas, origen étnico, nacionalidad, o la filosofía política de los Autores.

El Editor y su equipo de edición de los Holdings de ECORFAN® no divulgarán ninguna información sobre la Obra Científica enviado a cualquier persona que no sea el Autor correspondiente.

El Editor debe tomar decisiones justas e imparciales y garantizar un proceso de arbitraje por pares justa.

\section{Responsabilidades del Consejo Editorial}

La descripción de los procesos de revisión por pares es dado a conocer por el Consejo Editorial con el fin de que los Autores conozcan cuáles son los criterios de evaluación y estará siempre dispuesto a justificar cualquier controversia en el proceso de evaluación. En caso de Detección de Plagio a la Obra Científica el Comité notifica a los Autores por Violación al Derecho de Autoría Científica, Tecnológica y de Innovación.

\section{Responsabilidades del Comité Arbitral}

Los Árbitros se comprometen a notificar sobre cualquier conducta no ética por parte de los Autores y señalar toda la información que pueda ser motivo para rechazar la publicación de la Obra Científica.

Además, deben comprometerse a mantener de manera confidencial la información relacionada con la Obra Científica que evalúan.

Cualquier manuscrito recibido para su arbitraje debe ser tratado como documento confidencial, no se debe mostrar o discutir con otros expertos, excepto con autorización del Editor.

Los Árbitros se deben conducir de manera objetiva, toda crítica personal al Autor es inapropiada. 
Los Árbitros deben expresar sus puntos de vista con claridad y con argumentos válidos que contribuyan al que hacer Científico, Tecnológica y de Innovación del Autor.

Los Árbitros no deben evaluar los manuscritos en los que tienen conflictos de intereses y que se hayan notificado al Editor antes de someter la Obra Científica a evaluación.

\section{Responsabilidades de los Autores}

Los Autores deben garantizar que sus Obras Científicas son producto de su trabajo original y que los datos han sido obtenidos de manera ética.

Los Autores deben garantizar no han sido previamente publicados o que no estén siendo considerados en otra publicación seriada.

Los Autores deben seguir estrictamente las normas para la publicación de Obra Científica definidas por el Consejo Editorial.

Los Autores deben considerar que el plagio en todas sus formas constituye una conducta no ética editorial y es inaceptable, en consecuencia, cualquier manuscrito que incurra en plagio será eliminado y no considerado para su publicación.

Los Autores deben citar las publicaciones que han sido influyentes en la naturaleza de la Obra Científica presentado a arbitraje.

\section{Servicios de Información}

\section{Indización - Bases y Repositorios}

- $\quad$ RESEARCH GATE (Alemania)

- MENDELEY (Gestor de Referencias bibliográficas)

- GOOGLE SCHOLAR (Índices de citaciones-Google)

- $\quad$ REDIB (Red Iberoamericana de Innovación y Conocimiento Científico- CSIC)

\section{Servicios Editoriales}

Identificación de Citación e Índice $\mathrm{H}$

Administración del Formato de Originalidad y Autorización

Testeo del T-Book con PLAGSCAN

Evaluación de Obra Científica

Emisión de Certificado de Arbitraje

Edición de Obra Científica

Maquetación Web

Indización y Repositorio

Publicación de Obra Científica

Certificado de Obra Científica

Facturación por Servicio de Edición

\section{Política Editorial y Administración}

143 - 50 Itzopan Calle. La Florida, Ecatepec Municipio México Estado, 55120 Código postal, MX. Tel: +52 1552024 3918, +52 1556159 2296, +52 1554640 1298; Correo electrónico: contact@ecorfan.org www.ecorfan.org 


\section{ECORFAN®}

Editora en Jefe

RAMOS-ESCAMILLA, María. PhD

Redactor Principal

SERRUDO-GONZALES, Javier. BsC

\section{Asistente Editorial}

ROSALES-BORBOR, Eleana. BsC

SORIANO-VELASCO, Jesus. BsC

\section{Director Editorial}

PERALTA-CASTRO, Enrique. MsC

Editor Ejecutivo

VARGAS-DELGADO, Oscar. PhD

Editores de Producción

ESCAMILLA-BOUCHAN, Imelda. PhD

LUNA-SOTO, Vladimir. PhD

\section{Administración Empresarial}

REYES-VILLAO, Angélica. BsC

\section{Control de Producción}

RAMOS-ARANCIBIA, Alejandra. BsC

DÍAZ-OCAMPO, Javier. BsC

Editores Asociados

OLIVES-MALDONADO, Carlos. MsC

MIRANDA-GARCIA, Marta. PhD

CHIATCHOUA, Cesaire. PhD

SUYO-CRUZ, Gabriel. PhD

CENTENO-ROA, Ramona. MsC

ZAPATA-MONTES, Nery Javier. PhD

ALAS-SOLA, Gilberto Américo. PhD

MARTÍNEZ-HERRERA, Erick Obed. MsC

ILUNGA-MBUYAMBA, Elisée. MsC

IGLESIAS-SUAREZ, Fernando. MsC

VARGAS-DELGADO, Oscar. PhD

FUENTES-RODRÍGUEZ, Germán. MsC

\section{Publicidad y Patrocinio}

(ECORFAN $®$ - Mexico- Bolivia- Spain- Ecuador- Cameroon- Colombia- El Salvador- GuatemalaNicaragua- Peru- Paraguay- Democratic Republic of The Congo- Taiwan), sponsorships@ecorfan.org

\section{Licencias del Sitio}

03-2010-032610094200-01-Para material impreso, 03-2010-031613323600-01-Para material electrónico, 03-2010-032610105200-01-Para material fotográfico, 03-2010-032610115700-14-Para Compilación de Datos, 04 -2010-031613323600-01-Para su página Web, 19502-Para la Indización Iberoamericana y del Caribe, 20-281 HB9-Para la Indización en América Latina en Ciencias Sociales y Humanidades, 671-Para la Indización en Revistas Científicas Electrónicas España y América Latina, 7045008-Para su divulgación y edición en el Ministerio de Educación y Cultura-España, 25409-Para su repositorio en la Biblioteca Universitaria-Madrid, 16258-Para su indexación en Dialnet, 20589-Para Indización en el Directorio en los países de Iberoamérica y el Caribe, 15048-Para el registro internacional de Congresos y Coloquios. financingprograms@ecorfan.org 


\section{Oficinas de Gestión}

244 Itzopan, Ecatepec de Morelos-México.

21 Santa Lucía, CP-5220. Libertadores -Sucre-Bolivia.

38 Matacerquillas, CP-28411. Moralzarzal-Madrid-España.

18 Marcial Romero, CP-241550. Avenue, Salinas 1 - Santa Elena-Ecuador.

1047 La Raza Avenue -Santa Ana, Cusco-Peru.

Boulevard de la Liberté, Immeuble Kassap, CP-5963.Akwa- Douala-Cameroon.

Southwest Avenue, San Sebastian - León-Nicaragua.

6593 Kinshasa 31 - Republique Démocratique du Congo.

San Quentin Avenue, R 1-17 Miralvalle - San Salvador-El Salvador.

16 Kilometro, American Highway, House Terra Alta, D7 Mixco Zona 1-Guatemala.

105 Alberdi Rivarola Captain, CP-2060. Luque City- Paraguay.

Distrito YongHe, Zhongxin, calle 69. Taipei-Taiwán.

Calle 43 \# 30 -90 B. El Triunfo CP.50001. Bogotá-Colombia. 


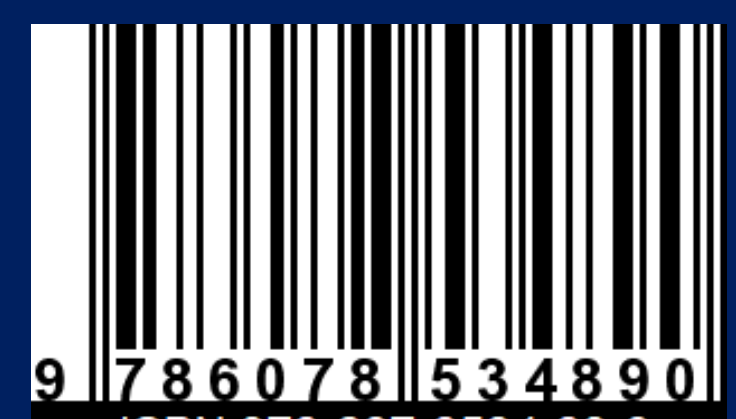
ISBN 978-607-8534-89-0

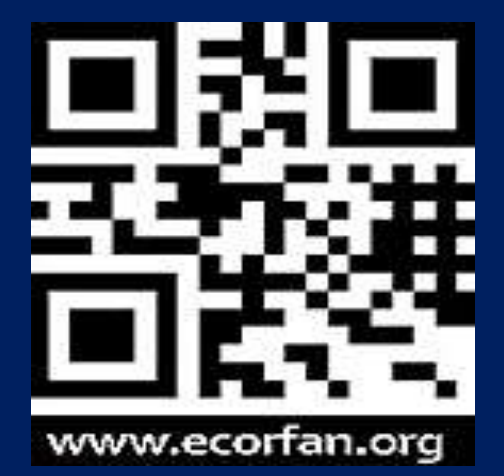

